GA-A15828

TTC-0119

\title{
EVALUATION OF FSV-1 CASK FOR THE TRANSPORT OF LWR IRRADIATED FUEL ASSEMBLIES
}

\author{
by \\ PROJECT STAFF
}

\begin{abstract}
Prepared under
Contract DE-AT03-80SF10791

for the San Francisco Operations Office

Department of Energy
\end{abstract}

DATE PUBLISHED: MAY 1980

\section{GENERAL ATOMIC COMPANY}




\section{DISCLAIMER}

This report was prepared as an account of work sponsored by an agency of the United States Government. Neither the United States Government nor any agency Thereof, nor any of their employees, makes any warranty, express or implied, or assumes any legal liability or responsibility for the accuracy, completeness, or usefulness of any information, apparatus, product, or process disclosed, or represents that its use would not infringe privately owned rights. Reference herein to any specific commercial product, process, or service by trade name, trademark, manufacturer, or otherwise does not necessarily constitute or imply its endorsement, recommendation, or favoring by the United States Government or any agency thereof. The views and opinions of authors expressed herein do not necessarily state or reflect those of the United States Government or any agency thereof. 


\section{DISCLAIMER}

Portions of this document may be illegible in electronic image products. Images are produced from the best available original document. 
This report was prepared as an account of work sponsored by an agency of the United States Government. Neither the United States nor any agency thereof, nor any of their employees, makes any warranty, expressed or implied, or assumes any legal liability or responsibility for any third party's use or the results of such use of any information, appartus, product or process disclosed in this report, or represents that its use by such third party would not infringe privately owned rights. 
GA-A15828

TTC-0119

\title{
EVALUATION OF FSV-1 CASK FOR THE TRANSPORT OF LWR IRRADIATED FUEL ASSEMBLIES

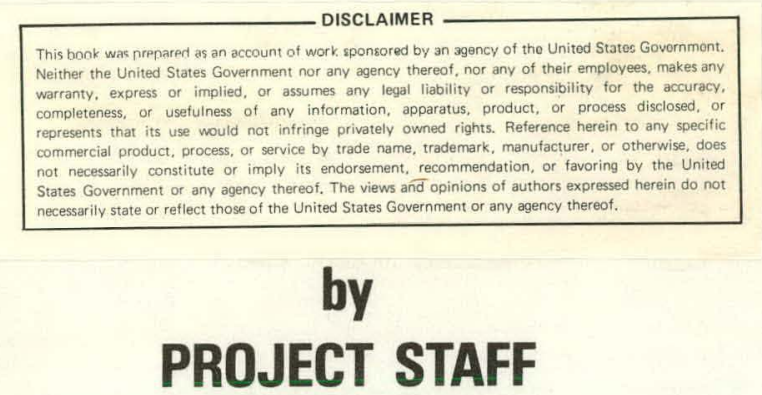

\begin{abstract}
Prepared under Contract DE-AT03-80SF10791 for the San Francisco Operations Office Department of Energy
\end{abstract}

GENERAL ATOMIC PROJECT 3325 DATE PUBLISHED: MAY 1980

\section{GENERAL ATOMIC COMPANY}




\section{THIS PAGE}

\section{WAS INTENTIONALLY \\ LEFT BLANK}




\section{ABSTRACT}

The Model FSV-l spent fuel shipping cask was designed by General Atomic Company (GA) to service the Fort St. Vrain (FSV) nuclear generating station, a High Temperature Gas Reactor (HTGR) owned and operated by Public Service Company of Colorado (PSC). This report presents an evaluation of the suitability of the FSV-1 cask for the transport of irradiated Light Water Reactor (LWR) fuel assemblies from both Pressurized Water Reactors (PWR) and Boiling Water Reactors (BWR). The FSV-I cask evaluation parameters covered a wide spectrum of LWR fuel assemblies, based on burnup in Megawatt Days/Metric Ton of Heavł Metal (MWD/MTHM) and years of decay since irradiation. The criteria for sultability included allowable radiation dose rates, cask surfiace and interior temperatures and the Gross Vehicle Weight (GVW) of the complete shipping system. 


\section{THIS PAGE}

\section{WAS INTENTIONALLY \\ LEFT BLANK}


ABSTRACT

\section{CONTENTS}

SUMMARY

Page

1. TASK DESCRIPTION 5

1.1 SCOPE 5

1.2 ASSUMPTIONS 5

1.3 DISCUSSION 6

2. LICENSING EVALUATION 7

2.1 STRUCTURAL 7

2.2 THERMAL 9

2.3 SHIELDING 14

2.4 CONTAINMENT 16

2.5 DISCUSSION 19

3. SHIELDING STUDY 21

3.1 INTRODUCTION

3.2 METHODOLOGY 24

3.3 SOURCE TERMS 34

3.4 COMPOSITION AND GEOMETRY 47

3.5 RESULTS 72

3.6 DISCUSSION 110

3.7 REFERENCES 111

4. WEIGHT STUDY 113

4.1 WEIGHT EVALUATION 113

4.2 OVVRWEIGHT SHIPMENTS 116

4.3 DISCUSSION 121

5. THERMAL STUDY 122

6. DRAWINGS 129

Drawing SK 3325-100, sheets 1 through 5

7. APPENDICES
A. Gamma and Neutron Source Strenghts
Table A-1, $A-2$ and A-3
B. Certificate of Compliance, number 6346, Revision 3
C. Design Drawings: GADR 55-2-1, 2 and 3
D. Boro-Silicone Properties 
1 Spectrum of LWR Irradiated Fuel Assemblies (F/A) that can be Transported in the Modified FSV-1 Cask. . . . . . . . . 2

2.2-1 Fuel Heat Load vs Exterior Surface Temperature with

External Neutron Shielding. . . . . . . . . . . .10

2.2-2 Fuel Heat Load vs Exterior Surface'Temperature with No

External Neutron Shielding. . . . . . . . . . . . 11

3-1 Neutron dose-to-flux conversion factors vs. neutron energy. . 26

3-2 Neutron dose-to-flux conversion factors vs. neutron energy. . 27

3-3 Neutron and gamma dose rates vs. additional gamma shiel.d thickness normalized to $0^{\prime \prime}$ additional gamma shielding. . . . 29

3-4 Neutron and gamma dose rates vs. neutron shleld thickiess normalized to 0 " neutron shield. . . . . . . .... . 30

3-5 Photon dose-to-flux conversion factors vs. photon energy. . . 31

3-6 PWR neutron source vs. burnup for 1 year decay. . . . . . 37

3-7 PWR neutron source vs. burnup for 2 year decay. . . . . . 38

3-8 PWR neutron source vs. burnup for 5 year decay. . . . . . 39

3-9 PWR neutron source vs. burnup for 10 year decay. . . . . . 40

3-10 Neutrón source vs. lecay time for various burnuns:, . . . . 42

3-11 PWR neutron source spectrum. . . . . . . . . . . . 44

3-12 Westinghouse $17 \times 17$ PWR Fuel Assembly . . . . . . . . 55

3-13 Geometry input for PATH PWR side calculation. . . . . . . 56

3-1 Goometry input for DTFX-PWR side calculation. . . . . . 57

3-15 General Electric 8 × 8 BWR Fuel Assemb1y. . . . . . . 58

3=16 Geometry input for PATH BWR side calculation. . . . . . . . 59

3-17 Geometry input for DTFX̄-BWR side calcularlon. . . . . . . . 60

3-18 Geometry input for PATH top of FSV-1 cask. . . . . . . . : . .61

3-19a Top and closure of as-built cask. . . . . . . . . . . 63

3-19b Bottom of FSV-1 Cask . . . . . . . . . . . : . . . 65

3-20 Geometry for top of FSV-1 cask for input into DTFX. . . . • 66 
3-21 New end closure design . . . . . . . . . . . . 67

3-22 Geometry input for PATH top of FSV-1 cask - new design . . . 68

3-23 Geometry for input for DTFX top of FSV-1 cask - new design . 69

3-24 Geometry input for PATH-bottom of FSV-1 cask. . . . . . . . 70

3-25 Geometry of input for DTFX- bottom of FSV-1 cask. . . . . 71

3-26 ZR and Mo neutron cross section vs. neutron energy. . . . . 51

3-27 Neutron dose rate vs. decay time for various burn-ups, no neutron shield, no additional gamna shield . . . . . . 74

3-28 PWR neutron dose rate vs. burnup for various decay times, no neutron shield, no additional gamma shield. . . . . . . 75

3-29 Neutron dose rate vs. distance from fuel element centerline. • 76

3-30 Neutron dose rate vs. distance from fuel element centerline. . 77

3-31 Gamma dose rate vs. burnup for various decay times, no gamma or neutron shield ................. . 78

3-32 Gamma dose rate vs. decay time for various burnup, $6 \mathrm{ft}$.

from personnel barrier . . . . . . . . . . . . . . 79

3-33 Total dose rate normalized to side of cask vs. distance away from side of cask. . . . . ... . . . . . . . 80

3-34 Total dose rate vs. burnup for several PWR decay times, no additional gamma shield, no neutron shield. . . . . . . 82

3-35 Total dose rate vs. burnup for several PWR decay times, no additional gamma shield, 3 in. neutron shield. . . . . . 83

3-36 Total dose rate vs. burnup for several PWR decay times, no additiúnal gamma shleld, b́ in. neutron shield. . . . . . 84

3-37 Total dose rate vs. burnup for several PWR decay times $6 \mathrm{ft}$. from personnel barrier- 1 inch additional gamma shield, 6 inches neutron shield. . . . . . . . . . . . 85

3-38 Total dose rate vs. burnup for several PWR decay times, 2 in. additional gamma shield, no neutron shield. . . . . 86

3-39 Total dose rate vs. burnup for several PWK decay times, 2 in. additional gamma shield, 2 in. neutron shield . . . . . 87

3-40 Burnup vs. decay time to yield $10 \mathrm{MREM} / \mathrm{HR} 6 \mathrm{ft}$. from personnel barrier for various neutron shield thicknesses, . 88

3-41 Burnup vs. decay time to yicld $10 \mathrm{MREM} / \mathrm{IR} 6 \mathrm{ft}$. froil personnel barrier for varlous neutron and gamma shield thicknesses. . . . . . . . . . . . . . . . 89 
PWR burnup vs. decay time to yield 5 MREM/HR $6 \mathrm{ft}$. from personnel barrier for various neutron and gamma shield thicknesses. . . . . . . . . . . . . . . . . 90

3-43 PWR burnup vs. decay time to yield 2 MREM/HR $6 \mathrm{ft}$. from personnel barrier for various neutron and gamma shield thicknesses..................... . 91

3-44 PWR neutron to gamma ratio vs. burnup with no additional gamma shield for various decay times and neutron shield thicknesses. . . . . . . . . . . . . . . .93

3-45 PWR neutron to gamma ratio vs. burnup with 2 in, additional gamma shield for various decay times and neutron shield thicknesses. . . . . . . . . . . . . . .94

3-46 Gamma dose rate $6 \mathrm{ft}$. from FSV fuel shipping cask loaded with 1 PWR fuel assembly 33,000 MWD/MTHM burnup . . . . . 103

4.2-1 Gross Vehicle Weight Limits. . . . . . . . . . . 117

5-1 TAC2D two-dimensional thermal model of upper half of

FSV-1 Cask (modified) . . . . . . . . . . . . 124

5-2 TAC2D results for the cask with no neutron shielding. . . 125

5-3 TAC2D results for the cask with 3 in. of external borosilicone shielding. . . . . . . . . . . . . 126

5-4 Afterheat (KW) vs. Decay Time (Years) for Various Burnups (MWD/MTHM)................... 127

\section{TABLES}

2.2-1 Cask Seal and Canister Temperatures . . . . . . . . 12

3-1 Summary of 1978 results - LWR fuel which could be shipped in FSV-1 cask . . . . . . . . . . . . . . 23

3-2 Source input and dose conversion factors for ORNL 36 groups. . . . . . . . . . . . . . . . . 28

3-3 Gamma-ray flux-tu-duse-rate conversion factors . . . . . 32

3-4 Neutron source $(\alpha, \eta)+$ spontaneous fission ........ . . .

3-5 Neutron source input into DTFX. . . . . . . . . . . 4 43

3-6 Gamma suurce terms for path input $\frac{\mathrm{MeV}}{\mathrm{cc} / \mathrm{sec}} . . . . . . .46$

3-7 PWR composition comparison . . . . . . . . . 48

3-8 BWR composition comparison based on SAND 79-0172. . . * 49

3-9 Nuclide concentrations for the fuel . . . . . . . . . 50 
3-10 Nuclide concentrations for Boro-Silicate (neutron shield). . 52

3-11 Nuclide concentrations for Gamma Shielding Materials . . . 54

3-12 Neutron dose rates $6 \mathrm{ft}$. from edge of transport vehicle. . 73

3-13 Uniform $10 \mathrm{mrem} / \mathrm{hr} 6 \mathrm{ft}$. from edge of transport vehicle. . 92

3-14 Total dose rate - mrem/hr - $6 \mathrm{ft}$. from end of truck (a) . . 98

3-15 Total dose rate at bottom of cask (a) mrem/hr. . . . . . 99

3-16 Dose rates $6 \mathrm{ft}$. from rear of truck due to $3 \mathrm{in}$. of added gamma shield on bottom................ 100

3-17 Total dose rate at a point 4 in. below top of cask - old. . 95

3-18a Total dose rate at a point 4 in. below top of cask - new. . .96

3-18b Total dose rate on top of cask - new.. . . . . . . . 966

3-19 PWR gamma source strength comparison. . . . . . . . . . . 104

3-20 Neutron source term comparison PWR fuel . . . . . . . . 105

3-21 FSV cask neutron results comparison (burnup in MWD/MTHM to meet stated conditions) one PWR element. . . . . . . 106

4.1-1 Weight Evaluation for the Model FSV-1 Cask Modified to Ship LWR fuel . . . . . . . . . . . . . . . . 115

4.2-1 State Weight Limits . . . . . . . . . . . . . 119 
Summary

Based on this evaluation, the FSV-I cask can be modified to be suitable for the transport of a significant spectrum of LWR irradiated fuel assemblies (Figure 1).

During the evaluation it was recognized that obtaining a revised Certificate of Compliance that added LWR fuel assemblies to the authorized contents of the FSV-l cask would constitute final approval of its suitability. Therefore, those regulatory requirements of 10CFR7I and 49CFR173, concerning contalnment and radiation would control the design modifications to the cask and the selection of suitable LWR irradiated fuel assemblies based on burnup and decay. Another concern outside of the Code of Federal Regulations was the impact of the modifications and the contents on the Gross Vehicle Weight (GVW) and any subsequent decrease in schedule flexibility when conducting overweight shipments. One further and unique constraint on any modifications to FSV-1 cask unit number 3 , is a contractual obligation with Public Service Company of Colorado (PSC) that this cask be made available,in case of spent fuel shipping problems, in the configuration for shipping HTGR fuel elements.

In addition to these required criteria, a desirable modification was the removal of the inner container to make available the largest possible cavity (17 $3 / 4$ inches in diameter by 188 inches long). Thus, the evaluation consisted of trade-offs between mandatory requirements, operational concerns, contractual constraints, and desirable features.

The containment requirement may be satisfied by the canister containing the PWR or BWR fuel assemblies, or by the modifed FSV-l cask closures or by some combination of both. The final identification of the containment boundaries will be determined when the design of the canisters is more definitive.

Al lowable radiation levels for the loaded cask are found in 49.CFR173.393, thus the gamma and neutron shielding capability of the cask will determine the selection of fuel assemblies that can be transported. Since the addition of shielding adds weight, the consideration of an acceptable GVW really controls the spectrum of acceptable LWR fuels. For this evaluation an upper limit of 78,000 pounds GVW was selected. At this weight, shipping operations without permits are possible in al.1 except 10 states and the District of Columbia. 
SPECTRUM OF LWR IRRADIATED FUEL ASSEMBLIES (F/A)

THAT CAN BE TRANSPORTED IN THE MODIFIED FSV-I

CASK - BASED ON 10 MREM/HR AT 6 FEET FROM TRANSPORT

VEHICLE.

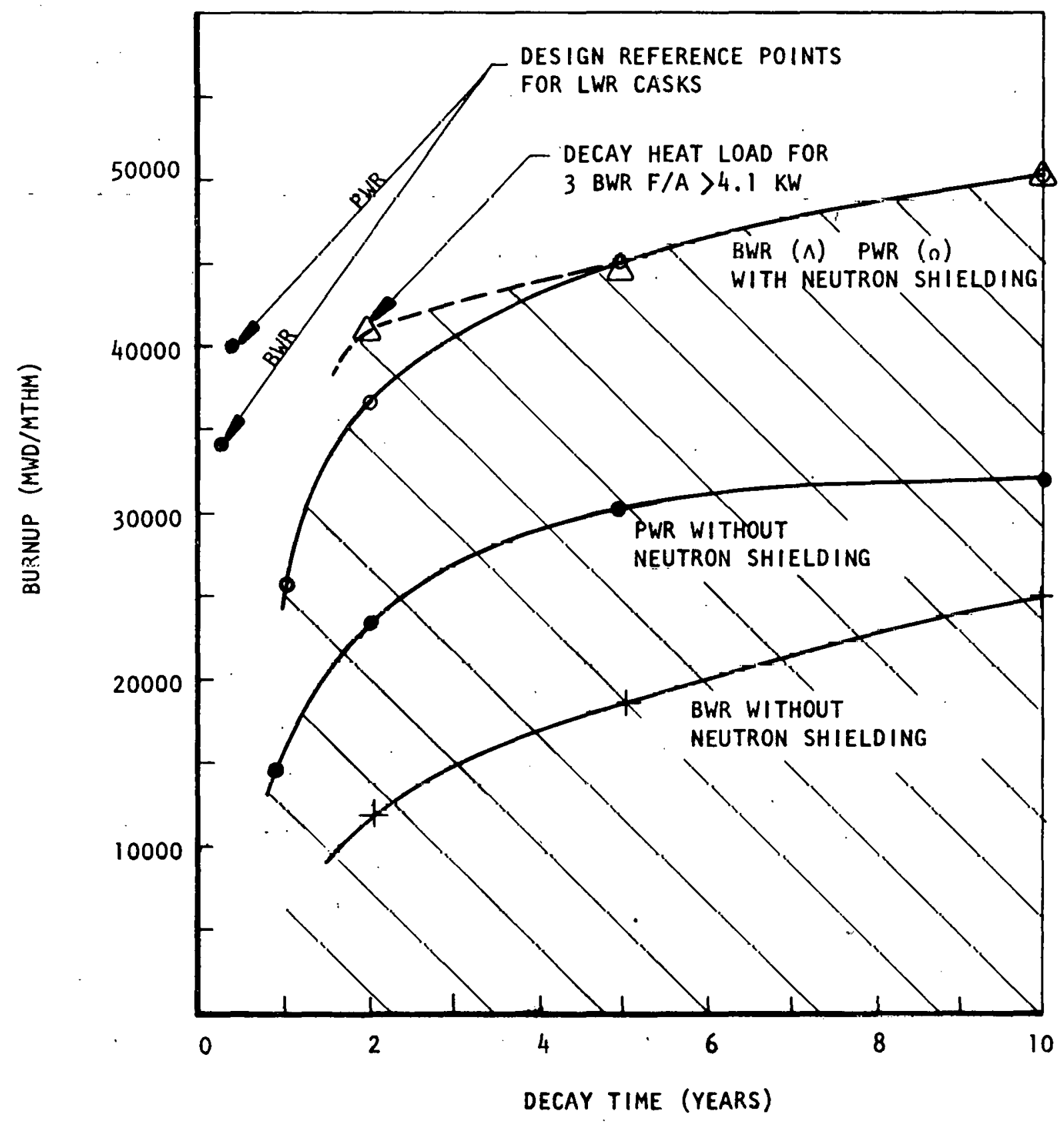

Figure 1 
Although many states allow 80,000 pound GVW shipments without permits, the maximum axle loadings and "bridge" formulas make it difficult tó operate a 5 axle tractor and semi-trailer combination in excess of 78,000 pounds, GVW.

Typical casks designed for the transport of LWR fuel assemblies can accept fuel heat loads of 10 to $12 \mathrm{KW}$ compared to $4.1 \mathrm{KW}$ for the FSV-1 cask. This limit of $4.1 \mathrm{KW}$, was based on the expected heat load from 6 fuel elements from the HTGR reactor rather than the capacity of cask and contents. As the evaluation developed it was apparent that the spectrum of LWR irradiated fuel elements that could be transported would be limited by shielding considerations rather than the $4.1 \mathrm{KW}$ fuel heat load limit except for the case of 3 BWR fuel assemblies with 42,000 MWD/MTHM burnup and 2 years decay time, which have a heat load of 4.2 KW. This is a very small area of the plot (Figure I) and with slightly less burnup or slightly more decay this fuel heat load will be less than 4.1 KW. No potential problems with the temperature of the canister, the inner closure seal assembly or the Boro-silicone neutron shielding were detected during the thermal studies. Accessible exterior surface temperatures of casks during transport are limited to $180^{\circ} \mathrm{F}$ by $49 \mathrm{CFR} 173$. Certain combinations of solar heat load, fuel heat load, and high ambient temperatures (generally in excess of $100^{\circ} \mathrm{F}$ ) will result in exterior surface temperatures in excess of $180^{\circ} \mathrm{F}$, therefore, a personnel barrier will be included in the modified design to make the exterior surfaces of the FSV-l cask inaccessible. It may be desirable to make this personnel barrier removable and thus only use it when required; and thus simplify handling operations.

This evaluation did not include a detailed structural analysis because of the constraints of schedule, budget and the preliminary nature of information concerning the canisters, however, careful attention was given the modified design in regard to maintaining the existing load paths and minimizing the increase in the total package (cask and contents) weight. Although additional structural analysis will be required to support the request for a revised Certificate of Compliance, this evaluation to date has not produced any serious concerns. 
LWR fuel assemblies when compared to HTGR fuel elements have differences in quantities of heavy metal, number of curies of fission products and neutron sources as listed below:

The FSV cask, during the transport of 6 HTGR irradiated fuel elements contains as a design basis:

$$
7.8 \mathrm{~kg} \text { of } \mathrm{U}_{235}
$$

$67.8 \mathrm{Kg}$ of Thorium

$1 \times 10^{6}$ Curies of fission products

A typical LWR cask during the transport of 1 PWR or 2 BWR irradiated fuel assemblies contains as design basis:

$$
\begin{aligned}
& 4.0 \mathrm{Kg} \text { of } U_{235} \text { and Plutonium } \\
& 3 \times 10^{6} \text { Curies of fission products } \\
& 9 \times 10^{9} \mathrm{n} / \mathrm{sec} \text { neutron source }
\end{aligned}
$$

These differences do not appear to have any Impact on the obtaining of a revised Certificate of Compliance, based on this evaluation. No design features, material properties, or existing regulations were identified that would preclude the issuance of a revision to the Certificate of Compliance to add a significant spectrum of LWR irradiated fuel assemblies to the authorized contents for a modified FSV-l cask. 


\subsection{TASK DESCRIPTION}

\subsection{Sčopë}

Evaluate the General Atomic Company, model FSV-1 Spent Fuel

Shipping Cask to assess its suitability for the transport of Light Water Reactor (LWR) irradiated fuel assemblies. Identify any required modifications and assess the acceptability of a request to amend the Certificate of Compliance to add LWR irradiated fuel, assemblies to the authorized contents.

Phase I Evaluation of LWR Fuel Shipping

- Calculate detailed neutron-gamma shielding for PWR/BWR fuel with age ( 1 to 10 years old) as parameter.

- Use scoplng thermal calculations to assess spent fuel package wall temperatures and fuel basket design requirements.

- Assess containment adequacy (alternate head arrangement, seal adequacy, leak-check capability, etc.).

- Analyze cask and vehicle weight in detail.

- Assess current status of state restrictions regarding 73,280 ib vs. 80,000 lb GVW.

- Prepare designlayouts and sketches to support technical assessment of feasibility and cost estimate.

- Perform structural engineering to insure package limitations are not exceeded.

- Prepare a detailed program cost and schedule proposal for design certificate amendment, and acquisition of the FSV cask, with supporting technical documentation.

Note: Phase II - Evaluation of HLW Shipping will be the subject of a later report.

\subsection{Assumptions}

This evaluation of the FSV-I cask was based on the following information and/or assumptions:

- Neutron and gamma source terms supplied by Sandia Laboratories utilizing the SANDIA-ORIGEN computer code. 
- The inner container of the FSV-1 cask is removed.

- LWR irradiated fuel assemblies will be in welded, gas tight canisters.

- The closure system will be modified to provide an inner closure which does not require an inner container.

- Criticality control can be accomplished by administrative methods or poison inserts. A criticality study will not be a part of this evaluation.

- The following ground scatter corrections factors were used: For neutrull duse rate 1.4 For gamma dose rate - 1.1

- The reference PWR tuel aśsembly canlsiter was assuniej to be 12.75 inches 0.0 . by 169.89 inches long, without the pintle.

- The reference BWR fuel assembly canister was assumed to be 16.00 inches 0.0 . by 169.89 inches long without the pintle.

- The maximum allowable dose rate will be $10 \mathrm{mrem} / \mathrm{hr}$ at a distance of 6 feet from the edge of the vehicle (49CFRI73.393).

- The maximum allowable dose rate on the surface of the inner closure will be $50 \mathrm{mrem} / \mathrm{hr}$.

\subsection{Discussion}

In the data supplied, the gamma source term for Ag $110 \mathrm{~m}$, assuried the emission of a $2.75 \mathrm{MeV}$ photon $10 n \%$ of the time. This assumption results in an over estimation of the gamma dose rate. The amount of this overestimation varies with decay time and with the thickness of the gamma and neutron shielding. Aísó, in comparlsun willı ullier valuez currently used in the nuclear industry, the SANDIA-ORIGEN code, $(\alpha \cdot n)$ conversion is believed to, be high by a factor of 2 .

Unfortunately these concerns about the supplied data wore not discovered until the shielding study was nearly complete. Schedule and budget constraints did not allow the shielding study to be redone, however, the appropriate corrections were incorporated into the results presented in the shielding evaluation (Seclion 2.3 and in the summary (figure 1).

The information used to define the size, shape, and weight of the PWR and BWR irradiated fuel assembly canisters, especially in the case of BWR fuel, was obtained from preliminary design concepts, therefore these envelopes should be verified and/or updated as soon as better information becomes available. 


\subsection{LICENSING EVALUATION}

Prior to any use of the FSV-I cask for the transport of LWR irradiated fuel assemblies, the Certificate of Compliance (COC) must be amended to add the LWR fuel assemblies to the authorized contents. During this evaluation, particular attention was directed toward making those hardware changes and selecting the LWR fuel assemblies that have the least impact on the existing COC and thus there is a high probability that a revised COC will be obtained. The following subsections summarize the structural, thermal, shielding, and containment evaluation.

\subsection{Structural Evaluation}

The model.FSV-1 cask consists of an inner container which provides for the containment of the radioactive material and an outer body which provides the gamma shielding and the structural integrity. The current operational configuration is shown on drawing GADR 55-2-2 (Ref. 7.2).

When the FSV-l cask is used to ship canisterized LWR fuel assemblies, the inner container will be removed to provide a larger cavity, and since the inner closure is part of the inner container, the cask body will be modified to accommodate an inner closure that provides the gamma shielding and an outer closure that provides the structural integrity. The proposed modification to the closure system is shown on drawing SK3325-100, Issue B, Sheet 5 (Ref. 6).

The new inner closure has an attached seal assembly consisting of concentric silicone rubber seals. An external port on the upper surface of this closure allows for the evacuation of the seal interspace and thus verification that the closure is sealed. The inner closure further has provisions for sampling the contents of the cask cavity.

An impact limiter, similar to the existing one but slightly modified to accommodate the new outer closure configuration, provides protection for the closure system during the accident conditions of transport. These above descrlbed modifications will make the FSV-1 cask suitable for the transportation of some canisterized LWR irradiated fuel assemblies, based 
on burnup and decay. To extend the spectrum of LWR fuel that can be transported i.e.: higher burnup and shorter decay times, neutron shielding must be added to the exterior of the cask. Several different neutron shielding materials were considered in various thicknesses. Based on the feasibility of fabrication, the acceptable weight increase and a reasonable increase in the spectrum of LWR fuel assemblies which could be transported, a 3 inch layer of Boro-Silicone, protected with a stainless steel shell was selected for the conceptual design.

The modified closure design as evaluated was devised to minimize the amount of new structural analysis required to support the request for a revision to the Certificate of Compliance. All load'paths have remained the same or equivalent and the same impact limiter design has been retained. The weight increase for the package (cask and contents) has been kept to a minimum consistent with the requirements. When configured for the transport of HTGR fuel elements, the package weight is 47,587 pounds and the maximum weight of the package when configured for the transport of LWR fuel assemblies is 51,783 pounds. This is an increase in weight of 4196 pounds or $8.8 \%$. 


\subsection{Thermal Evaluation}

A thermal analysis was performed for a FSV-I cask as modified for shipping LWR spent fuel. The objective of the analysis was to determine the allowable fuel decay heat for a given cask surface temperature and the corresponding seal and canister temperatures. The following cask configurations regarding neutron shielding were considered: a cask with no additional shielding and a cask with 3 inches of external Borosilicone neutron shielding.

The curves (Figures 2.2-1 and 2.2-2) showing the allowable decay heat vs. the cask exterior temperature were generated assuming onedimensional, steady-state heat flow and balancing the heat fluxes at the exterior surface of the cask.

Figure 2.2-1 is the plot of the exterior surface temperature of the cask, without additional shielding vs. the fuel heat load. The ambient temperature is $130^{\circ} \mathrm{F}$, the insolation is $96 \mathrm{BTU} / \mathrm{HR} \mathrm{FT}^{2}$ (3314 watts solar heat load) and the surface emissivity is 0.5 .

Figure 2.2-2 is the plot of the exterior surface temperature with 3 inches of Boro-silicone neutron shielding added vs. the fuel heat load. The Boro-silicone is covered with a stainless steel protective skin which has a surface emissivity of 0.5 , the ambient temperature is $130^{\circ} \mathrm{F}$ and the insolation is 96 BTU/HR FT ( 4273 watts solar heat load).

Table 2.2-1 shows maximum, canister temperature, the inner and outer seal temperatures and the fuel heat load for the different cask shielding concepts. The results are for the $130^{\circ} \mathrm{F}$ day, an insolation of $96 \mathrm{BTU} / \mathrm{HR}{ }^{2} \mathrm{FT}$ and a cask surface temperature of $180^{\circ} \mathrm{F}$. The reported temperatures are for nominal internal gaps. The seal temperatures could vary approximately $\pm 5^{\circ} \mathrm{F}$ depending on gap selection, and the canister temperature could vary approximately $\pm 40^{\circ} \mathrm{F}$.

The external surface temperature of $180^{\circ} \mathrm{F}$ (Ref, 49CFR173.393) was selected to establish the maximum fuel heat load that could be transported without the use of a personnel barrier to prevent access to the surface of the cask. An insolation of 96 BTU/HR FT (Ref. GADR-55, Addendum I) and an ambient temperature of $130^{\circ} \mathrm{F}$ (Ref. USNRC Reg. Guide 7.8 were applied.' 


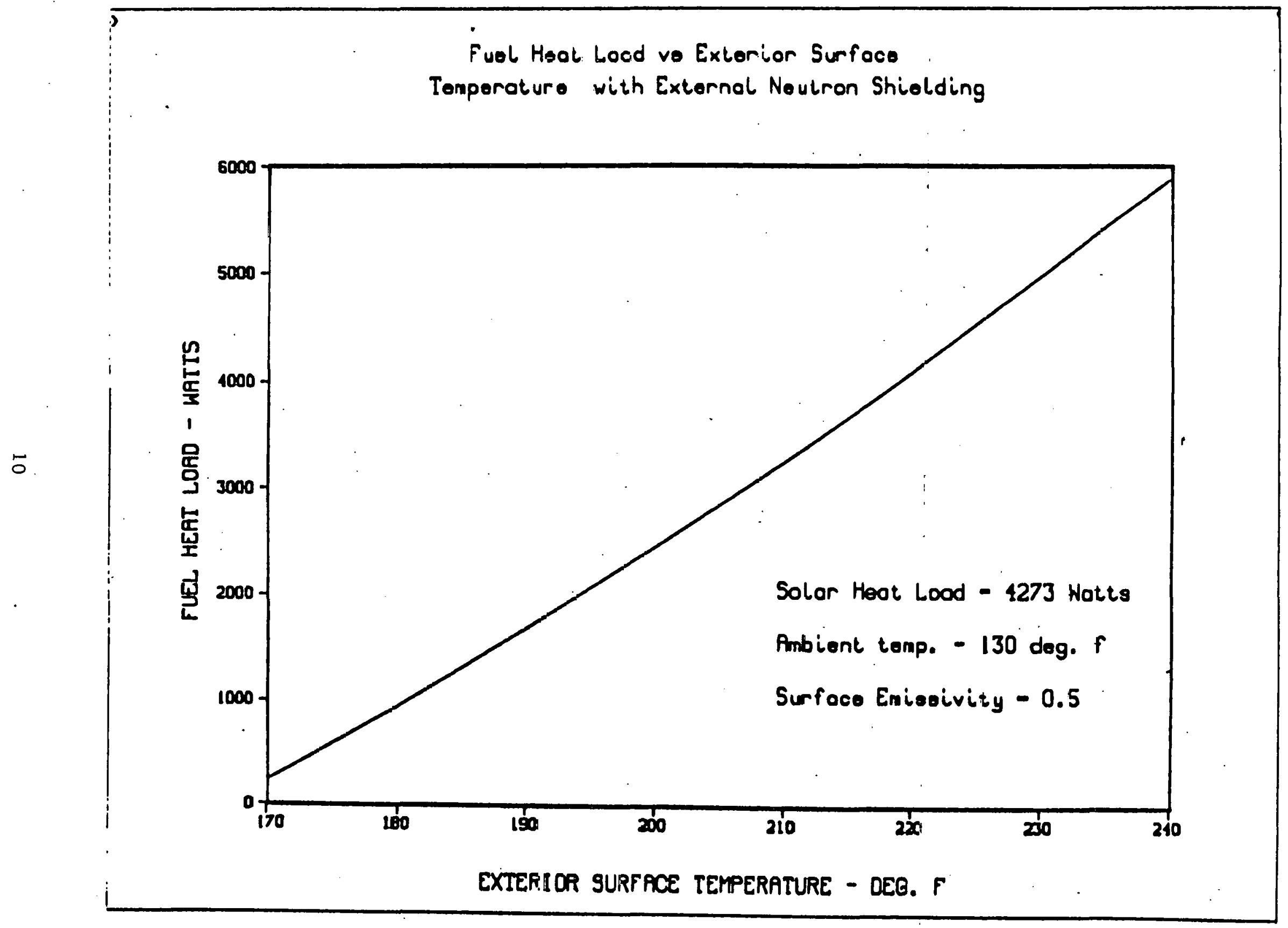

Figure 2.2-1 


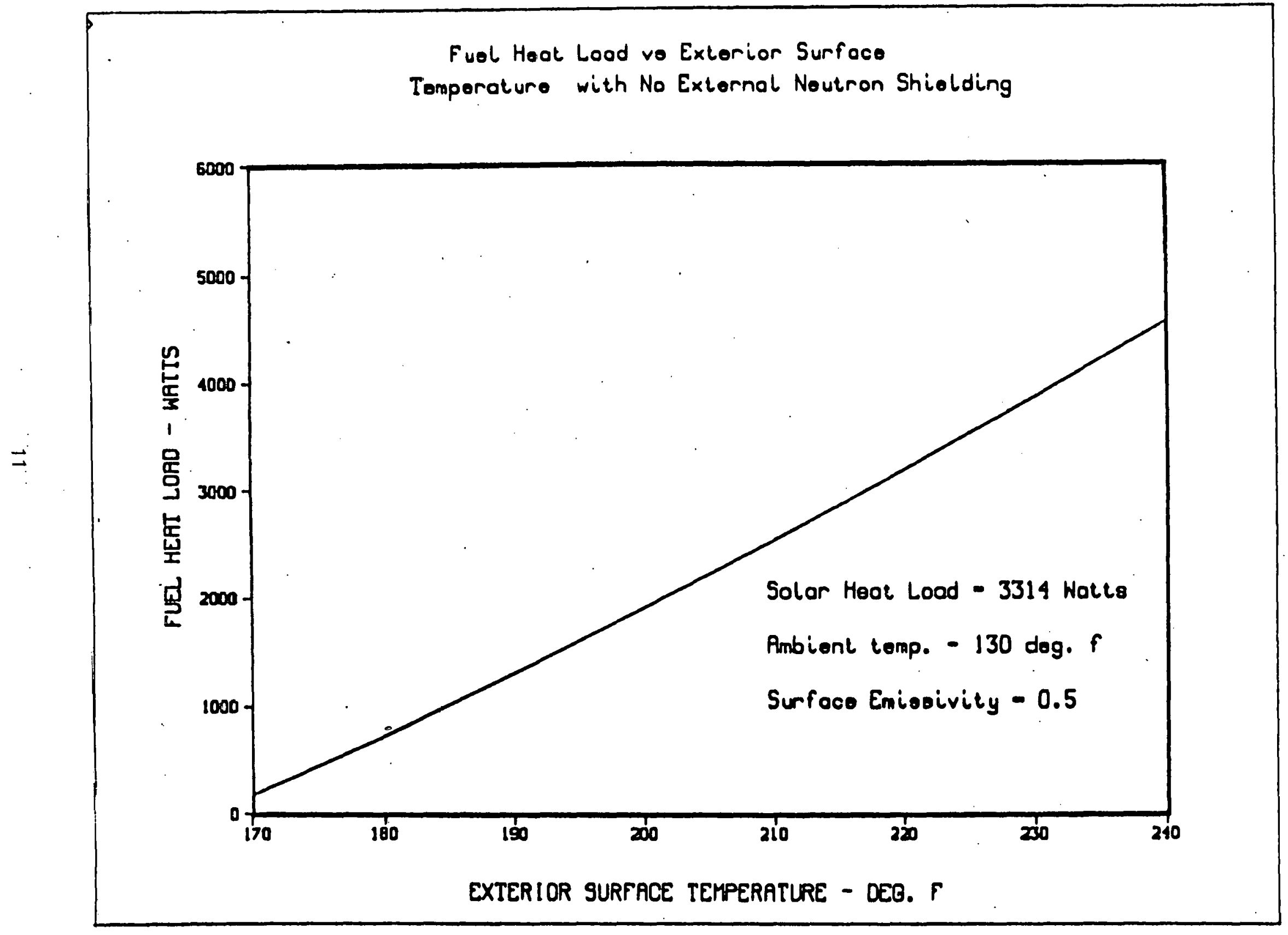

Figure 2.2-2 
CASK SEAL AND CANISTER TEMPERATURES

$\left(130^{\circ} \mathrm{F}\right.$ Ambient, $96 \mathrm{Btu} / \mathrm{hr} \mathrm{ft}^{2}$ Insolation and a Cask Exterior Temperature of $180^{\circ} \mathrm{F}$ )

$\begin{array}{cccc} & \text { First } & \text { Second } & \text { Fuel Heat } \\ \begin{array}{c}\text { Canister } \\ \left({ }^{\circ} \text { F }\right)\end{array} & \text { Seal } & \text { Seal } & \text { Load } \\ & \left({ }^{\circ} \text { F }\right) & \left({ }^{\circ} \text { F }\right) & \text { (watts) }\end{array}$

Unchielded rask

264

184

184

830

Boro-silicone external

281

200

200

895

shielding

Note: The USNRC Certificate of Compliance (6346 Rev 3) for the FSV-1 cask allows for contents with a maximum fuel heat load of 4.1 kilowatts. By allowing the exterior temperature to increase above $180^{\circ} \mathrm{F}$ the fuel heat load can be increased to the 4100 watt limit without exceeding the allowable seal temperature of $400^{\circ} \mathrm{F}$. 
Using this criteria the allowable fuel heat load is approximately 895 watts for the cask with neutron shielding and 830 watts for the cask without neutron shielding. These limits would not be very restrictive for PWR fuel assemblies after 5 years decay but would be restrictive for remaining spectrum of LWR fuel assemblies. Based on this analysis a personnel barrier will be included in the modifications to the FSV-I cask, however, the surface temperature of the cask will vary nearly directly as the ambient air temperature. Thus when the ambient temperature is expected to be $100^{\circ} \mathrm{F}$ or lower, all but a few LWR fuel assemblies with the highest heat loads can be transported without the use of the personnel barrier. 


\subsection{Shielding Evaluation}

The model FSV-l cask was evaluated for suitability for the shipment of Light Water Reactor (LWR) fuel; either one Pressurized Water Reactor (PWR) or three Boiling Water Reactor (BWR) fuel assemblies. Radiation dose rates were calculated based on the existing cask shielding and for several cases of additional gamma and neutron shielding. Both PWR and BWR fuels with a range of burnup and decay times were considered as the radiation source. Although several options of supplemental gamma and neutron shielding were analyzed, the addition of 3 inches of Boro-Silicone neutron shielding to the exterior of the FSV-l cask has been selected as the optimum for added shielding.

The Department of Transportation (DOT) external radiation dose rate (per 49CFR173.393) limit of $10 \mathrm{mrem} / \mathrm{hr}$ at 6 feet from the edge of the transport vehicle was used to determine which fuel assemblies. could be transported. Based on this determination the maximum burnup in Megawatt Days/Metric Ton Heavy Metal (MWD/MTHM) and the associated minimum decay time for each fuel type are:

\section{Transportable with No Supplemental Shielding}

$\begin{array}{lccc}\text { Type } & \text { Qudllilily } & \text { Burllup (MD/MTHM) } & \text { Decay (years) } \\ \text { PWR } & 1 & 15,000 & 1 \\ \text { PWR } & 1 & 23,000 & 2 \\ \text { PWR } & 1 & 30,000 & 5 \\ \text { PWR } & 1 & 32,000 & 10 \\ \text { BWR } & 3 & - & 1 \\ \text { BWR } & 3 & 12,500 & 2 \\ \text { BWR } & 3 & 18,000 & 5 \\ \text { BWR } & 3 & 25,000 & 10\end{array}$

Transportable with 3 Inches of Boro-Silicone Neutron Shielding

$\begin{array}{rrrr}\text { PWR } & 1 & 26,000 & 1 \\ \text { PWR } & 1 & 37,000 & 2 \\ \text { PWR } & 1 & 45,000 & 5 \\ \text { PWR } & 1 & >50,000 & 10 \\ \text { BWR } & 3 & - & 1 \\ \text { BWR } & 3 & 42,000 & 2 \\ \text { BWR } & 3 & 43,000 & 5 \\ \text { BWR } & 3 & >50,000 & 10\end{array}$

Note: The values in this table have been revised to reduce the SANDIA-ORIGEN $(\alpha, n)$ conversion by a factor of 2 and zero out the $2.75 \mathrm{MeV}$ group. 
The trade-off between burnup and decay for no additional shielding and for 3 inches of Boro-silicone neutron shielding is graphically displayed in Figure 2.3-1.

The information presented in this summary of the shielding evaluation has been revised to include a correction for the gamma decay and $\alpha, n$ conversion in the SANDIA-ORIGEN code. The data reported in the balance of the shielding evaluation is uncorrected. Due to the nature of the error in the reference code the uncorrected results are conservative, i.e.: LWR fuel assemblies with higher burnup and shorter decay time can be transported without exceeding the $10 \mathrm{mrem} / \mathrm{hr}$ at 6 feet criteria: 


\subsection{Containment Evaluation}

During the transport of HTGR fuel elements in the FSV-l cask, the primary containment boundary is provided by the inner container (reference 7.2). This inner container closure has a seal assembly with two concentric, silicone rubber seals. This arrangement provides for a seal interspace which is evacuated and the pressure rise monitored to verify an acceptable leakage rate prior to each use. The outer closure which seals to the cask body has a similar seal arrangement, which is tested for an acceptable. leakage rate as part of the annual testing and maintenance program for the FSV-I cask.

For this evaluation of the suitability of the cask for the transport of LWR irradiated fuel assemblies, the inner container is removed from the FSV-I cask to provide a larger cavity, and thus accommodate larger canisters. Without the inner container, the regulatory requirements for primary containment must be satisfied by other components of the shipping package, i.e. cask and/or contents.

There are four possibilities for providing the required containment during both the normal and accident conditions of transport:

Case 1 - Design the modified cask closure seals to satisfy the regulatory requirements concerning leakage rates for both normal and accident conditions of transport.

Case 2 - Design the LWR fuel canister to satisfy the regulatory requirements for "special form" material.

Case $3^{\prime}$ - Design the canister as a "containment vessel" and design the cask body to protect this "containment vessel".

Case 4 - Design the canister as a "containment vessel" fur nurmal conditions of transport and design the cask body closure to provide containment during accident conditions of transport.

For Case 1, the USNRC Regulatory Guide 7.4 "Leakage Tests on Packages for Shipment of Radioactive Materials", provides guidance to satisfy the requirements of $10 C F R 71$ by establishing leakage rates and leakage tests in accordance with ANSI N14.5, "Draft Amerlcan National Standard for Leakage Tests on Packages for Shipment of Radioactive Materials." 
The mechanical integrity of the cladding on LWR fuel elements should be adequate to provide containment of the pellets and the gases during the normal conditions of transport and could possibly provide containment during the accident conditions. The design and use of impact limiters probably controls whether the LWR fuel element cladding can survive the impact portion of the accident conditions of transport. Since the FSV-I cask does not use an impact limiter on the bottom of the cask, the survivability of the fuel element cladding is doubtful, and the closure seals will need to satisfy the leakage rates allowable for accident conditions of transport.

For Case 2 the regulatory requirements are imposed by $10 C F R 71$, subpart A, section 71.4 (0) (2) as follows:

"(0) "Special form" means any of the following physical forms of licensed material of any transport group:

(2) The material is securely contained in a capsule having no dimension less than 0.5 millimeter or at least one dimension greater than five millimeters, which will retain its contents if subjected to the tests prescribed in Appendix D of this part; and which is constructed of materials which do not melt, sublime, or ignite in air at $1,475^{\circ} \mathrm{F}$, and do not dissolve or convert into dispersible form to the extent of more than 0.005 percent by weight by immersion for 1 week in water at $68^{\circ} \mathrm{F}$. or in air at $86^{\circ} \mathrm{F} . "$

1OCFR, Part 71, APPENDIX D - TESTS FOR SPECIAL FORM LICENSED MATERIAL

"1. Free Drop - A free drop through a distance of 30 feet onto a flat essentially unyielding horizontal surface, striking the surface in such a position as to suffer maximum damage.

2. Percussion - Impact of the flat circular end of a 1 inch diameter steel rod weighing 3 pounds, dropped through a distance of 40 inches. The capsule or material shall be placed on a sheet of lead, of hardness number 3.5 to 4.5 on the Vickers scale, and not more than 1 inch thick, supported by a smooth essentially unyielding surface.

3. Heating - Heating in air to a temperature of $1,475^{\circ} \mathrm{F}$. and remaining at that temperature for a period of 10 minutes.

4. Immersion - Immersion for 24 hours in water at room temperature. The water shall be at $\mathrm{pH} 6-\mathrm{pH} 8$, with a maximum conductivity of 10 micromhos per centimeter." 
If the canister is qualified as "special form", the only containment concern will be the air or gas that occupies the space inside the cask and outside of the canister. This air or gas will not be "primary coolant" as defined in 10 CFR 71 but rather part of the authorized contents of the cask. If this air or gas contains no radioactivity, the closure seal can be considered a secondary seal. If the air or gas contains radioactivity, the leakage rate and leakage test determined per ANSI N14.5 will be applied to the inner closure seals.

For Case 3, the canister provides the containment as in case 2 , however, does not quallfy as "special form", but is protected by the cask body during the normal and accldent conditions of transport. Ihis "conlainment vessel" must be leakage tested per USNRC Regulatory Guide 7.4, prior to each shipment.

For Case 4 the canister functions as a "containment vessel" during" - the normal conditions of transport but is not designed nor protected by the cask body such that it survives the accident conditions of transport. The cask closure seals must, for this case, be leakage tested per USNRC Regulatory Guide 7.4 , using ANSI N14.5 to establish allowable leakage rates for the accident conditions of transport, prior to each shipment. This case is very sImllar to Llie LWR irradiated fuel shipping casks that can depend on the fuel rod cladding for containment during the normal conditinns of transport.

The present design concept for the FSV-l cask, modified for the transport of LWR irradiated fuel assemblies does provide for a seal assembly as part of the inner closure. This seal assembly can be leakaye tested and thus satisfy the requirements for a containment boundary. When the canister design is finalized, and its contribucion tuward satisfying primary containment is evaluated, the cask closure design and the cask handling (leakage testing) procedurcs can then be optimized. 


\subsection{Discussion of License Evaluation}

The final test of the suitability of the FSV-1 cask, appropriately modified, for the transport of LWR irradiated fuel assemblies will be the issuance of a revision to the Certificate of Compliance, which adds the LWR fuel the the authorized contents.

During this evaluation, considerable care has been used in the selection of the neutron shielding material, in the selection of the candidate LWR irradiated fuel assemblies and the design modifications, to limit the amount of analysis that will be required to support the request for a revision to the Certificate of Compliance.

Structural load paths for the modified design are the same or equivalent to the existing design. The weight increase in the package has been limited to slightly less than $9 \%$. Further structural analysis will be required to determine if the existing cask structure can accept this increase in weight. For most load conditions the applied stress levels are sufficiently below the allowable stress levels to accommodate this increase in the loads.

The current Certificate of Compliance authorizes contents with a total heat load of 4.1 kilowatts. Some of the LWR irradiated fuel assemblies selected for transport in the modified FSV-l cask could have a heat load, slightly greater than $4.1 \mathrm{kw}$. The existing fuel heat load limit is based on the expected decay heat from 6 irradiated HTGR fuel elements after 100 days decay rather than any finite capacity of the FSV-I cask. If it is desirable to ship the few LWR fuel assemblies with decay heat in excess of $4.1 \mathrm{kw}$, the appropriate revision to the Certificate of Compliance appears feasible.

The spectrum of LWR irradiated fuel assemblies that can be transported in the modified FSV-l cask will be limited by the neutron and gamma shielding. Specific radiation levels, external to the cask, arc not a part of clie Certificate of Compliance, however, the regulatory requirement of 49CFR173.393 must be satisfied prior to each shlpment. Therefore, that spectrum of LWR fuel assemblies that will not exceed the allowable radiation levels, should be identified in the authorized contents. 
Since the containment boudary for the FSV-l cask, when configured for the transport of HTGR fuel, is provided by the inner container, removing this container during the transport of LWR fuel assemblies will require that another containment boundary be identified in the revised Certificate of Compliance. Containment of radioactive material within a shipping package (cask and contents) may be provided by the cask or the contents or some kombination of both, i.e. the contents may provide containment for normal conditions of transport and the cask may provide containment for accident conditions of transport.

The design concept for the modified inner closure for the FSV-1 has provisions for a seal that can be leakage tested and thus satisfy the requirements for a containment boundary. There are two existing penetrations in the base of the cask body that will become part of the containment boundary when the inner container is removed. Although the seals associated with these penetrations are not easily leakage tested, these penetrations are not opened and closed when the cask is loaded or unloaded and thus the seals are not disturbed and a periodic leakage test may be justifiable. 


\subsection{INTRODUCTION}

\subsubsection{Design Shielding Analysis for HTGR Fuel}

The Final Design Report for the FSV-1 fuel shipping cask (Ref. 3-1) describes the engineering analyses which.led to the final design shown in Reference 6.2. It covers the physical dimensions and materials of construction, weight calculations, stress analysis, shielding analysis, heat transfer analysis, criticality analysis, and several other facets of the overall design.

The original shielding analysis for the FSV-I cask was performed in 1967 utilizing the PATH gamma shielding code (Ref. 3-2). At that time, little was known about the possible emission of neutrons from spent fuel, but fortunately later studies (Ref. 3-3) showed that the neution emission from HTGR spent fuel was minimal because of the numerous capture events needed to transmute $\mathrm{TH}-232$ or $\mathrm{U}-233$ to $\mathrm{Cm}-242$ or $\mathrm{Cm}-244$. Hence, the design of the FSV-l cask with only stainless steel and depleted uranium gamma shielding proved to be the correct approach for the transport of HTGR spent fuel.

In 1977 and 1978 the closure system for the FSV cask was reanalyzed and modified in order to reduce the external radiation levels during the cask handling procedures. Details of this modification are reported in an addendum to the original design report. (Ref. 3-4).

Finally, in 1979 some actual dose-rate measurements became available when the cask was used to transport a surveillance spent fuel element from Fort St. Vrain to GA. The calculated gamma dose rates on the surface of the cask were within a factor of two of the measured dose rates (Ref. 3-5), and hence, the shielding design of the cask for the transport of HTGR fuel elements is essentially as claimed in the design report. 


\subsubsection{Earlier LWR Application Studies}

Possible use of the FSV-I cask for the shipment of LWR spent fuel was first considered in 1971 (Ref. 3-6). It was recognized at this time that some form of neutron shielding might have to be added in order to accommodate LWR fuel with appreciable burnup. A series of independent studies on LWR shipping cask concepts (Ref. 3-7) confirmed this conclusion.

Further studies were performed on shipping cask applications in 1978 (Ref. 3-8): It was assumed that the FSV-1 cask could accommodate one PWR assembly or four BWR assemblies, and that only neucrun bliielding could be added to the cask. The preliminary results from this 1978 study are shown in Table 3-1.

As will be shown, these earlier results, especially for the PWR, did correctly predict the trend of noutron shield requirements for the FSV-1 cask. However, a much more accurate analysis was needed, utilizing up-dated source terms and adequate computer calculations.

\subsubsection{Purpose of Present Shielding Study}

The purpose of the present shielding study on the FSV-l cask is to determine with a good degree of certainty its adequacy to transpuit LWR spent fuel elements with or without additional shielding. It differs from previous studies in making more extensive use of discrete ordinates transport calculations and utilizing more timely and complete injut information on source terms and fuel element configuration. The planned steps in this study included:

1. Gather input infurmation (burnup, specific power, power distribution, decay time, source terms, geometry, composition, container details, changes in dose rate criteria if any, etc.)

2. Calculate side neutron dose rates as function of neutron shielding thickness and location using the I-D DTFX transport code. Also calculate secondary fissions and capture gamma production. 
TABLE $3-1$

SUMMARY OF 1978 RESULTS - LWR FUEL WHICH COULD BE SHIPPED IN FSV-1 CASK

\begin{tabular}{|c|c|c|}
\hline \multirow[b]{2}{*}{. } & \multicolumn{2}{|c|}{ Burnup (MWD/MTHM) } \\
\hline & PWR & BWR \\
\hline \multirow{2}{*}{\multicolumn{3}{|c|}{$\begin{array}{l}\text { No Additional Shielding } \\
\text { Decay Time (yr) }\end{array}$}} \\
\hline & & \\
\hline 1 & Unfeasible & Unfeastble \\
\hline 2 & 20,000 & 18,000 \\
\hline 3 & 23,500 & 22,000 \\
\hline 10 & 26,500 & 24,500 \\
\hline \multicolumn{3}{|c|}{$\begin{array}{l}\text { 4-in. Neutron Shielding Added } \\
\text { Decay Time }(\mathrm{yr})\end{array}$} \\
\hline 1 & Unfeasible & Unfeasible \\
\hline 2 & 37,500 & 37,000 \\
\hline 3 & 45,000 & 41,500 \\
\hline 10 & $>50,000$ & 50,000 \\
\hline
\end{tabular}


3. Calculate side gamma dose rates as function of neutron shielding thickness and location, including primary and secondary sources, using the PATH gamma-shielding code or DTFX transport code.

4. Create parametric curves from 2 and 3 to permit a selection of neutron/gamma split and appropriate neutron shield thickness. Include approximate corrections for ground scattering.

5. Perform dose rate calculations at ends of cask.

This shielding writeup will cover the methodology and calculational approach, source terms, geometry and compositions, and results. Presentation of the results has been carefully tailored to provide the qulckest answer to the question "How can the FSV-I best carry LWR tuel of $x$ burnup. and $Y$ decay time?"

\subsection{METHODOLOGY AND CALCULATIONAL APPROACH}

\subsubsection{Design Criteria}

The maximum permissible radiation dose rates during transport are established by Title 49, Code of Federal Regulations, Part 173,393. The specific limit used for this study is: $10 \mathrm{mrem} / \mathrm{hr}$ at a distance of 6 foet from the edge nf the transport vehicle. Design guidance from the NWTS Test Program further limits the radiation dose rate rur cunlacl operations to a maximum of $50 \mathrm{mrem} / \mathrm{hr}$. This 1 imit of $50 \mathrm{mrcm} / \mathrm{hr}$ is applicable to the outer surface of the inner closure prior to the installation of the outer closure.

\subsubsection{Direct Neutron Calculations}

Direct neutron calculations were performed using the one-dimensional transport code DTFX (Ref. 3-20). This code numerically solves (by the method of discrete ordinates) the multigroup form of the neutron transport equation in one-dimensional plane, cylindrical, and spherical geometries. Due to the long cylindrical geometries involved, one-dimensional analysis is more than adequate. The DTFX code just described was chosen because of its calculational method and simplicity of use. 
The neutron flux-to-dose-rate conversion factors used in the DTFX calculations were obtained from Ref. 3-9 and are shown in Figs. 3-1 and 3-2 for neutron energies from $10^{-8}$ to $10^{2} \mathrm{MeV}$. Table 3-2 gives the conversion factors for the energy ranges used in DTFX.

Neutron calculations were performed using a neutron spectrum normalized to $1 \mathrm{n} / \mathrm{cm}^{3}-\mathrm{sec}$. The results of the DTFX computer calculation were then multiplied by the appropriate neutron source strength for a fuel element with a specific burnup and decay time. The cylindrical calculations were run in the $P_{3}, S_{8}$ application. Slab geometry was utilized with $S_{16}$ quadrature for the top and bottom dose rate calculation with correction factors applied to the results to correct for the actual finite slab geometry.

The DTFX neutron calculations were run for two cases: (1) the FSV-I cask without additional shielding and (2) the FSV-I cask with 3 in. of nuetron shield added to the outside. Both of these cases considered no additional gamma shield. In order for parametric studies to be analyzed, Figs, 3-3 and 3-4 were utilized for neutron dose rate generation. For example, the neutron data for no neutron shield and 1 in. gamma shield is generated by multiplying the data for no neutron and no gamma shield by the 1 in. factor in Fig. 3-3. The same method is applied to all other studies.

\subsubsection{Direct Gamma Calculations}

Uirect gamma calculations were accomplished with the help of the point-kernel computer code PATH (Ref. 3-2). This code is based upon exponential attenuation from source point to dose point, adjusted by appropriate buildup factors. The flux-to-dose-rate conversion factors were adjusted to comply with the ANS Standard 6.1.1 (Ref. 3-9). This data standard is shown in Fig. 3-5 for gammas with energies between $10^{-2}$ and $10^{2} \mathrm{MeV}$. Table 3-3 tabulates these factors for 38 discrete photon energles. Corrections for multilayer buildup were also applled, since the calculations performed by most point-kernel codes take into account only one-layer bulldup factors. Corrections for two-layer configurations of iron and uranium (Ref. 3-10) were applled when deemed appropriate. 


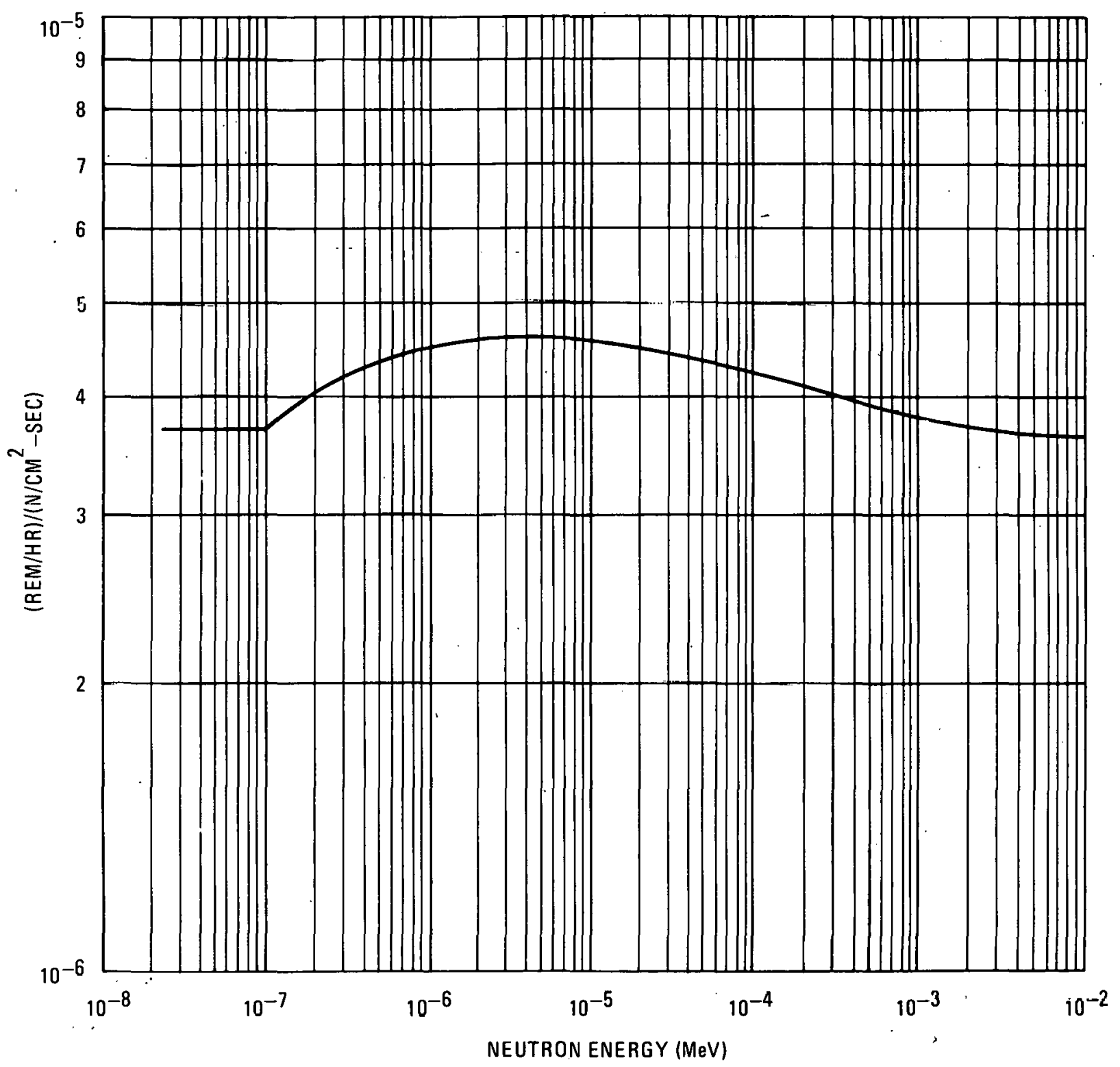

F1g. 3.1. Neutron dose-to-flux conversion factore

vs. neutron energy 


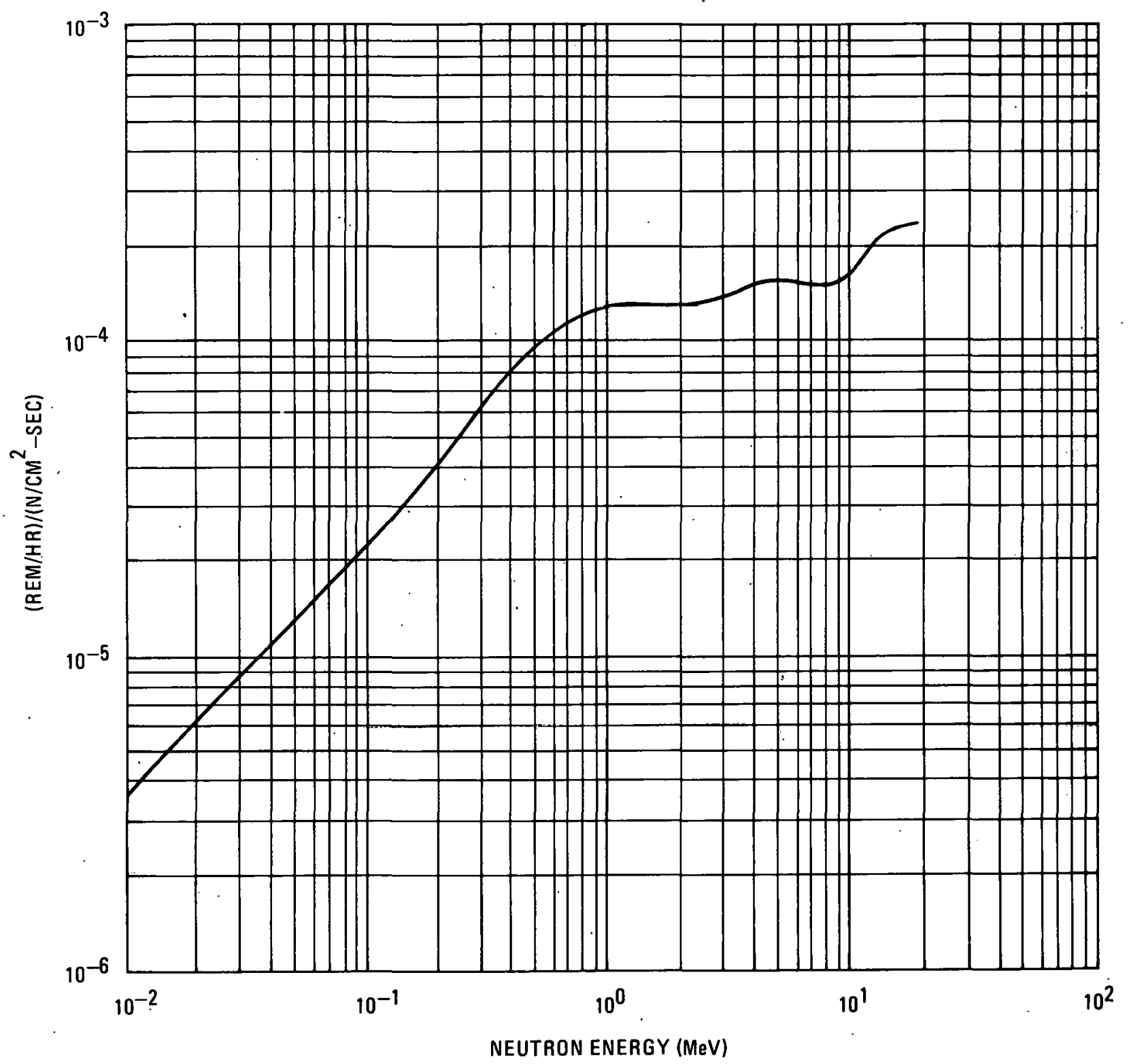

F1g. 3-2. Neutron dose-to-flux conversion factors vs. neutron energy 
TABLE 3-2

SOURCE INPUT AND DOSE CONVERSION FACTORS FOR ORNL 36 GROUPS

\begin{tabular}{|c|c|c|c|}
\hline Group (a) & Energy Range & $\begin{array}{c}\text { Midpoint } \\
\text { Energy }\end{array}$ & $\begin{array}{l}\text { Conversion Factor } \\
\left(\frac{\mathrm{rem} / \mathrm{hr}}{\text { Particles } / \mathrm{cm}^{2}-\mathrm{sec}}\right)\end{array}$ \\
\hline $\begin{array}{r}1 \\
2 \\
3 \\
4 \\
5 \\
6 \\
7 \\
8 \\
9 \\
10 \\
11 \\
12 \\
13 \\
14 \\
15 \\
16 \\
17 \\
18 \\
19 \\
20 \\
21 \\
22 \\
23 \\
24 \\
25 \\
26 \\
27 \\
28 \\
29 \\
30 \\
31 \\
32 \\
33 \\
34 \\
35 \\
36\end{array}$ & $\begin{array}{l}14.9-6.70 \mathrm{MeV} \\
6.70-3.68 \\
3.68-2.02 \\
2.02-1.35 \\
1.35-0.907 \\
0.907-0.498 \\
0.498-0.334 \\
0.334-0.18 .3 \\
0.183-0.123 \\
123-52.5 \mathrm{KeV} \\
52.5-40.9 \\
40.9-24.8 \\
24.8-15.0 \\
15.0-7.10 \\
7.10-3.35 \\
3.35-1.23 \\
1.23-0.454 \\
0.454-0.101 \\
101-47.9 \mathrm{eV} \\
47.9-22.6 \\
22.6-10.7 \\
10.7-2.38 \\
2.38-1.13 \\
1.13-0.414 \\
0.414-0.1 \\
0.1-0.0 \\
13-8 \mathrm{MeV} \\
8-1.92 \\
4.92-3.03 \\
3.03-1.86 \\
1.86-1.15 \\
1.15-0.105 \\
0.705-0.34 \\
0.34-0.129 \\
0.129-0.049 \\
0.049-0.03 \\
\end{array}$ & $\begin{array}{l}10.8 \mathrm{MeV} \\
5.19 \\
2.85 \\
1.68 \\
1.13 \\
0.7 \\
0.42 \\
0.26 \\
0.15 \\
87.8 \mathrm{KeV} \\
46.9 \\
32.9 \\
19.9 \\
11.0 \\
5.2 \\
2.3 \\
0.84 \\
0.28 \\
74.5 \mathrm{eV} \\
35.3 \\
16.7 \\
6.5 \\
1.8 \\
0.77 \\
0.26 \\
0.05 \\
10.5 \mathrm{MeV} \\
6.5 \\
4.0 \\
2.5 \\
1.5 \\
0.93 \\
0.53 \\
0.24 \\
0.09 \\
0.04\end{array}$ & $\begin{array}{l}1.6-4 \\
1.5-4 \\
1.3-4 \\
1.3-4 \\
1.3-4 \\
1.1-4 \\
8.1-5 \\
5.2-5 \\
3.0-5 \\
2.0-5 \\
1.2-5 \\
9.1-6 \\
6.0-6 \\
3.8-6 \\
3.6-6 \\
3.7-6 \\
3.8-6 \\
4.0-6 \\
4.2-6 \\
4.3-6 \\
4.4-6 \\
4.5-6 \\
4.4-6 \\
4.3-6 \\
4.1-6 \\
3.7-6 \\
9.3-6 \\
6.9-6 \\
5.0-6 \\
3.6-6 \\
2.7-6 \\
1.9-6 \\
1.2-6 \\
5.9-7 \\
2.8-7 \\
4.4-7\end{array}$ \\
\hline
\end{tabular}

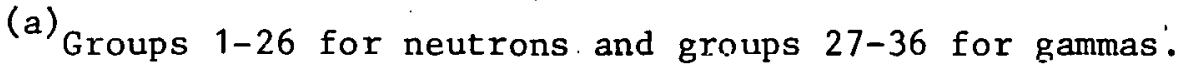




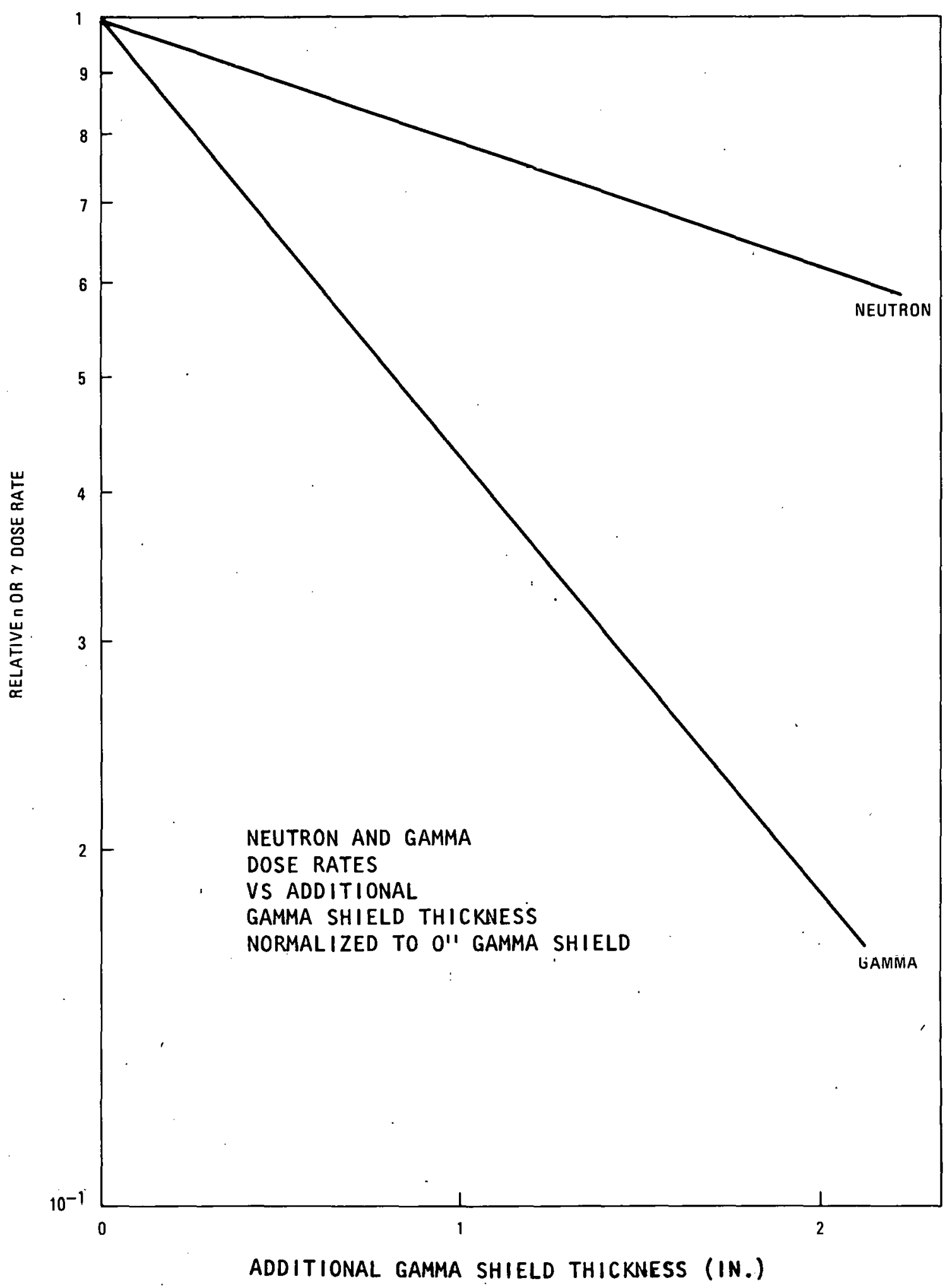

F1g, 3-3. Neutron and gamma dose rates vs additipnal gamma shield thickness normalized to 0 " additional gamma shielding 


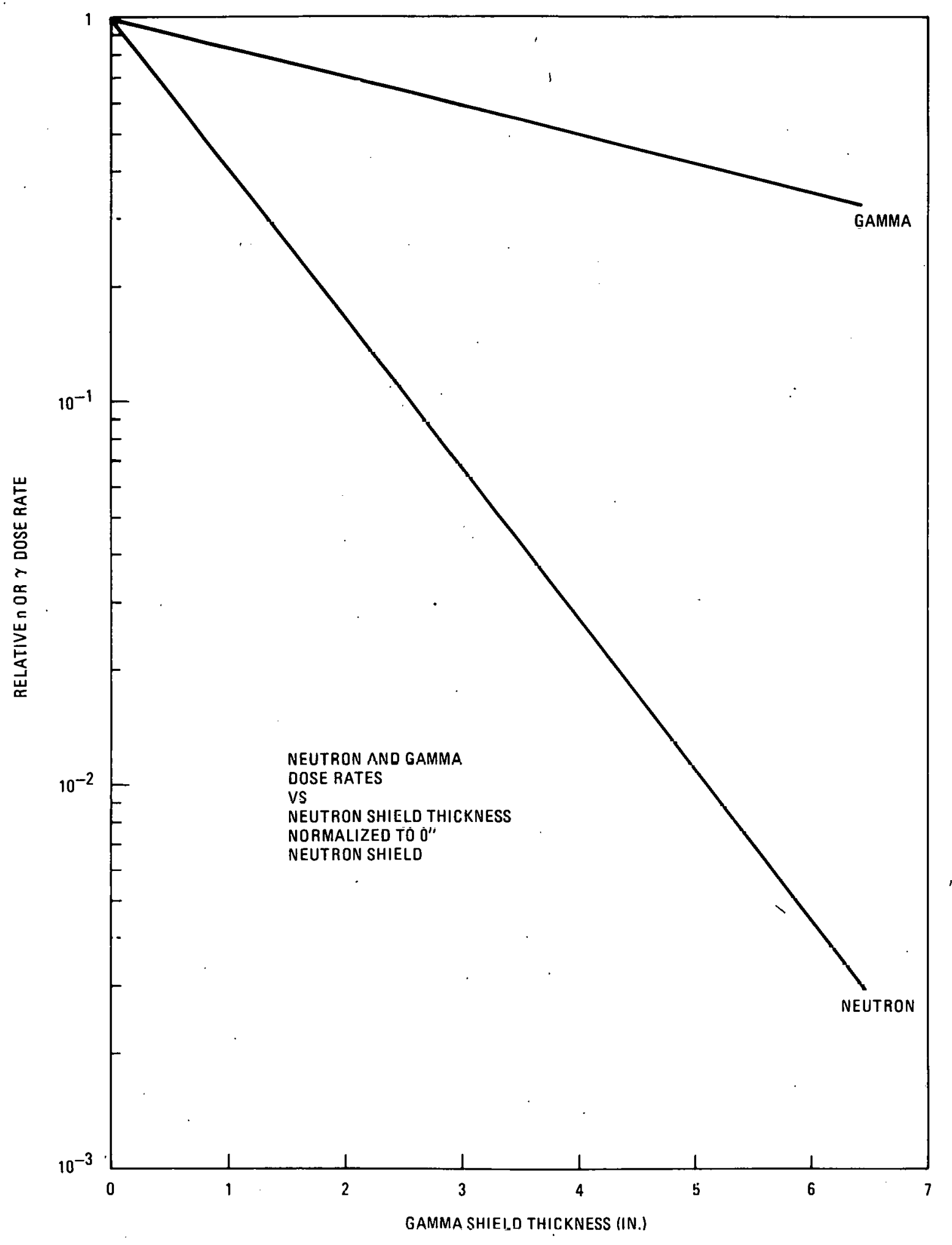

Fig. 3-4. Neutron and gamma dose rates vs neutron shield thickness normalized to 0 " neutron shield 


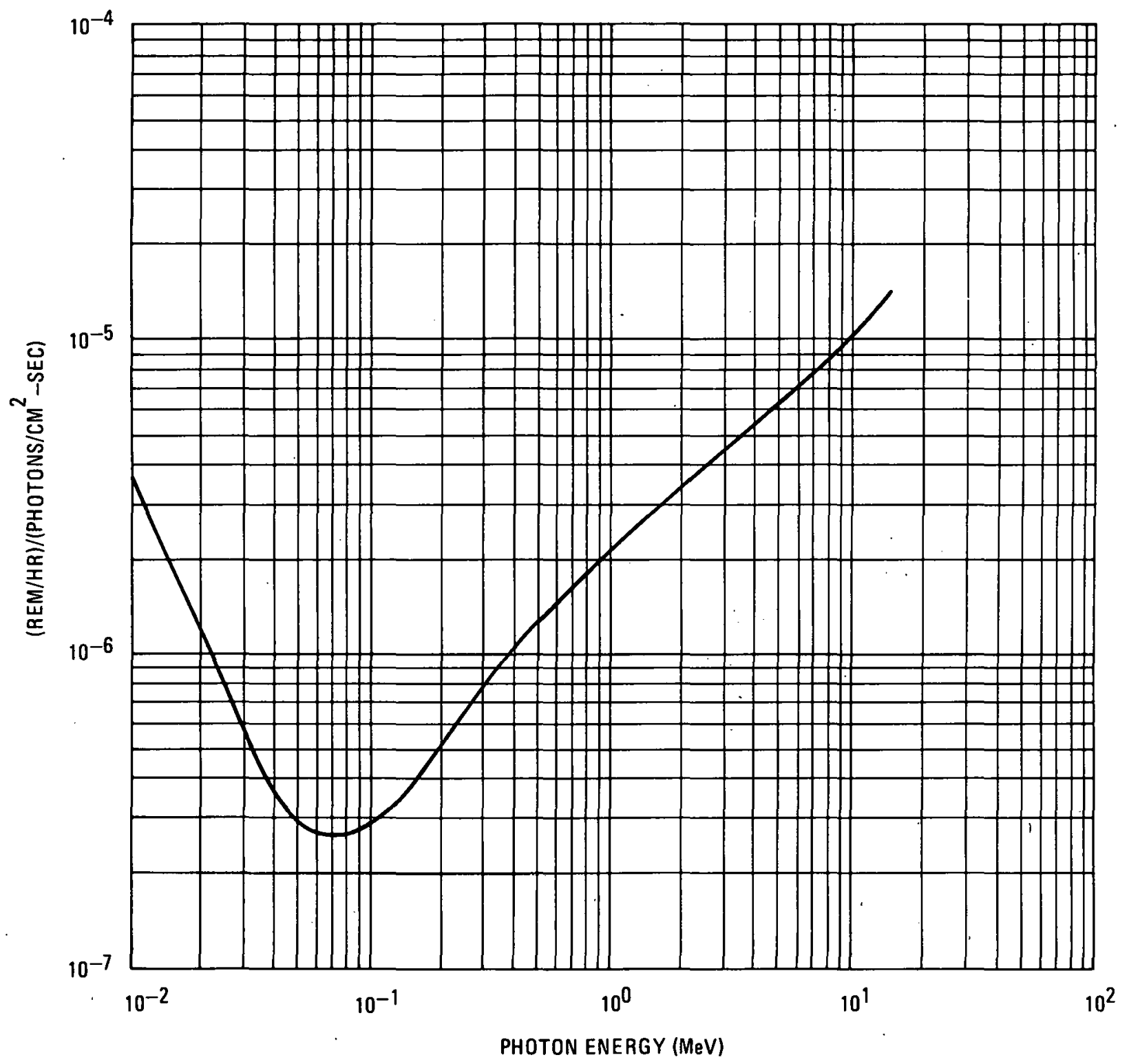

Fig. 3-5. Photon dose-to-flux conversion factors vs. photon energy 
TABLE 3-3

GAMMA-RAY FLUX-TO-DOSE-RATE CONVERSION FACTORS

\begin{tabular}{|c|c|}
\hline $\begin{array}{c}\text { Photon Energy } \\
(\mathrm{MeV})\end{array}$ & $\begin{array}{c}(\mathrm{rem} / \mathrm{hr}) / \\
\left.\text { (photon } / \mathrm{cm}^{2}-\mathrm{sec}\right)\end{array}$ \\
\hline 0.01. & $3.96-06$ \\
\hline 0.03 & $5.82-07$ \\
\hline 0.05 & $2.90-07$ \\
\hline 0.07 & $2.58-07$ \\
\hline 0.1 & $2.83-07$ \\
\hline 0.15 & $3.79-07$ \\
\hline 0.2 & $5.01-07$ \\
\hline 0.25 & $6.31-07$ \\
\hline 0.3 & $7.59-07$ \\
\hline 0.35 & $8.78=07$ \\
\hline 0.4 & $9.85-07$ \\
\hline 0.45 & $1.08-06$ \\
\hline 0.5 & $1.17-06$ \\
\hline 0.55 & $1.27-06$ \\
\hline 0.6 & $1.36-06$ \\
\hline 0.65 & $1.44-06$ \\
\hline 0.7 & $1.52-06$ \\
\hline 0.8 & $1.68-06$ \\
\hline 1.0 & $1.98-06$ \\
\hline 1.4 & $2.51-06$ \\
\hline 1.8 & $2 . y y-06$ \\
\hline 2.2 & $3.42-06$ \\
\hline 2.6 & $3.87-06$ \\
\hline 2.8 & $4.01-06$ \\
\hline 3.25 & $4.41-06$ \\
\hline 3.75 & $4.83-06$ \\
\hline 4.25 & $5.23-06$ \\
\hline 4.75 & $5.60-06$ \\
\hline 5.0 & $5,80-06$ \\
\hline 5.25 & $6.01-06$ \\
\hline 5.75 & $6.38-06$ \\
\hline 6.25 & $6.74=06$ \\
\hline 6.75 & $7.11-06$ \\
\hline 7.5 & $7.66=06$ \\
\hline 9.0 & $8.77-06$ \\
\hline 11.0 & $1.03-05$ \\
\hline 13.0 & $1.18-05$ \\
\hline 15.0 & $1.33-05$ \\
\hline
\end{tabular}


All PATH gamma-ray calculations for PWR fuel were run assuming that the fuel element burnup was 20,000 MWD/MTHM with a decay time of $1 \mathrm{yr}$. Calculational results for the remaining cases of burnup and decay time were obtained using the following equation:

$$
\begin{aligned}
& D R(B, t)=\sum_{i=1}^{6} D R_{i}(20000,1) \times \frac{s_{i}(B, t)}{s_{i}(20000,1)} \\
& \text { where } D R(B, t)=\text { total dose rate due to a fuel element with } \\
& \text { burnup } B \text { and decay time } t, R / h r \text {, } \\
& \mathbf{i} \text { = gamma energy group index, } \\
& \operatorname{DR}_{i}(20000,1)=\text { dose rate due to energy group } i \text { with burnup } \\
& \text { equal to } 20,000 \text { MWD/MTHM and decay time equal } \\
& \text { to } 1 \mathrm{yr}, \mathrm{R} / \mathrm{hr} \text {, } \\
& S_{i}(B, t)=\text { source strength of energy group } i \text { for a specific } \\
& \text { burnup } B \text { and decay time } t \text {, photons } / \mathrm{cm}^{3}-\mathrm{sec} \text {., } \\
& S_{i}(20000,1)=\text { source strength of energy group } i \text { for a burnup } \\
& \text { of } 20,000 \mathrm{MWD} / \mathrm{MTHM} \text { and decay time } 1 \mathrm{yr} \text {, photons } / \mathrm{cm}^{3}-\mathrm{sec} \text {. }
\end{aligned}
$$

PATH gamma calculations off the side of the cask considered 0,3 , and 6-in. of neutron shield added to the outside. Parametric studies involving extra added gamma shield were calculated the same way as the neutron studies explained earlier. Dose point locations were taken $6 \mathrm{ft}$. from the edge of the transport vehicle (119 in. from center of cask). Gamma calculations for the rear of the cask considered dose point locations on the bottom surface of the cask and $6 \mathrm{ft}$. from the rear of the cransport vehicle (154 in. from bottom of cask).

\subsubsection{Ground Scattering}

The effect of ground scattering of radiation has been widely calculated and reported in the literature (for instance, see Ref. 3-11). Much of this work was done in connection with the Aircraft Nuclear Propulsion program, the space program, and the civil defense program. 
The ground-scattered dose rate from the NL 10/24 cask was calculated in some detail by NL Industries (Ref. 3-12). For the normal case of $6 \mathrm{ft}$. from the edge of the transport vehicle, the ground-scattered neutron dose rate was $40 \%$ of the direct neutron dose rate, while the ground-scattered gamma dose rate was $2.3 \%$ of the direct gamma dose rate. Other investigators have found somewhat higher gamma scattering percentages (Ket. 3-11). For this shielding study, the correction factors for ground scatter were taken as 1.4 for neutrons and 1.1 for gammas.

\subsection{SOURCE TERMS}

Neutron and gamma source terms were supplicd by Sandia Laboratories, utilizing the SANDIA-ORIGEN computer code (Ref. 3-13). ORIGEN runs were made for the following four cases:

Case 1: PWR fuel assembly, 20,000 MWD/MTHM burnup, 37.3 MW/MTHM specific power, $3.3 \%$ enrichment, $80 \%$ load factor, fuel removed from core just before end of second year in reactor.

Case 2: FWR fucl assembly, 33000 MWD/MTHM burnup, other quantities same as Case 1 , fuel removed from core after three years.

Case 3: PWR fuel assembly, 40,000 MWD/MiHM burnup, 45.2 MW/MTHM specific power, other' quantities same as case 2.

Case 4: BWR fuel assembly, 34,000 MWD/MTHM burnup, 2.66\% enrichment, $80 \%$ load factor, fuel removed after four years, variable specific power as follows:

$\begin{array}{ll}33.3 \mathrm{MW} / \mathrm{MTHM} & \text { 1st burnup phase } \\ 32.0 \mathrm{MW} / \mathrm{MTHM} & \text { 2nd burnup phase } \\ 29.4 \mathrm{MW} / \mathrm{MTHM} & \text { 3rd burnup phase } \\ 28.8 \mathrm{MW} / \mathrm{MTHM} & 4 \text { th burnup phase }\end{array}$

ORIGEN, with its extensive and impressive printout, is only-as good as its stored nuclear data. An effort will be made in the near future to identify the differences between ORIGEN-1, SANDIA-ORIGEN, and ORIGEN-2. In the meantime, a general discussion of the source terms and their relative importance will have to suffice. 


\subsubsection{Fission Products}

SANDIA-ORIGEN calculates the inventories of 708 fission products. The flux and burnup calculations utilize only three neutron-energy groups (fast, resonance, thermal). These three groups are collapsed into a single group for the actual burnup calculations. Presumably, the cross section averaging is done for an average $\mathrm{mix}$ of fuel, moderator, fission products, actinides, poison, and structure at an average temperature. As certain high-cross-section products build up, it is obvious that the single-group cross sections will become more and more approximate (as self-shielding and flux spectrum changes occur). Therefore, uncertainties in the fission-product inventories -- especially for high burnup -- are to be expected.

The ORIGEN code prints out a complete nuclide listing of fission products as a function of decay time, in units of gram atoms, grams, and curies. These quantities are then converted to watts of decay heat and $\mathrm{MeV} / \mathrm{sec}$ of gamma emission (by photon energy group). In Table A-l of the appendix, the gamma source strengths for the three PWR cases and the single BWR case are reproduced directly from the SANDIA-ORIGBN runs.

There is no direct way to clearly identify which nuclides are contributing the most to the shielded dose rate, since the nuclide emissions are summed together. However, as will be shown later, the 1.99- and 2.75$\mathrm{MeV}$ photon groups are the most important, thus strongly suggesting that $\mathrm{Pr}-144$ is a major contributor to the shielded gamma dose rate at one to three years' decay. The $2.75 \mathrm{MeV}$ energy group contributor was found to be (erroneously) Ag-110m, a matter which will be discussed later. In any follow-on study, the fission yeelds, absorption cross sections, and emission spectra being used in ORIGEN for Ce/Pr-144 and Ru/Rh-106 should be carefully evaluated.

\subsection{2 "Actinides}

The actinldes of most importance to the FSV-l cask shielding study. are $\mathrm{Pu}-238, \mathrm{Cm}-242$, and $\mathrm{Cm}-244$, all of which emit neutrons by spontaneous fission and/or alpha-n reactions. The ORIGEN code tabulates actinides by 
gram-atoms, grams, and curies, along with conversions to watts and $\mathrm{n} / \mathrm{sec}$. The actinide listing is a little more helpful than the fission product listing in that neuțron emission rates are given by nuclide.. For example, the $\mathrm{CM}-244$. emission rates are $2.38+3(\alpha, n)$ neutrons/Ci-sec and $1.41+5$ spontaneous. fission neutrons/Ci-sec. The $(\alpha, n)$ yield is approximately twice that calculated for $\mathrm{UO}_{2}$ (Ref. 3-14). In the case of $\mathrm{Cm}_{\mathrm{I}}-242$, the $(\alpha, n)$ yield used in ORIGEN is $2910 \mathrm{n} / \mathrm{Ci}-\mathrm{sec}$, a factor of $2.5 \mathrm{higher}$. Therefore, the neutron source terms (as listed in Table A2 of the appendix) are probably somewhat curservative. The relative yields of $\mathrm{Cm} 242$ and $\mathrm{Cm} 244$ are shown graphically in Figs. 3-6 to 3-9.

\subsubsection{Activitatinn Products}

The ORIGEN code also calculates activation products (i.e. structural materials; activitated fission products such as Cs-134 are considered under fission products). This information is not partlcularly relevant to this study for three reasons:

1. Most of the fuel assembly structure is located at either end of the asscmbly, but in the SANDIA-QRIGEN runs it is homogenized with the fuel. Thus, the structural activitalion levels are not necessarily correct.

2. Stainless steel was assumed to be completely free of cobalt.

3. In any event, gamma emission from the structural materials is negligible compared with that from the fission products (compare Table A-3 with Table A-1 In the appendix).

\subsubsection{Input Data}

The neutron source strength data used as input for. DTFX is due to the actinides present in the fuel assembly. Table 3-4 and Fig. 3-10 give the neutron source strengths for different PWR and BWR burnups as a function of decay time. The neutron source spcctrum was also obtained from Ref. 3-12. Table 3-5 shows the spectrum collapsed into the DTFX input energy groups and normalized to 1 neutron $/ \mathrm{cm}^{3}-\mathrm{sec}$. This source spectrum is also shown in Fig. 3-11 and agrees quite well with previously published work (Ref.3-15). 


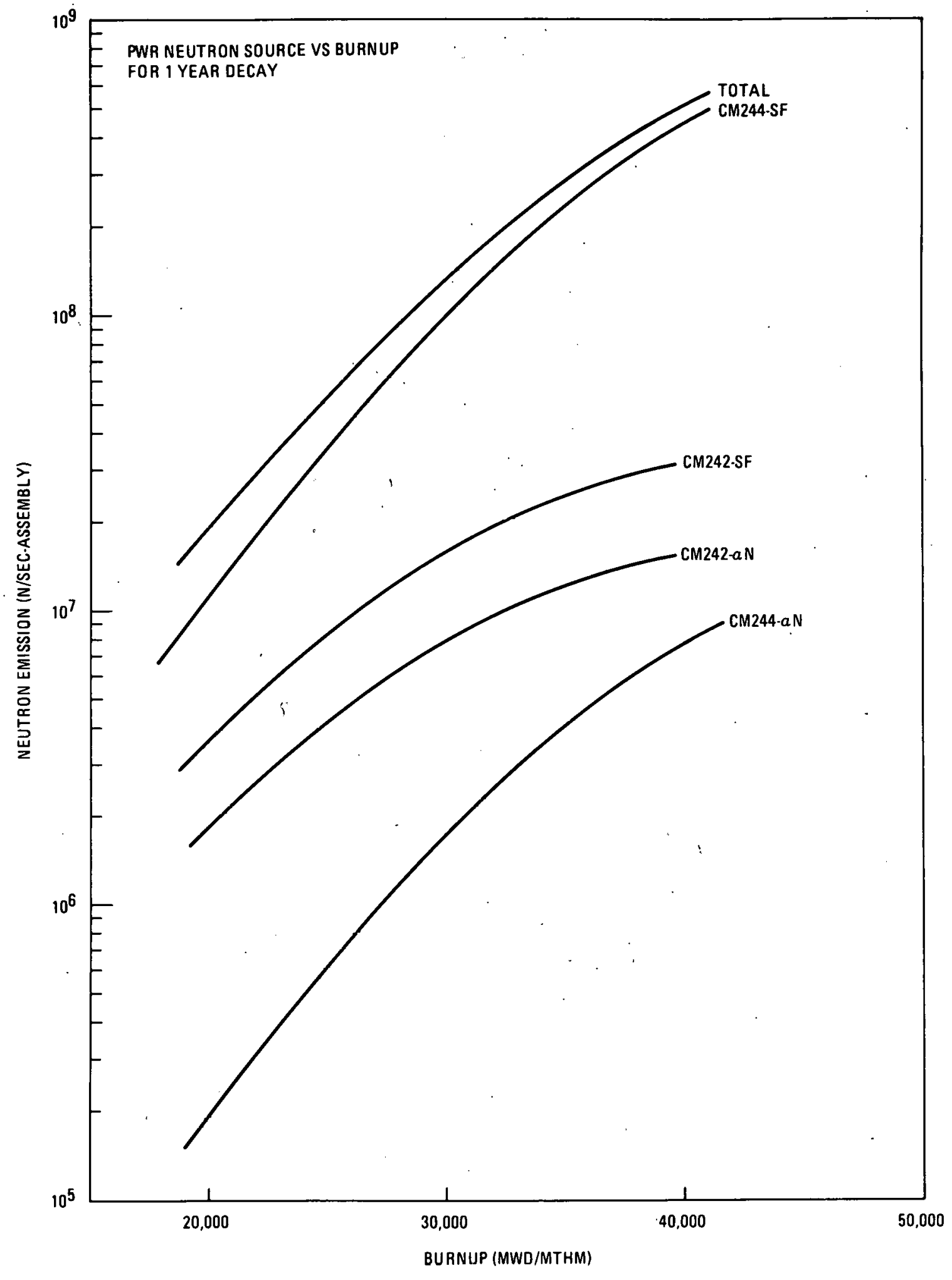

Fig. 3-6. PWR neutron source vs burnup for 1 year decay 


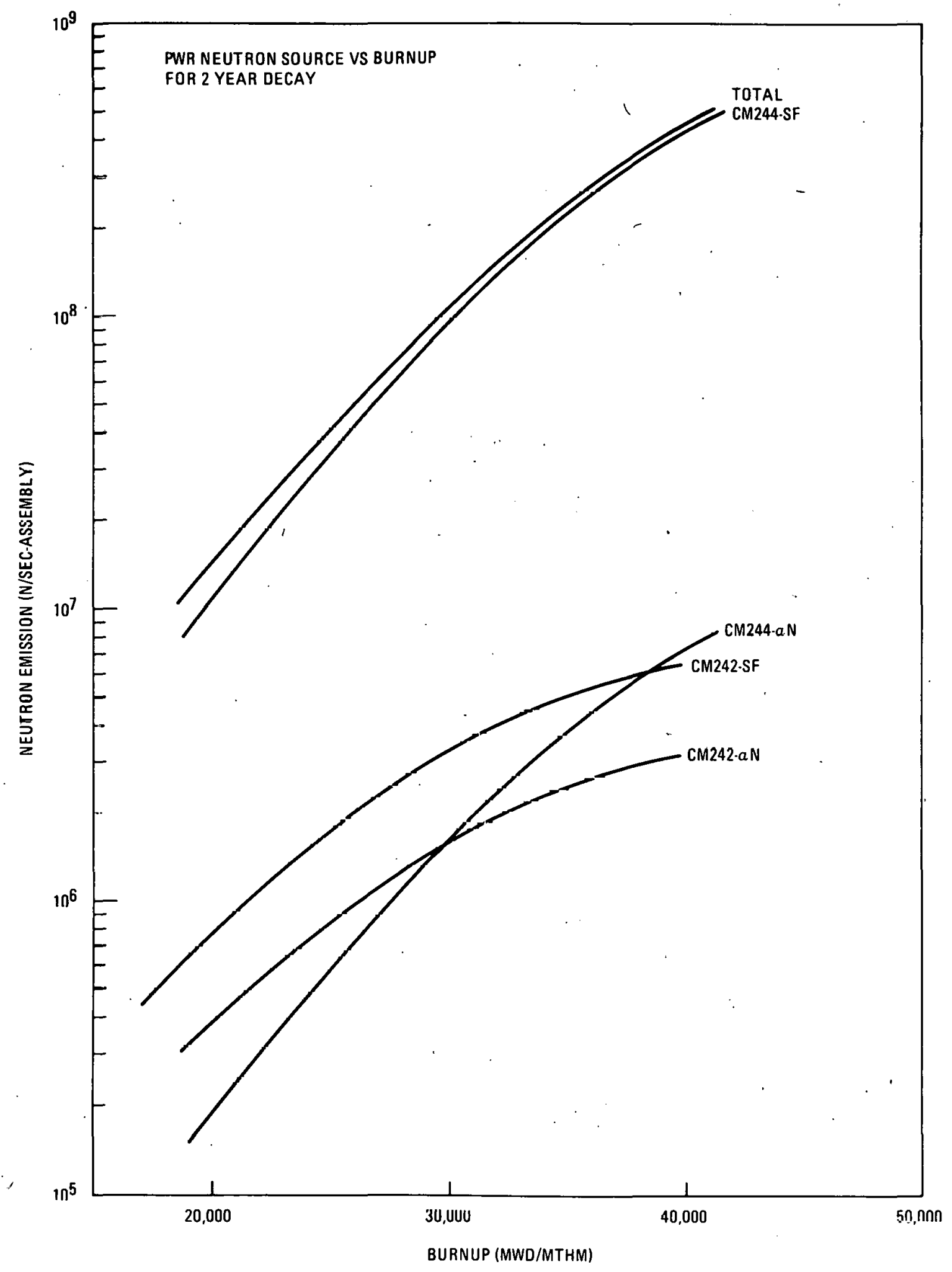

Fig. 3-7. PWR neutron source vs burnup for 2 year decay 


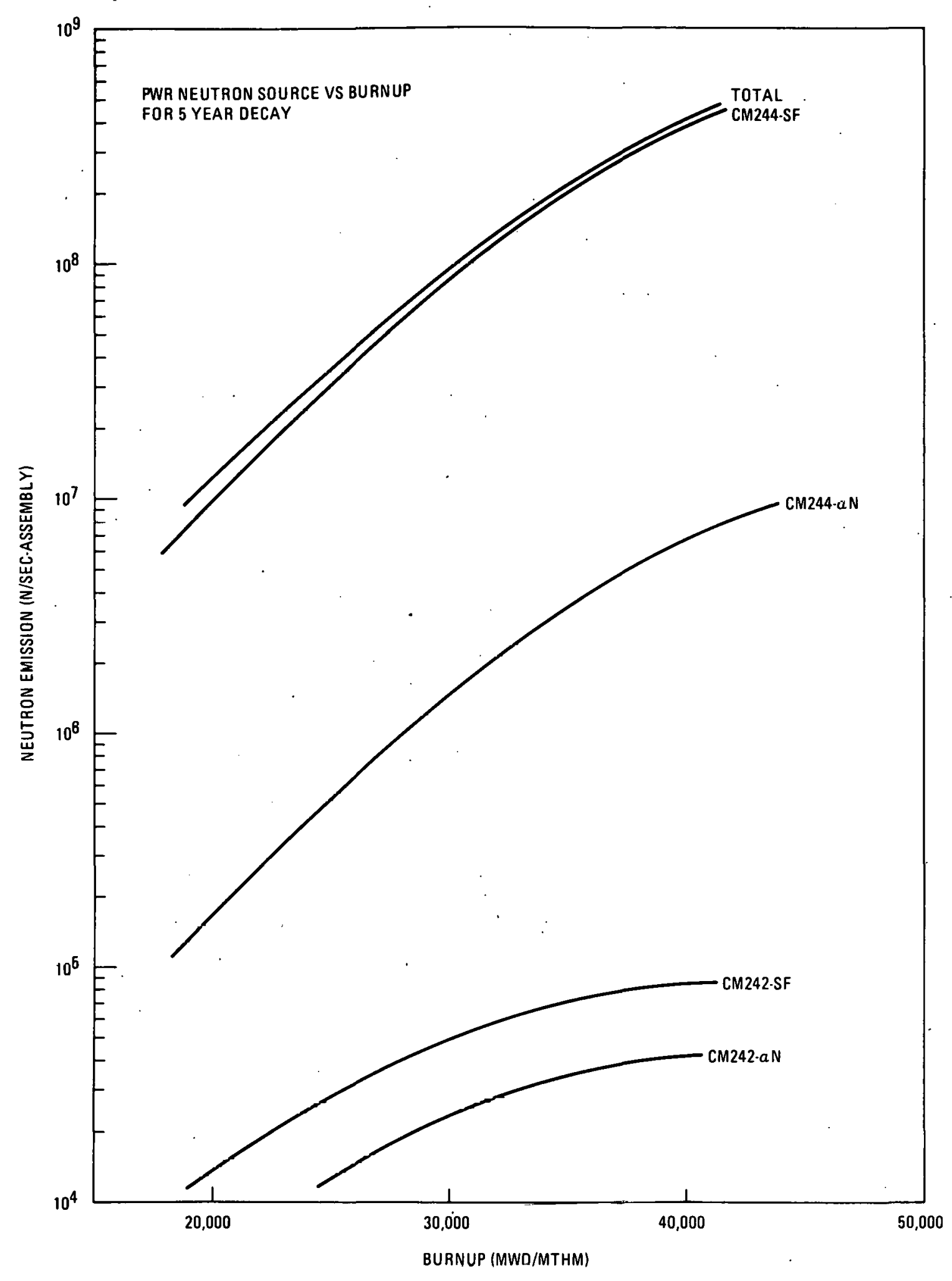

Fig. 3-8. PWR neutron source vs hirnup for 5 year decay 


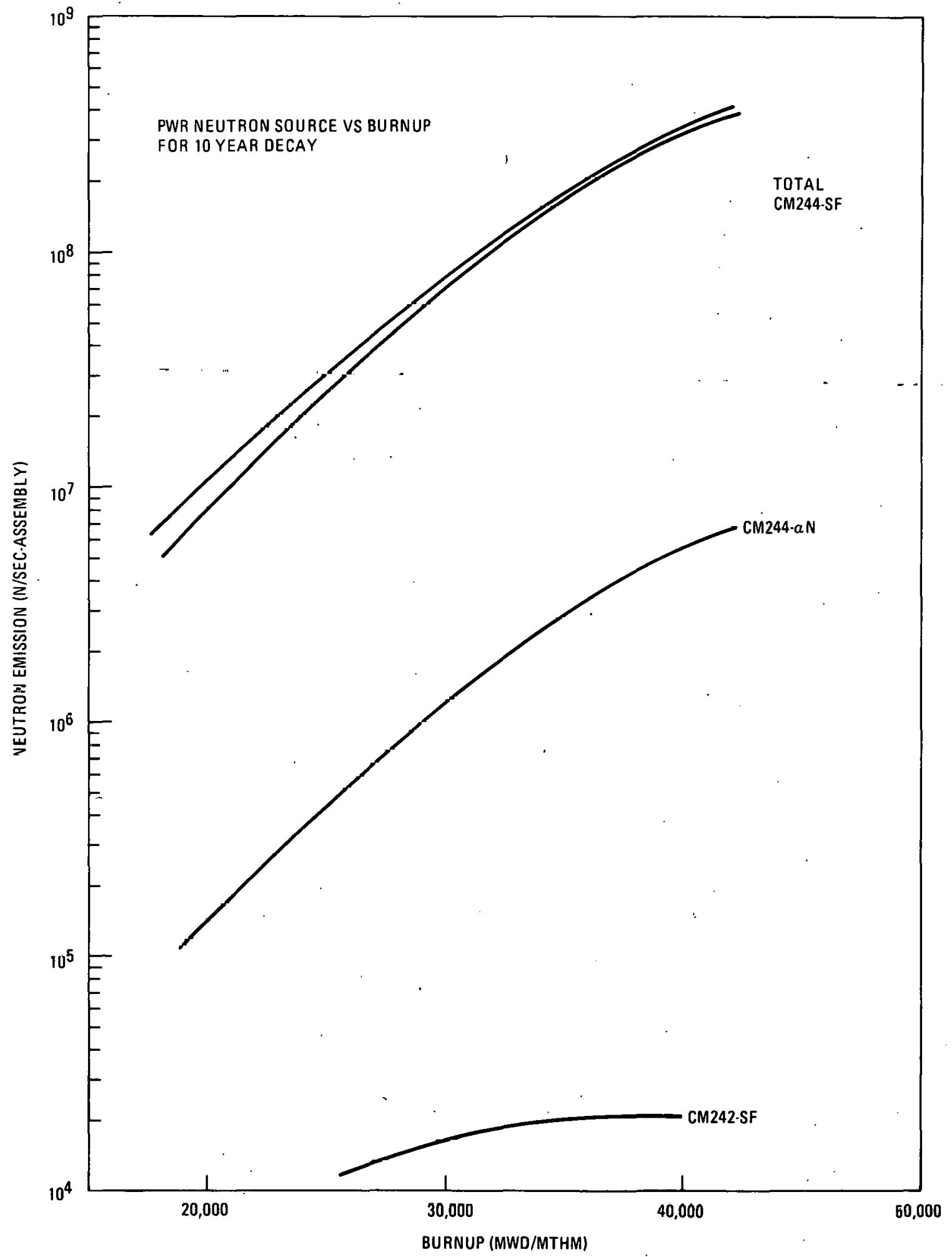

Fig. 3-9. PWR neutron source vs burnup for 10 year decay 40 
IABLE 3-4

NEUTRON SOURCE $(\alpha, n)+$ SPONTANEOUS FISSION

\begin{tabular}{l|c|c|c|c|c}
\hline \multirow{2}{*}{ Fuel } & \multirow{2}{*}{$\begin{array}{c}\text { Burnup } \\
\text { MWD/MTHM }\end{array}$} & \multicolumn{4}{|c}{ Decay Time $\left(\mathrm{n} / \mathrm{cm}^{3}-\mathrm{sec}\right)$} \\
\cline { 3 - 6 } PWR & 20,000 & $1.022+2$ & $7.715+1$ & $6.548+1$ & $5.737+1$ \\
PWR & 33,000 & $1.132+3$ & $9.651+2$ & $8.344+2$ & $6.974+2$ \\
PWR & 40,000 & $2.77 .8+3$ & $2.489+3$ & $2.179+3$ & $1.812+3$ \\
BWR & 34,000 & $1.718+3$ & $1.487+3$ & $1.29+3$ & $1.077+3$ \\
\hline
\end{tabular}




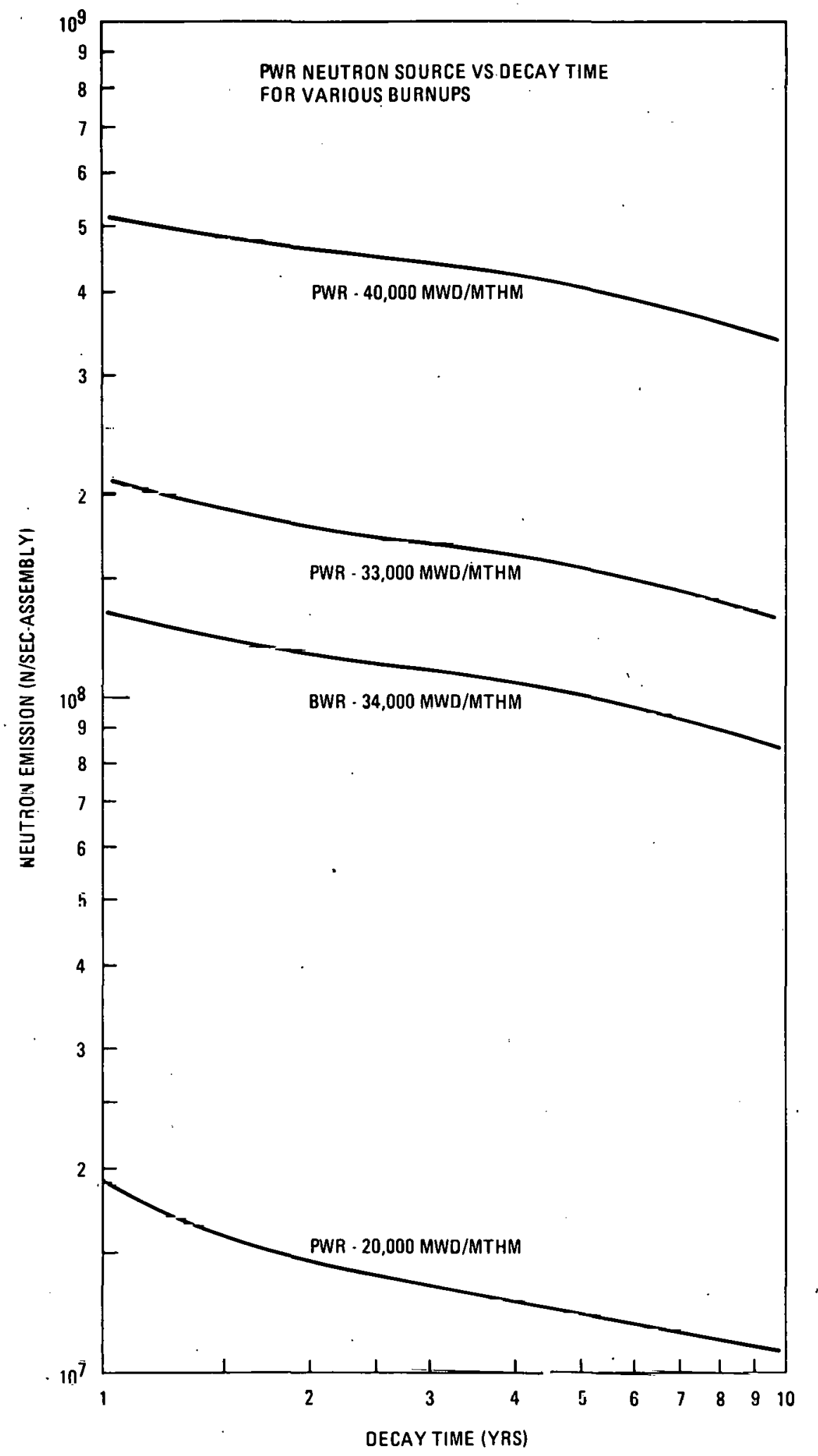

F1g. 3-10. Neutron source vs decay time for various burnups 
TABLE 3-5

NEUTRON SOURCE INPUT INTO DTFX

\begin{tabular}{l|l}
\hline $\begin{array}{c}\text { Energy Range } \\
(\mathrm{MeV})\end{array}$ & $\mathrm{n} / \mathrm{cm}^{3}-\mathrm{sec}$ \\
\hline $6.7-14.07$ & 0.014 \\
$3.68-6.7$ & 0.106 \\
$2.02-3.68$ & 0.417 \\
$1.35-2.02$ & 0.157 \\
$0.907-1.35$ & 0.108 \\
$0.498-0.907$ & 0.117 \\
$0.334-0.498$ & 0.080 \\
Total & 1.00 \\
\hline
\end{tabular}




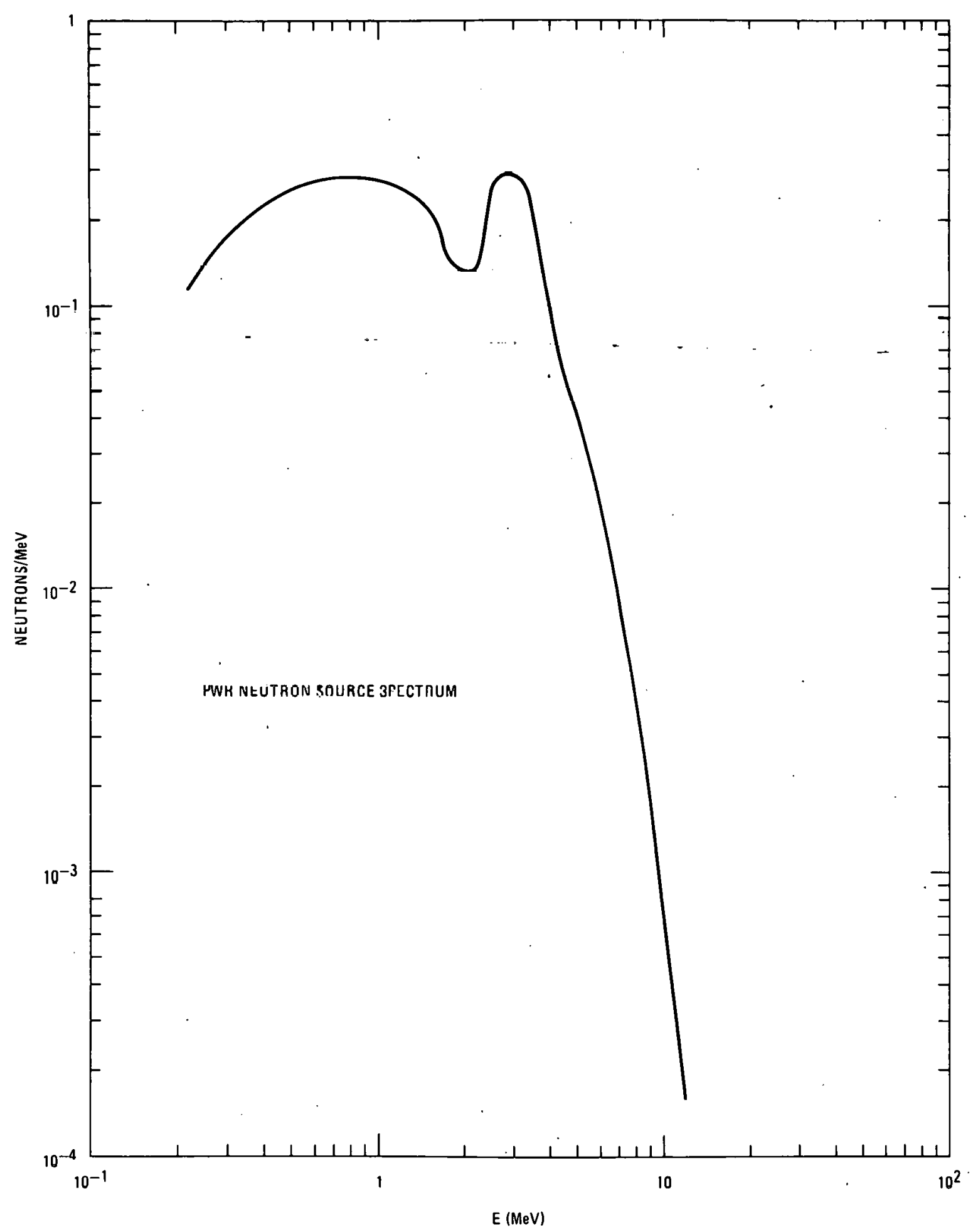

Fig. 3-11. PWR neutron source spectrum 
The gamma sources used as input for PATH are a combination of source strengths due to actinides, fission products, and activation products. Table 3-6 shows the source strengths broken into six energy groups for PWR and BWR fuel elements with various burnups and decay times. Actually, the only six energy groups input into PATH are those for the case of a fuel element with a specific burnup of 20,000 MWD/MTHM and a decay time of $1 \mathrm{yr}$. All other dose rate calculations are found utilizing the method in section 3.2.3. It should be noted that the gamma source terms assume no initial cobalt content in the stainless steel structure of the fuel elements. This neglected concentration of about $2000 \mathrm{ppm}$ may change the dose rate results on the top and bottom of the cask where the majority of the fuel assembly structure is located. 
TABLE 3-6

GAMMA SOURCE TERMS FOR PATH INPUT $\frac{\mathrm{MeV}}{\mathrm{cc} / \mathrm{sec}}$

$\bar{E}(\mathrm{MeV})$

DECAY TIME (YEARS)

PWR 20,000 MWD/MTHM

$\begin{array}{lllll}.63 & 1.894+10 & 1.112+10 & 5.46+9 & 3.018+9 \\ 1.1 & 9.0+8 & 6.622+8 & 3.584+8 & 1.998+8 \\ 1.55 & 5.348+8 & 3.262+8 & 9.485+7 & 1.642+7 \\ 1.99 & 5.134+8 & 2.216+8 & 1.529+7 & 2.045+5 \\ 2.38 & 1.165+7 & 8.808+6 & 1.135+6 & 3.674+4 \\ 2.11 & 1.067+8 & 3.954+7 & 2.085+6 & 3.00+4\end{array}$

PWR 33,000 MWD/MTHM

$\begin{array}{lllll}.63 & 4.101+10 & 2.513+10 & 1.149+10 & 5.487+9 \\ 1.1 & 2.217+9 & 1.702+9 & 9.88+8 & 5.646+8 \\ 1.55 & 1.184+9 & 7.657+8 & 2.439+8 & 4.348+7 \\ 1.99 & 7.043+8 & 2.926+8 & 2.13+7 & 2.96+5 \\ 2.38 & 3.195+7 & 1.609+7 & 2.054+6 & 6.664+4 \\ 2.75 & 3.603+8 & 1.328+8 & 6.782+6 & 7.577+4\end{array}$

PWR 40,000 MWD/MTHM

$\begin{array}{lllll}.63 & 5.652+10 & 3.525+10 & 1.567+10 & 7.022+9 \\ 1.1 & 3.099+9 & 2.388+9 & 1.389+9 & 7.907+8 \\ 1.55 & 1.678+9 & 1.098+9 & 3.564+8 & 6.393+7 \\ 1.99 & 8.654+8 & 3.597+8 & 2.627+7 & 3.697+5 \\ 2.38 & 4.211+7 & 2.12+7 & 2.707+6 & 8.808+4 \\ 2.75 & 5.828+8 & 2.146+8 & 1.088+7 & 1.124+5\end{array}$

DWNR 34,000 MWD/MTHM

$\begin{array}{lllll}.63 & 3.542+10 & 2.284+10 & 1.06+10 & 5.132+9 \\ 1.1 & 2.095+9 & 1.637+9 & 9.811+8 & 5.705+8 \\ 1.55 & 1.028+9 & 6.758+8 & 2.205+8 & 3.958+7 \\ 1.99 & 4.919+8 & 2.048+8 & 1.505+1 & 2.159+5 \\ 2.38 & 2.683+7 & 1.35+7 & 1.725+6 & 5.609+4 \\ 2.75 & 3.396+8 & 1.25+8 & 6.361+6 & 7.333+4\end{array}$




\subsection{COMPOSITION AND GEOMETRY}

\subsubsection{Compositions}

\section{4 .1 .1 Fuel.}

Fuel assembly compositions vary depending on the reference from which they are obtained. One major factor for this difference is the discrepancy in the fuel assembly structure used in the calculations. One reference may include the end structure while others may not. Table 3-7 shows a comparison between other referenced PWR fuel elemental compositions and the conservative averages used in this study.

To determine conservative averages for BWR fuel elemental compositions a comparison was made between PWR and BWR taken from Ref. 3-18 and shown in Table 3-8. Note that when the elemental compositions are:compared for PWR and BWR fuel assemblies in units of grams per unit cross sectional area the values obtained are very close to one another. With this data the conclusion is that the same volumetric atomic concentrations as those found in PWR fuel assemblies may be used for BWR fuel assemblies. The actual nuclide concentrations used for the fuel region in this study are found in Table 3-9.

From Table 3-9 a change was made since $\mathrm{Zr}$ cross sections were not available in the General Atomic data base. For. DTFX calculations, Mo cross sections were adjusted to resemble as close as possible, the $\mathrm{Zr}$ cross sections. To accomplish this, the Mo absorption cross section was reduced to zero and the total cross section was reduced accordingly. Fig. 3-26 shows the relation between the actual $\mathrm{Zr}$ cross section and that used as input into DTFX. For PATH. calculations Mo. gamma attenuation data was substituted for that of $\mathrm{Zr}$.

\subsubsection{Neutron Shield Material}

The neutron shleld material chosen for this study is a commercial product named Boro-silicone, with properties as specified in Ref. 3-18. This material has a recommended temperature limit of $400^{\circ} \mathrm{F}\left(205^{\circ} \mathrm{C}\right)$ along with properties of good machinability and capability of casting in the field. Table 3-10 lists the nuclides and their weight percent along with their atomic densitles. 
TABLE 3-7

PWR COMPOSITION COMPARISON

\begin{tabular}{|c|c|c|c|}
\hline \multirow[b]{2}{*}{ Element } & \multicolumn{3}{|c|}{ Grams per Assembly } \\
\hline & $\begin{array}{l}\text { National Lead } \\
\text { (Ref. 3-12) }\end{array}$ & $\begin{array}{l}\text { Sandia } \\
(\text { Ref. 3-17) }\end{array}$ & $\begin{array}{c}\text { Conservative Averages } \\
\text { Used in This Study }\end{array}$ \\
\hline 0 & 57,300 & 61,400 & 60,000 \\
\hline $\mathrm{Cr}$ & 122 & 3,110 & \\
\hline Fe & 471 & 8,105 & \\
\hline $\mathrm{Ni}$ & 2,530 & 3,825 & \\
\hline $\mathrm{Zr}$ & 102,000 & 125,800 & 100,000 \\
\hline $\mathrm{U}-238$ & 396,000 & 427,000 & 400,000 \\
\hline U-235 & 2,500 & $2,400-3,500$ & 3,000 \\
\hline $\mathrm{Pu}-239$ & 1,990 & 2,425 & 2,500 \\
\hline $\mathrm{Pu}-240$ & 548 & $1,000-1,100$ & $1,00 \overline{0}$ \\
\hline $\mathrm{Si}$ & & 100 & 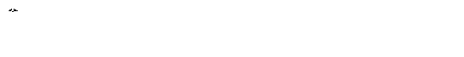 \\
\hline Mn & & 200 & \\
\hline $\mathrm{Nb}$ & & 280 & \\
\hline Mn & & 170 & \\
\hline Sn & & 2,054 & \\
\hline Note: & $\begin{array}{l}\text { ia's compositi } \\
\text { assembly. Fo } \\
\text { ents were omit } \\
\text { he present sti }\end{array}$ & $\begin{array}{l}\text { includes the } \\
\text { onservatism, } \\
\text { for side do }\end{array}$ & $\begin{array}{l}\text { nd structure of the } \\
\text { hese structural } \\
\text { rate calculations }\end{array}$ \\
\hline
\end{tabular}


TABLE 3-8

BWR COMPOSITION COMPARISON BASED ON SAND79-0172

\begin{tabular}{l|c|c|c|c}
\hline Element & $\begin{array}{c}\text { PWR Grams } \\
\text { per Assemb1y }\end{array}$ & $\begin{array}{c}\text { PWR Grams } \\
\text { per Unit } \\
\text { 3 Assemb1ies }\end{array}$ & $\begin{array}{c}\text { BWR Grams } \\
\text { Cros Sectional } \\
\text { prea }\end{array}$ & $\begin{array}{c}\text { Unit } \\
\text { Cross Sectional } \\
\text { Area }\end{array}$ \\
\hline $\mathrm{Zr}$ & 125,800 & 161,760 & 244 & 252 \\
$\mathrm{O}$ & 61,400 & 73,800 & 119 & 115 \\
$\mathrm{U}-238$ \\
$\begin{array}{l}\mathrm{U}-235 \\
\mathrm{Pu}-239\end{array}$ & 456,000 & 547,000 & 885 & 851 \\
$\mathrm{Pu}-240$ & $1,000-1,100$ & 3,000 & 4,72 & 4.67 \\
\hline
\end{tabular}

Conclusion: Use the same volumetric atom concentrations for BWR as for PWR. 
TABLE 3-9

NUCLIDE CONCENTRATIONS FOR THE FUEL

\begin{tabular}{l|c|l}
\hline Nuclide & gm/assembly & at/b-cm \\
\hline 0 & $6.0+4$ & $1.2-2$ \\
$\mathrm{Zr}$ & $1.0+5$ & $3.51-3$ \\
$\mathrm{U}-238$ & $4.0+5$ & $5.39-3$ \\
$\mathrm{U}-235$ & $3.0+3$ & $4.09-5$ \\
$\mathrm{Pu}-239$ & $2.5+3$ & $3.41-5$ \\
$\mathrm{Pu}-240$ & $1.0+3$ & $1.34-5$ \\
\hline
\end{tabular}




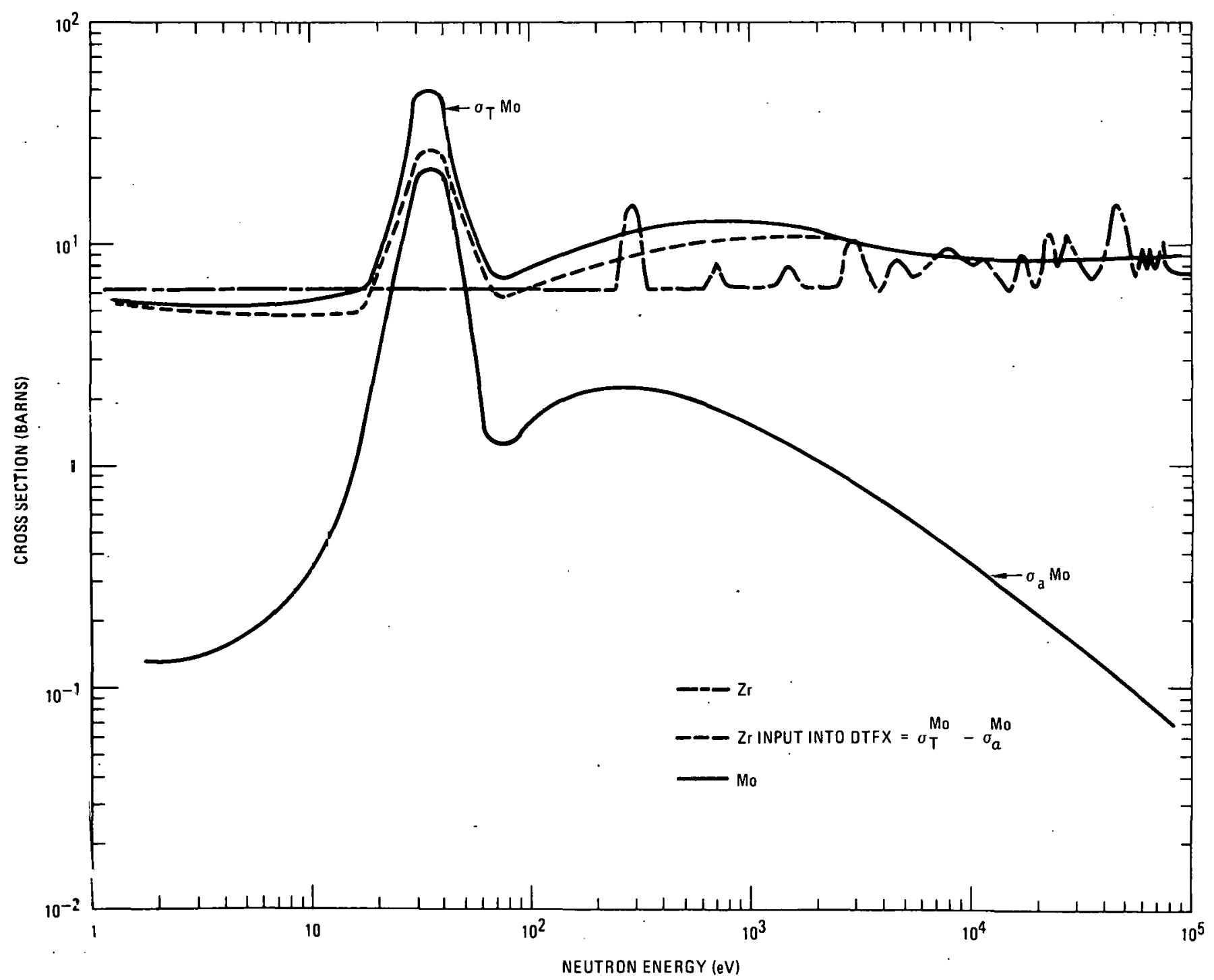

Fig. 3-25. $\mathrm{Zr}$ and Mo neutron cross section vs. neutron energy 
TABLE $3-10$

NUCLIDE CONCENTRATIONS FOR BORO-SILICATE (NEUTRON SHIELD)

\begin{tabular}{l|c|c}
\hline Nuc1ide & wt $\%$ & at $/ \mathrm{b}-\mathrm{cm}$ \\
\hline $\mathrm{O}$ & 46.77 & $2.82-2$ \\
$\mathrm{Si}$ & 17.63 & $6.05-3$ \\
$\mathrm{Al}$ & 17.36 & $6.20-3$ \\
$\mathrm{C}$ & 10.9 & $8.75-3$ \\
$\mathrm{H}$ & 4.63 & $4.43-2$ \\
$\mathrm{Ca}$ & 1.03 & $2.48-1$ \\
$\mathrm{~B}-10$ & 0.20 & $1.8-4$ \\
$\mathrm{~B}-11$ & 0.81 & $7.21-4$ \\
$\mathrm{Na}$ & 0.39 & $1.64-4$ \\
$\mathrm{Mg}$ & 0.19 & $7.54-5$ \\
\hline
\end{tabular}




\subsubsection{Gamma Shield Material}

Depleted uranium was taken as 0.2 wt $\% U-235$ and 99.8 wt $\%$ U-238. These nuclide concentrations along with those for air and iron are shown in Table 3-11.

\section{4 .2 Geometry}

\subsubsection{Side}

The geometry for a Westinghouse $17 \times 17$ PWR fuel assembly was obtained from Ref. 3-16 and is shown in Fig. 3-12. For all PWR calculation, one fuel assembly was considered placed inside a 12-in. schedule 40 pipe $12 \mathrm{ft}$. long and centered inside the cask. For side calculations performed by PATH the fuel was taken as rectangularly homogenized and positioned in the geometry shown in Fig. 3-13. Dose points were located off the corner of the fuel element where the highest dose rates would be obtained. For DTFX side calculations, the cylindrical geometry shown in Fig. 3-14 was utllized. In this case the iron pipe and steel structure inside the cask have been homogenized to fill the area between the fuel and depleted uranium regions. The equivalent thickness of iron is 2.6 $\mathrm{cm}$. in this region.

The geometry for a General Electric $8 \times 8$ BWR fuel assembly was also obtained from Ref. 3-16 and is shown in Fig. 3-15. For all BWR dose rate cadculations, three homogenized fuel elements were considered placed inside a 16 inch schedule 40 pipe and centered inside the cask. The PATH geometry is shown in Fig. 3-16 along with the dose point locations. The geometry for BWR side calculations performed by DTFX (Fig. 3-17) is the same as that for the PWR case except that the reduced density iron between the fuel and depleted uranium has an equivalent thickness of $2.9 \mathrm{~cm}$.

\section{4 .2 .2 Top}

Due to the nature of the obtainable information of PWR and BWR fuel assemblies, the top and bottom configurations were taken as the same for both. The top of the fuel assembly was, broken down into the 5 regions shown in Fig. 3-18. All regions are homogenized except for the upper tie plate region in which the actual geometry was used. 
TABLE 3-11

NUCLIDE CONCENTRATIONS FOR GAMMA SHIELDING MATERIALS

\begin{tabular}{l|c|c}
\hline \multicolumn{1}{c|}{ Materia1 } & Nuclide & at $/ \mathrm{b}-\mathrm{cm}$ \\
\hline Depleted Uranium & U-235 & $9.69-5$ \\
& U-238 & $4.77-2$ \\
Air & $\mathrm{N}$ & $4.9-5$ \\
Iron & Fe & $8.51=2$ \\
\hline
\end{tabular}




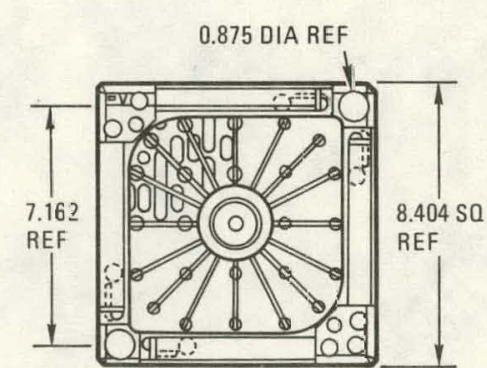

TOP VIEW

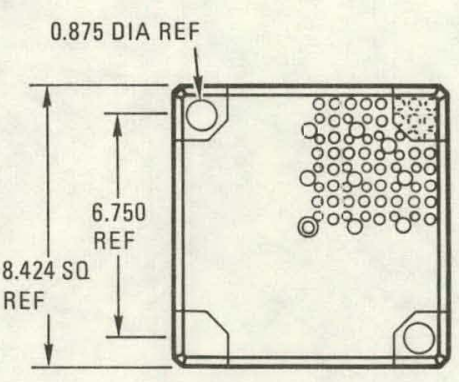

BOTTOM VIEW
BOTTOM NOZZLE

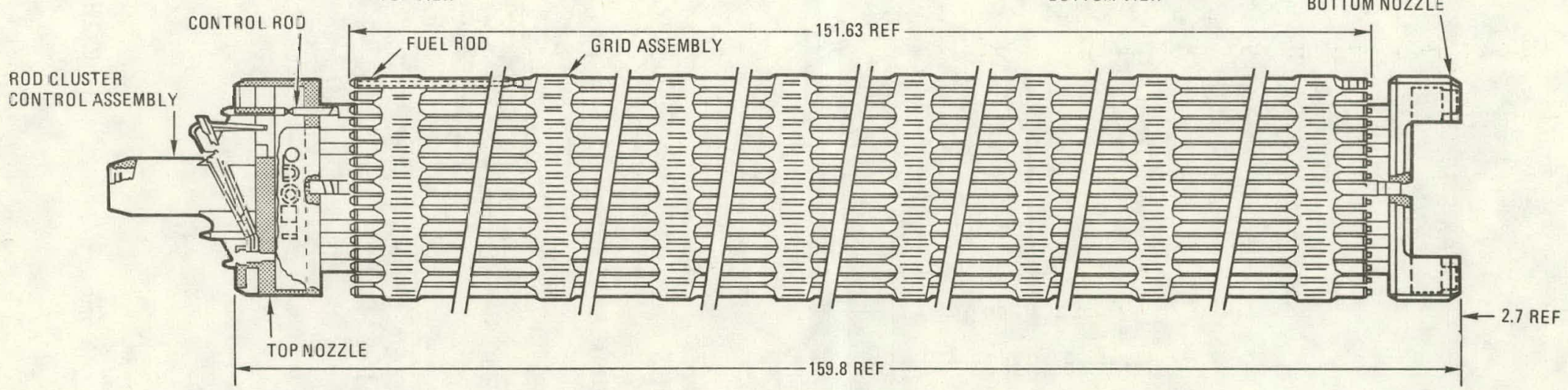

Fig. 3-12. Westinghouse $17 \times 17$ PWR Fuel Assembly 


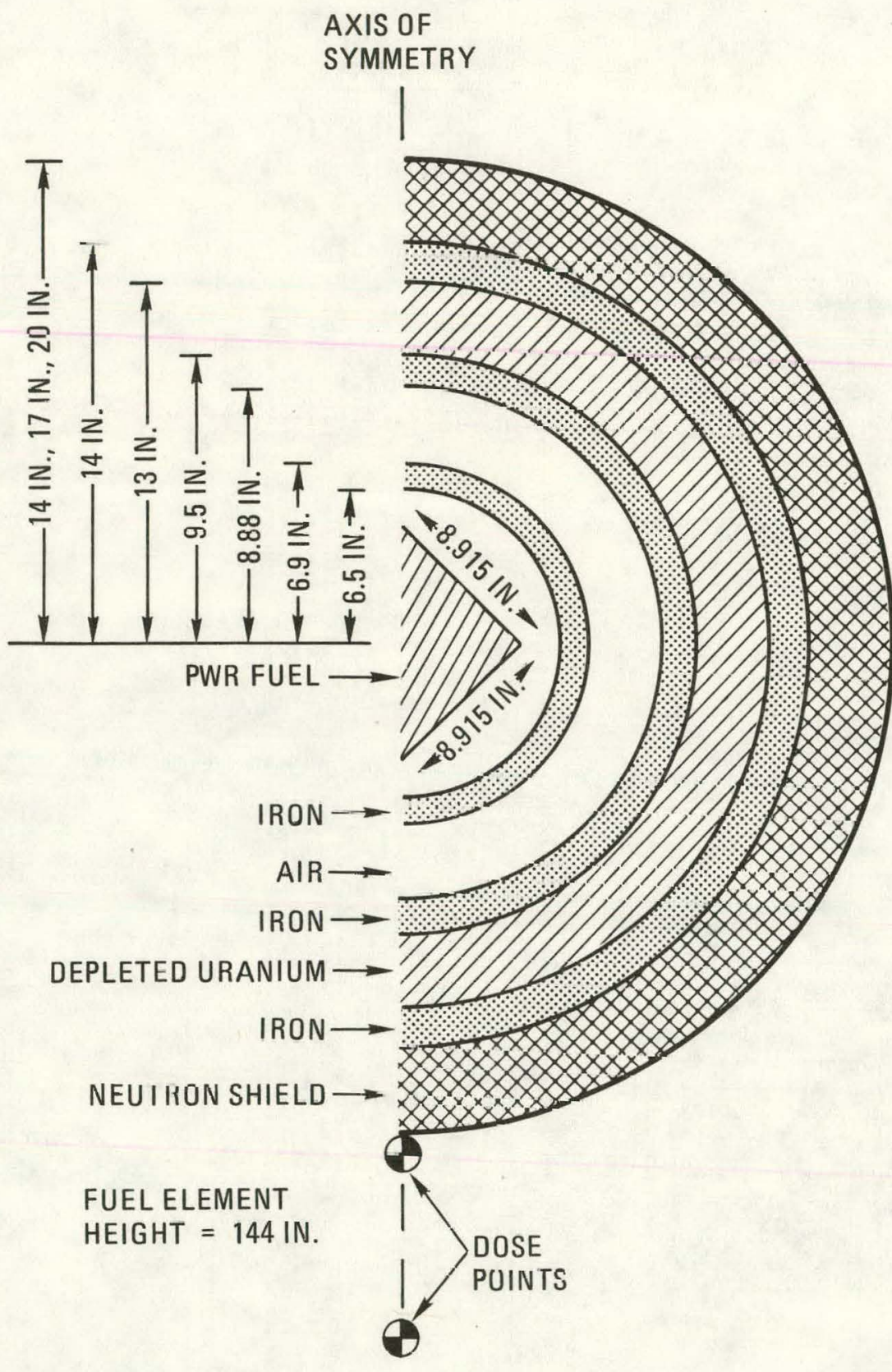

Fig. 3-13. Geometry input for PATH PWR side calculation 

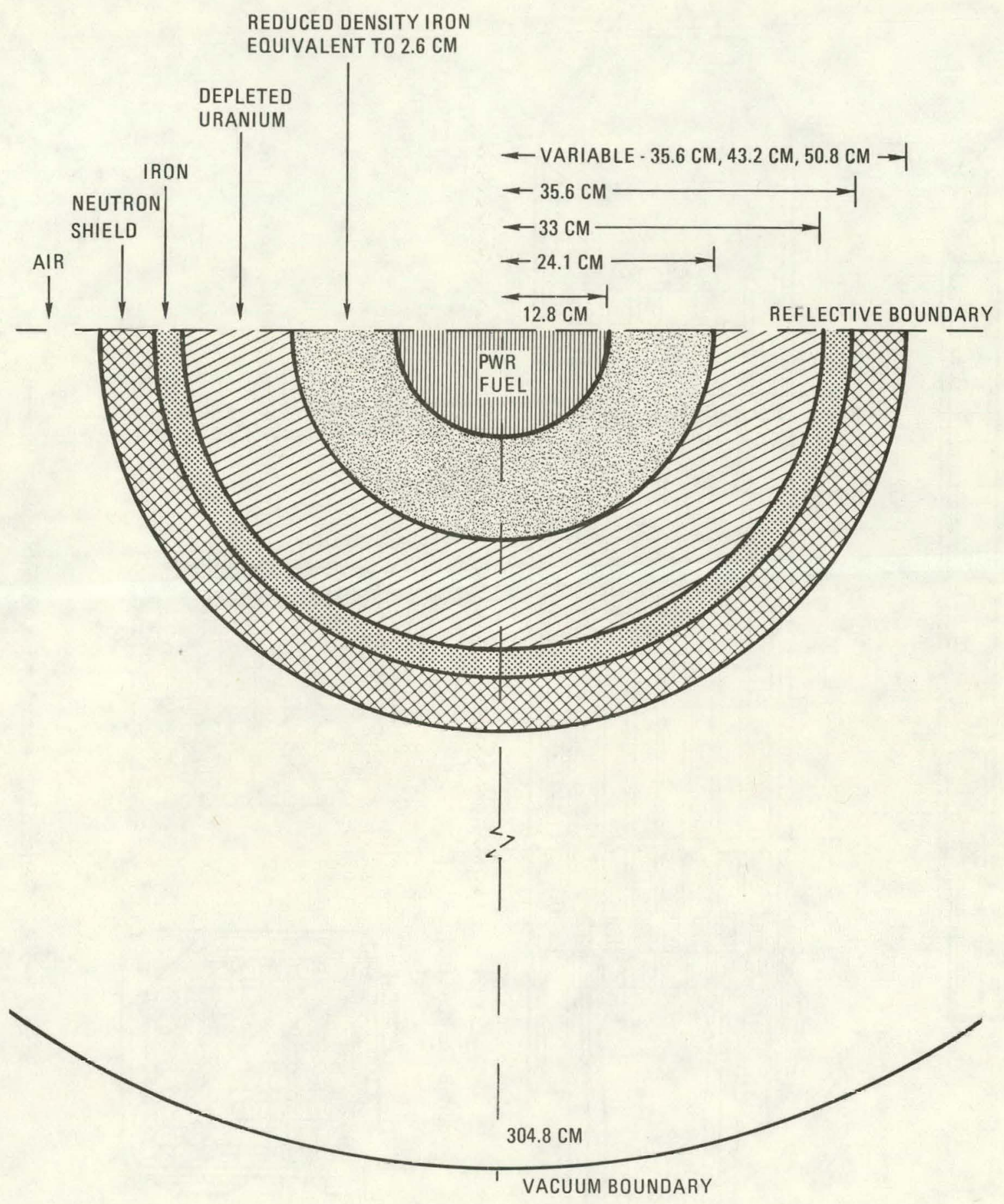

Fig. 3-14. Geometry input for DTFX-PWR side calculation 
TYPICAL FUEL ROD
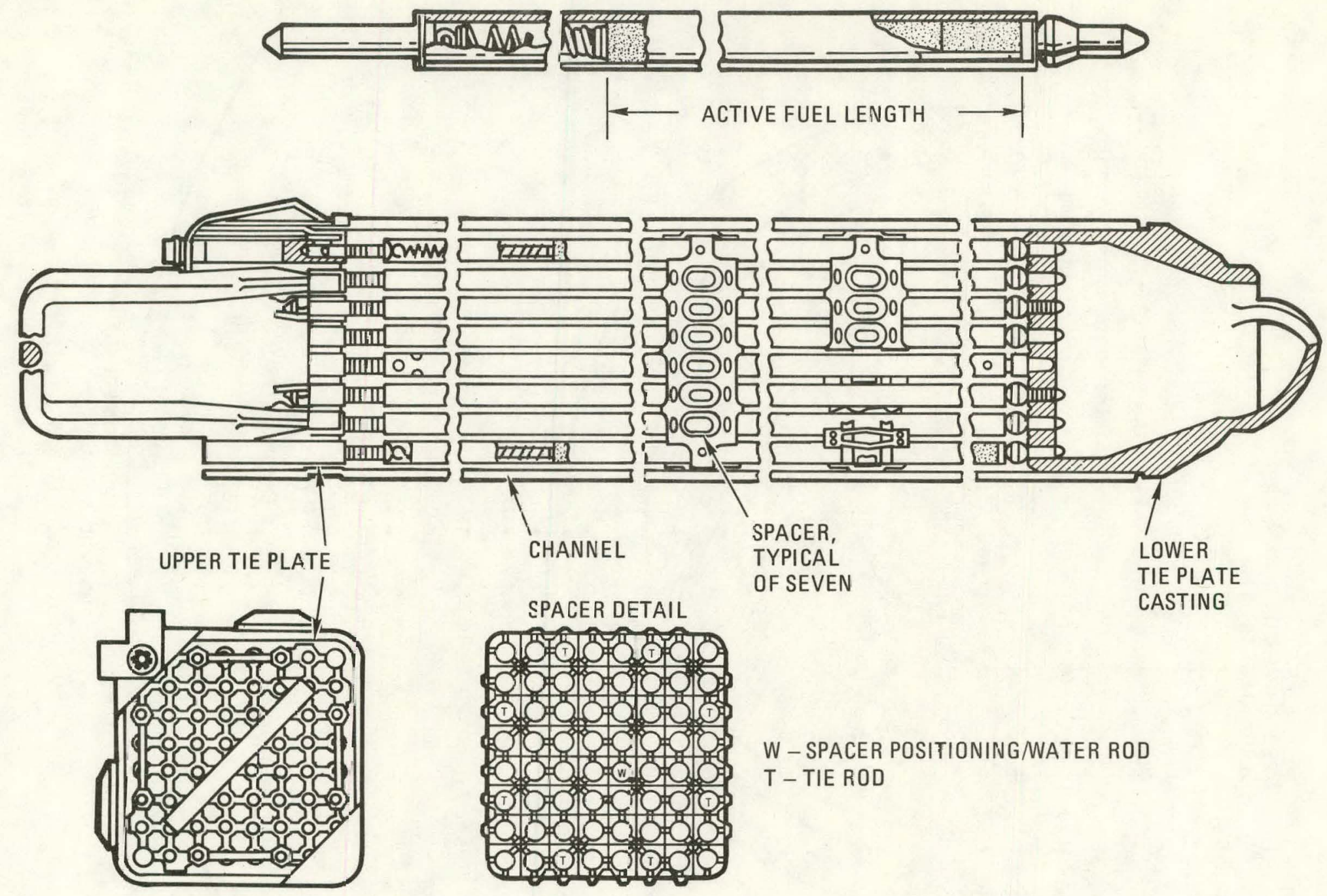

Fig. 3-15. General Electric 8 × 8 BWR Fuel Assembly 


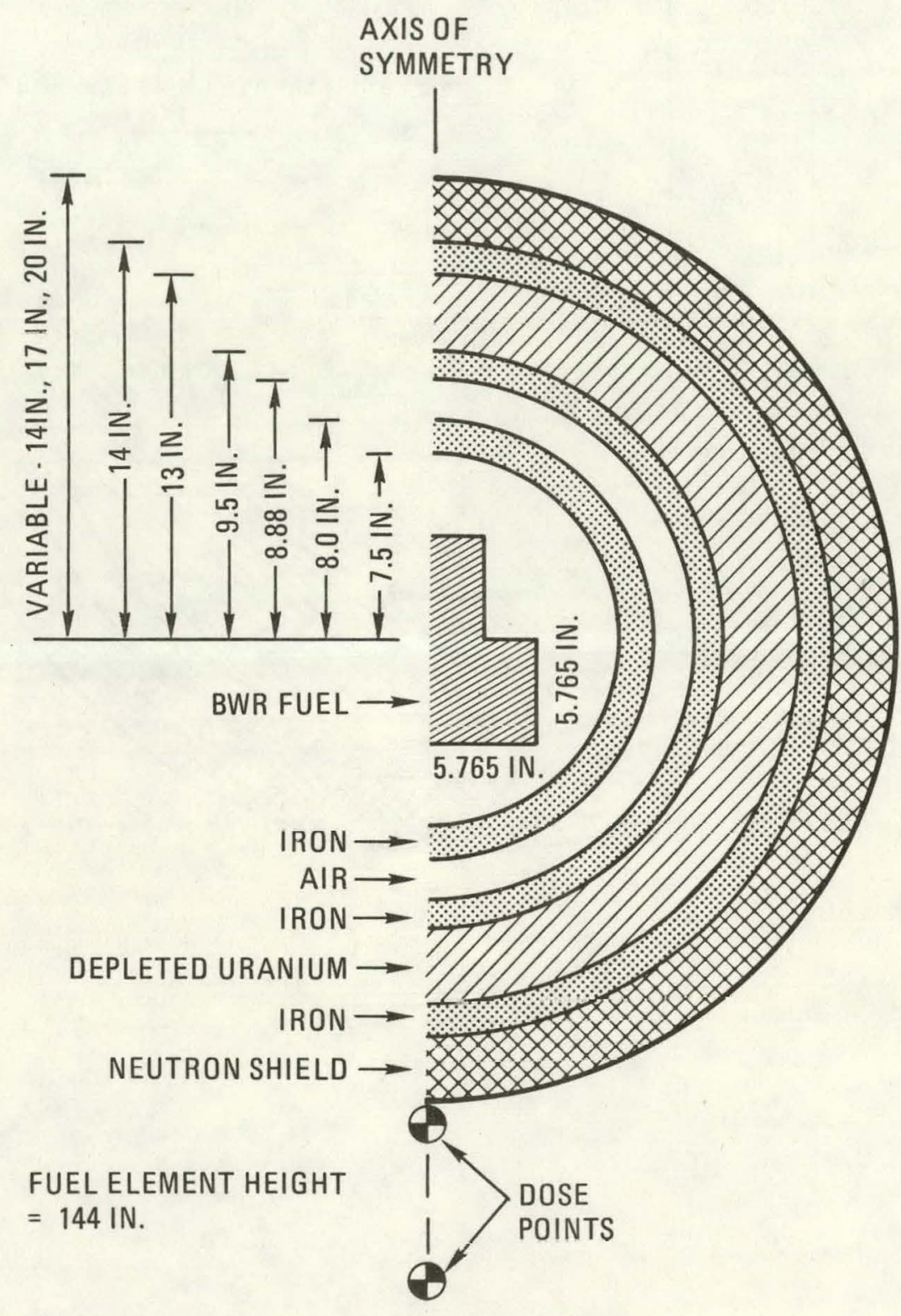

Fig. 3-16. Geometry input for PATH BWR side calculation 

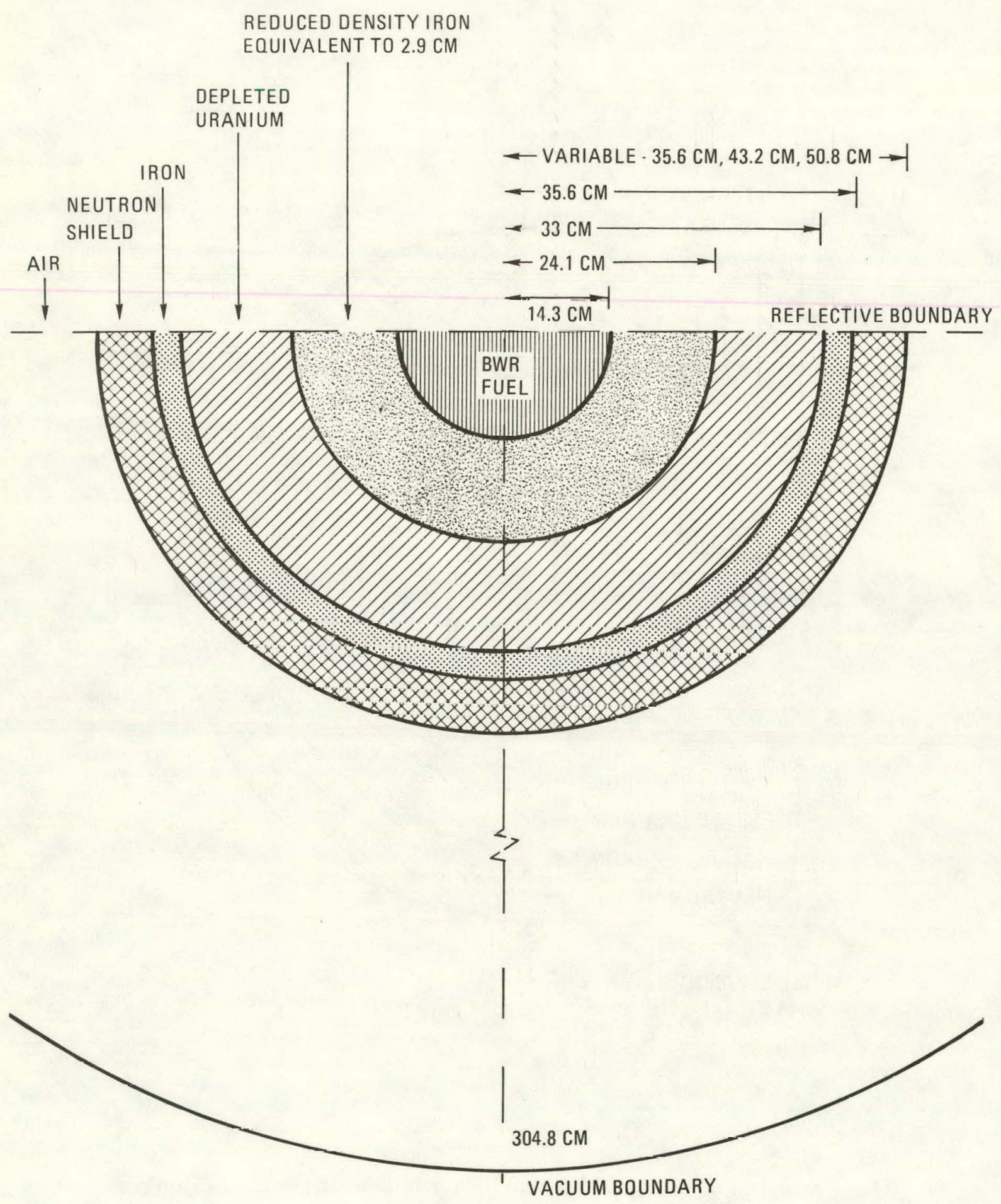

Fig. 3-17. Geometry input for DTFX-BWR side calculation 


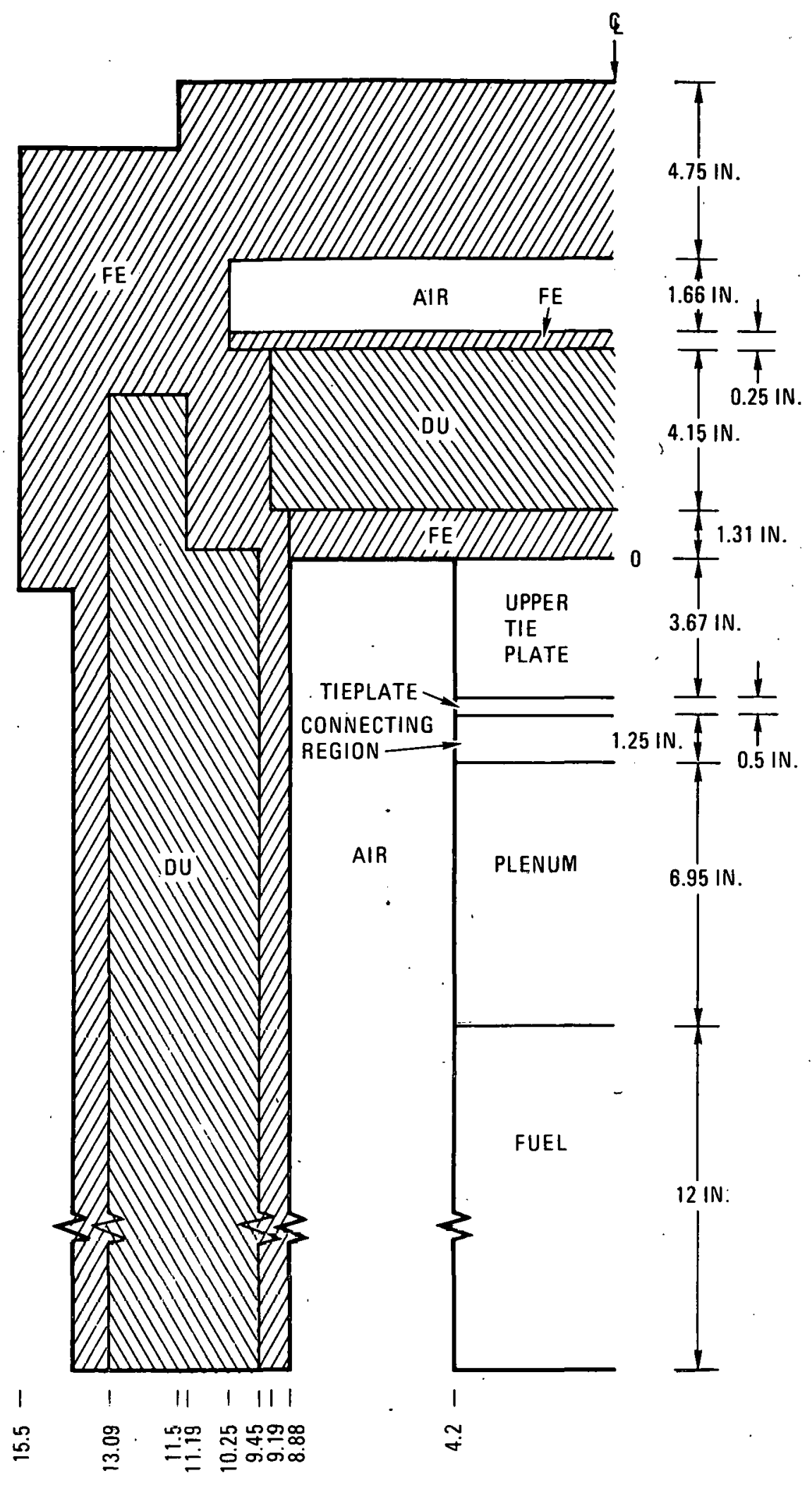

Fig. 3-18. Geometry input for PATI top of FiS-1 cask 
The homogenized densities of each region were calculated from actual dimensions found in Ref. 3-16. These fuel regions were placed as close to the top of the cask as possible, so that conservative dose rates could be obtained. Two designs of cask closures were considered. Both cases consider the closures (Fig. 3-19a) with the inner container of the cask removed. In the first case the inner closure is lower in the cask body by the thickness of the container flange and has an air gap formed above it. The PATH geometry is shown in Fig, 3-18 and all regions are included. The geometry input for DTFX appears in Fig. 3-20. All low density regions have been removed su as to roduce unneressary computer time. The second case considers an entircly new closure design, as shown in Fig. 3-21. The geometry for PATH calculations is drawn in Fig. 3-22. The geometry input for DTFX is shown in Fig. 3-23. Once again, all low density regions have been removed. In both closure designs the dose rate calculations were performed at dose point locatinns where the dose rate is a maximum.

\subsubsection{Bottom}

The bottom of the FSV-1 cask is shown in Fiy. $319 \mathrm{~b}$. This figure also includes the 2-in. steel bottom of the imier container. In considering the shielding analysis previously done on the cask (Kef. 3-4) this extra 2 inches of steel was retained in our analysis even though the inner rontainer has been removed. The PATH geometry for this case is shown in Fig. 3-24 along with the location of the dose points. The lower tie plate region of the fuel assembly has been ignored because its geometry does not come into considerations when dose puiuts arc located along the center axls of the fucl assembly. Also, the iron thicknesses of both the fuel rod bottom end pluy and grill area of the lower tie plate have been added together and considered as one region. For the geometry of DTFX calculations (Fig. 3-25) all iron in consideration was placed into one region while all low density material inside the cask was removed. In both the DTFX and PATH dose rate calculations the dose point locations extended $6 \mathrm{ft}$. beyond the edge of the transport vehicle. 


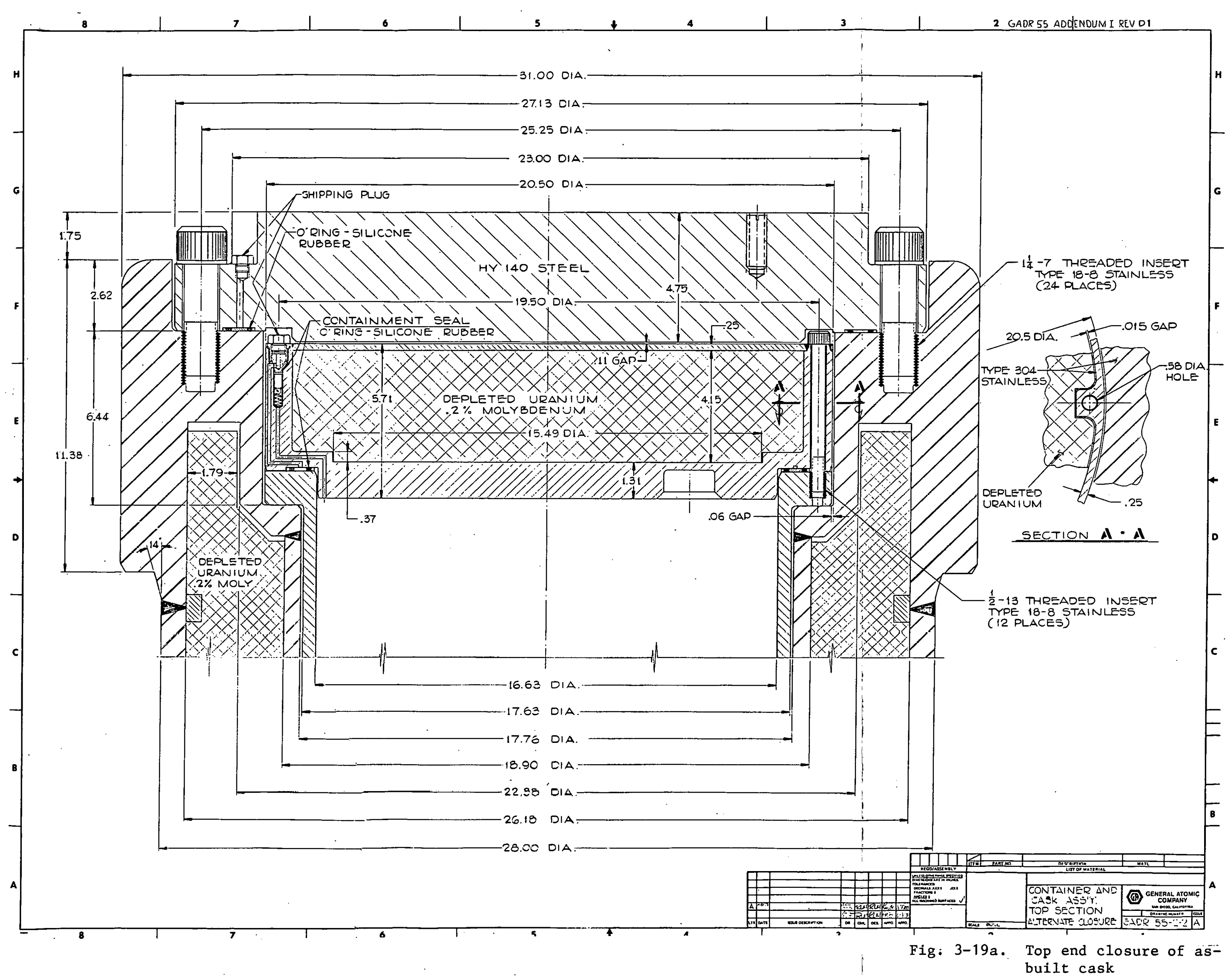




\section{THIS PAGE}

\section{WAS INTENTIONALLY \\ LEFT BLANK}




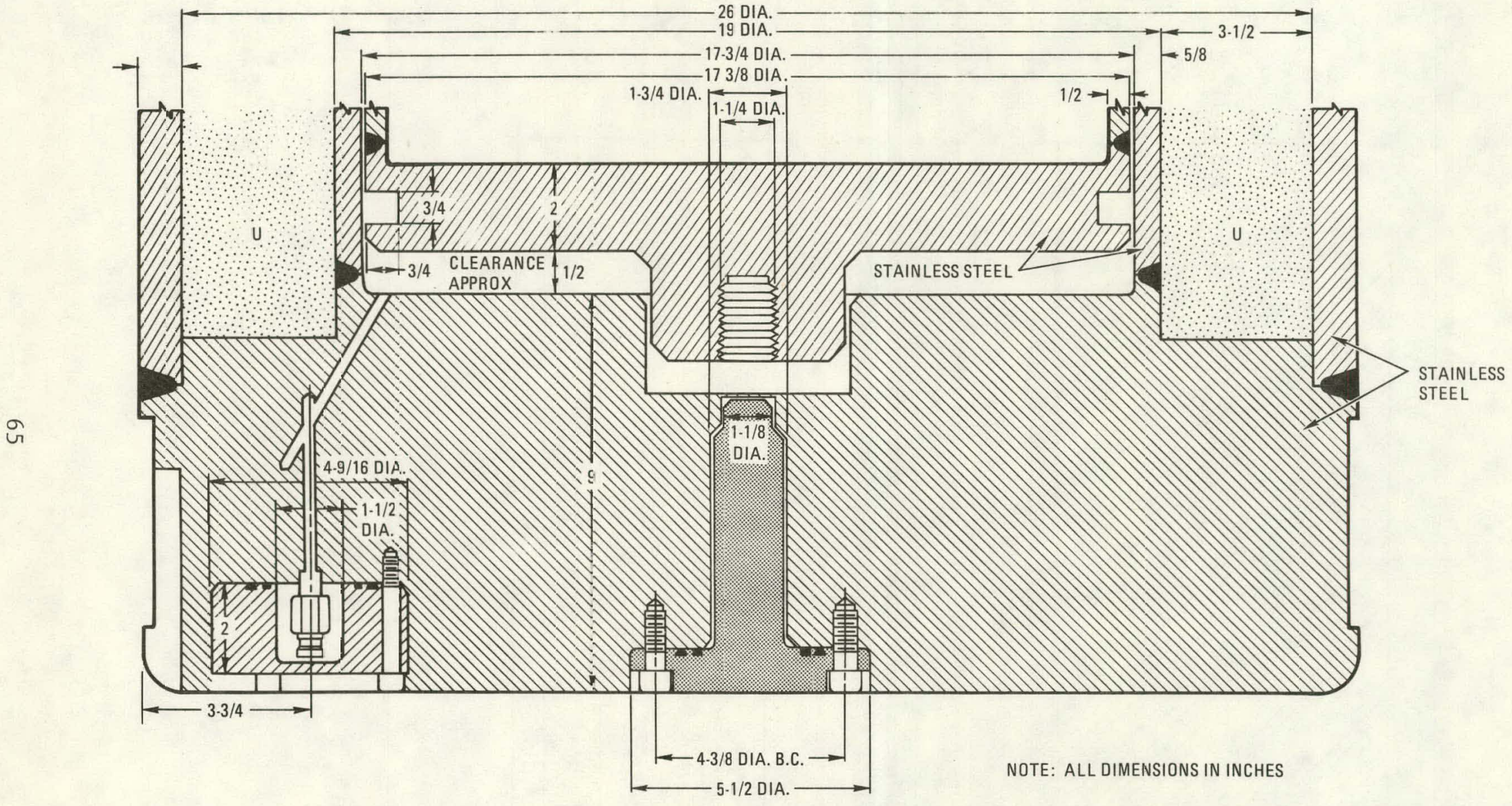

Fig, 3-19b. Bottom of FSV-1 Cask 


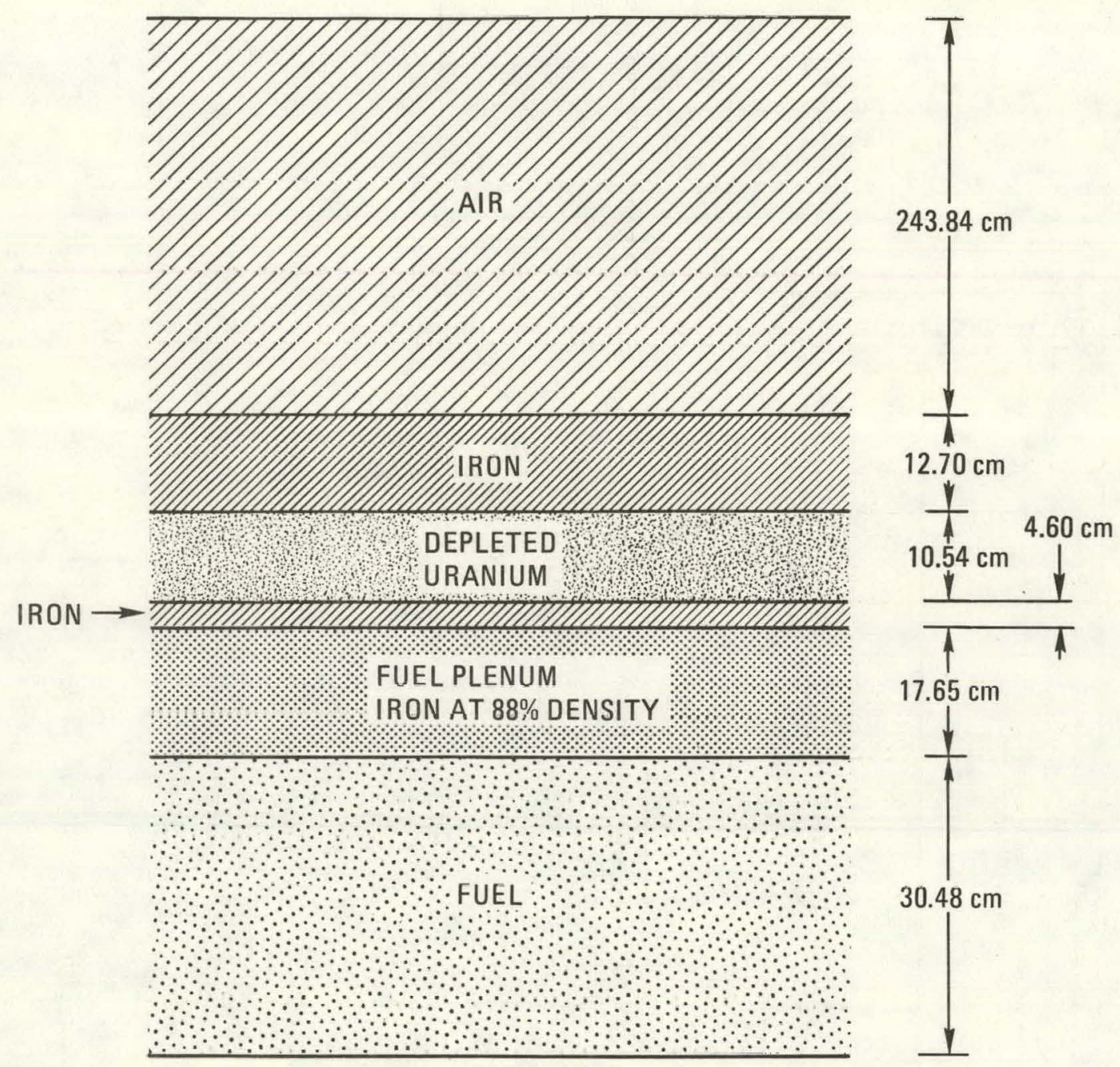

Fig. 3-20. Geometry for top of FSV-1 cask for input into DTFX 

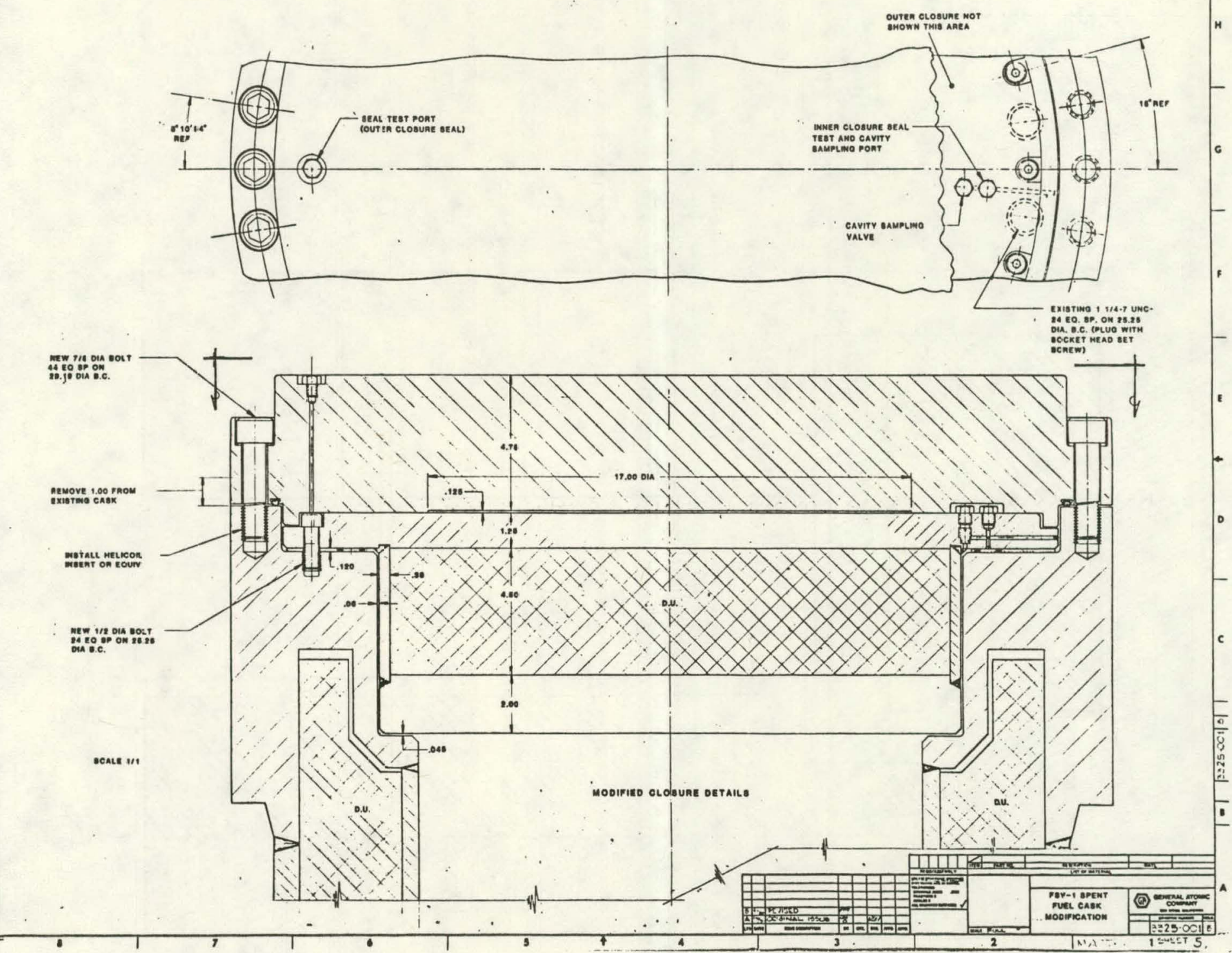

Fig. 3-21. New end closure design 


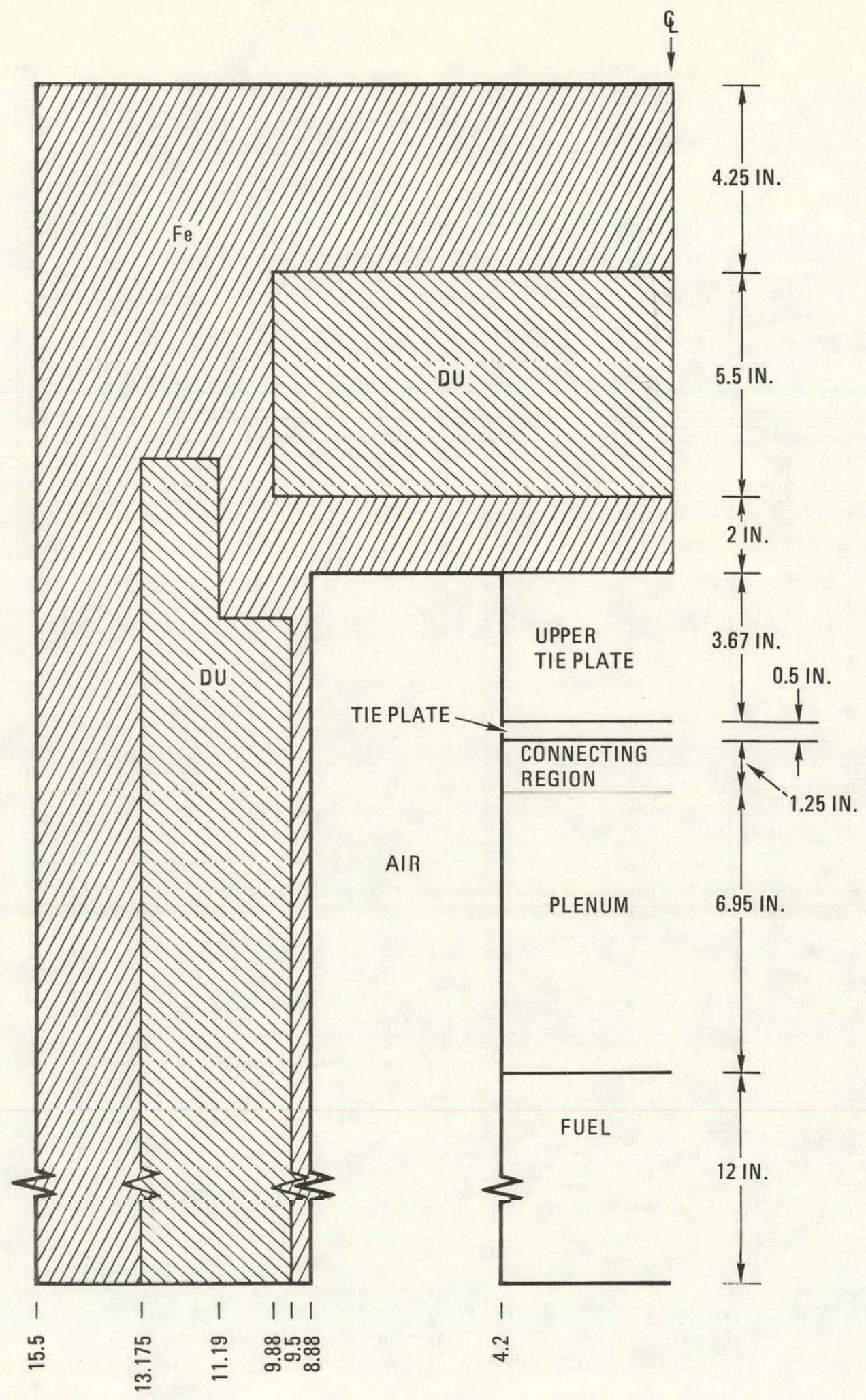

Fig. 3-22. Geometry input for PATH top of FSV-1 cask new design 


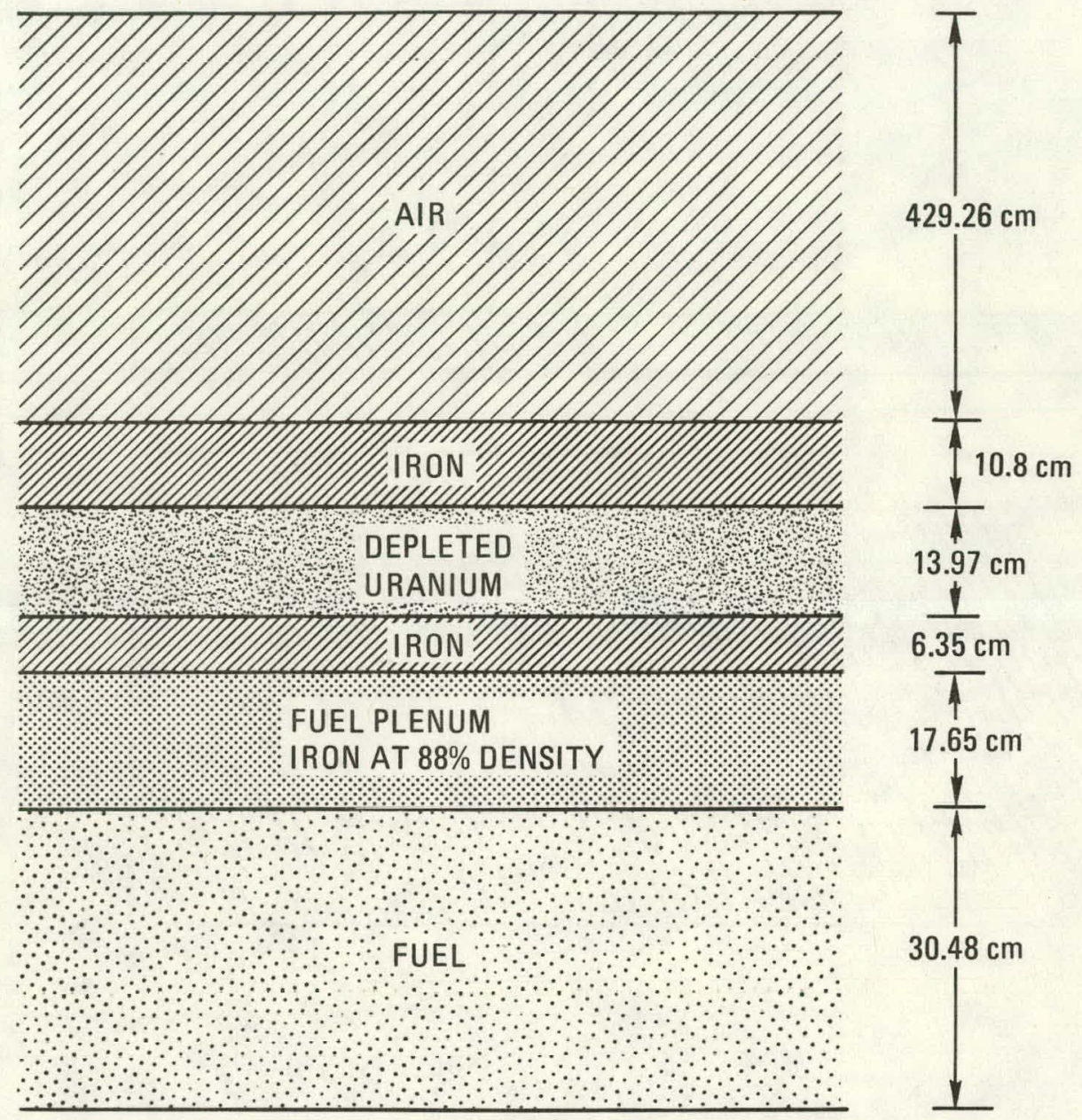

Fig. 3-23. Geometry for input for DTFX top of FSV-1 cask new design 


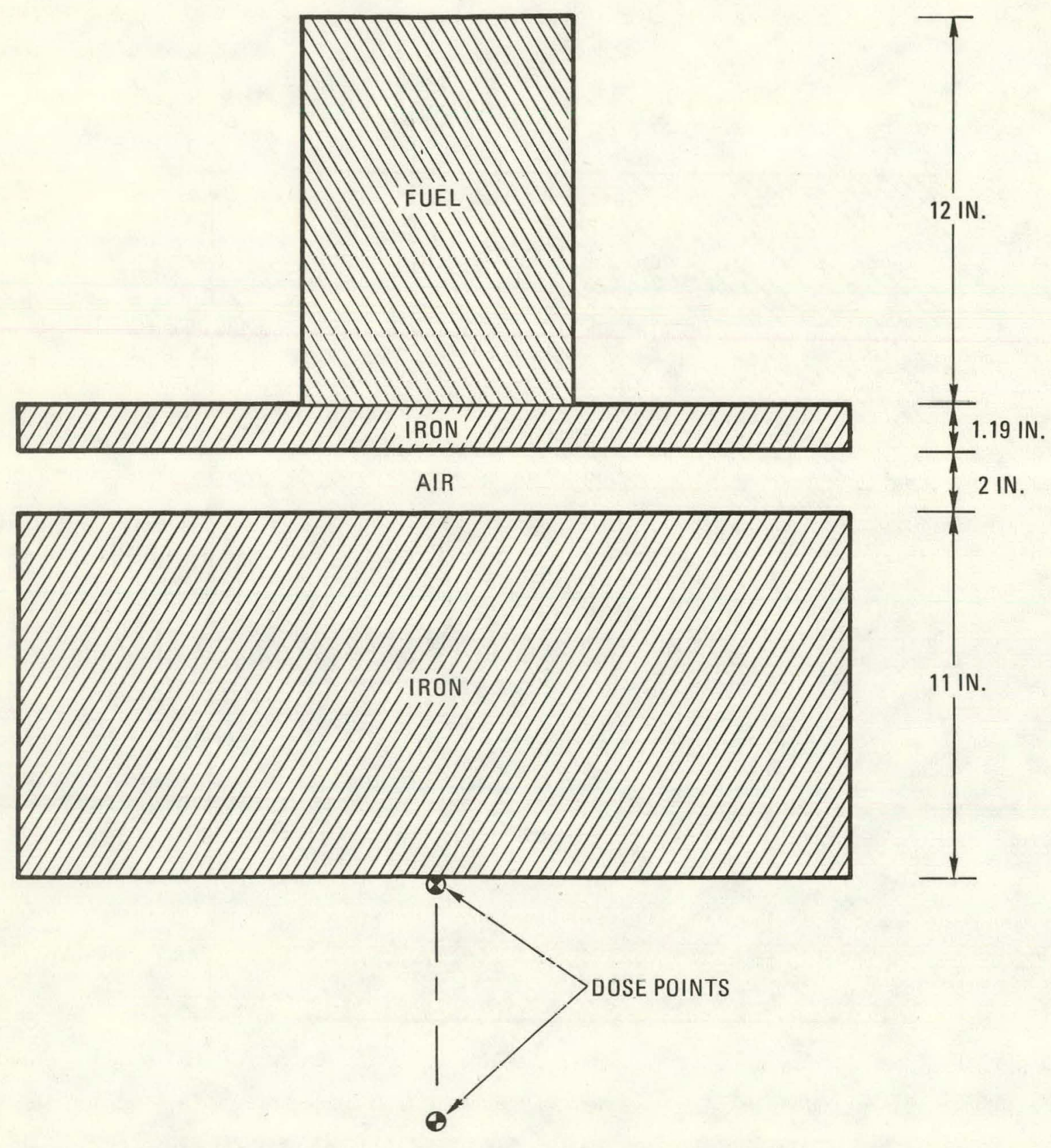

Fig. 3-24. Geometry input for PATH-bottom of FSV-1 cask 

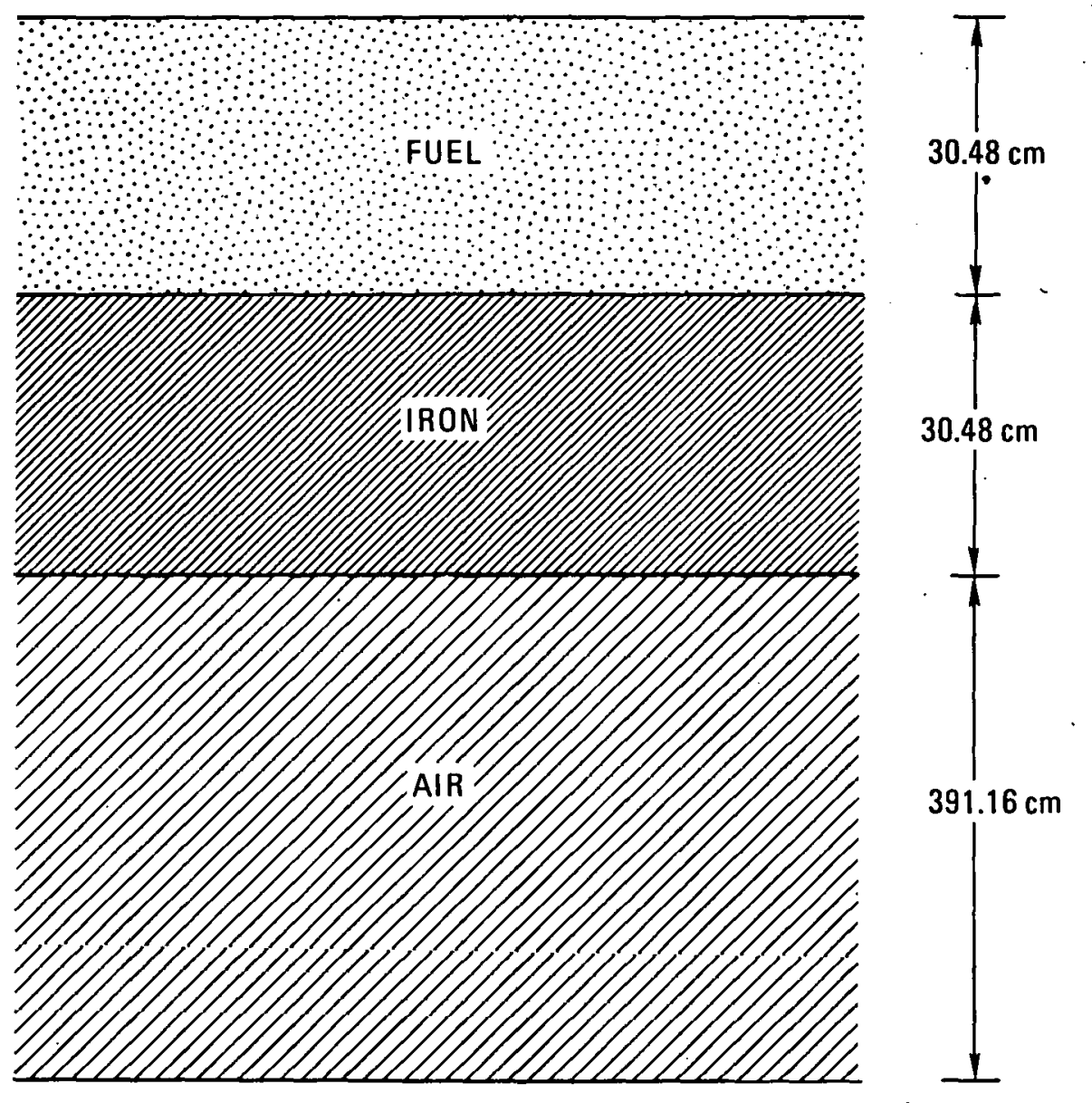

Fig. 3-25. Geometry of input for DTFX - bottom of FSV-1 cask 


\subsection{RESULTS}

\section{$3.5 .1 \quad$ PWR}

\subsubsection{Side}

Dose rates from the side of the cask were considered for both PWR and BWR fuel assemblies. PATH calculations considered dose rates on the side of the cask and $6 \mathrm{ft}$. from the edge of the transport vehicle, for neutron shield thicknesses of 0,3 , and $6 \mathrm{in}$. Dose rate calculations performed by DTFX considered 0 and $3 \mathrm{in}$. neutron shield for the same dose points as those in PATH.

3.5.1.1.1 Neutrons. The results of neutron dose rates $6 \mathrm{ft}$ from the edge of the transport vehicle due to one PWR fuel assembly within the cask are shown in Table 3-12 and Figs. 3-27 and 3-28 for various combinations of burnup, decay time, and neutron shield with no added extra gamma shield.

The total neutron dose rate per source neutron has been broken down into primary and secondary contributions in Fig. 3-29 for the different regions in the as-built cask. Also shown is the secondary gamma dose rate due to the primary source neutrons. The neutron dose rate breakdown is shown again in Fig. 3-30 for the case of 3-in. of neutron shield added to the cask. It is interesting lu nute that secondary neutrons contribute $15 \%$ to $35 \%$ as much to the dose rate as do the primary neutrons.

Values of neutron dose rates for other shielding combinations may be found with the help of Figs. $3-3$ and 3-4 and the method described in Section 3.2.2.

\subsection{Gammas. The results of yduma slde dose rates $6 \mathrm{ft}$ from the} edge of the transport vehicle are shown in Figs. 3-31 and 3-32 at various decay times and burnups for the case with no extra neutron or gamma shielding. Dose rates for other cases are found by using the data shown in Figs. 3-3 and 3-4 and the methods described in Section 3.2.2.

Dose rate information regarding a change in dose point location may need to be known. Figure 3-33 normalizes the total dose rate to the side of the cask and allows one to transform dose rates to any location between the cask and $6 \mathrm{ft}$ from the edge of the transport vehicle. 
TABLE 3-12

NEUTRON DOSE RATES 6 FT FROM EDGE OF TRANSPORT VEHICLE MREM/HR

\begin{tabular}{|c|c|c|c|c|c|c|}
\hline \multirow{2}{*}{$\begin{array}{l}\text { Neutron } \\
\text { Shield } \\
\text { (in.) }\end{array}$} & \multirow{2}{*}{$\begin{array}{l}\text { Gamma } \\
\text { Shield } \\
\text { (in.) }\end{array}$} & \multirow{2}{*}{$\begin{array}{c}\text { Burnup } \\
\text { (MWD/MTHM) }\end{array}$} & \multicolumn{4}{|c|}{ Decay Time } \\
\hline & & & $l y r$ & $2 y r$ & $5 y r$ & $10 y r$ \\
\hline & & & PWR & & & \\
\hline \multirow[t]{3}{*}{0} & 0 & 20,000 & 1.71 & 1.29 & 1.09 & 0.96 \\
\hline & & 33,000 & 18.90 & 16.10 & 13.90 & 11.70 \\
\hline & & 40,000 & 46.40 & 41.60 & 36.40 & 30.30 \\
\hline \multirow[t]{3}{*}{3} & 0 & 20,000 & 0.20 & 0.15 & 0.13 & 0.11 \\
\hline & & 33,000 & 2.20 & 1.88 & 1.62 & 1.36 \\
\hline & & 40,000 & 5.40 & 4.84 & 4.24 & 3.52 \\
\hline \multirow[t]{4}{*}{6} & 0 & 20,000 & 0.01 & 0.01 & 0.01 & 0.01 \\
\hline & & 33,000 & 0.14 & 0.12 & 0.10 & 0.09 \\
\hline & & 40,000 & 0.35 & 0.31 & 0.28 & 0.23 \\
\hline & & & BWR & & - & \\
\hline 0 & 0 & 34,000 & 34.60 & 29.90 & 26.00 & 21.70 \\
\hline 3 & 0 & 34,000 & 3.99 & 3.45 & 3.00 & 2.50 \\
\hline 6 & 0 & 34,000 & 0.26 & 0.22 & 0.20 & 0.16 \\
\hline
\end{tabular}




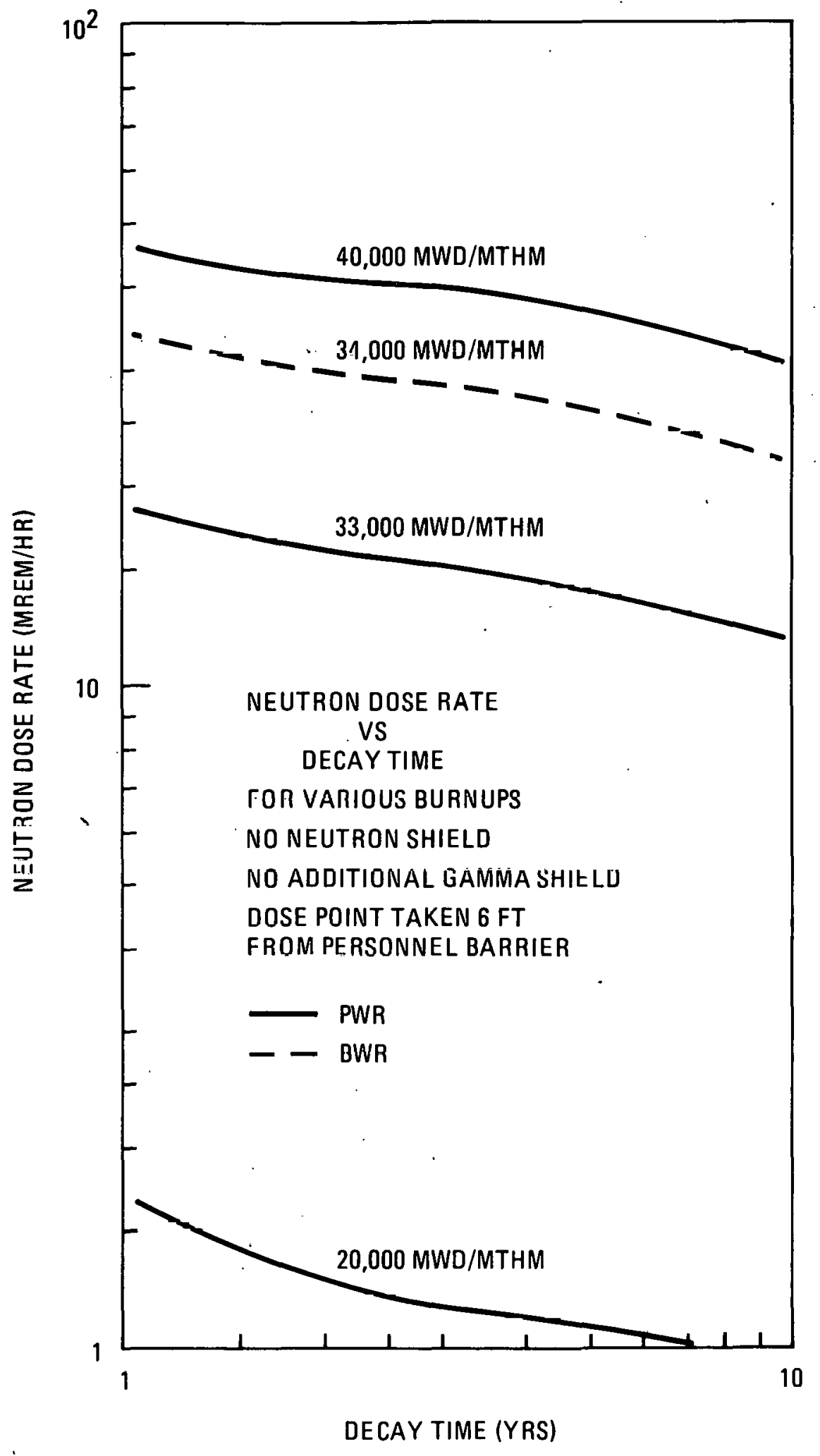

Fig. 3-27. Neutron dose rate vs decay time for various burnups, no neutron shield, no additional gamma shield 


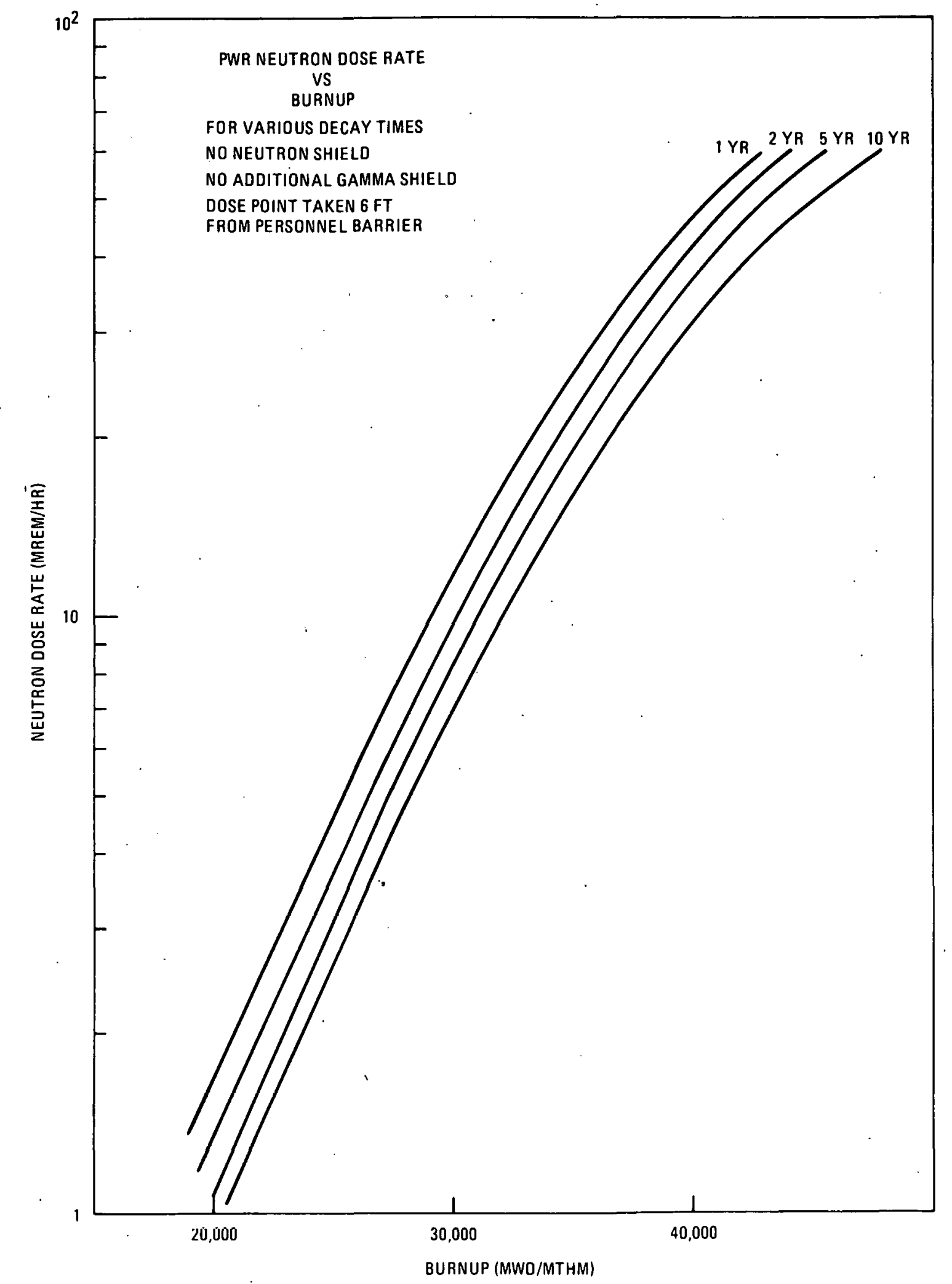

Fig. 3-28. PWR neutron dose rate vs burnup for various decay rimes, no neulron shleld, no additional gamma shield 


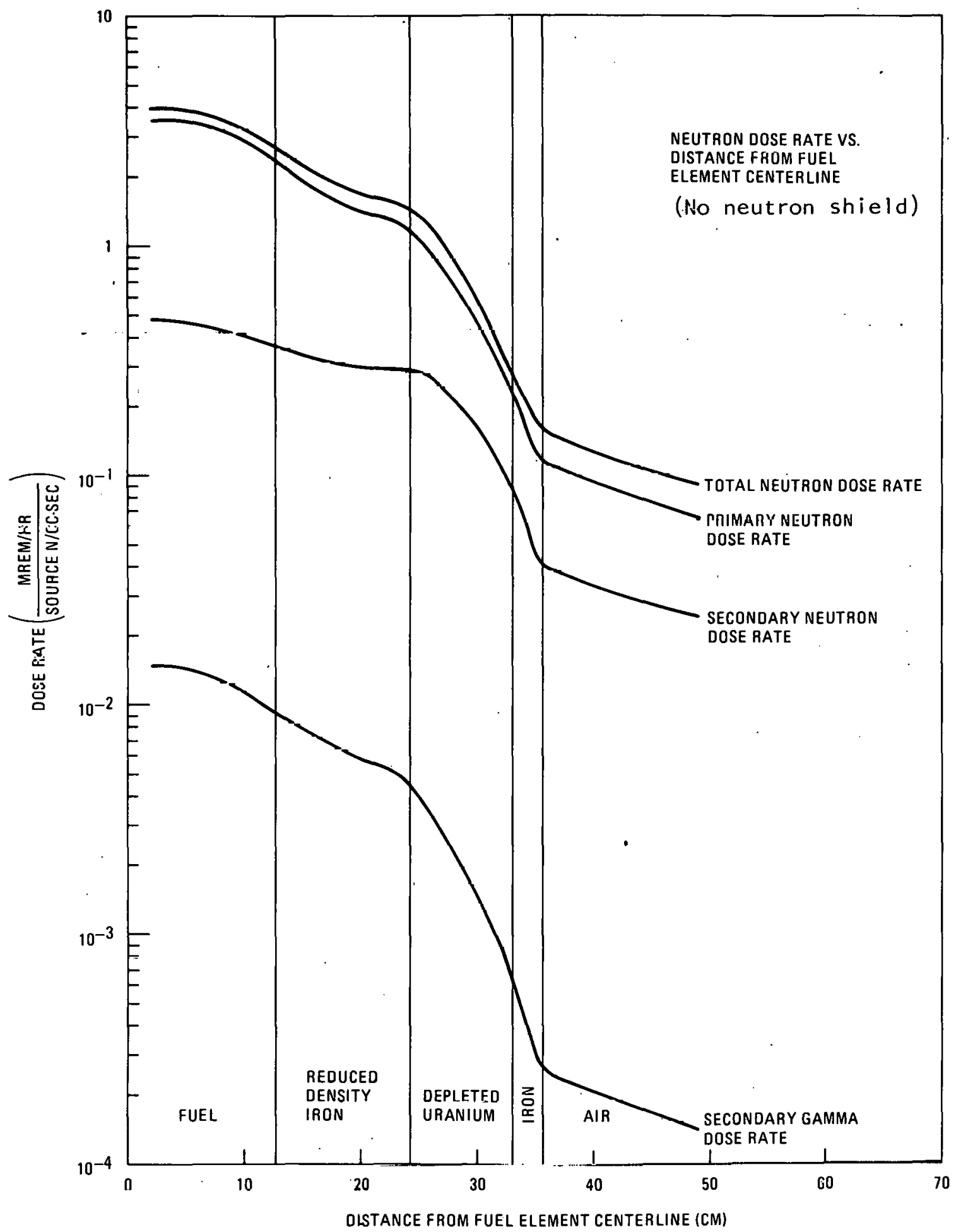

Fig. 3-29. Ncutron dose rate vs distance from fuel element centerline (no neutron shield) 


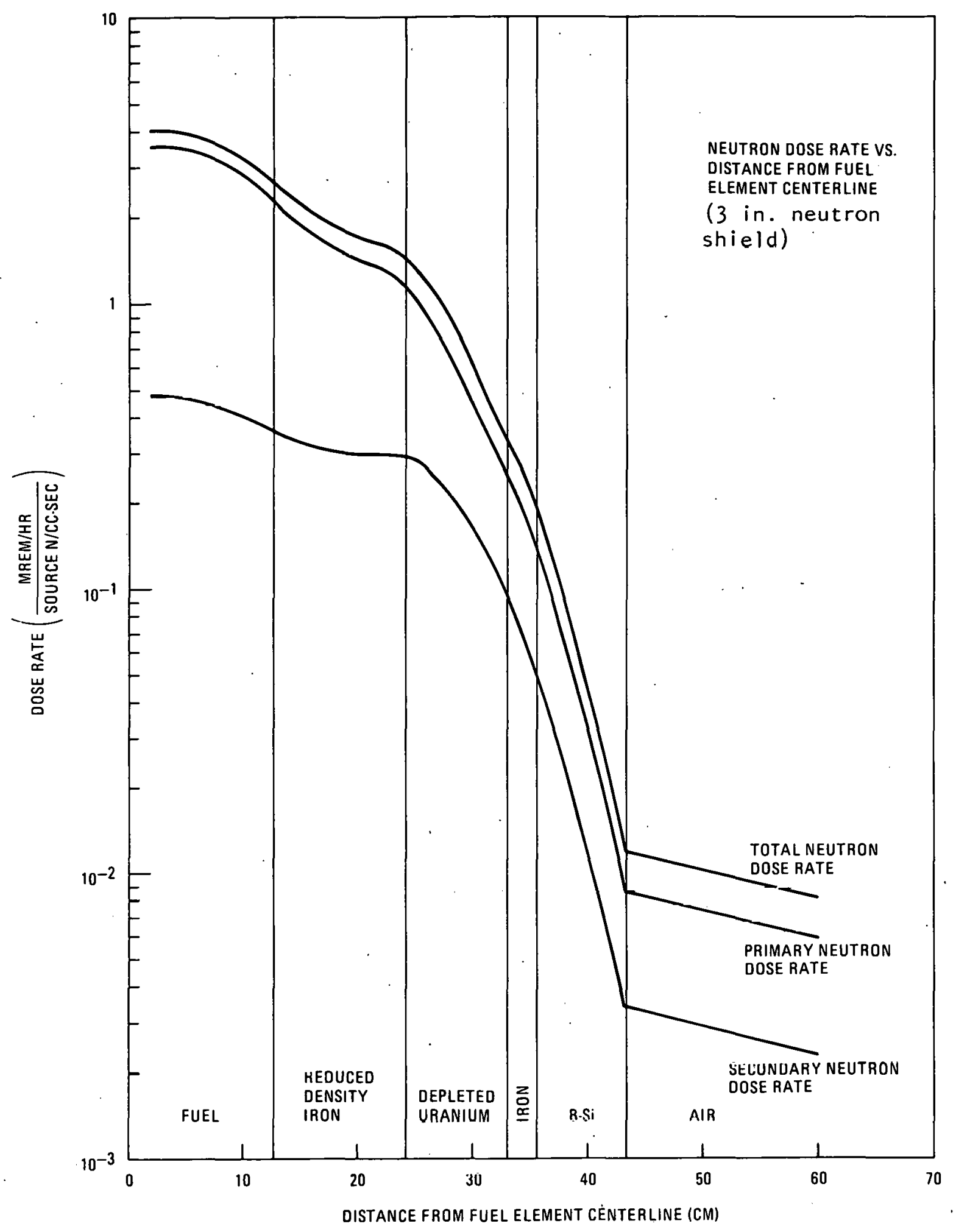

F1g. 3-30. Neutron dose rate vs distance from fuel element centerline ( 3 in. neutron shield) 


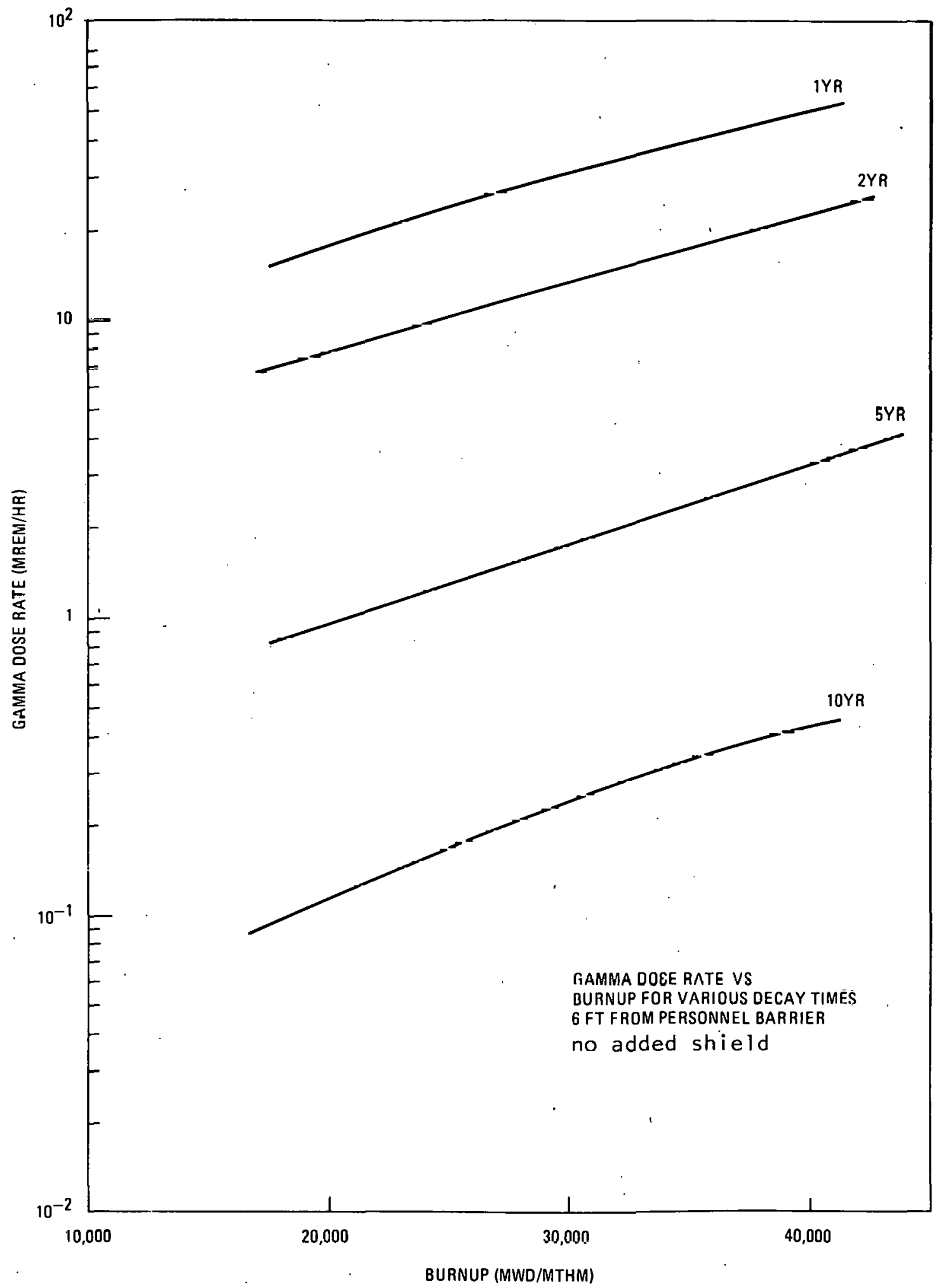

Fig. 3-31. Gamma dose rate vs, burnup for various decay times, no added shield. 


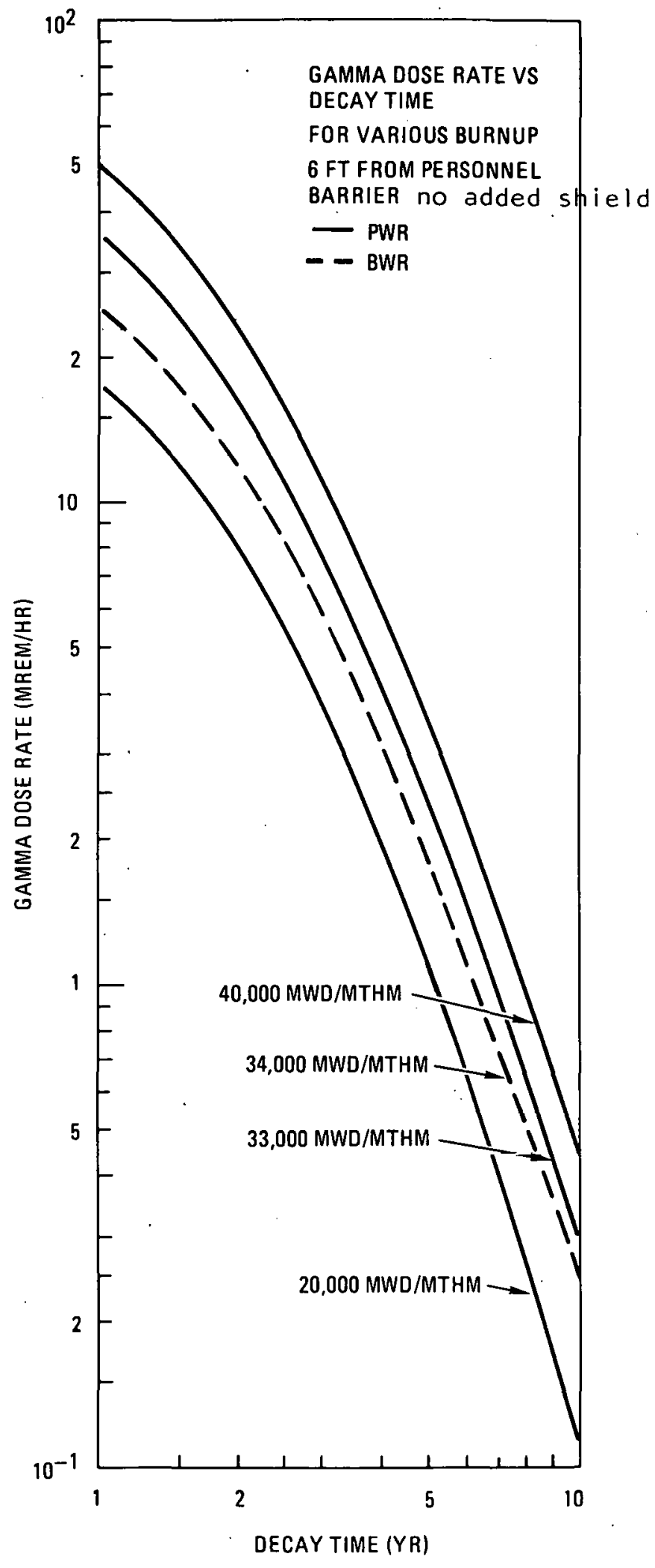

'Fig. 3-32. Gamma dose rate vs decay time for various burnup $6 \mathrm{ft}$ from personnel barrier, no added shield. 


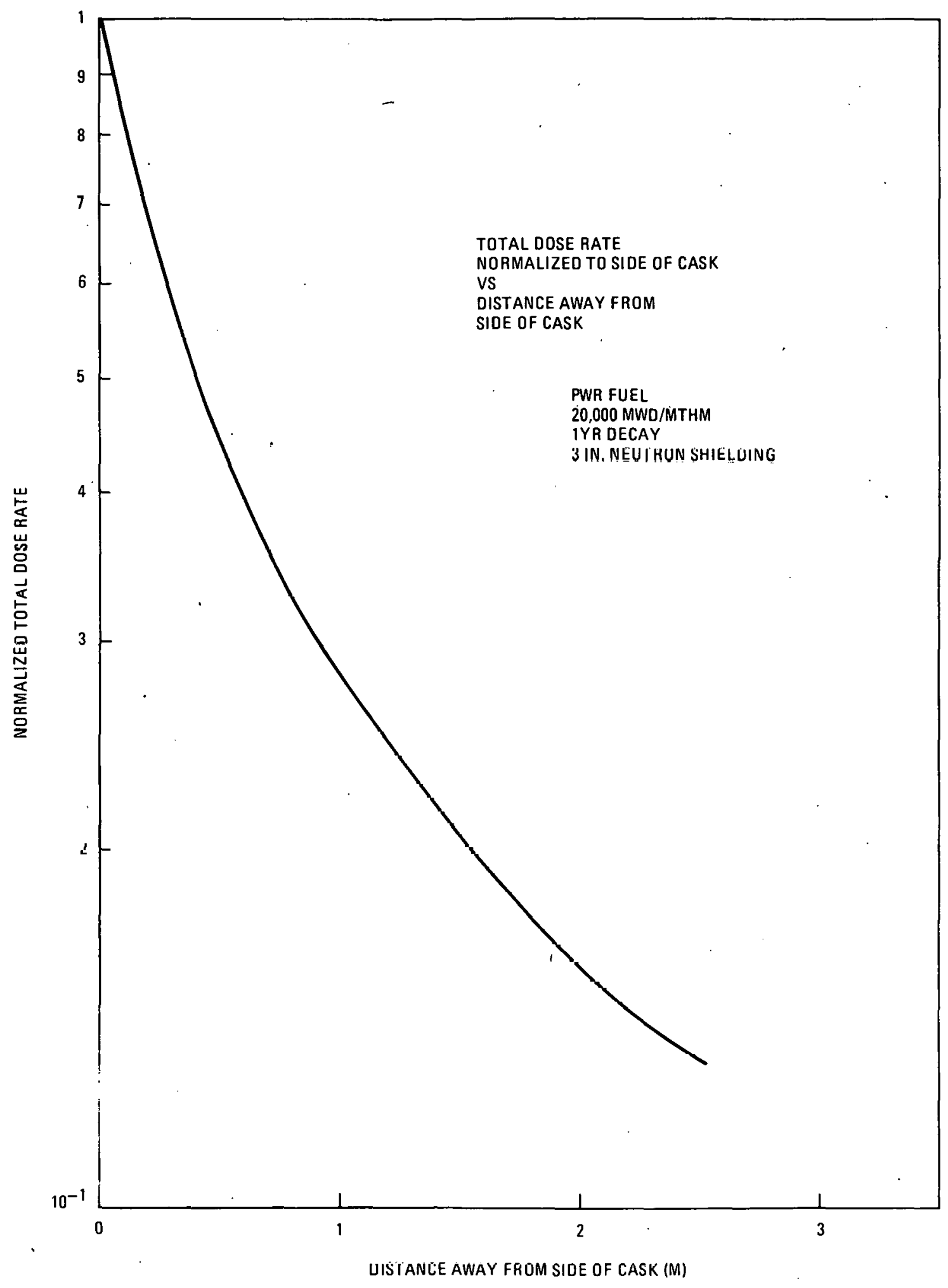

Fig. 3-33. Total dose rate normalized to side of cask vs' distance away from side of cask 
3.5.1.1.3 Total Dose Rates. Total dose rates (neutron + gamma) $6 \mathrm{ft}$ from the edge of the transport vehicle are plotted against burnup for various decay times and shielding thicknesses in Figs. 3-34 through 3-39. From these figures parametric curves of constant shield combinations can be determined once a maximum dose rate has been set. These curves are shown in Figs. 3-40 through 3-43 for maximum dose rates of 10,5 , and 2 $\mathrm{mrem} / \mathrm{hr}$, respectively. Table 3-13 shows the same data as the figure for a $10 \mathrm{mrem} / \mathrm{hr}$ dose rate criteria but in tabular form. One can see that the maximum burnup permissible with the as-built cask (no additional neutron or gamma shielding) for a decay time of $5 \mathrm{yr}$ is 30,000 MWD/MTHM. If $3 \mathrm{in}$. of neutron shielding are added, the minimum decay time is reduced to $2 \mathrm{yr}$, and so on. From Table 3-13 and Fig. 3-40, one has all the information necessary for PWR fuel to determine the maximum or minimum value of burnup, decay time, or shield thickness.

The ratio of neutron to gamma dose rates as a function of burnup is shown in Figs. 3-44 and 3-45 for various shield thicknesses and decay times.

\subsubsection{PWR Top Results}

0ld Design. This concept involved removing the inner linner and lowering the inner closure 1.25 inches (see section 3.4.2.2). Dose rates, considering primary radiations only (no secondary neutrons) were calculated for the outer surface of the inner closure and the adjoining cask body surfaces. For the results see Table 3-17. Most cases of burnup and decay result in dose rates that exceed the $50 \mathrm{mrem} / \mathrm{hr}$ criteria, fortunately this concept is no longer being considered.

New Design. This concept uses new inner and outer closures as shown on Figure 3-21. Dose rates were calculated for the outer surface of the inner closure and the adjoining cask body surfares. For the results see Table 3-18a. Again, most cases of burnup and decay result in dose rates that exceed the $50 \mathrm{mrem} / \mathrm{hr}$ criteria. The addition of gamma and/or neutron shielding as part of the canister support basket can reduce these dose rates to satisfy the $50 \mathrm{mrem} / \mathrm{hr}$ criteria.

Tulal duse rates for the same cases of burnup and decay were calculated for the outer surface of the outer closure. These results are shown in Table 3-18b. 


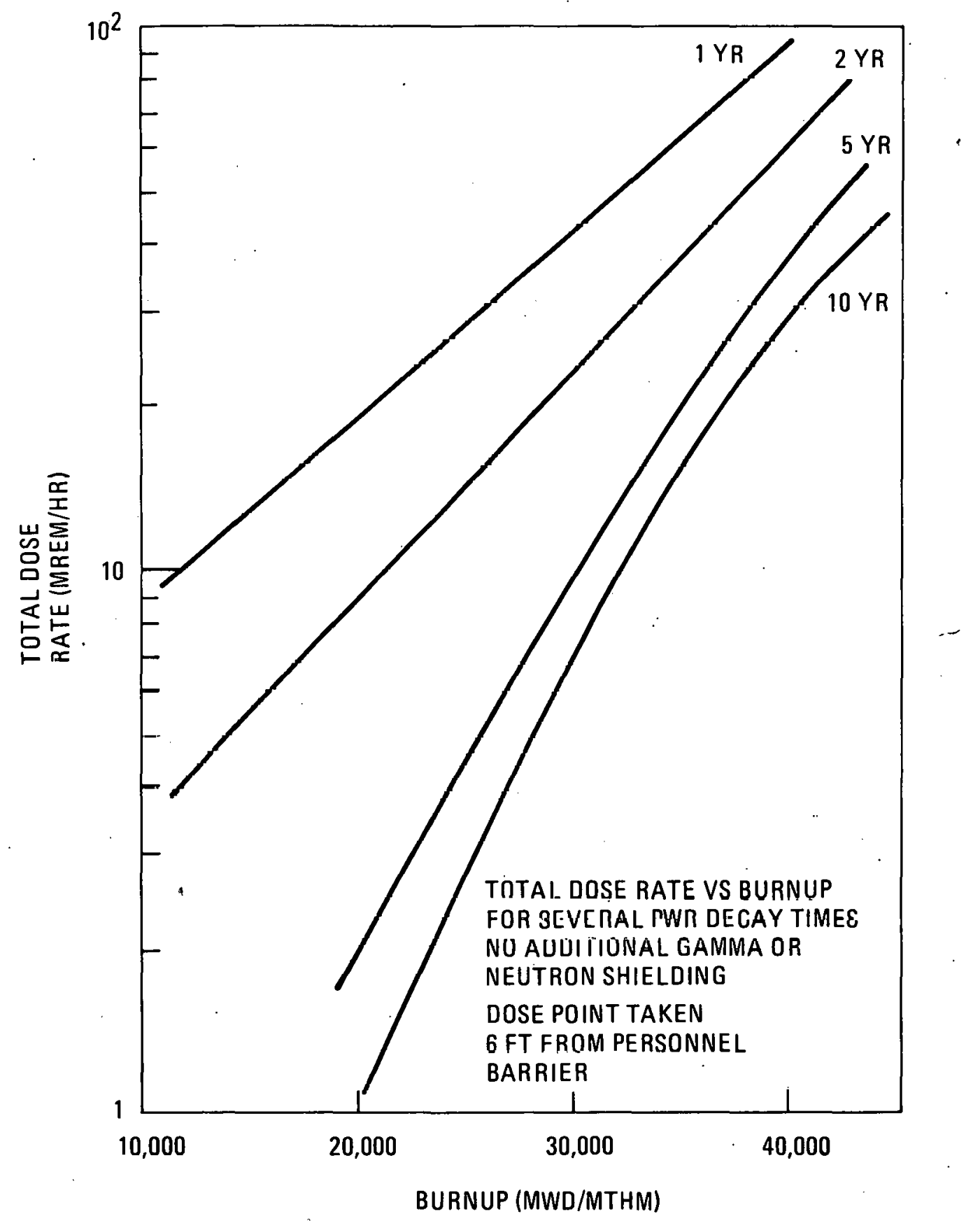

Fig. 3-34. Total dose rate vs burnup for several PWR decay times. no additional gamma shield, no neutron shield 


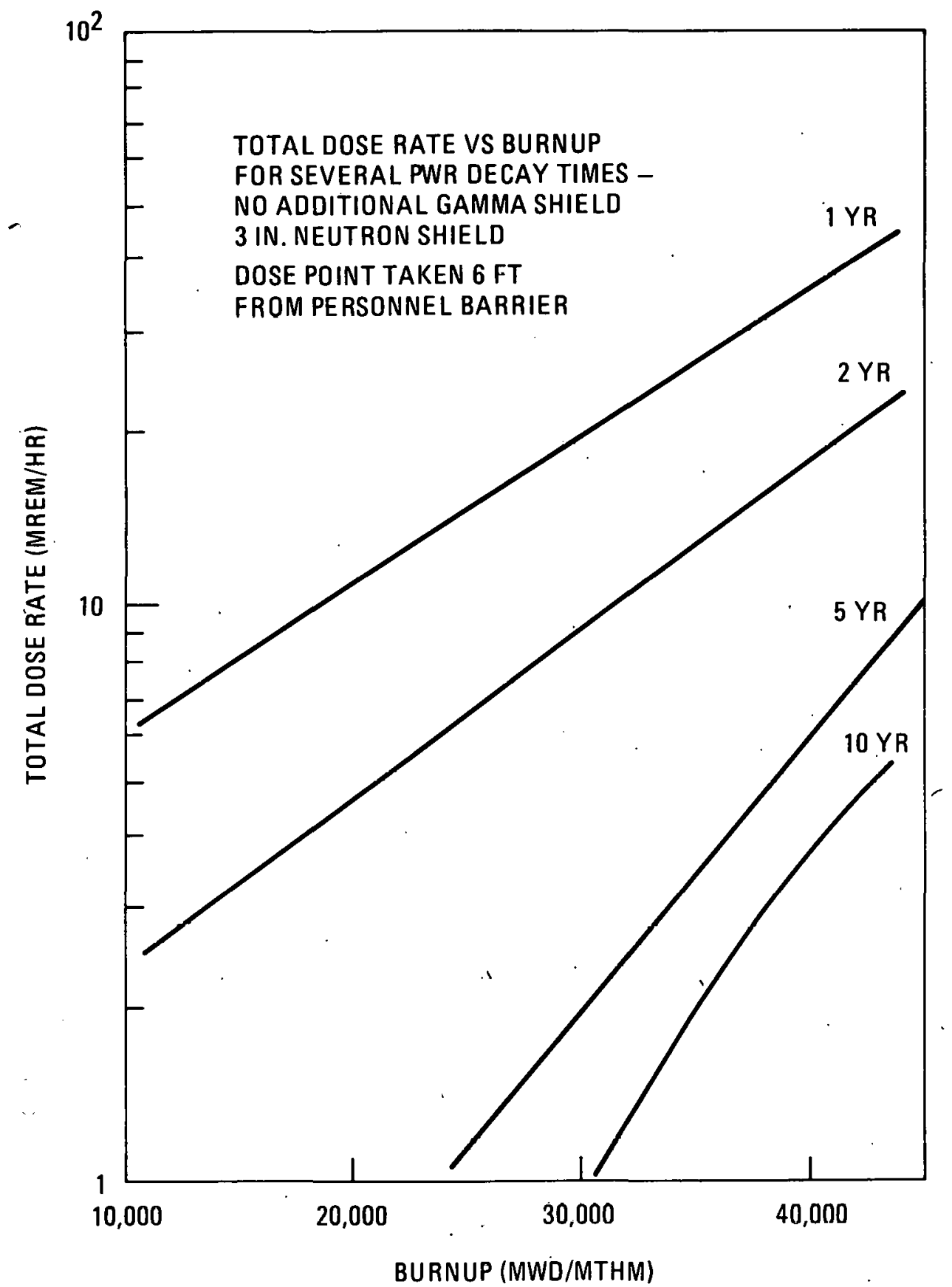

Fig. 3-35. Total dose rate vs burnup for several PWR decay times, no additional gamma shi.el,d, 3 in. neutron shield 


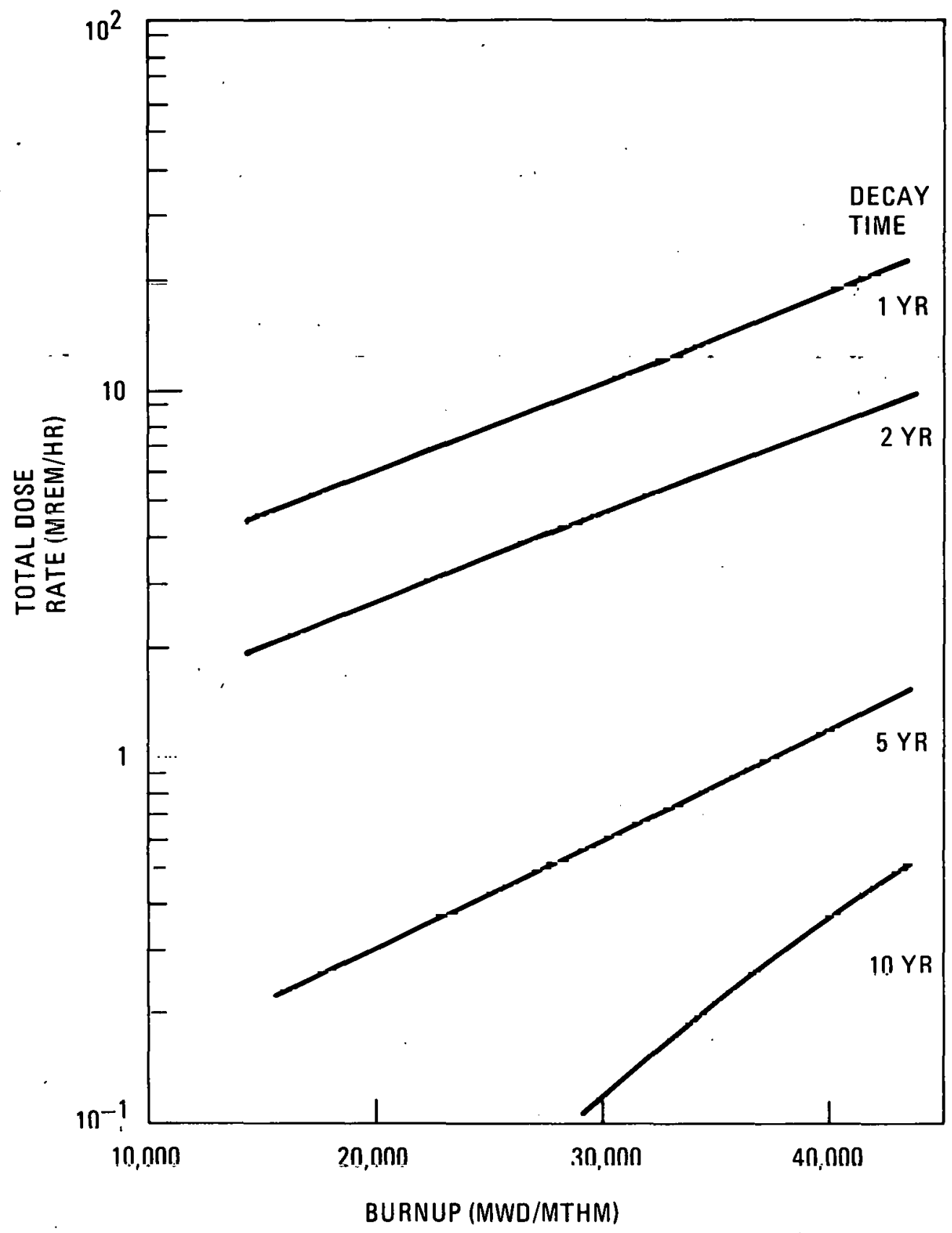

Fig. 3-36. Total dose rate vs burnup for several PWR decay times, no additional gamma shield, 6 in. neutron shield 


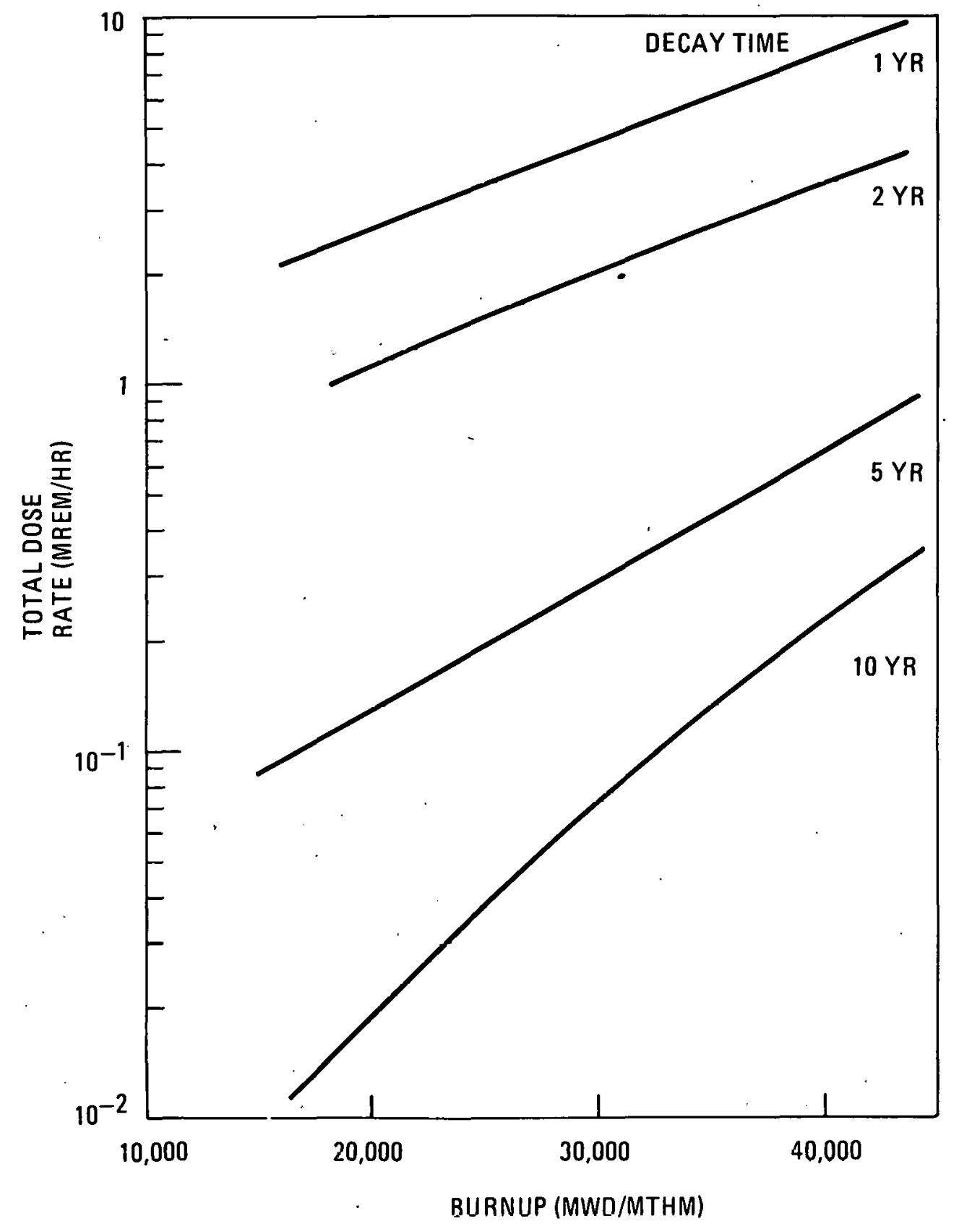

Fig. 3-37. Total dose rate vs burnup for several PWR decay times $6 \mathrm{ft}$ from personnel barrier, 1 inch additional gamma shield, 6 inches neutron shield 


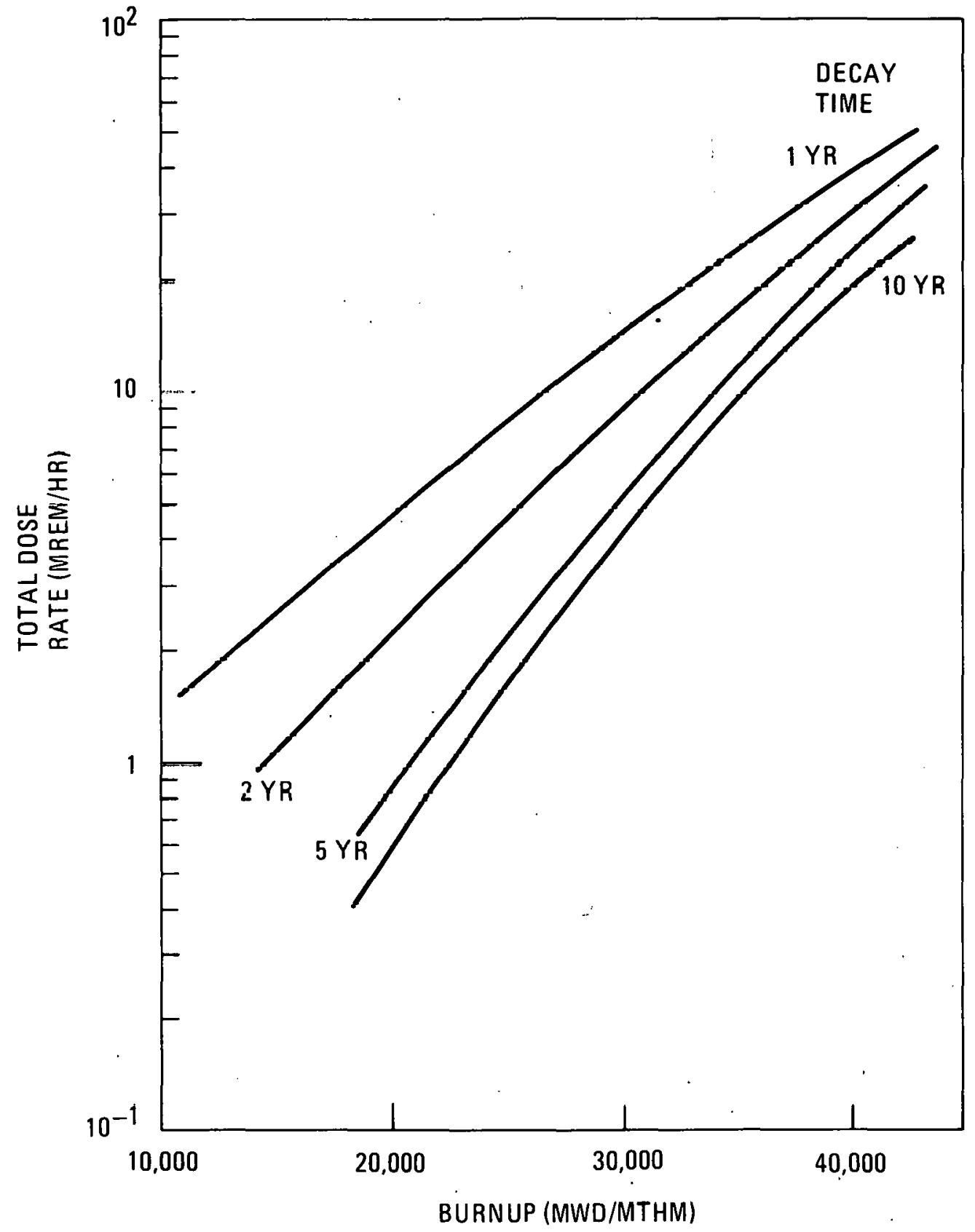

Fig. 3-38. Total dose rate vs burnup for several PWR decay times, 2 in. additional gamma shield, no neutron shield 


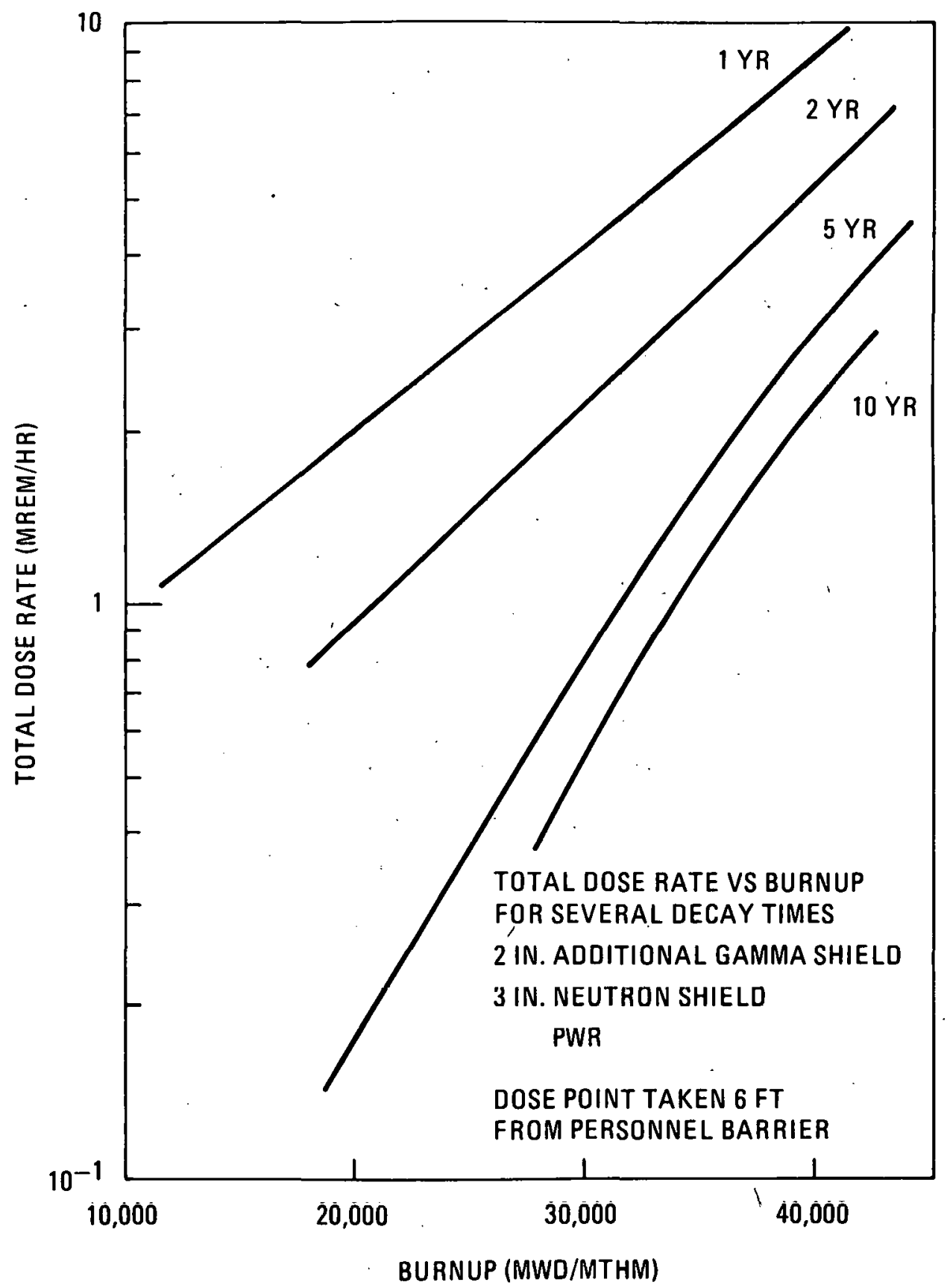

Fig. 3-39. Total dose rate vs burnup for several PWR decay times - 2 in, additional gamma shteld, 3 in. neutron shield, 


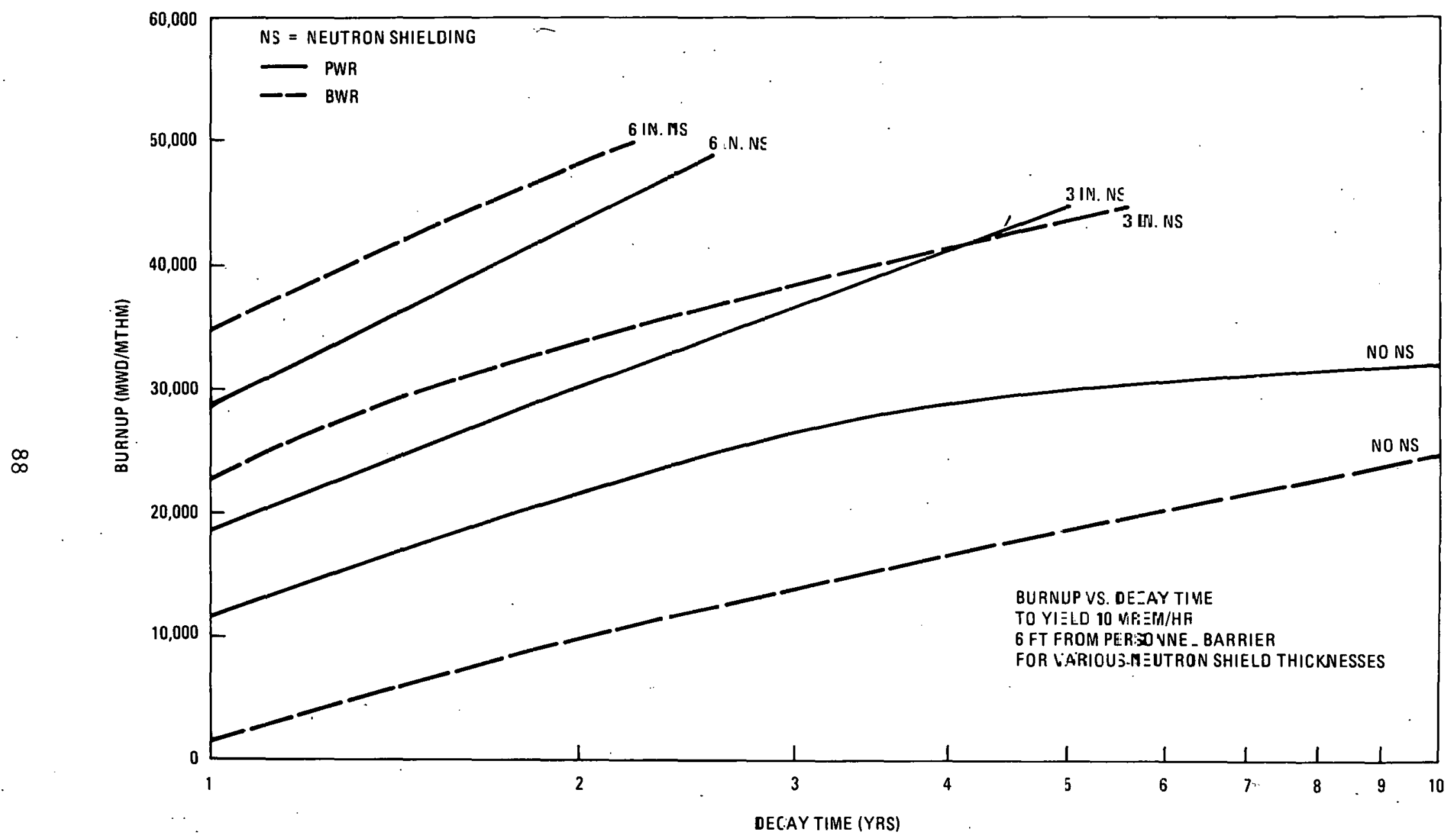

Fig. 3-40. Burnup vs decay time to yield 10 MREM/HR $6 \mathrm{ft}$ from personnel bar:ier for various neatren shiele thizknesses 


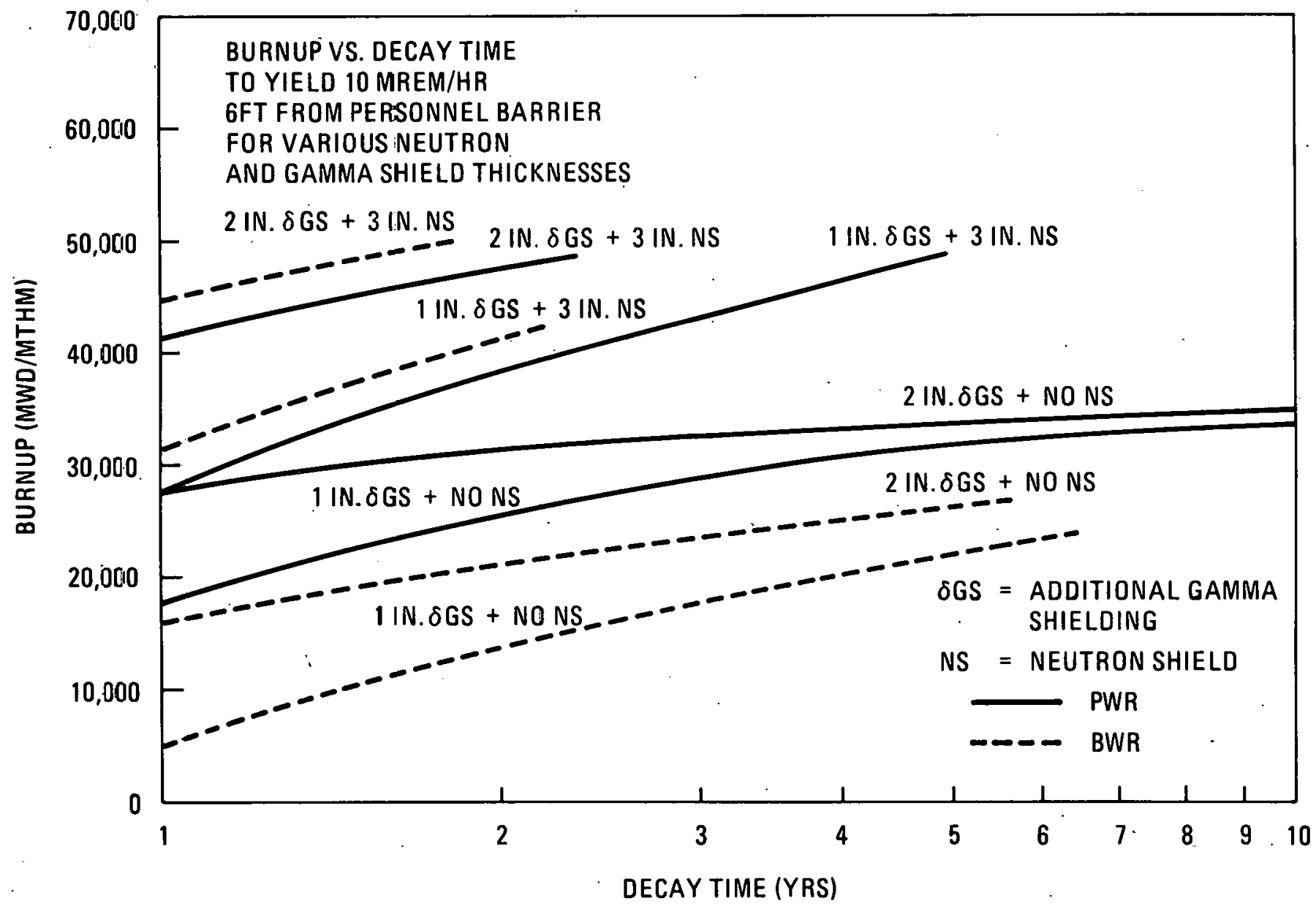

Fig. 3-41. Burnup vs decay time to yield 10 MREM/HR $6 \mathrm{ft}$ from personnel barrier for various neutron and gamma shield thicknesses 


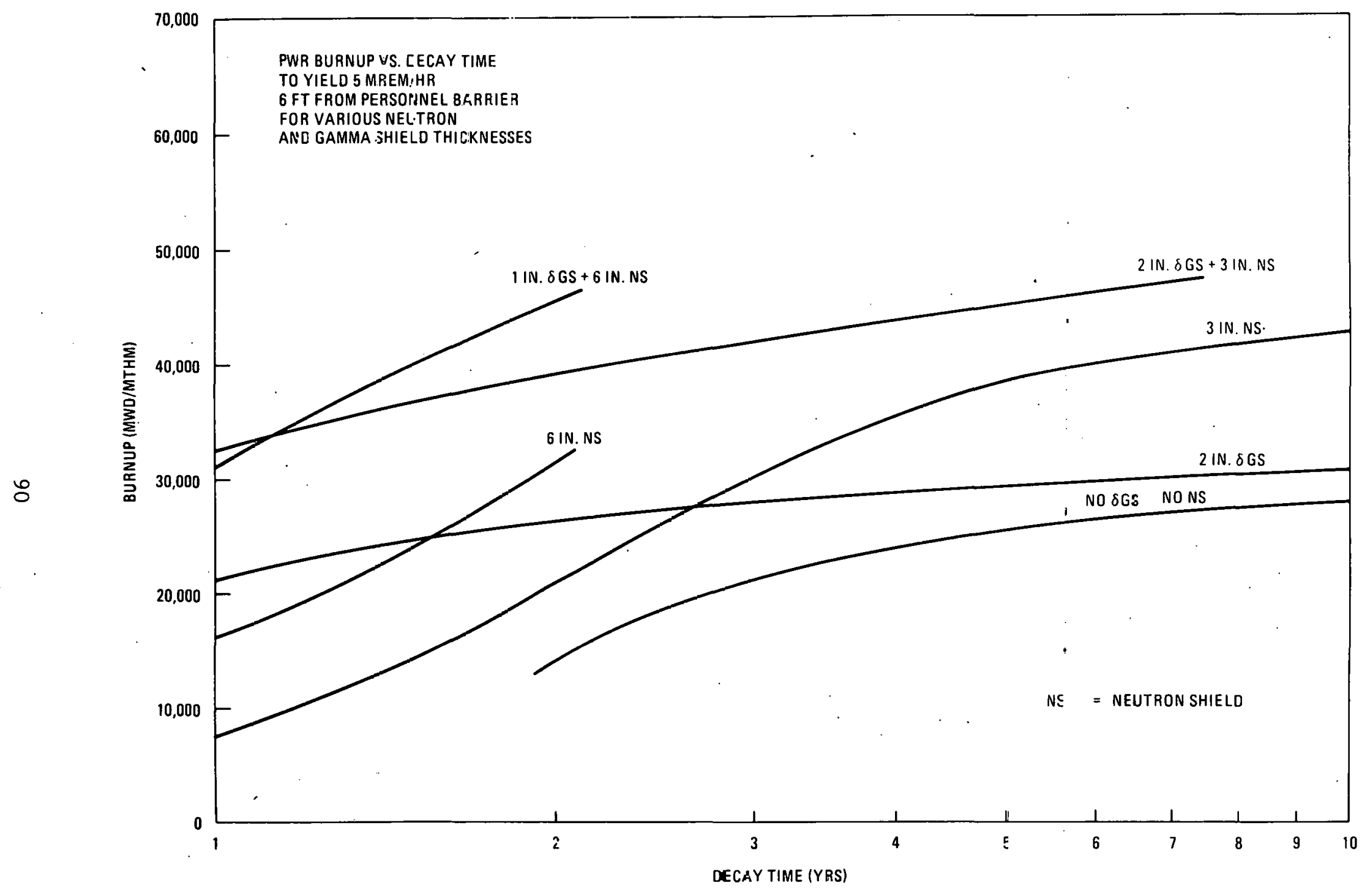

Fig. 3-42. PWR burnup $v \leqslant$ decay time to yield 5 MREM/HR 6 ft from personnel barrier for various neutron and ganma shield thickr.esses 


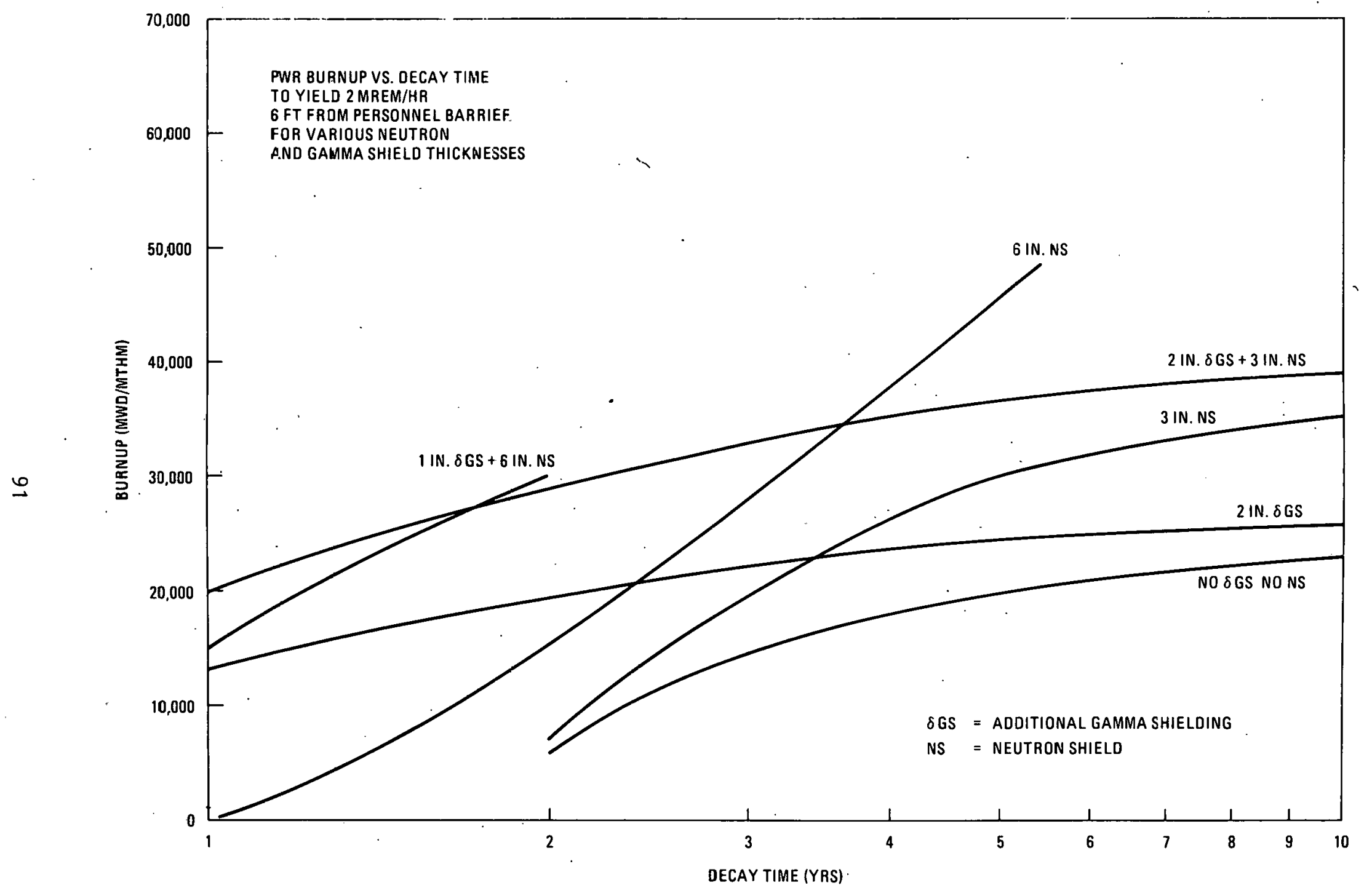

Fig. 3-43. PWR burnup vs decay time to yield 2 MREM/HR $6 \mathrm{ft}$ from personnel barrier for various neutron and gamma shield thicknesses 
TABLE $3-13$

UNIFORM 10 MREM/HR 6 FT FROM EDGE OF TRANSPORT VEHICLE

\begin{tabular}{|c|c|c|c|c|}
\hline \multirow{2}{*}{$\begin{array}{l}\text { Additional } \\
\text { Neutron } \\
\text { Shield } \\
\text { (in.) } \\
\end{array}$} & \multirow{2}{*}{$\begin{array}{c}\text { Additional } \\
\text { Gamma } \\
\text { Shield } \\
\text { (in.) }\end{array}$} & \multirow{2}{*}{$\begin{array}{l}\text { Decay } \\
\text { Time } \\
\text { (yr) }\end{array}$} & \multicolumn{2}{|c|}{$\begin{array}{c}\text { Permissible Burnup } \\
\text { (MWD/MTHM) }\end{array}$} \\
\hline & & & PWR & BWR \\
\hline 0 & 0 & $\begin{array}{r}1 \\
2 \\
5 \\
10\end{array}$ & $\begin{array}{l}11 \\
21 \\
30 \\
32\end{array}$ & $\begin{array}{l}19 \\
25\end{array}$ \\
\hline 3 & 0. & $\begin{array}{l}1 \\
2 \\
5\end{array}$ & $\begin{array}{l}18.5 \\
30 \\
44.5\end{array}$ & $\begin{array}{l}18.5 \\
34 \\
43\end{array}$ \\
\hline 6 & 0 & $\begin{array}{l}1 \\
2 \\
5\end{array}$ & $\begin{aligned} & 29 \\
& 43.5 \\
\times & 50\end{aligned}$ & $\begin{aligned} & 34.5 \\
& 48 \\
> & 50\end{aligned}$ \\
\hline 0 & 1 & $\begin{array}{r}1 \\
2 \\
5 \\
10\end{array}$ & $\begin{array}{l}18 \\
25.5 \\
32 \\
33.5\end{array}$ & $\begin{array}{l}5 \\
14 \\
22.5 \\
28\end{array}$ \\
\hline 3 & 1 & $\begin{array}{l}1 \\
2 \\
5\end{array}$ & $\begin{array}{l}27.5 \\
38.5 \\
49\end{array}$ & $\begin{aligned} & 31.5 \\
& 41.5 \\
&> 50\end{aligned}$ \\
\hline 6 & 1 & $\begin{array}{l}1 \\
2\end{array}$ & $\begin{array}{r}44 \\
>50\end{array}$ & $\begin{array}{l}>50 \\
>50\end{array}$ \\
\hline 0 & 2 & $\begin{array}{r}1 \\
2 \\
5 \\
10\end{array}$ & $\begin{array}{l}27.5 \\
31 \\
34 \\
35\end{array}$ & $\begin{array}{l}16 \\
21 \\
26.5 \\
31\end{array}$ \\
\hline 3 & 2 & $\begin{array}{l}1 \\
2 \\
5\end{array}$ & $\begin{aligned} & 41 \\
& 47.5 \\
> & 50\end{aligned}$ & $\begin{aligned} & 44.5 \\
> & 50 \\
> & 50\end{aligned}$ \\
\hline
\end{tabular}




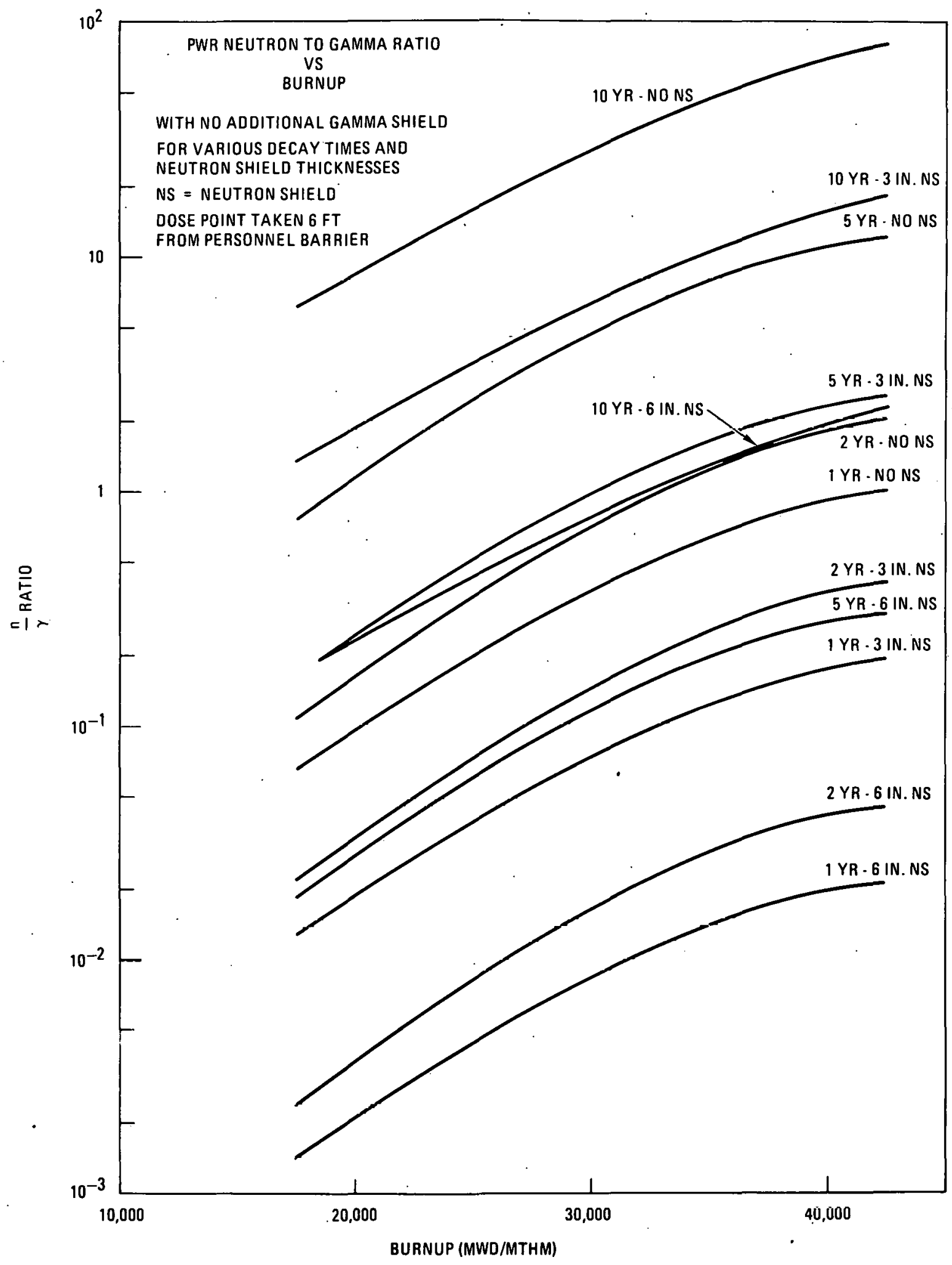

Fig. 3-44. PWR neutron to gamma ratio vs burnup with no additional gamma shield for various decay times and neutron shield thicknesses 


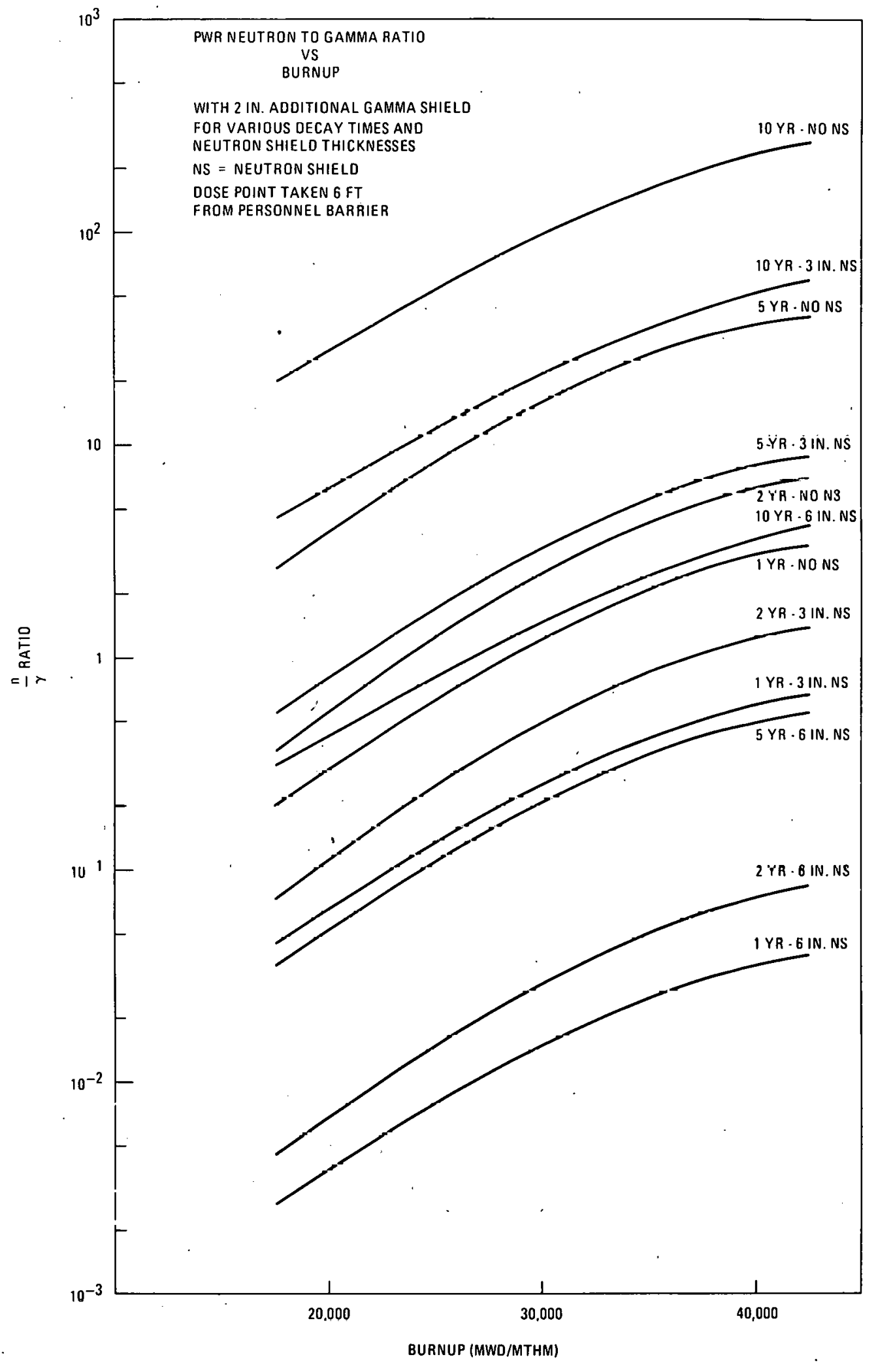

Fig. 3-45. PWR neutron to gamma ratio vs burnup with 2 in. additional gamma shield for various decay times and neutron shield thicknesses 
TABLE 3-17

TOTAL DOSE RATE AT SURFACE OF INNER

CLOSURE - OLD DESIGN

mrem/hr

\begin{tabular}{c|c|c|c|c}
\hline \multirow{2}{*}{$\begin{array}{c}\text { Burnup } \\
\text { (MWD/MTHM) }\end{array}$} & \multicolumn{4}{|c}{ Decay Time } \\
\cline { 2 - 5 } & $1 \mathrm{yr}$ & $2 \mathrm{yr}$ & $5 \mathrm{yr}$ & $10 \mathrm{yr}$ \\
\hline 20,000 & 230 & 119 & 33.6 & 14.5 \\
33,000 & 528 & 308 & 128 & 74 \\
40,000 & 819 & 510 & 252 & 161 \\
\hline
\end{tabular}


TABLE 3-18a

TOTAL DOSE RATE AT: SURFACE OF INNER

CLOSURE - NEW DESIGN

$\mathrm{mrem} / \mathrm{hr}$

\begin{tabular}{c|c|c|c|c}
\hline \multirow{2}{*}{$\begin{array}{c}\text { Burnup } \\
\text { (MWn/MTHM) }\end{array}$} & \multicolumn{4}{|c}{ Decay Time } \\
\cline { 2 - 5 } & $1 \mathrm{yr}$ & $2 \mathrm{yr}$ & $5 \mathrm{yr}$ & $10 \mathrm{yr}$ \\
\hline 20,000 & 54.9 & 27.6 & 8.1 & 4.4 \\
33,000 & 163 & 102 & 56.5 & 41.5 \\
40,000 & 296 & 206 & 136 & 104 \\
\hline
\end{tabular}

TABLE 3-18b

TOTAL DOSE RATE AT SURFACE OF OUTER

CLOSURE - NEW DESIGN

$\mathrm{mrem} / \mathrm{hr}$

\begin{tabular}{c|c|c|c|c}
\hline & \multicolumn{4}{|c|}{$\mathrm{mrem} / \mathrm{hr}$} \\
\cline { 2 - 5 } $\begin{array}{c}\text { Burnup } \\
\text { (MWD/MTHM) }\end{array}$ & $1 \mathrm{yr}$ & $2 \mathrm{yr}$ & $5 \mathrm{yr}$ & $10 \mathrm{yr}$ \\
\hline 20,000 & 1.0 & 0.8 & 0.7 & 0.6 \\
33,000 & 11.8 & 10 & 8.7 & 7.3 \\
40,000 & 29 & 26 & 23 & 19 \\
\hline
\end{tabular}




\subsubsection{PWR Bottom Results}

Dose rate results from the bottom were calculated assuming that the bottom of the inner container remained within the cask. These results are shown in Table 3-14 for a dose point location $6 \mathrm{ft}$ from the rear of the transport vehicle (154 in. from the bottom of the cask). An extra 3 inches of gamma shield will be required for the bottom to insure that the surface dose rate does not exceed $200 \mathrm{mrem} / \mathrm{hr}$ for the worst case of 40,000 MWD/MTHM burnup fuel with 1 yr. decay. With this additional 3 inches of gamma shielding on the bottom, the new dose rates located $6 \mathrm{ft}$ from the rear of the transport vehicle are shown in Table 3-16. Dose rates without this additional shielding are shown on Table 3-15.

\subsubsection{BWR}

Neutron and gamma dose rate results for the BWR case are limited, since only one value of burnup was considered, $(34,000 \mathrm{MWD} / \mathrm{MTHM})$. Because of the large extrapolations necessary, these results are to be taken with only general trends in mind. No conclusions should be drawn because the errors involved may be large.

\subsubsection{Side}

\subsection{Neutrons}

Neutron dose rates were calculated to a distance of $6 \mathrm{ft}$ from the edge of the transport vehicle. The results are plotted in Fig. 3-27 against the fuel assembly decay time for the case of no additional gamma shield. Neutron dose rates for other gamma shield thicknesses were calculated using the method described in Section 3.2.2.

\subsection{Gammas}

- Gamma dose rates $6 \mathrm{ft}$ from the edge of the transport vehicle are plotted against decay time in Fig. 3-32 for a burnup of 34,000 MWD/MTHM.

\subsubsection{3 Totol Dose Rutcs. The method for determining parametric} relationships between all of the variables considered in this report does not hold when there is only one burnup considered, as in the BWR case. Therefore, an assumption has been made and applied which may have large erroes involved but nonetheless gives an insight into the allowable burnups and decay times required. It has been assumed that when plotting the total dose rate versus burnup for constant decay time the resulting 
TABLE $3-14$
TOTAL DOSE RATE - m rem/hr - 6 FT FROM END OF TRUCK

\begin{tabular}{c|c|c|c|c}
\hline $\begin{array}{c}\text { Burnup } \\
\text { (MWD/MTHM) }\end{array}$ & $1 \mathrm{yr}$ & $2 \mathrm{yr}$ & $5 \mathrm{yr}$ & $10 \mathrm{yr}$ \\
\hline 20,000 & 1.11 & 0.5 & 0.18 & 0.11 \\
33,000 & 3.86 & 2.55 & 1.59 & 1.21 \\
40,000 & 7.51 & 5.54 & 3.98 & 3.17 \\
\hline
\end{tabular}

(a) Includes factors 1.1 for gamma and 1.4 for neutrons. 
$\begin{aligned} \text { TABLE } & 3-15 \\ \text { TOTAL DOSE RATE AT } & \text { BOTTOM OF CASK }\end{aligned}$

\begin{tabular}{c|c|c|c|c}
\hline $\begin{array}{c}\text { Burnup } \\
\text { (MWD/MTHM) }\end{array}$ & $1 \mathrm{yr}$ & $2 \mathrm{yr}$ & $5 \mathrm{yr}$ & $10 \mathrm{yr}$ \\
\hline 20,000 & 93.8 & 42.2 & 1.5 .2 & 9.3 \\
33,000 & 326.2 & 215.5 & 1.34 .4 & 104.8 \\
40,000 & 634.6 & 468.1 & 336.3 & 267.9 \\
\hline
\end{tabular}

(a) $84.5 \times$ dose rate $6 \mathrm{Ft}$. from truck (Table 3-14) 
TABLE $3-16$

DOSE RATES 6 FT FROM REAR OF TRUCK DUE TO 3 IN. OF ADDED GAMMA SHIELD ON BOTTOM*

$\mathrm{m} \mathrm{rem} / \mathrm{hr}$

\begin{tabular}{c|c|c|c|c}
\hline $\begin{array}{c}\text { (MWD/MTHM) } \\
\text { Burnup }\end{array}$ & $1 \mathrm{yr}$ & $2 \mathrm{yr}$ & $5 \mathrm{yr}$ & $10 \mathrm{yr}$ \\
\hline 20,000 & 0.13 & 0.08 & 0.06 & 0.05 \\
33,000 & 1.03 & 0.84 & 0.70 & 0.58 \\
40,000 & 2.43 & 2.12 & 1.82 & 1.51 \\
\hline
\end{tabular}

* 154 Inches from bottom of cask 
curve for BWR data has the same slope as for PWR data. With this in mind, the BWR parametric results are presented in Table 3-13 and figs. 3-40 and 3-41 for the case of $10 \mathrm{mrem} / \mathrm{hr}$ at $6 \mathrm{ft}$ from the edge of the transport vehicle.

\subsubsection{BWR Top and Bottom}

The dose rates due to BWR furl with a burnup of $34,000 \mathrm{MWD} / \mathrm{MTHM}$ will be about $70 \%$ of those due to PWR fuel with 33,000 MWD/MTHM burnup.

\subsubsection{PWR/BWR Comparison}

For the same burnup, the BWR fuel assembly is characterized by a volumetric neutron source $60 \%$ higher than that of the PWR fuel, primarily as a result of the lower U-235 enrichment in BWR fuel and the consequent higher neutron absorption rate in U-238 (eventually leading to curium). Although the BWR gamma source is $30 \%$ lower than the PWR source, the neutron difference has the most impact on the relative suitability of the FSV-l cask to carry LWR fuel, particularly if no neutron shielding is added. Thus, the summary Table 3-13 shows that with no neutron shielding and a decay time of 2 yr., the cask can carry PWR fuel with a burnup of 21,000 MWD/MTHM. Three more years decay time is needed to carry the BWR fuel with the same burnup. With a thick neutron shield, the positions of the PWR and BWR reverse with the cask being able to carry slightly higher BWR burnups.

One other obvious aspect should be pointed out in a PWR/BWR comparison. If the BWR dose rates are too high, one (instead of three) assemblies could be transported, whereas there is no such "out" for PWR fuel. 
Finally, it should be emphasized that the results for BWR fuel reported herein are based on only one ORIGEN case, namely for 34,000 MWD/MTHM burnup, and that some of the large extrapolations from this one case lead to larger uncertainties in BWR results than in PWR results. The limiting BWR burnups for no additional shielding are particularly crude numbers.

\subsubsection{Comparison with Earlier Results}

The earlier work mentioned in the Introduction (Ref. 3-8) can be compared against the present results. Lamma dose races are cumpared ill Fig. 3-46. The rather wide divergence is apparently due to a differencc in source terms between Ref. 3-8 and the SANDIA-ORIGEN output, as shown in Table 3-19.

GA experience has been that photon emission at energies greater than $2.2 \mathrm{MeV}$ is completely negligible. This conclusion is borne out by a recent study performed by SAI for EPRI (Ref. 3-19). At 1 yr decay the LWR fission product spectrum is given as $3.9 \times 10^{-4} \mathrm{MeV} / \mathrm{fission}-$ group for 1.8-2.2 MeV photons and only $4.4 \times 10^{-13} \mathrm{MeV} / \mathrm{fission}-g r o u p$ for the $>2.6 \mathrm{MeV}$ group.

Since for the worst cases the ORIGEN-generated $2.75-\mathrm{MeV}$ source group contributes $60 \%$ of the total gamma dose rate, a large positive error in this group greatly penalizes the predicted performance of the cask. Future studies should be directed at improving the accuracy of the SANDIA-ORIGEN gamma spectrum and achieving consistency with that published by other authors.

Table 3-20 provides a comparison between neutron results from Ref. 3-8 and the present study. In spite of the fact that the SANDIA-ORIGEN calculations utillzed an apparently high value of the $(\alpha, n)$ conversion, the present neutron results show higher permissible burrup than the Ref. 3-8 results. The reason for this reverse comparison can be sought in the original source terms used in each study, as shown in Table 3-21.

However, this table also shows the differences in the wrong direction. It is tentatively concluded, therefore, that the neutron attenuation and dose estimates in Ref. 3-8 were on the conservative side. 


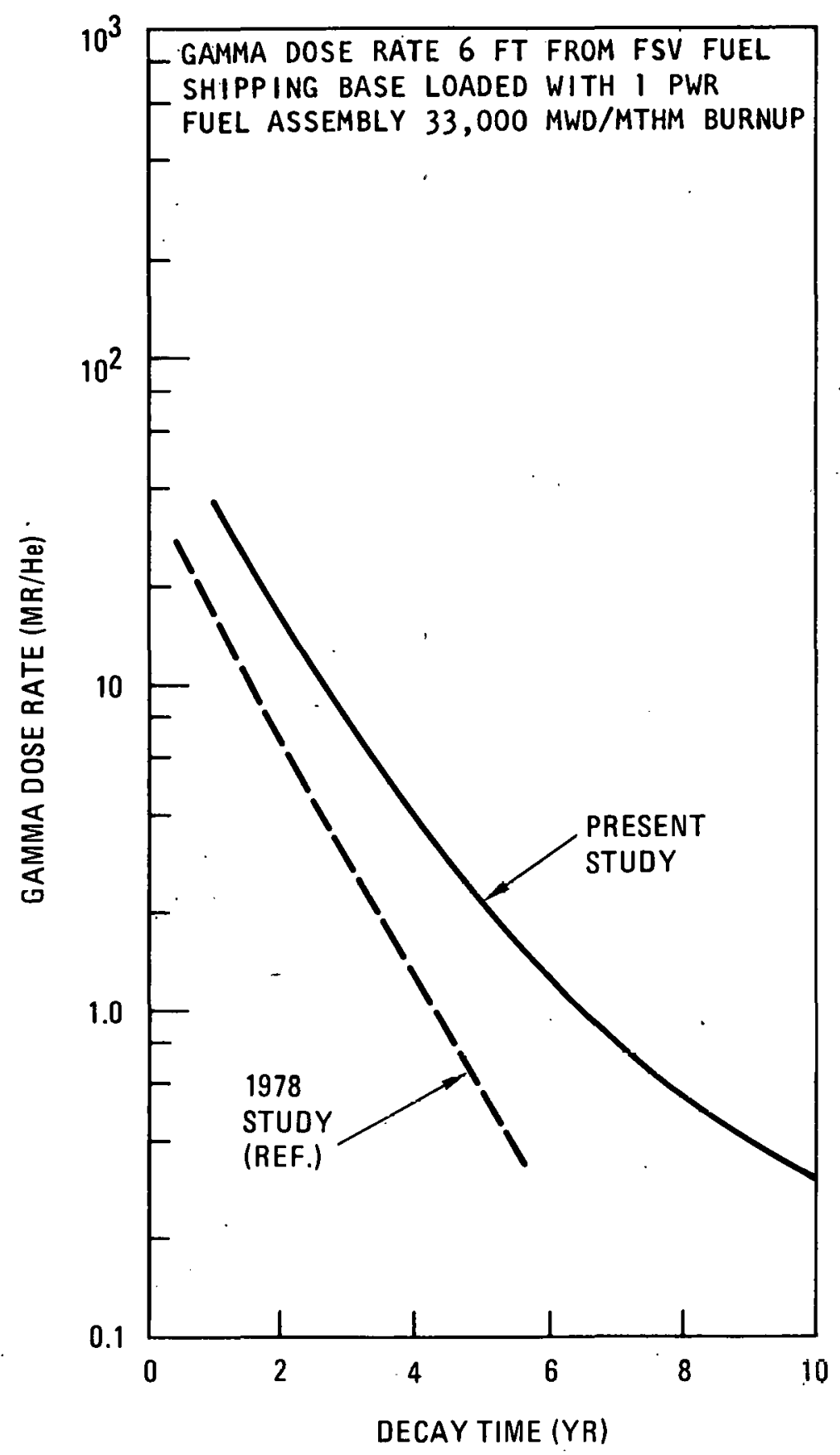

Fig. 3-46. Gamma dose rate $6 \mathrm{ft}$ from FSV fuel shipping cask loaded with 1 PWR fuel assembly 33,000 MWD/MTHM burnup 
TABLE $3-19$

PWR GAMMA SOURCE STRENGTH COMPARISON $(\mathrm{MeV} / \mathrm{cc}-\mathrm{sec})$

\begin{tabular}{l|c|c|c|c|c|c}
\hline \multirow{2}{*}{$\begin{array}{l}\text { Gamma } \\
\begin{array}{l}\text { Energy } \\
(\mathrm{MeV})\end{array}\end{array}$} & \multicolumn{2}{|c|}{1 yr Decay } & \multicolumn{2}{c|}{ J yı Decay } & \multicolumn{2}{c}{10 yr Decay } \\
\cline { 2 - 7 } & Ref. 3-8 & SANDIA & Ref. 3-8 & SANDIA & Ref. 3-8 & SANDIA \\
\hline $1.8-2.2$ & $1.02+9$ & $7.0+8$ & $3.21+7$ & $2.1+7$ & $4.71+5$ & $2.96+5$ \\
$2.5-3.0$ & $\mathrm{Nil}$ & $3.6+8$ & $\mathrm{Nil}$ & $6.78+6$ & $\mathrm{Nil}$ & $7.58+4$ \\
\hline
\end{tabular}


TABLE 3-20

NEUTRON SOURCE TERM COMPARISON PWR FUEL

\begin{tabular}{c|c|c|c}
\hline & \multirow{2}{*}{$\begin{array}{c}\text { Decay } \\
\text { Burnup }\end{array}$} & \multicolumn{2}{|c}{ neutrons/sec-g U } \\
\cline { 3 - 4 } (MWD/MTHM) & $\begin{array}{c}\text { Time } \\
\text { (yr) }\end{array}$ & Ref. 3-8 & $\begin{array}{c}\text { Present } \\
\text { Study (a) }\end{array}$ \\
\hline \multirow{2}{*}{20,000} & 1 & 65 & 66 \\
& 2 & 40 & 50 \\
& 10 & 25 & 37 \\
33,000 & 1 & 600 & 730 \\
& 2 & 500 & 625 \\
& 10 & 350 & 440 \\
40,000 & 1 & 1500 & 1800 \\
& 2 & 1300 & 1600 \\
& 10 & 900 & 1170 \\
\hline
\end{tabular}

(a) Includes secondary neutrons. 
TABLE $\quad 3-21$

FSV CASK NEUTRON RESULTS COMPARISON

(BURNUP IN MWD/MTHM TO MEET STATED CONDITIONS)

ONE PWR ELEMENT

\begin{tabular}{|c|c|c|c|c|c|c|}
\hline \multirow{2}{*}{ ' } & \multicolumn{3}{|c|}{$\begin{array}{l}10 \mathrm{mrem} / \mathrm{hr} \text { at } 6 \mathrm{ft} \text {, } \\
\text { No Neutron Shielding } \\
\text { or } \\
2 \mathrm{mrem} / \mathrm{hr} \text { at. } 6 \mathrm{ft} \text { with } \\
2 \text {-in. Neutron. Shielding } \\
\text { Decay (yr) }\end{array}$} & \multicolumn{3}{|c|}{$\begin{array}{l}10 \mathrm{mrcm} / \mathrm{hr} \text { at } 6 \mathrm{ft} \text { with } \\
2 \text {-in. Neutron Shielding } \\
\text { or } \\
2 \mathrm{mrem} / \mathrm{hr} \text { at } 6 \mathrm{ft} \text { with } \\
4-\mathrm{in} \text {. Neutron Shielding } \\
\text { Decdy (yr) }\end{array}$} \\
\hline & 1 & 2 & 10 & 1 & 2 & 10 \\
\hline Ref. 3-8 & 22,500 & 24,500 & 26,500 & 32,000 & 33,500 & 36,000 \\
\hline Present study & 29,000 & 30,000 & 32,000 & 43,000 & 44,000 & 48,000 \\
\hline
\end{tabular}




\subsubsection{Uncertainties}

Uncertainties in an analysis such as this can be significant and can be both of the systematic and random types. Eventual dose rate measurements of the FSV-1 cask containing LWR fuel may closely agree with predictions only because of compensating errors. This study would be incomplete without at least a qualitative assessment of the sources and magnitudes of errors.

\subsubsection{Source Terms - gamma. The assumption that Agllom emits a $2.75 \mathrm{MeV}$} photon $100 \%$ of the time caused an overestimation of gamma dose rates. It is possible that numerous other gamma source term errors exist, either in gamma decay spectra, half lives, branching ratios, fission yields, or the actual burnup calculation. It is estimated that the gamma source terms at 1 year decay are uncertain by $\pm 50 \%$ (after correcting for $\mathrm{Ag} 110 \mathrm{~m}$ ), and at 10 years decay are uncertain by $\pm 75 \%$.

\subsubsection{Source Terms - neutron. The $(\alpha, n)$ neutron intensity can be uncertain} by a factor of 2 , since published data in literature displays that much variation. The spontaneous fission rates are much better known.

The inventories of neutron-producing actinides are also uncertain, especially with the one-group burnup calculation used in the SANDIA-ORIGEN code.

The net uncertainty in neutron source is believed to be such that the real source could be a factor of 2 higher or a factor of 4 lower.

\subsubsection{Nuclear Data - cross sections The cross sections used in DTFX and} PATH are adequate for shield engineering, but probably cannot produce better than $\pm 50 \%$ accuracy through a thick shield. Use of the adjusted Mo cross sections in lieu of $\mathrm{Zr}$ cross sections could result in an uncertainty of $\pm 25 \%$.

\subsubsection{Nuclear Data - spectra. The accuracy of the neutron spectrum is not} believed to have any major impact on the attenuation or dose rate calculations,

3 5.5.5 Nuclear Data - buildup factors. Buildup factors. based on older dose conversion factors are known to be inaccurate (about $\pm 50 \%$, depending on material, number of mfp's, and gamma energy). Furthermore, buildup factors for complex multi-media configurations which contain short circuit paths are 
known to be erroneous. At the side of the FSV-l cask, with its simple geometry, buildup is assumed to be accurate within a factor of 1.5; at the ends of the cask a factor of 2 should be allowed for.

\subsubsection{Nuclear Data - dose conversion factors. Since corrections were} made in the analysis for the latest ANS Standard 6.1.1 dose conversion factors, these data are not thought to be a major source of error.

\subsubsection{Geometry. Treating the cask as infinitely long instead of a} finite length leads to an overestimate of the side neutron dose rates, perhaps by $25 \%$.

The neutron correction factors applied to. the ends of the cask were derived from Rockwell (to correct from an infinite slab geometry to a disc source). Again, it is doubtful that the correction has better than $\pm 50 \%$ accuracy.

The effects of homogenizing the assembly, converting from a square to circular cross section, and simplifying the end hardware are all believed to be negligible.

3.5.5.8 Compositions. Uncertainties in the compositions of the materials used in these analyses arise from the lack of obtainable information.' For example, the detailed compositions of the fuel assembly, stainless steel and neutron shielding are not exactly known. Substitutions have been made such as assuming that stainless steel and cast iron are $100 \%$ iron. The uncertainty involved in this is negligible for gamma calculations, but an error of $\pm 20 \%$ is possible for neutron calculations.

Uncertainties in the densleles of the maleridis ale due to composition generalizations used in the calculations. These generallzations are inliuduced with methods such as homogenizing the fuel assemblies while ignoring their steel support structure. Such generalizations should produce conservative results.

\subsubsection{Calculational Method. Uncertainties in the method of calculation} are inherent in the computer codes used In this analysis. The uncertainties in DTFX arise from infinite geometry consideration along with quadrature $\left(\mathrm{s}_{16}, \mathrm{~S}_{8}\right)$ considerations. Errors inherent to PATH include the material, single layer buildup factors (factor of 2 on the dose rate) and the breakup 
of the source into a finite number of points (about $\pm 10 \%$ - depending on the geometry).

3.5.5.10 Overall Uncertainty. Combining all of the above systematic and random uncertainties into a single uncertainty factor can be approximated by first separating the uncertainties into the two categories:

Random Uncertainties

gamma source terms

neutron source terms

cross sections - general

cross section - Mo

buildup factors

composition

calculational methods
Systematic Uncertanties Agl10m

$(\alpha, \eta)$ conversion

geometry

The random plus uncertainty for the neutron dose rate is:

$\sqrt{(100 \%)^{2}+(50 \%)^{2}+(25 \%)^{2}+(20 \%)^{2}+(10 \%)^{2}}=+117 \%$

Thus, the neutron dose rate could be a factor of approximately 2.2 higher or lower due to random uncertainties. The neutron dose rate could be a factor of approximately 2.7 lower due to systematic uncertainties, and, the combined uncertainty for the neutron dose rate is approximately a factor of 1.0 higher and $\underline{3.5}$ lower.

The random plus uncertainty for the gamma dose rate is:

$$
\sqrt{(50 \%)^{2}+(50 \%)^{2}+(50 \%)^{2}+(10 \%)^{2}}=+87 \%
$$

Thus, the gamma dose rate due to random uncertainties is approximately a factor of 1.87 higher or lower. The gamma dose rate correction factor for systematic undertainties is a factor of 1.25 lower (for $\mathrm{Ag} 110 \mathrm{~m}$ ). 
Thus the combined uncertainty for the gamma dose rate is approximately a factor of 1.5 higher and 2.3 lower.

Taking the case where $25 \%$ of the total dose rate is neutrons and $75 \%$ is gammas, the overall approximate uncertainty factors for the dose rate are: 1.4 higher and 2.5 lower, i.e., if the calculated dose rate 6 feet from the vehicle is $10 \mathrm{mrem} / \mathrm{hr}$, the actual dose rate could be as high as 14 $\mathrm{mrem} / \mathrm{hr}$ or as low as $4 \mathrm{mrem} / \mathrm{hr}$.

\subsection{DISCUSSION}

The FSV-I fuel shipping cask has been shown to be adequate wi thout additional shielding to carry one PWR spent fuel element which has experienced 21,000 MWD/MTHM burnup and $2 \mathrm{yr}$. decay. The external dose rate $6 \mathrm{ft}$. from the edge of the transport vehicle will be $10 \mathrm{mrem} / \mathrm{hr}$. or less. This dose rate is comprised of $8 \mathrm{mrem} / \mathrm{hr}$. gamma radiation and $2 \mathrm{mrem} / \mathrm{hr}$. neutrons.

The uncertainties in this study are on the conservative side. If:

1. The SANDIA-ORIGEN $(\alpha, n)$ conversion is reduced by a factor of 2 , the neutron dose rate will be reduced by $15 \%$.

2. The SANDIA-ORIGEN 2.75-MeV gamma group. zeroed out, the gamma dose rate will be reduced by $25 \%$.

or the maximum permissible burnup can be allowed to rise to 225,000 MWD/MTHM for a dose rate constraint of $10 \mathrm{mrem} / \mathrm{hr}$.

Because of a higher neutron source strength, BWR fuel elements are more difficult to accommodate in the FSV-l cask without additional shielding. Five years decay is needed to carry three 19,000 MWD/MTHM BWR fuel elements and meet the $10 \mathrm{mrem} / \mathrm{hr}$. constraint. However, the 2.75-MeV gamma correction is somewhat larger for BWR fuel, so the FSV-1 cask might potentially handle 25,000-MWD/MTHM BWR fuel with 5=yr. decay.

Addition of shielding to the FSV-l cask greatly enhances the options for carrying LWR spent fuel. The addition of:

1. 6-in. of neutron shielding and 1 in. of gamma shielding, or

2. 3-in. of neutron shielding and 2 in. of gamma shielding. permits carrying the highest burnup LWR fuel after only one year decay.

It is concluded that from a shielding standpoint the FSV-l cask has considerably versitility for the transport of LWR spent fuel. 


\subsection{REFERENCES}

3-1.' C. R. Davis, et al., "Final Design Report for Fort St. Vrain Fuel Shipping Cask with As-Built Information," GADR-55, November 5, 1971.

3-2. Clark, S. S., and B. A. Éngholm, "PATH - A Highly Flexible, General Purpose Gamma Shielding Program,". General Atomic Report GA-9908, December 10, 1969.

3-3. Sund, R. E., et al., "Calculations of Neutron Radiation Levels from HTGR Spent Fuel," Fifth Int. Conference on Reactor Shielding, Knoxville, TN, April 1977.

3-4. Nichols, M. K., "Final Design Report for Fort St. Vrain Fuel Shipping Cask," GADR-55, Addendum I, August 1978.

3-5. Engholm, B. A., "FSV Shipping Cask Measurements vs. Calculations," General Atomic unpublished data, September 26, 1979.

3-6. Finch, W. C., "Interim Report - Shielding of FSV-1 Cask for Transportation of LWR Spent Fuel," General Atomic unpublished data, April 14; 1971.

3-7. Engholm, B. A., "Shielding Aspects of LWR Spent Fuel Shipping Casks," CONF-710801, Vo1: 2, August 16, 1971.

3-8. Engholm, B. A., and S. Su, "Use of Peach Bottom and FSV Casks for LWR Fuel Shipping," General Atomic unpublished data, December 1, 1978.

3-9. "Neutron and Gamma Ray Flux-to-Dose Rate Factors," ANS Standard 6.1.1-1977.

3-10. Engholm, B. A., "Gamma Buildup in Two-Layer Configurations of Iron/ Lead or Iron/Uranium, General Atomic unpublished data, October 14, 1968.

3-11. Blizard, E. P., "Reactor Handbook - Shielding," Chapter 15, Interscience, 1962.

3-12. SAR for NL Industries, NL 10/24 Cask Docket No: 71-9023.

3-13. Bennett, D. E., "SANDIA-ORIGEN User's Manual," SAND79-0299, May 1979.

3-14. Sund, R. E., "Neutron Yields in HTGR Fuel," General Atomic unpublished data, October 15, 1980.

3-15. Enghold, B. A., "Shielding Aspects of LWR Spent Fuel Shipping Casks," 3-16. Battelle Topical Report 
3-17. Sutherland, S. H., and D. E. Bennett, "Defense High-Level Waste and Spent Fuel Characterization for Geologic Waste Respositories [sic]," SAND79-0172, September 1979.

3-18. Reactor Experiments, Inc., 1978-79 Catalog.

3-19. Stamatelatos, M. G., and L. Huszar, "Radiation Source Terms in LWR and LMFBR Spent Fue1," EPRI WP-948, December 1978.

3-2n. Mathews, D., "Edition 17 of the DTFX Code," FMD:066:DM:79, June 7, 1979 . 


\subsection{SYSTEM WEIGHT EVALUATION FOR THE FSV-I CASK, MODIFIED TO TRANSPORT} LWR FUEL

The FSV- 1 Cask, Unit number 1 and 2 with its transport semi-trailer and tractor was designed to operate as a legal system throughout the United States, i.e.; at a Gross Vehicle Weight (GVW) of 73,280 pounds or less. The weight distribution is.such that the limit of 32,000 pounds for a tandem axle group is not exceeded. These two units are presently owned and operated by Public Service Company of Colorado.

When FSV-1 Cask Unit number 3, presently owned and operated by General Atomic Company was fabricated, the extendable trailers used with Units 1 and 2 were not available. In order to satisfy the unique requirements of the Fort St. Vrain Nuclear Plant, using a fixed length trailer, it was necessary to mount the cask well to the rear of the trailer. This shift in location, increased the load on the rear axle group to approximately 42,000 pounds and therefore a 3 axle trailer was specified and obtained. This configuration was designed to operate as a legal weight system in those states necessary to transport spent fuel from the Fort St. Vrain reactor in Colorado to the storage facility in Idaho. Individual states have different weight limits for 3 axle groups and thus overweight permits would be required to operate this system in some states.

Four different system weights for the model FSV-l cask as modified for the transport of canisterized Light Water Reactor (LWR) spent fuel assemblies were developed as part of this evaluation. The system weight is the total weight of the shipping package, the contents, the tiedowns, the semi-traller and the tractor, i.e., the GVW. The weight of the various components of the FSV-1 CAsk which must be modified for the transport of LWR fuel assemblies are shown in Table 4.1-1. The four cases considered are:

Case 1. no additional shielding - one PWR fuel assembly

Case 2. no additional shielding - three BWR fuel assemblies

Case 3. added neutron shielding - one PWR fuel assembly

Case 4. added neutron shlelding - three BWR fuel assemblles. The system weight for Case 1 is nearly the same as the operating system weight for the FSV-l cask configured for the transport of HTGR fuel elements, and thus could operate as a legal weight shipment in some states and overweight in others, as presently mounted on the 3 axie trailer. 
Since the expected GVW of 72,920 pounds is just slightly below the 73,280 pound GVW that is legal in all states, it appears likely that with the cask located in the optimum position on a new tandem axle trailer, the actual GVW would be less than 73,280 pounds and the tandem axle loading less than 32,000 pounds.

With the addition of the neutron shielding and the additional weight of three BWR fuel assemblies and their canister it will not be possible to operate at a system weight of 73,280 pounds or less. Forty states now have GVW limits of 80,000 pounds or more, however, there are some other limitations that suggest that the practical limit for a tandem axle semi-trailer with a three axle tractor is about 78,000 pounds. About half of the states limit the load on a tandem axle group to 34,000 pounds and a practical $1 / \mathrm{mlt}$ for the steerlng axle of the tractor is about 10,000 , thus for the 5 axle tractor and semi-trailer combination under consideration, 78,000 pounds is a practical limit. In states that use "bridge formulas" the distance between the steering axle and the rear axle of the trailer is used to limit the allowable GVW. As an example in the state of California, a 5 axle tractor and semi-trailer combination must measure 48 feet to allow operations at 78,000 pounds.

The maximum flexibility for shipping LWR canisterized fuel assemblies can be achieved by mounting the modified F FV -1 Cask in the optimum location on a new tandem axle trailer. With this configuration and a light weight tractor, the shipping system should operate at 73,280 pounds or less for Case 1 and at 78,000 pounds or less for Cases 2,3, and 4, with the axle loadings within the allowable limits in all states. 
WEIGHT EVALUATION FOR THE MODEL FSV - I CASK

MODIFIED TO SHIP LWR FUEL

WITHOUT ANY ADDITIONAL SHIELDING

ONE PWR

FUEL ASSEMBLY

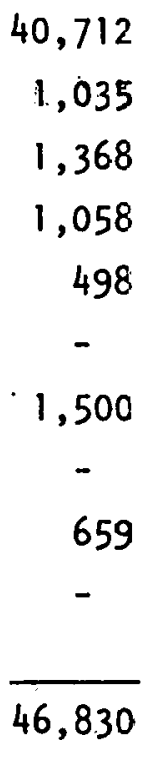

FRONT TIE DOWN

REAR TIE DOWN

¿PERSONNEL BARR IER

$\because$ TRA ILER

TRACTOR

TOTAL GVW$$
\frac{14,000}{72,920}
$$

THREE BWR

FUEL ASSEMBLY

$$
\begin{gathered}
40,712 \\
1,035 \\
1,368 \\
1,058 \\
- \\
1,310 \\
- \\
2,250
\end{gathered}
$$

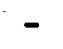

520

48,253

370

1,120

600

10,000

14,000

74,343
WITH $3^{\prime \prime}$ BORO-SILICONE NEUTRON SHIELDING

ONE PWR

THREE BWR

\author{
FUEL ASSEMBLY
}

FUEL ASSEMBLY

$$
\begin{gathered}
40,712 \\
1,035 \\
1,368 \\
1,058 \\
498 \\
- \\
1,500 \\
-
\end{gathered}
$$

659

$$
-
$$

$$
\frac{3.530}{50,360}
$$

40.712

1,035

1,368

1,058

-

1,310

$-$

2,250

520

$$
3,530
$$$$
51,783
$$

$$
\begin{array}{r}
370 \\
1,120 \\
600 \\
10,000 \\
14,000 \\
\hline
\end{array}
$$$$
76,450
$$

370

1,120

600

10,000

14,000 


\subsection{IMPACT OF OVERWEIGHT TRUCK SHIPMENTS}

The 1979 summary of State Size and Weight Limits prepared by the Truck Trailer Manufacturers Association was used as a basis for evaluating the impact of operating the General Atomic Company, model FSV-1 cask system at a Gross Vehicle Weight (GVW) in excess of 73,280 pounds. At the present time only 10 states and the District of Columbia limit GVW's to 73,280 pounds $(73,000$ pounds for Connecticut). (See Table 4.2-1.) Due to the location of these states, they effectively block all vehicles from operating in excess of 73,280 pounds, across the middle of the U.S. and restrict operations on the East Coast. (See Fig.4.2-1.) Permits to operate vehicles in excess of 73,280 pounds are avallable In each of these 10 states and the District of Columbia, however, the limitations for the overweight operations vary from state to state. Some states restrict vehicles operating with overweight permits to travel during daylight hours only. Some states require several days to process an application for a permit to operate an overweight vehicle.

Operating overweight vehicles with permits as required by the various states will require more attention to the planning and scheduling of shipments, however, General Atomic Company was involved with Philadelphia Electric Company and Tri-state Motor Transit Company during the shipment of spent fuel from Peach Bottom I located near Delta, Pennsylvania to the storage facility near Idaho Falls, Idaho. About 90 shipments were made using the model PB-1 Cask System operating at a GVW of over 100,000 pounds with only minor scheduling problems.

The GVW limits for the various states invollve some rather complex regulations whlch are continually changing, are sometimes restricted to certain highways and may be restricled during certain scosons. Table 4.2-1 should be used for a reference only and the individual states contacted for all specific shipping operations. 


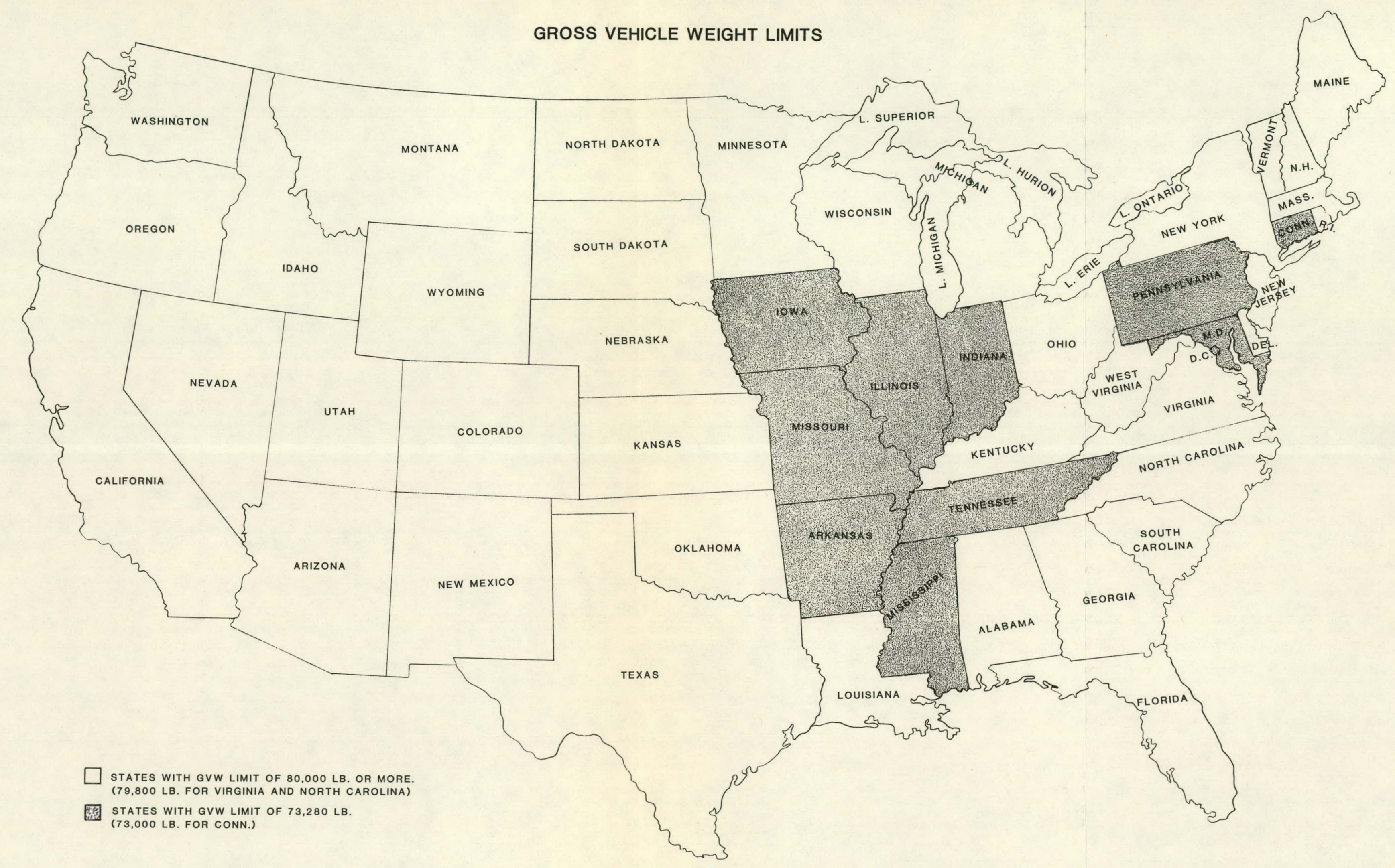

Figure 4.2-1 


\section{THIS PAGE}

\section{WAS INTENTIONALLY \\ LEFT BLANK}




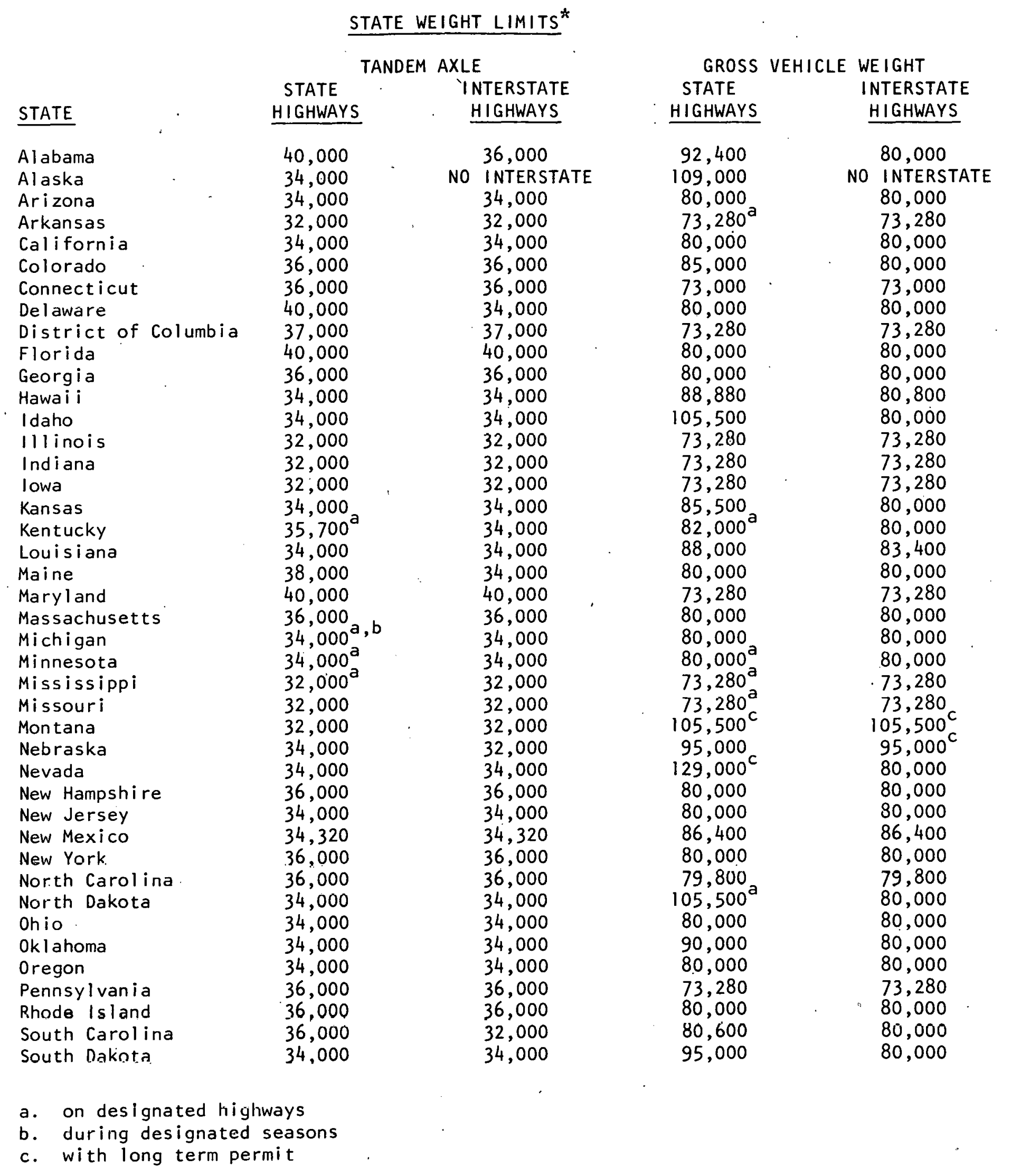

Table 4.2-1 
TANDEM AXLE

STATE

STATE

Tennessee

Texas

Utah

Vermont

Virginia

Washington

West Virginia

Wisconsin

Wyoming
HIGHWAYS

32,000

34,000

34,000

37,800

34,000

34,000

34,000

34,000

36,000
GROSS VEHICLE WEIGHT

INTERSTATE

HIGHWAYS

32,000

34,000

34,000

36,000

34,000

34,000

34,000

34,000

36,000
STATE

HIGHWAYS

73,280

80,000

80,000

80,000

79,800

80,000

$80,000^{\mathrm{a}}$

80,000

101,000
INTERSTATE HIGHWAYS

73,280

80,000

80,000

80,000

79,800

80,000

80,000

80,000

80,000

a: on designated highways

b. during designated seasons

c. with long term permit

STATE SIZE LIMITS

The most restrictive limits for a 5 axle, tractor and semi-trailer combination are:

$$
\begin{aligned}
& \text { Height }-13 \text { feet, } 6 \text { inches } \\
& \text { Width }-96 \text { inches } \\
& \text { Length }-55 \text { feet }
\end{aligned}
$$

*Reference: 1979 Chart published by Truck Trailer Manufacturers Assoclation: 


\subsection{DISCUSSION}

The major impact of operating with overweight permits, will be some loss of flexibility of scheduling. When compared to the impact of satisfying the requirement of the U.S. Nuclear Regulatory Comission in regard to a safeguanded shipment of radioactive materials i.e.: approved route, contacts with law enforcement agencies, scheduled reporting, contingency plans, and etc., the impact of operating with overweight permits will be minimal.

The FSV-1 Cask as modified for the transport of LWR fuels can be operatedas: a legalweight system $(73,280$ pound GVW) for shipments of PWR fuel assemblies that do not require the addition of neutron shielding. The qualifying PWR fuel assemblies can be selected by burnup and decay time. Note that due to the greater weight of the three BWR fuel elements with that canister and spacer, the system weight will be greater than $73,280 \mathrm{GVW}$. The added capability of the modified FSV-l cask with neutron shielding to carry a wider spectrum of LWR irradiated fuel assemblies should justify the loss of schedule flexibility required to operate with overweight permits. The Boro-Silicone neutron shielding will be designed such that the segments can be removed and should be removed to allow legal weight operations when possible. 
5. THERMAL STUDY

A TAC2D two-dimensional (radial-axial) thermal model of the upper onehalf of the cask was developed to calculate interior temperatures. The model is illustrated in Figure $5-1$ and it is similar to the TAC2D model used in the design report (GADR-55, Addenduml) for the FSV-1 fuel shipping cask. Property values were also taken from the reference report, except for the Boro-silicone. (a) Nominal gaps as given in Figure 5-1 were used between internal components $\left({ }^{(b)}\right.$ Conduction and radiation heat transfer occur across the gaps. Natural convection and radiation were modeled for the cavities between the cask inner barrel and the fuel canister. The fuel canister was assumed to be supported by four circular plates each 1 inch thick. The fuel region of the TAC2D model is not a true simulation of a LWR fuel bundle. Thus, only the TAC2D temperatures up to and including the fuel canister are valid. The plywood impact limiter was not included in the TAC2D model in order to save nodal points. Instead, the cask surface which is covered by the impact limiter was assumed to be adiabatic in the TAC2D model. The center plane was also assumed adiabatic. Figures 5-2 and 5-3 give the TAC2D steady state temperatures for the interior of the two cask configurations.

Flgure 5-4 is a plot of the afterheat in kilowatts for PWR and BWR fuel assemblies vs. the decay time in years for various fuel burnup. The curves are for a single fuel assembly, therefore it is necessary to multiply the values obtained for BWR fuels by 3 since the BWR canister contains 3 fuel assemblies.

The allowable fuel heat load is sensitive to the exterior cask temperature. An increase in the exterior temperature of $10^{\circ} \mathrm{F}$ (from $180^{\circ} \mathrm{F}$ to $130^{\circ} \mathrm{F}$ ) allows the fuel heat load to increase approximately 50\%. At these exterior temperatures the fuel heat load is only about 15-25\% of the total surface heat transfer. Since the solar heat load remains fixed with exterinr temperature, increasing the exterior temperature by a small amount enables the fuel heat load to be increased significantly. As the exterior temperature increases above $200^{\circ} \mathrm{F}$. the fuel heat load becomes more comparable to the solar heat load. Small increases in the exterior temperature no longer 
produce as dramatic increases in the allowable fuel heat load. Since the temperature difference between an interior point and a surface point is proportional to the fuel heat load, this temperature difference and the cask interior temperatures are also sensitive to slight changes in the cask exterior temperature.

(a) Boro-Silicone is a product of Reactor Experiments, Inc. (see Appendix $D$ for material properties).

(b) The same model was used for the modified FSV-I cask with the neutron shield except that a .060 gap and the 3 inch neutron shield was added external to the cask outer barrel. 


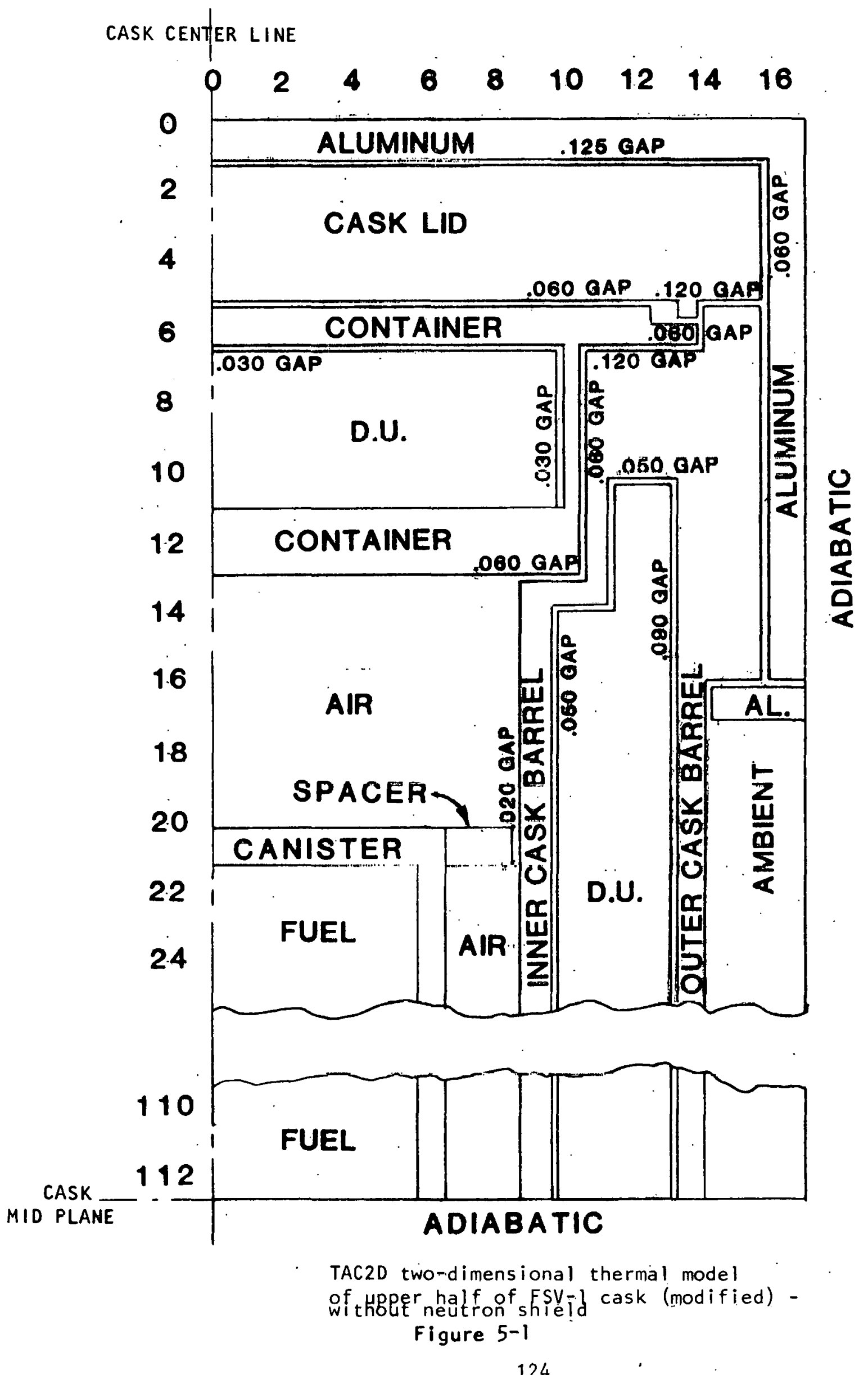


TEMPERATURES

THE RADIAL (I) DIRECTION IS HORIZONTAL

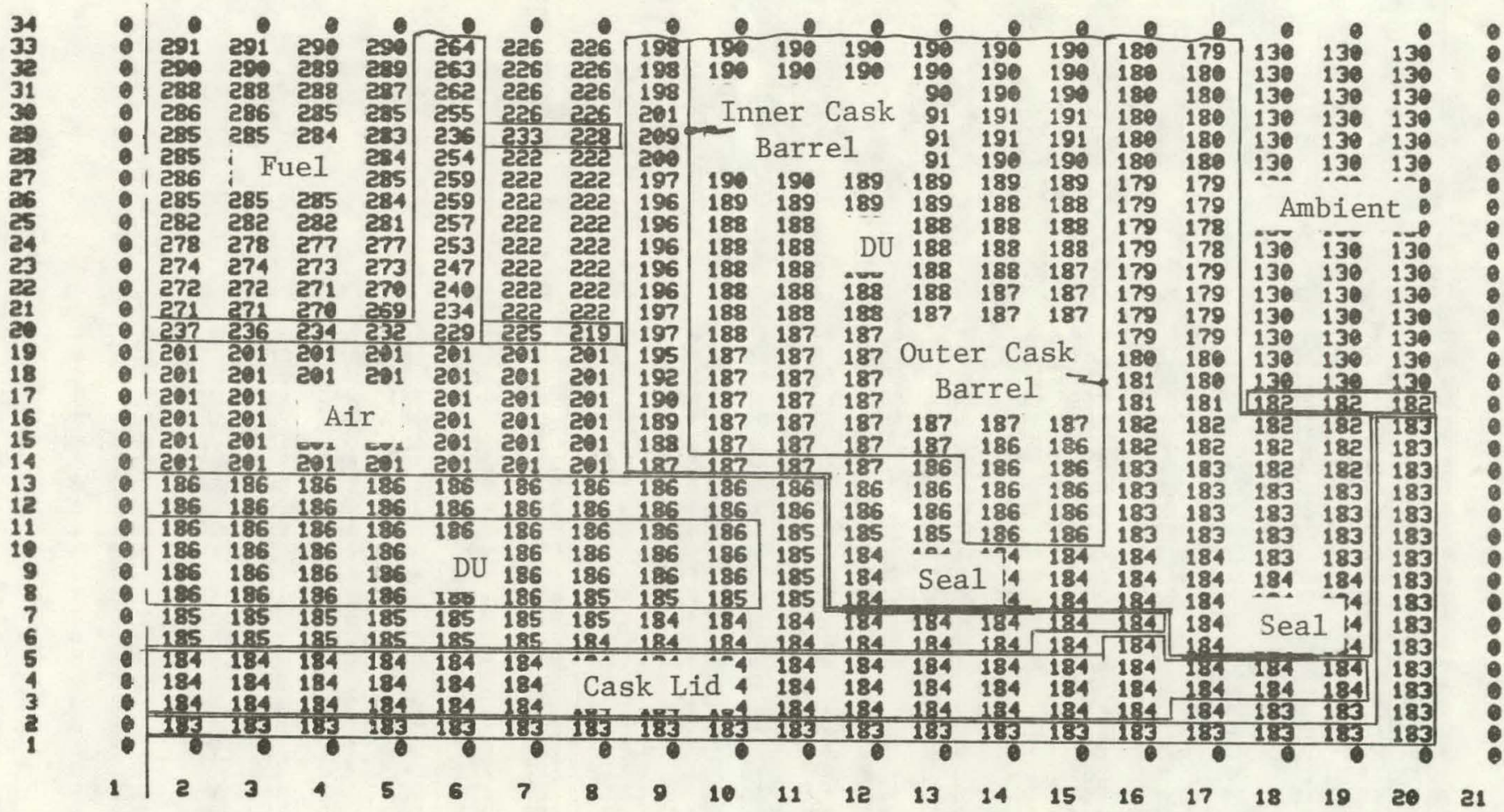

TAC2D results for the cask with no neutron shielding 
TEMPERATURES (F)

THE RADIAL (I) DIRECTION IS HORIZONTAL

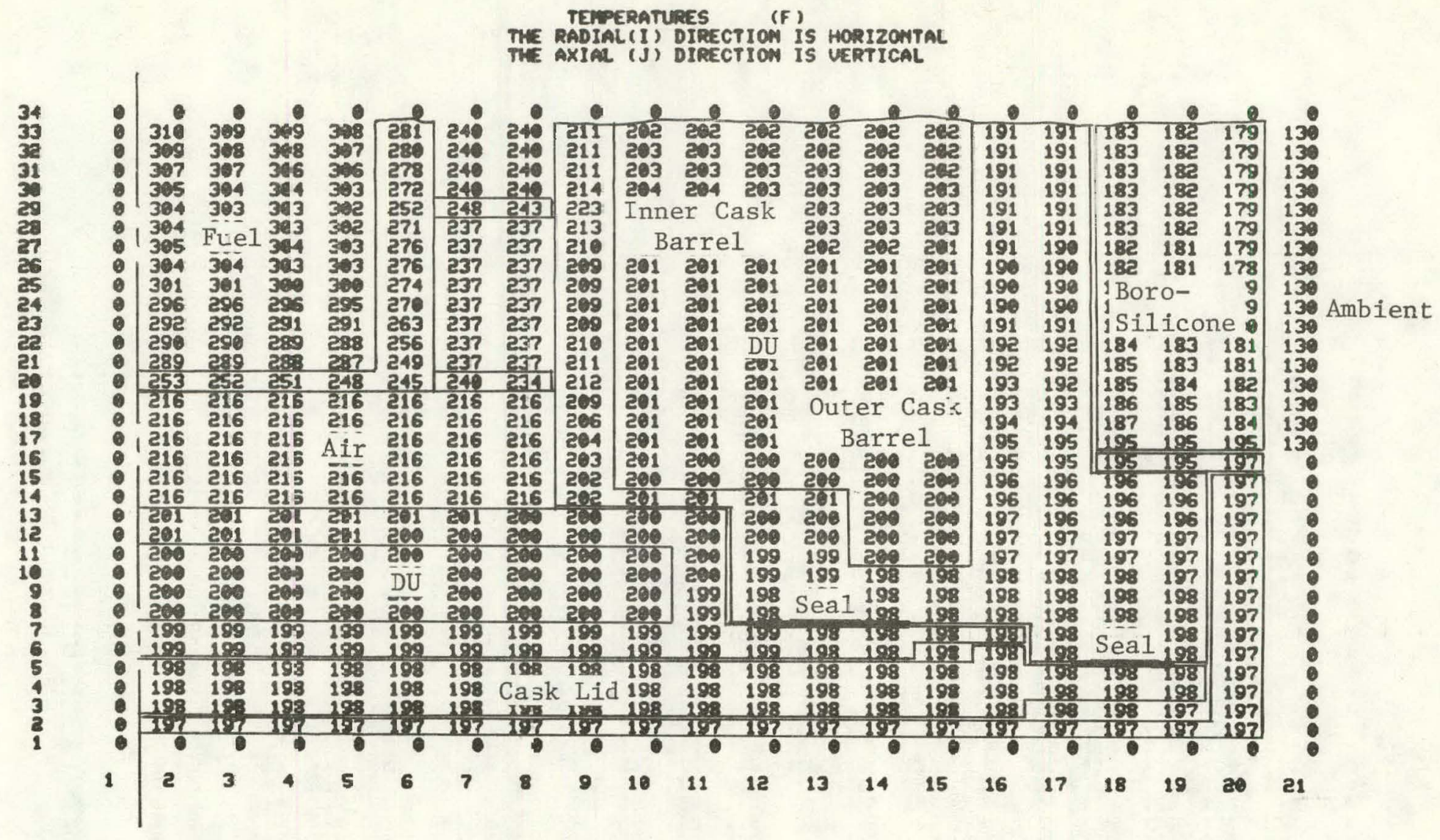

TAC2D results for the cask with 3 in, of external boro-silicone shielding

Figure 5-3 
AFTERHEAT (KW) VS. DECAY TIME (YEARS)

FOR VARIOUS BURNUPS (MWD/MTHM)

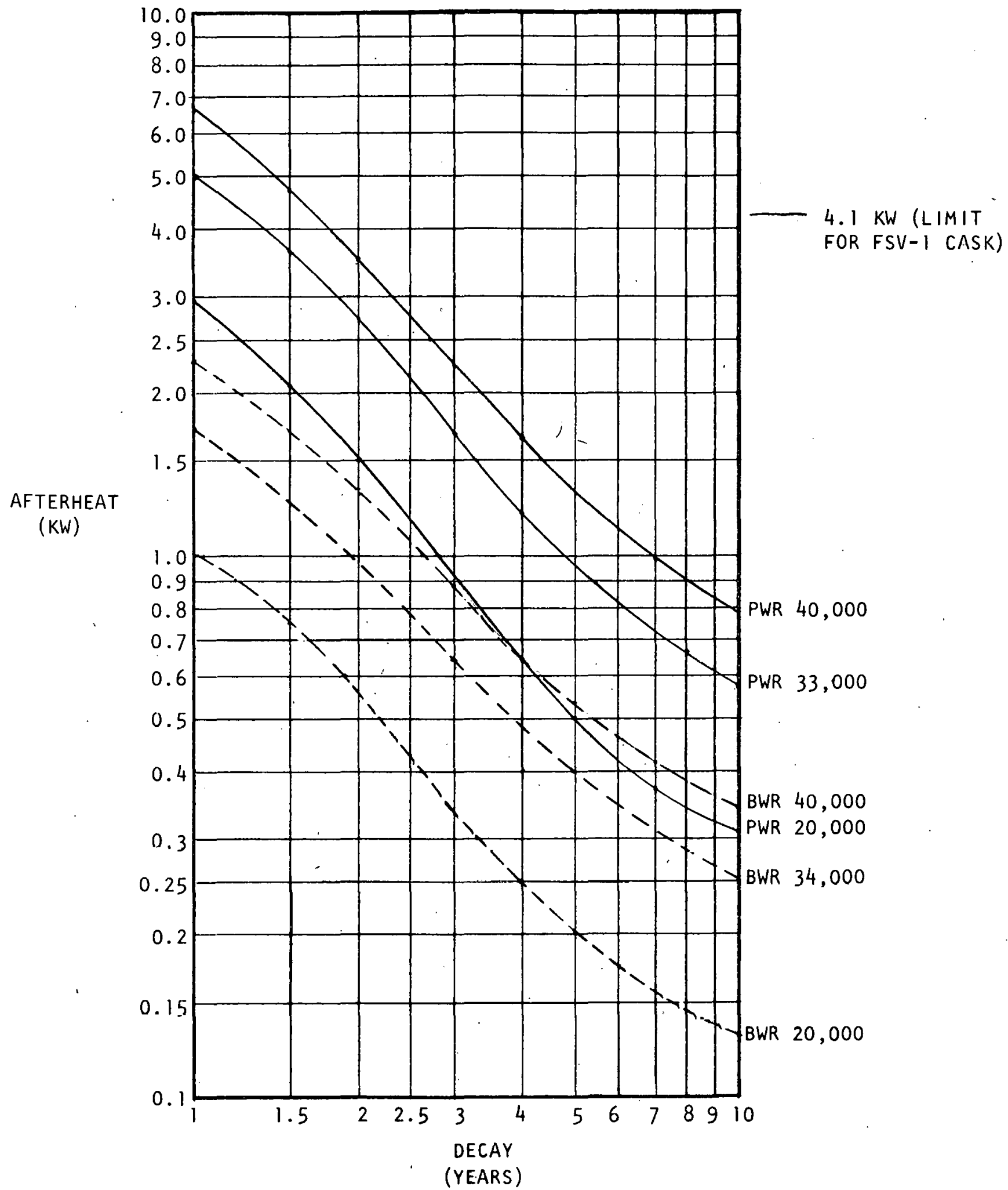

Figure $5-4$ 


\section{THIS PAGE}

\section{WAS INTENTIONALLY \\ LEFT BLANK}




\subsection{DRAWINGS}




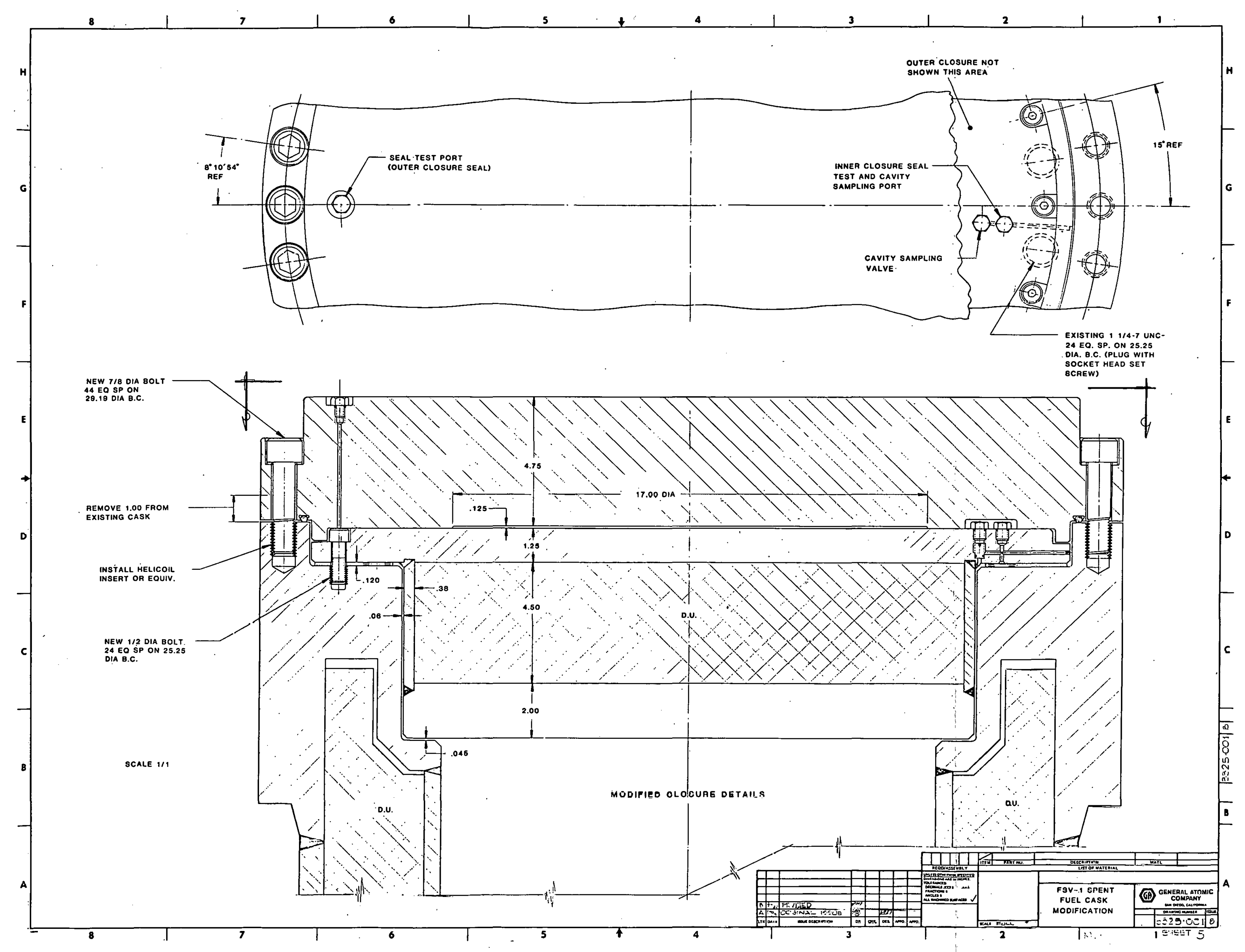




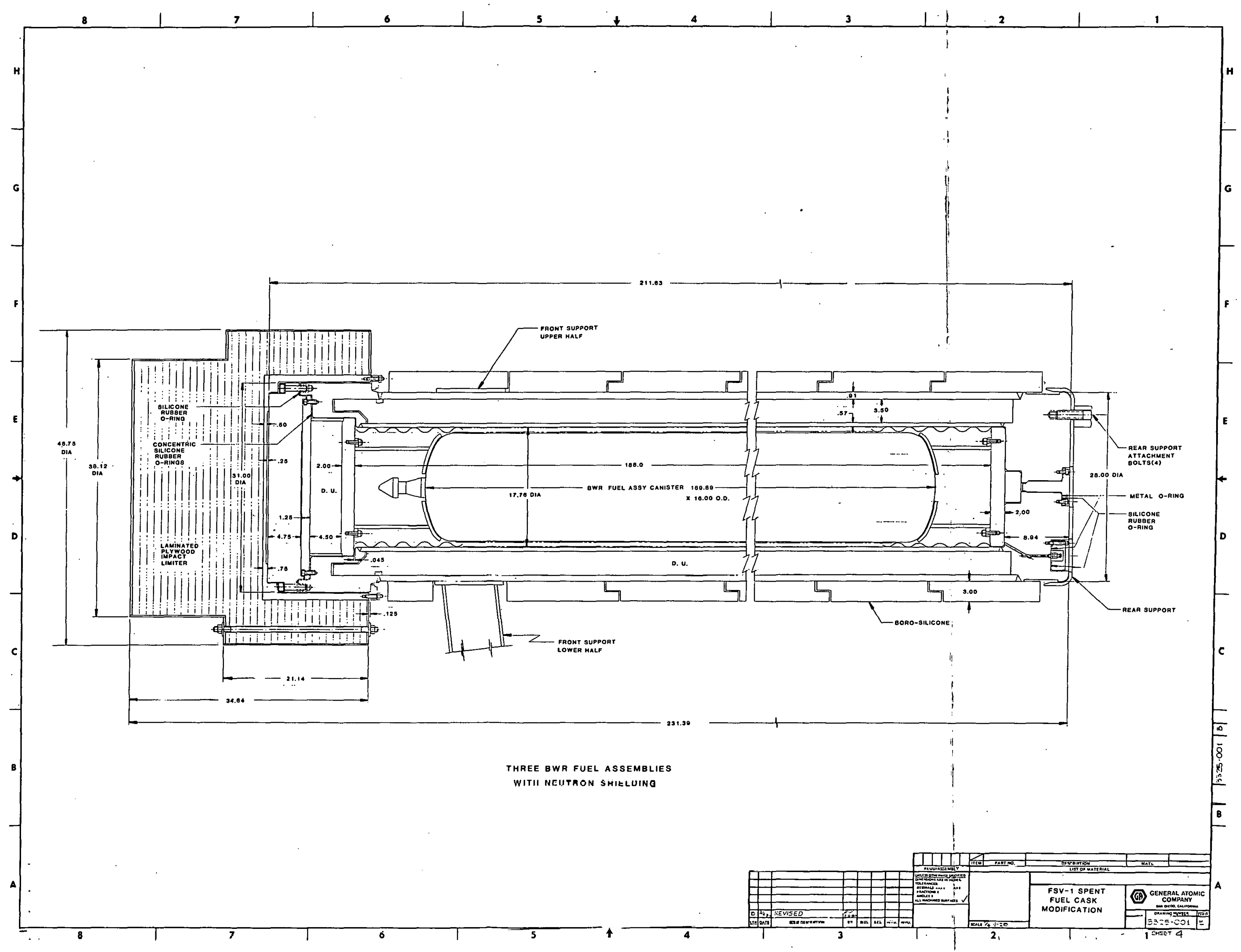




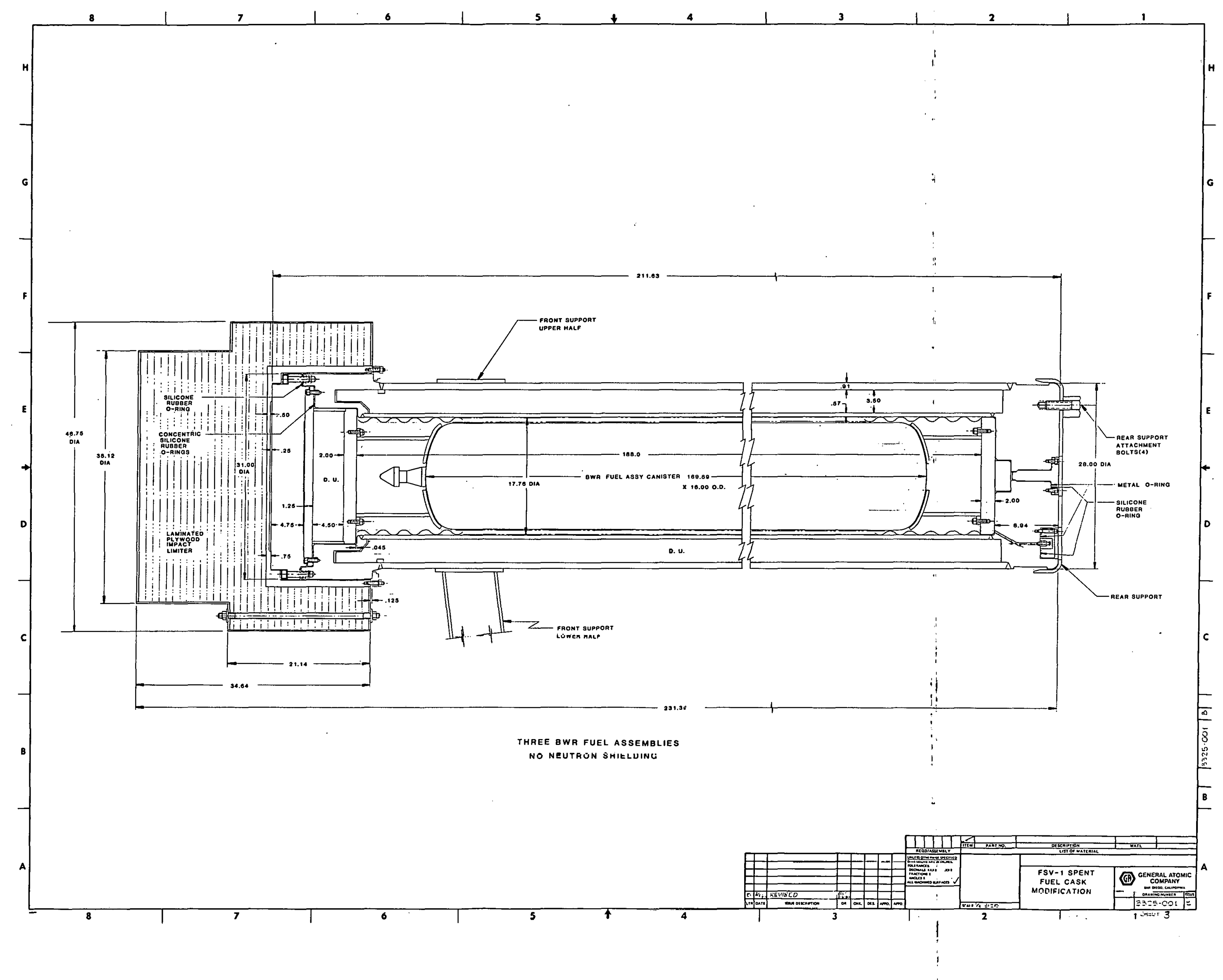




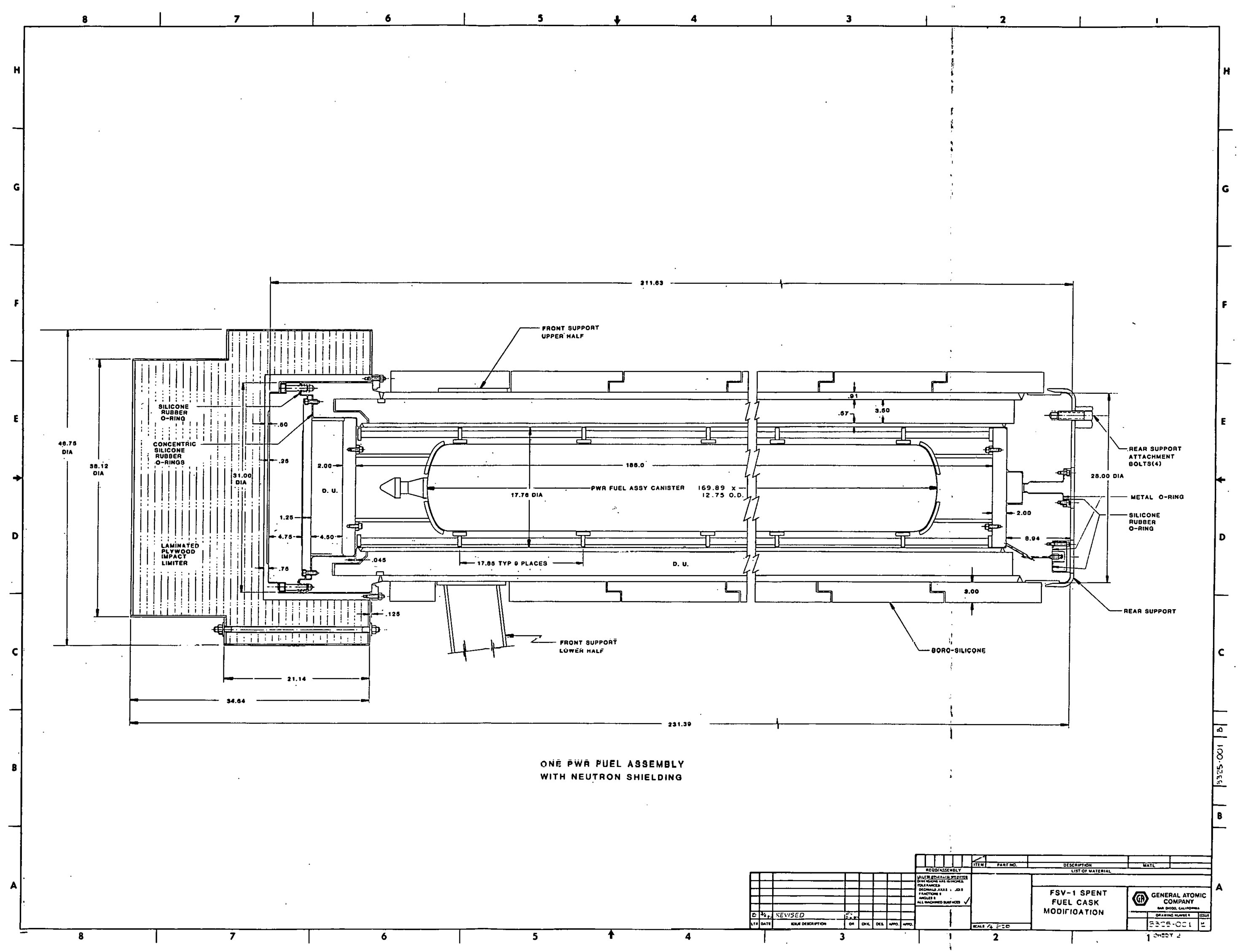




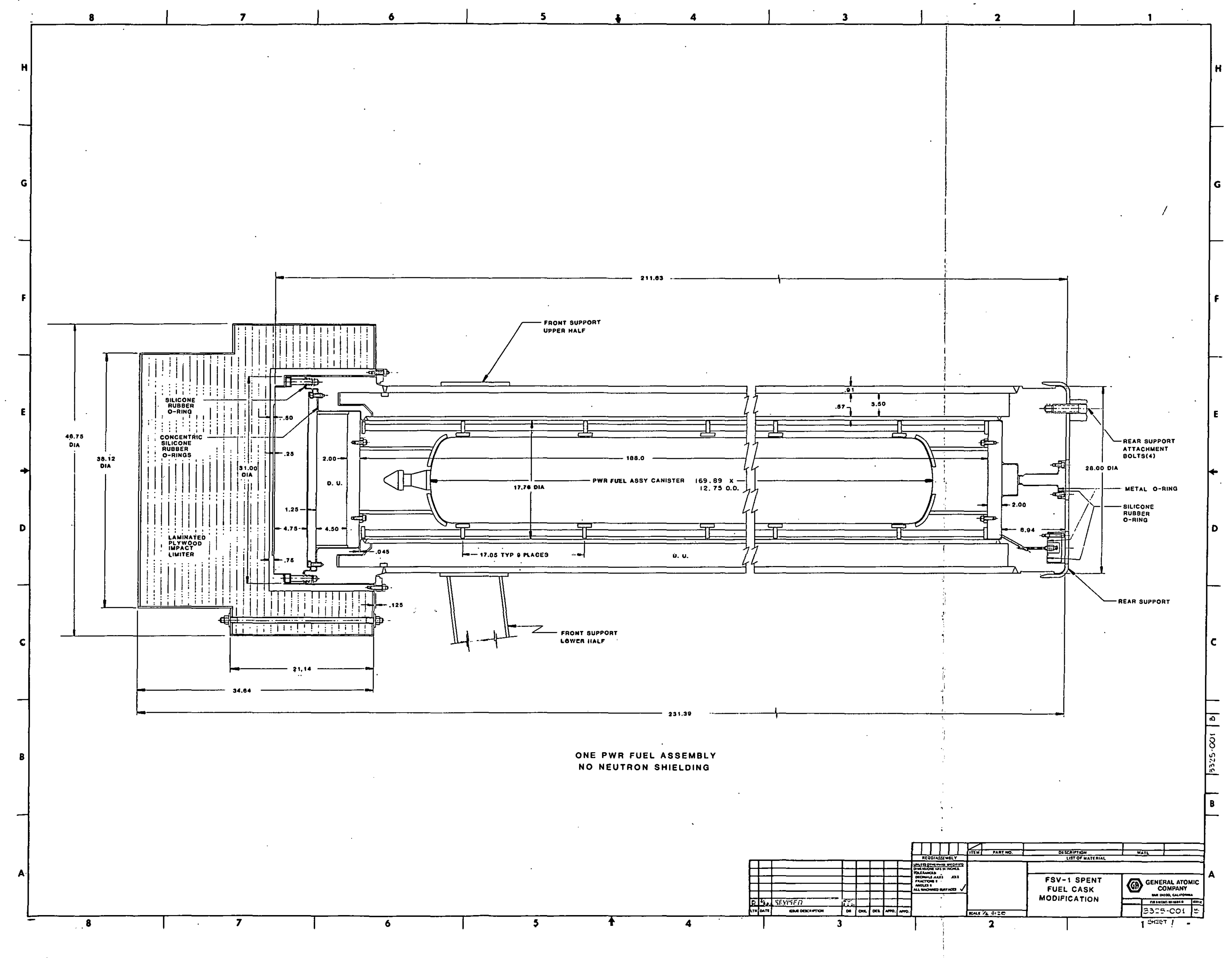




\section{PAGES 135 to 140 WERE INTENTIONALLY LEFT BLANK}


7.0 APPENDIX 


\section{THIS PAGE}

\section{WAS INTENTIONALLY \\ LEFT BLANK}




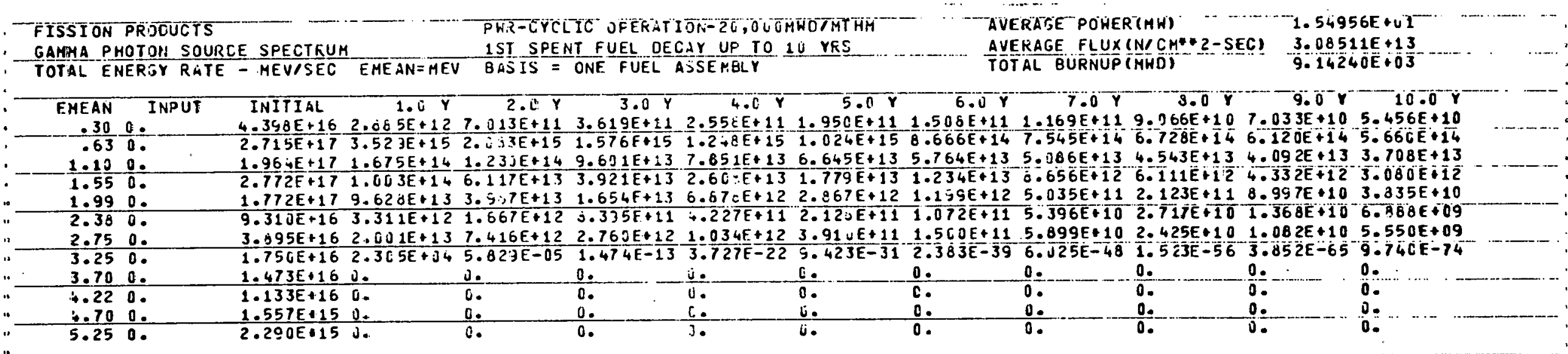

\footnotetext{
TOTAL 0 .

$1.146 E+103.913 E+152.317 E+151.732 E+151.361 E+151.111 E+159.332 E+148.148 E+147.247 E+146.575 E+146.062 E+14$
}

$\overrightarrow{\mathrm{\omega}}$

FISSICN PRODUCTS GAMHA PHOTON SOURCE SPECTRUA
TCIAL EAERGY RAIE - MEVISEE
FWR-CYCLIC OPERAIICN-3 Z,OEOMWD/MITH 1 SI SPENT FUEL DECAY UP TO 10 YRS EASIS = ONE FUEL ASSEMGLY
AVERAGE POWER(MU) $1.70 \hat{2} \overline{3} 0 \mathrm{C}+(1)$ AVERAGE FLUX(N/CM\#-2-SEC) 3.E431EE+1? IOTAL BURNUP (MHO)
1. $50 E 54 E+04$

$9.0 \times \quad 10.0$

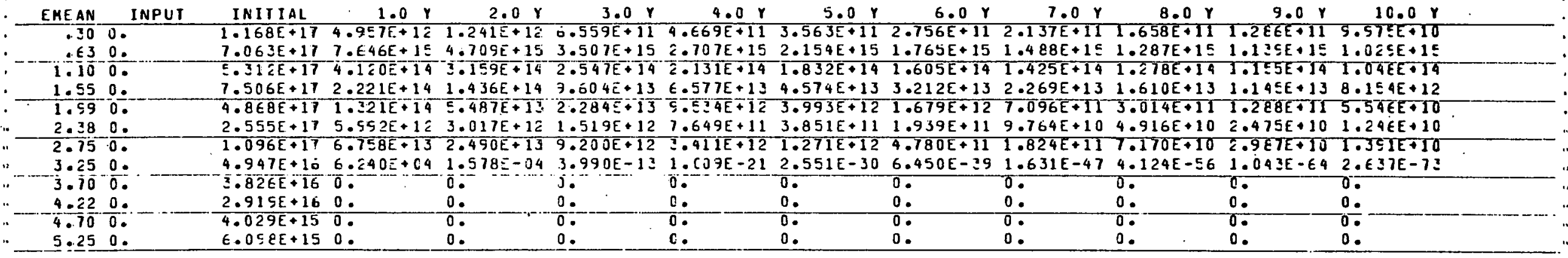

TOIAL 0 .

$3.084 E+18 \quad 8.451 E+1 E E .253 E+153.892 E+15 \geq .000 E+152.389 E+151.961 E+151.654 E+151.431 E+151.2 E 6 E+151.142 E+15$ 
Table A-1 Fission Product Gamma Source Strengthis cont'd.

FISS ION PRODUCTS

GAMMA PHOTON SOLRCE SPECTRUM

IOIAL ENERGY RATE - YEV!SEC

EMEAN INPUT

INITIAL

$i-0 \quad r$

IST SPENT OPERAJICN-40.0OJMWO/MIHM

IST SPENT FUEL DECAY UP TO 10 YAS

ENIS = ONE FUEL ASSEMALY
AVERAGE POWER (MH) TOTAL BURNUP(MHO)
$2.06340 E+C 1$

$1.82611 \mathrm{E}+09$

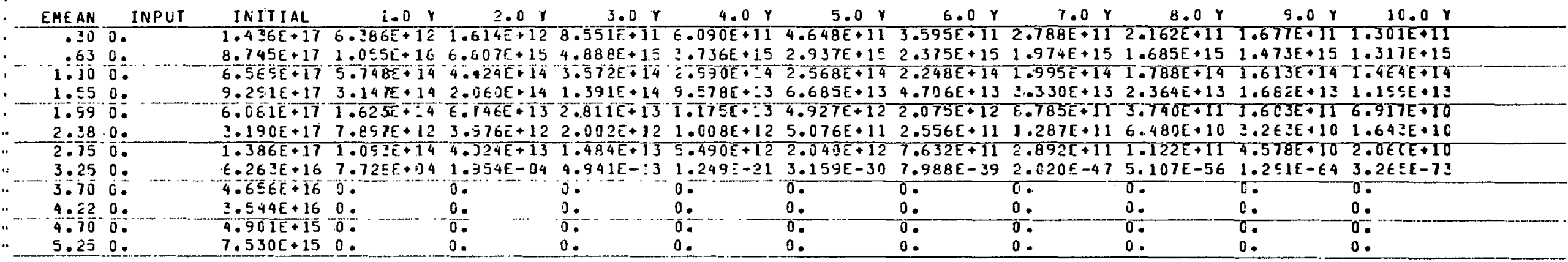

JOIAL 0 .

$3.827 E+18 \quad 1.172 E+1 E \quad 7.2 E Q E+15 \quad 5.430 E+15 \quad 4.149 E+1 E 3.269 E+15 \quad 2.650 E+152.208 E+151.888 E+151.652 E+151.47 E E+15$

$\stackrel{\vec{\sim}}{\mathbb{f}}$

FISSION PRODUCTS

GE SIO HUR G-4 CYILE-2.66 HLC HEH
1 ST SFENT FUEL DECAY UP TO IO YAS

GAMHA PHOTON SOURCE SPECIRUM

AVEBAGE PQWER(

AVE ₹ TGE FLUX (N/CH. 2-SEC) $-5.65 .0 .50 E \pm 0.0$

TOTAL ENERGY RATE - MEY ISEC EMEANEMEV BASIS = ONE FUEL ASSEMELY

TOIAL BURNUP (MHO)

$6.21555 E+03$

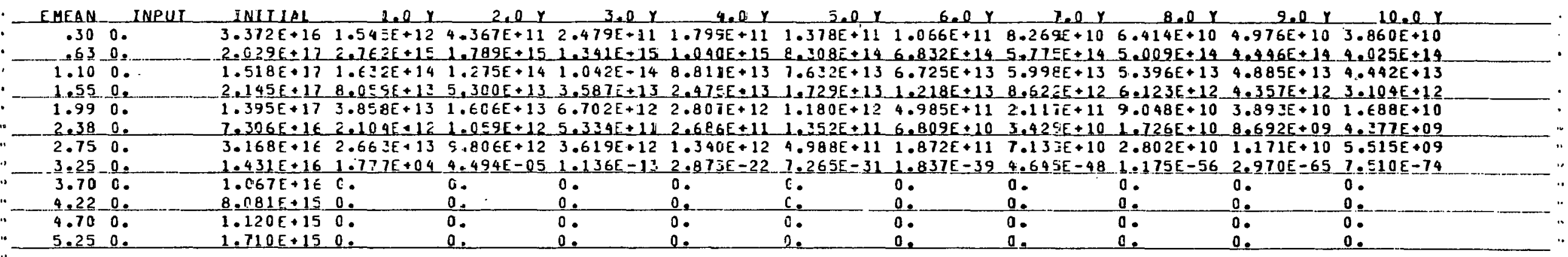

IOIAL 0.

$8 . \underline{E} 1 E+17 \geq .075 E+151.997 E+151.492 E+151.157 E+15 \quad 5.264 E+147.635 E+146.46 .5 E+14.5 .612 E+14 \quad 4.979 E+14 \quad 4.501 E+14$ 
Table A-2 Neutron Source Strength

ACTINIOÉES

NUEL IDE LISTING,

ALPHA N NEUTRON RATE - NEUTISEC
P FE-CYCLIC OPEKATION-2L,OOOOMHOTMTHM

1 I SPEAT FUEL DECAY UP TO 1 I YRS

BAS IS $=$ ONE FUEL ASSE MBLY
AVERAGE FOWER(MW)

AVERAGE FLUX (N/CM
$1.54956 \mathrm{E}+01$

$3.08511 E+13$

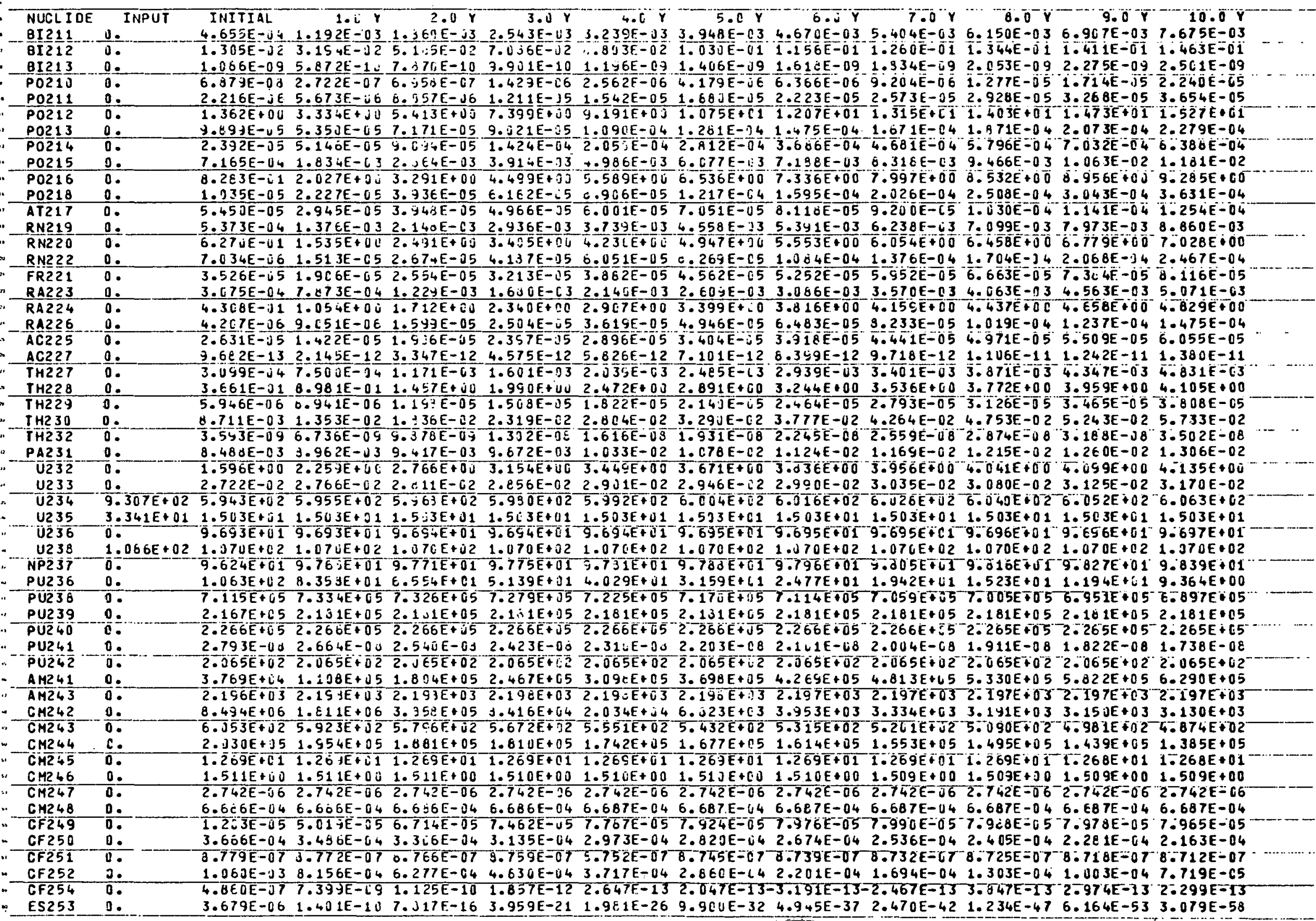

TOTAL $1.073 E+03 \quad 9.894 E+06 \quad 3.30 U E+06 \quad 1.936 E+06 \quad 1.638 E+J 6 \quad 1.675 E+06 \quad 1.713 E+8 E \quad 1.752 E+06 \quad 1.794 E+06 \quad 1.835 E+06 \quad 1.873 E+06 \quad 1.909 E+066$ 
Table A-2 Neutron Source Strength cont'd.

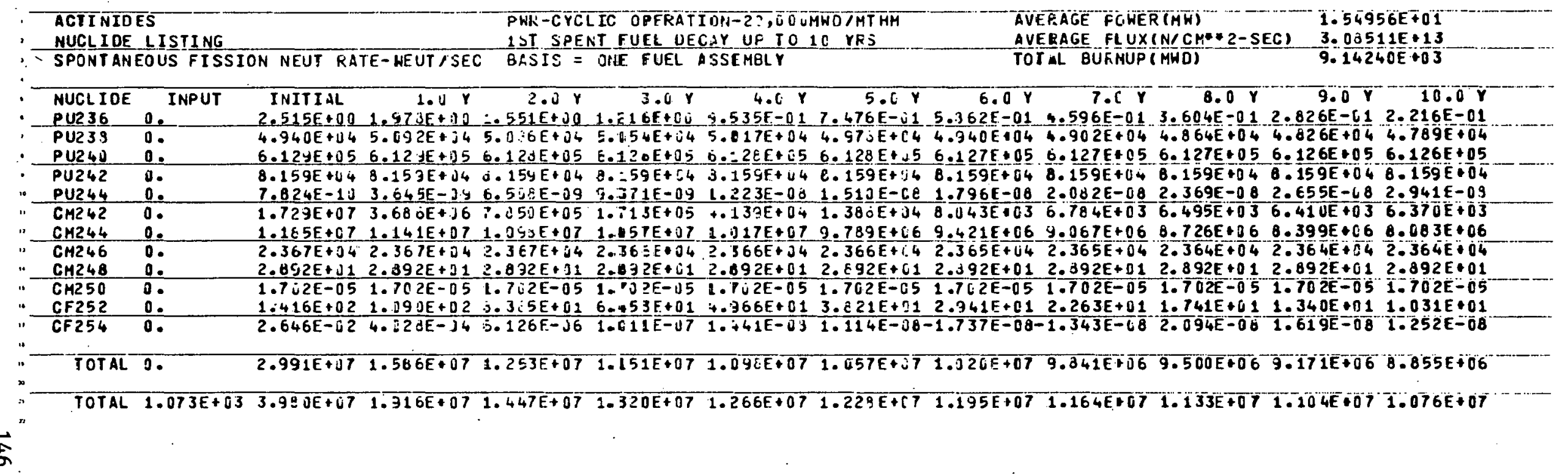


ACTINIDES

ALCLICE LISTING
ALFHA N NEUTRON RATE - NEUT/SEC
Table A-2 Neutron Soarce Strength cont'd.

PWR-CYCLIC OPERAIICN-33,00OAHD/MTHA BASIS $=$ ONE FUEL ASSEMBLY
BAT SPET OECAY UP TO
AVERAGE POHER(MW) AVERAGE FLUX(N) CM
$1.70220 E+01$ $3 . E 43] E E+1$ ?
$1.50 E 54 E+04$

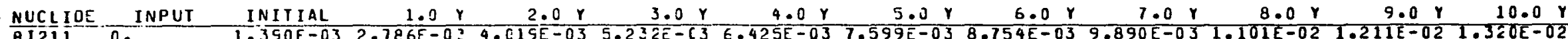

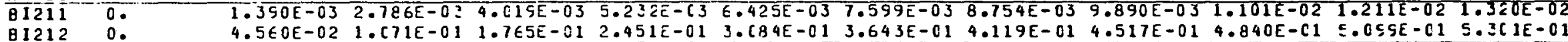

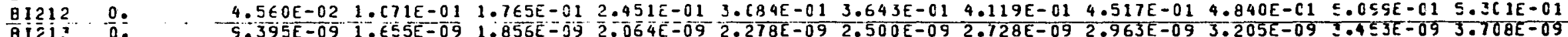

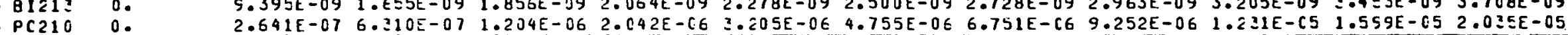

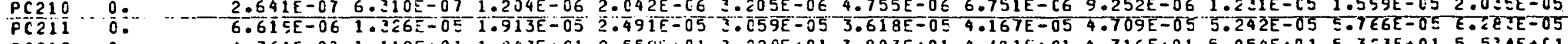

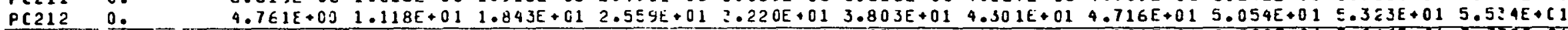

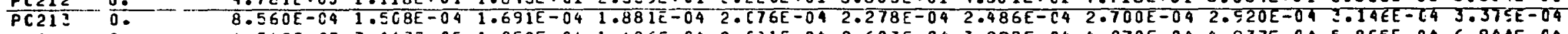

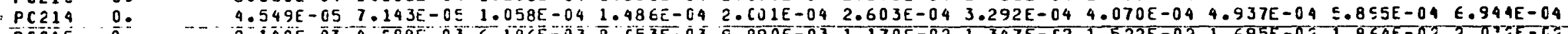

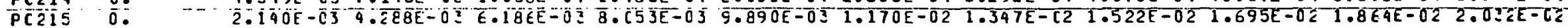
(1)

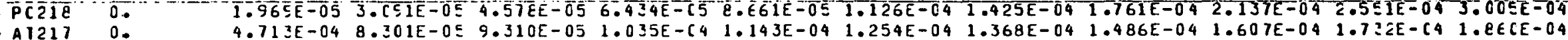

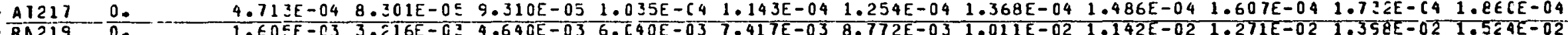

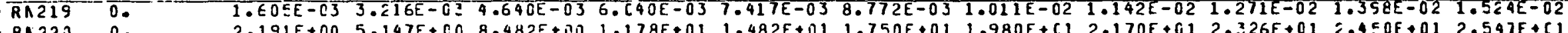

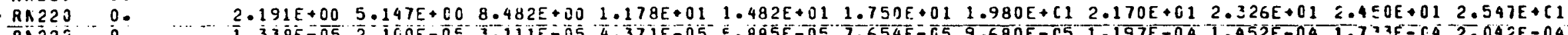

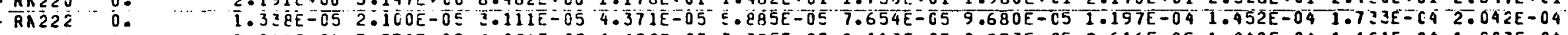

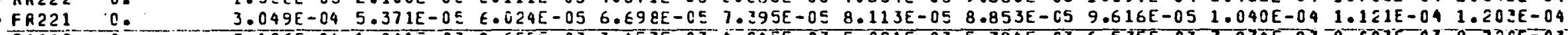

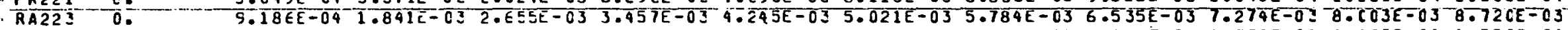

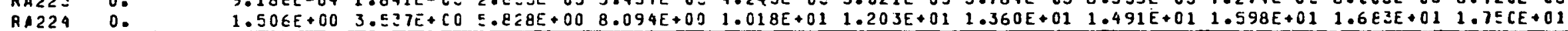

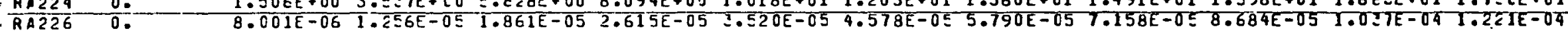
RA226 O $2.275 E-044 . C O T E-054.494 E-054.997 E-055.517 E-056.053 E-056.605 E-057.174 E-057.759 E-058.3 E G E-058.97 E E-0 E$

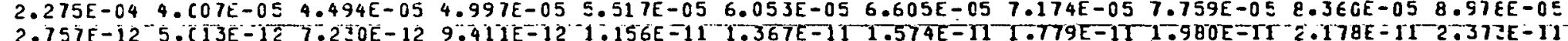
$9.082 E-041.753 E-032.530 E-03 \quad 3.293 E-034 . C 44 E-034.783 E-035.510 E-036.225 E-036.930 E-03 \quad 7.624 E-038.30 E E-63$

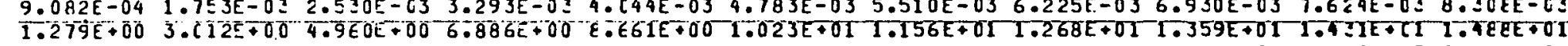

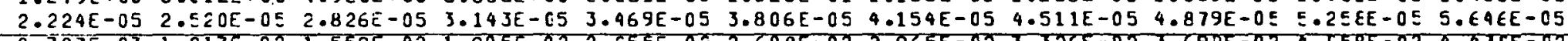

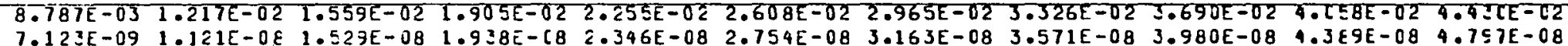
$7.123 E-091.121 E-0 E 1.527 E-08$ 1.938E-C8 $2.346 E-082.754 E-08 \quad 3.163 E-08$ 3.571E-08 3.980E-08 $1.3 E 9 E-08-4.75 E-08$ $1.677 E-02$ 1.E?

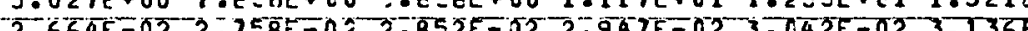

1.235 $.15 E E+024.202 E+02 \quad 4.248 E+02 \quad 4.295 E+02 \quad 4.341 E+02 \quad 4.380 E+02 \quad 4.431 E+C 2 \quad 4.476 E+024.521 E+024.5 E 5 E+02 \quad 4.605 E+02$ .

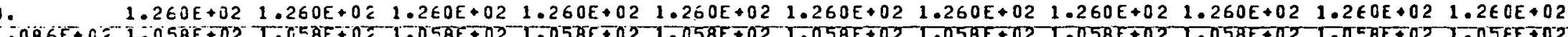
$1.086 E+021.058 E+021.058 E+02=1.058 E+02$ 1.058E+02 1.058E+02 1.058E+02 1.058E+02 1.058E+02 1.058E+02 1.058E+02 1.05EE+02 0. $\quad 2.005 E+022 . C E 3 E+0 Z 2.064 E+022.064 E+022.066 E+02 \quad 2.067 E+022.069 E+022.071 E+022.073 E+022007 E E+02 \quad 2.07 E E+02$

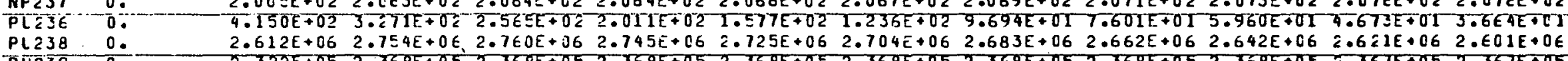

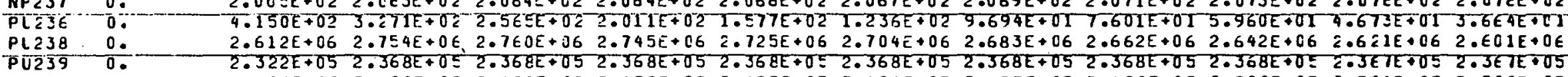
PU239 $\mathrm{PL}: 240$ $P L 242 \quad 0$ PŨ $24 \bar{a}$ AN 2410 AP243 0 . $3.4 E \varepsilon E+05 \quad 3.450 E+05 \quad 3.452 E+05 \quad 3.493 E+05 \quad 3.495 E+05 \quad 3.496 E+05 \quad 3.497 E+05 \quad 3.498 E+05 \quad 3.500 E+05 \quad 2.5 C 1 E+05 \quad 3.502 E+05$

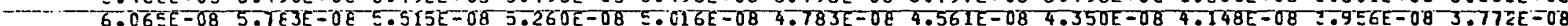
$8.57 E E+028.576 E+0 E \quad 8.576 E+02 \quad 8.576 E+02 \quad 8.576 E+028.576 E+02 \quad 8.576 E+028.576 E+028.576 E+02 \quad E .57 E E+028.576 E+02$

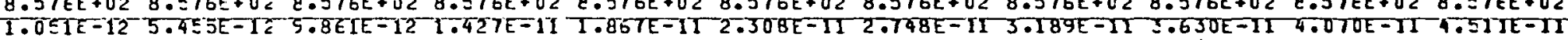

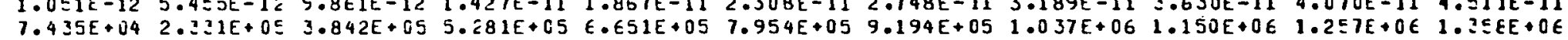

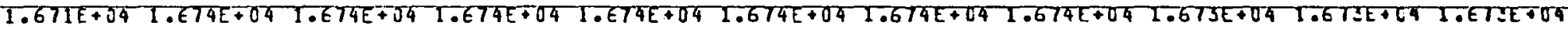
$4.878 E+07 \quad 1.040 E+07 \quad 2.207 E+06 \quad 4.750 E+05 \quad 1.082 E+05 \quad 3.055 E+04 \quad 1.409 E+04 \quad 1.057 E+04 \quad 9.791 E+03 \quad 9.552 E+03 \quad 5.516 E+03$ $5.274 E+035.1 E 1 E+0 ? 5.050 E+03 \quad 4.942 E+[3-4.83 E E+0 ?-4.7 ? 2 E+[3-4.631 E+034.532 E+03-4.434 E+C 3-4.325 E+03-4.246 E+03$ $3.051 E+06 \quad 2.537 E+C E \quad 2.827 E+06 \quad 2.721 E+06 \quad Z . E 18 E+0 E \quad 2.520 E+0 E \quad 2.425 E+C 6 \quad 2.334 E+06 \quad 2.247 E+06 \quad 2.1 E Z E+06 \quad 2.021 E+06$ $2.979 E+02-2.974 E+022.974 E+022.974 E+022.573 E+022.973 E+022.973 E+022.973 E+022.572 E+022.972 E+022.972 E+02$ $7.127 E+017.126 E+01 \quad 7.125 E+01 \quad 7.124 E+017.123 E+017.122 E+017.121 E+017.120 E+017.119 E+017.118 E+C 17.117 E+01$

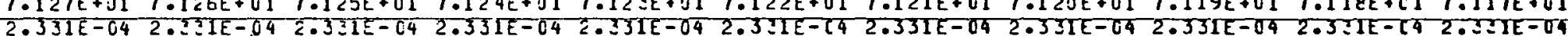
$1.106 E-01$ 1.106E-01 1.10SE-01 1.106E-01 1.106E-01 1.10SE-01 1.106E-01 1.106E-01 1.136E-01 $1.106 E-011.106 E-01$

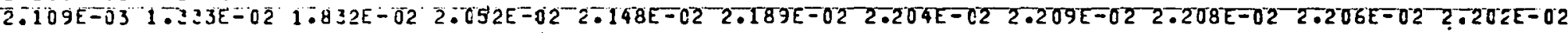

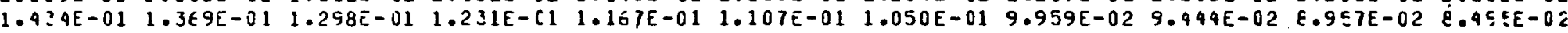

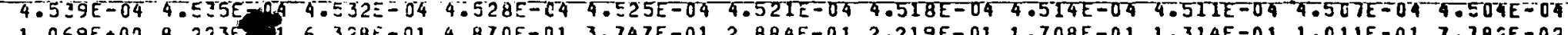
$1.069 E+00 \quad 8.223 E-1 \quad 6.328 E-01 \quad 4.870 E-01 \quad 3.747 E-012.884 E-0120.219 E-01 \quad 1.708 E-01 \quad 1.314 E-01 \quad 1.011 E-01 \quad 7.782 E-02$

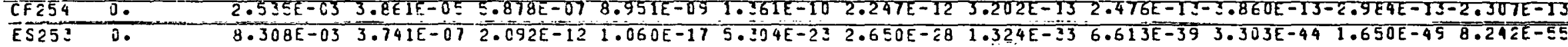


Table A-2 Neutron Source Strength cont'd.

ACIINIDES

PHR -CYCLIC OPERAIICH-33.00OMHO/M THA

NLCL ICE LIST ING

IST SFEATT TUEL DECAY UP TO 10 YRS

AVERAGE POHER(MH) AVERAGE FLUX (N/CMACZ
IOTAL BURNUP (MHC) SFCNIANEOUS FISSICR NEUT RATE-AEUT/SEC ZASIS = ONE FUEL ASSEMJL 1. $50 \in \leq 4 E+0$,

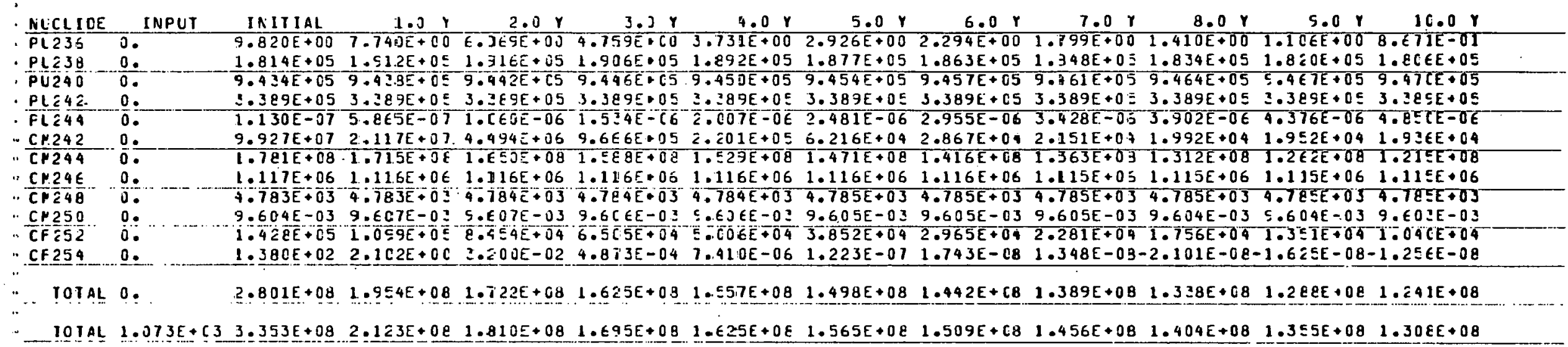


Table A-2. Neutron Soarce Strength cont'd.

ACTIAIOES

NUCLIDE LISTING

ALFHA A NEUTRON RATE - AEUTISEC
PWR-EYCL IC OPERAIICN-40.00ON WD/MIHM

PASIS = ONE FUEL ASSEMBLY
AVERAGE POWER(MH)

TOTAL BURNUP(MHO)
$2.0 E 340 E+C 1$ $1.59108 E+13$

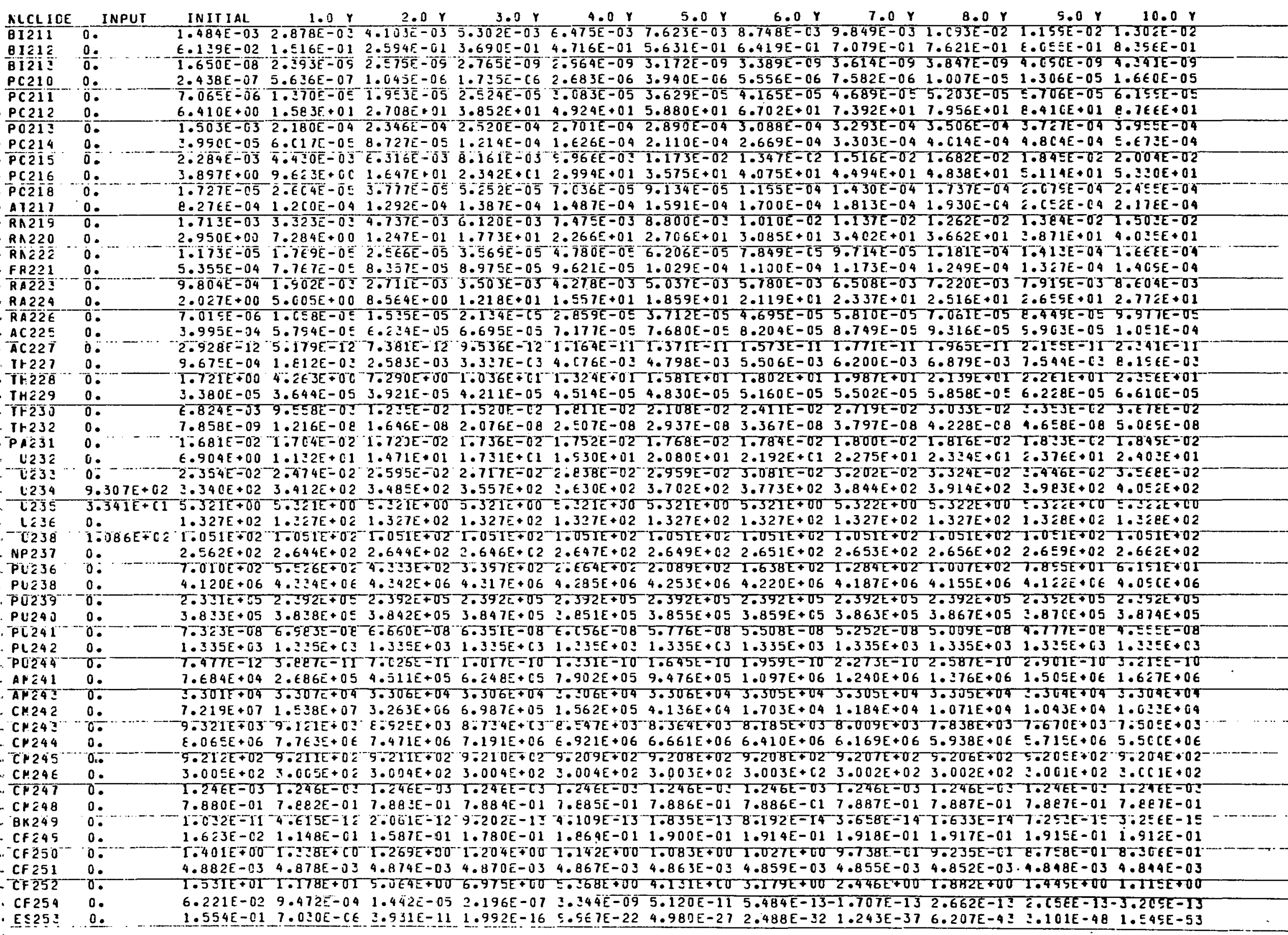

IOIAL $1.073 E+038.512 E+072.842 E+071.620 E+071.350 E+071.282 E+071.257 E+071.241 E+071.228 E+071.215 E+071.202 E+071.150 E+07$ 
Table A-2 Neutron Source Strength cont'd.

ACIINIOES

FLR-CYCLIC OPERATICN-CO, ODOMGOOMTHH

AVERAGE POHER(MH)

$2.06340 E+01$

NUCL ICE LISTING

AVERAGE FLUXCN/CMAC

$1.82611 E+C 4$

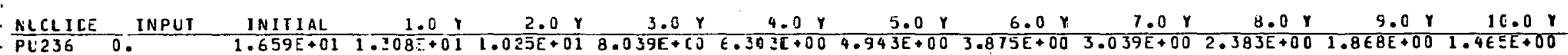

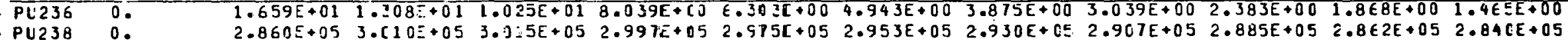

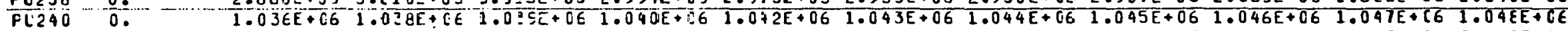

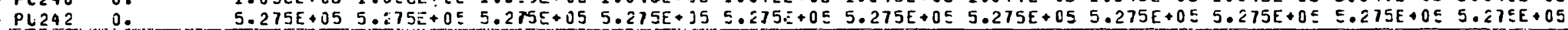

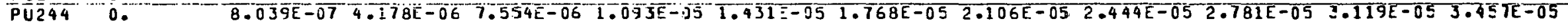

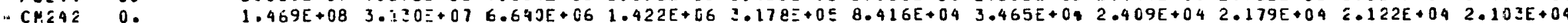

C C C4

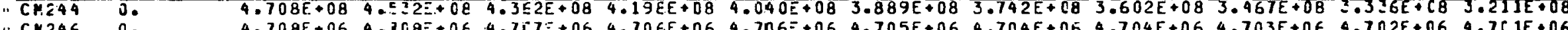

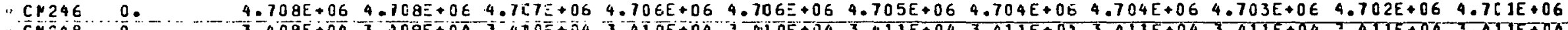

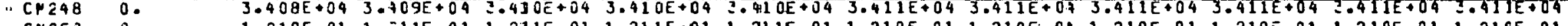

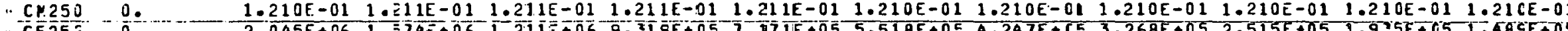

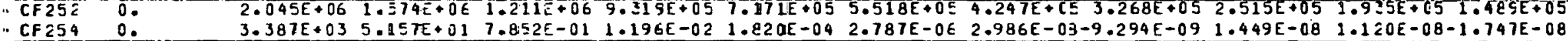

. TOIAL 0

$\overrightarrow{\mathrm{O}}$

$E .2 E 4 E+08 \quad 4.5 \angle 7 E+0 E \quad 4.507 E+08 \quad 4.288 E+08 \quad 4.117 E+08 \quad 3.961 E+08 \quad 3.813 E+08 \quad 3.671 E+08 \quad 3.535 E+08 \quad 2.4[4 E+08 \quad 3.275 E+08$

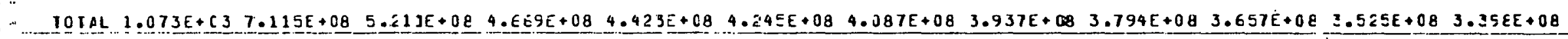


Table A-2 Neutron Source Strength cont'd,

ACI INIDES

NUCLIOE ISTING

ALPHA NEUIRON RAIF = NEULSEC
1 LE STL ALR $6=9$ CYCLE $=2.6 .6$ H $\angle C$ HIG

BASISE ONE FUEL ASSEMALY
AVERAGE POHER(AH)

AVERAGE FLUX (N/CM = I

IOIAL BURNUP SHWDS
$5.65050 E+00$ $3.42695 E+13$ $6.21555 E+0$

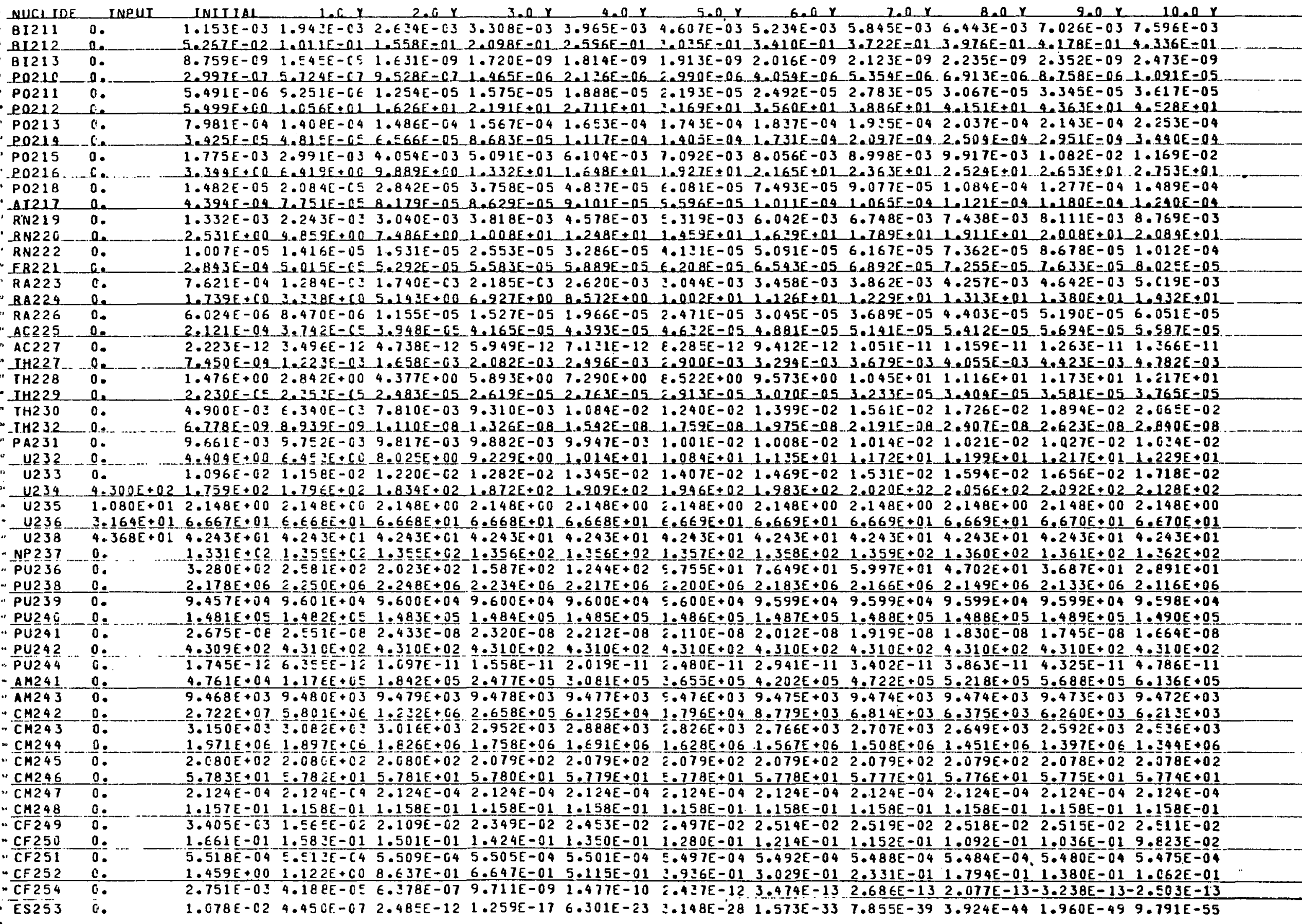

TOTAL $5.161 E+02 \quad 3.168 E+071.032 E+C 75.745 E+C 64.763 E+06 \quad 4.536 E+C 64.470 E+064.437 E+064.411 E+064.387 E+064.363 E+0 E 4.335 E+06$ 
Table A-2 Heutron Source Strength cont'd.$$
\text { ACILINIDES }
$$$$
\text { GE STO BHR 6-4 CYCLE - E.E.6_H/C HIGH }
$$$$
1 \text { ST SFENT FUEL CECAY LP TO } 1 \text { : YRS }
$$

AVERAGE POHER(MH)

HWI $\quad 5.65050 E+0.0$ NUCLIDE LISTING

1ST SFENT FUEL LECAY LP

TOIAL BURNUP (HHD) $3.42655 E+13$

SPONIANEOUS FISSION NEUI FAIE-BEUISEC BESIS = ONE FUEI PSSEMELY $6.21555 E .03$

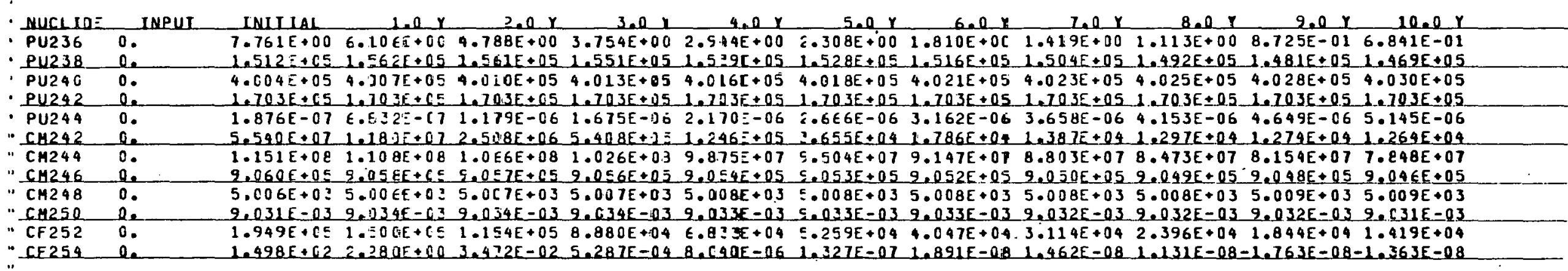

"CF

"IOTAL a.

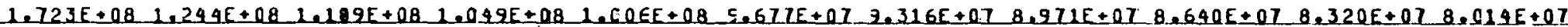

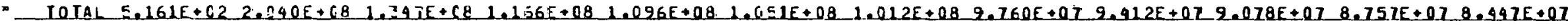

$\overrightarrow{\mathrm{N}}$ 


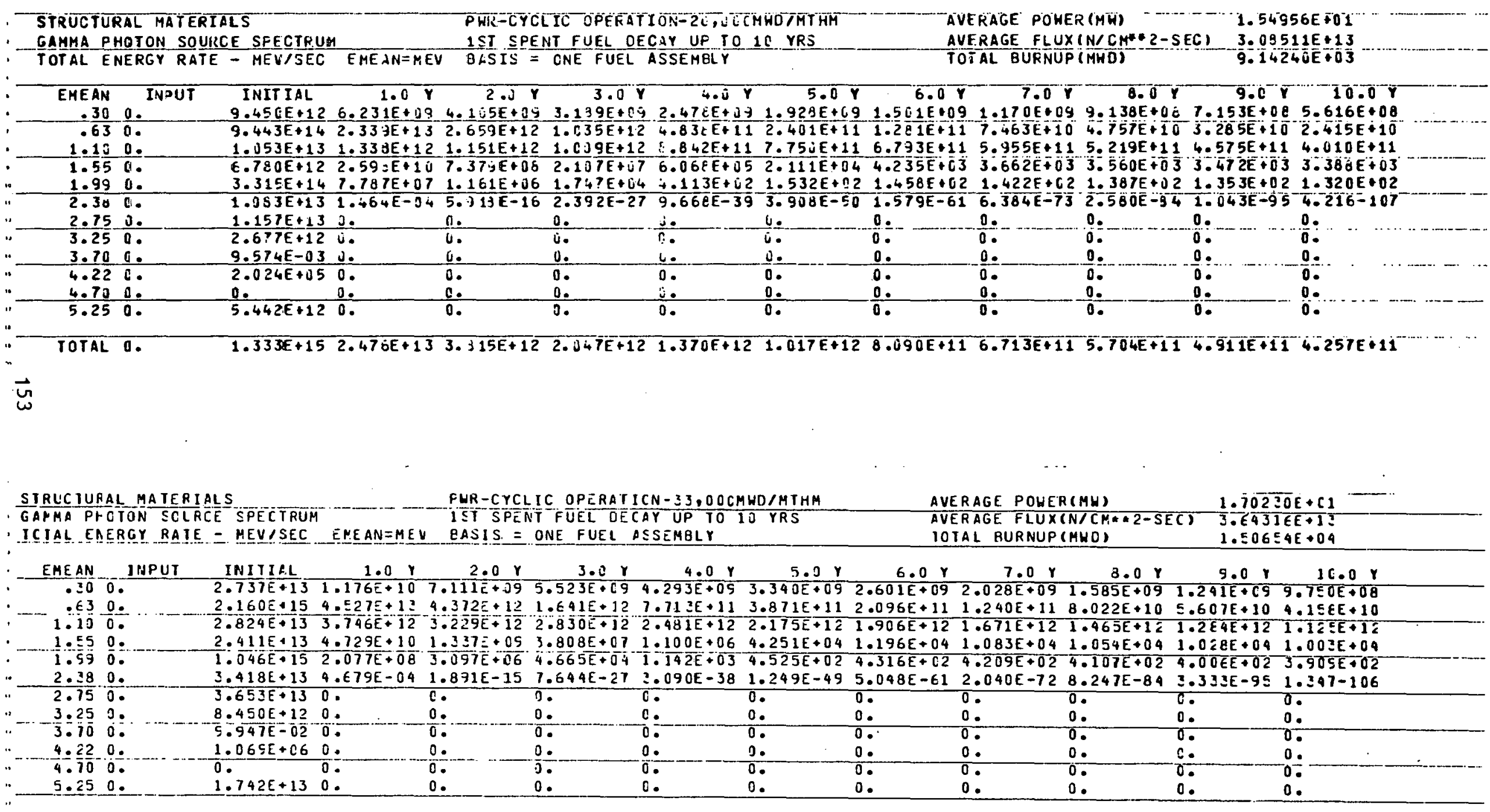


Table A-3 Structurdl Mater:al Gamma Source Strengths cont'd.

SIRLCIURAL MATERIALS

GAMHA PHOTON SOLRCE SPECTRUH

TOTAL ENERGY RAIE - PEVISEC
PLA-CYCLIC OPERAIICN-4C, 200 NWO/ MTHM FUEL CÉCAY UP TO 10 YRS

EASIS = ONE FUEL ASSEMGL
AVERAGE POHER (MH)

$2.06340 E+(1)$ (S) $4.59108 E+13$

$1.82611 E+04$

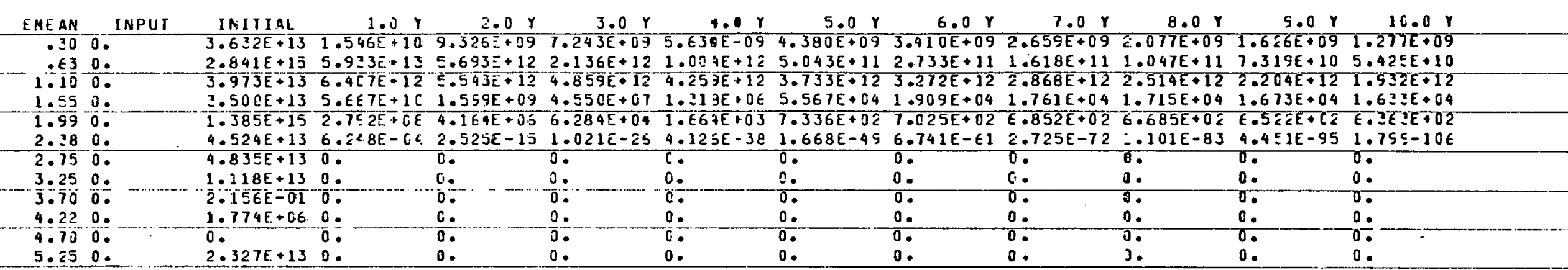

YOIAL $0 . \quad \ldots \quad 4.464 E+156.581 E+131.12 E E+137.002 E+125.269 E+124.242 E+123.549 E+123.033 E+122.621 E+122.278 E+121.987 E+12$
SIRUCJURAL HAIERIALS

GAMHA ?HOTON SOURCE SPECIFUM

IOIAL ENERGY RATE - MEVISEC
GE SIO BHR E-4 CYCLE-2.66 HLC HLEH

EASIS = ONE FUEL ASSEHELY
AVEZAGE POUERYHUI

AVE $2 A G E$ FLUX (N/CME $2-S E C O$ TOTAL BURNUP (HWD)
$5.6 .5050 E+00$ $6.21555 \underline{5}+03$

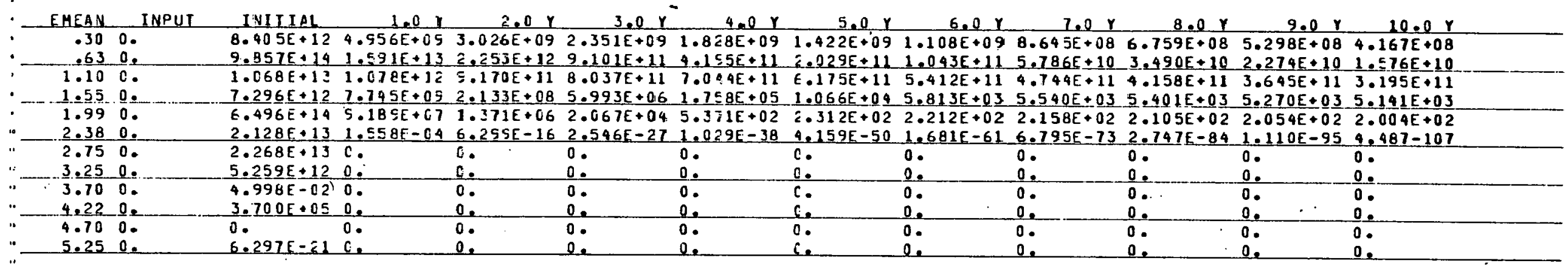

IOIAL 0.

$1.711 E+15 \quad 1.700 E+133.173 E+121.71 E E+121.126 E+128.218 E+116.466 E+115.331 E+114.514 E+113.878 E+113.357 E+11$ 
APPENDIX B 


\section{THIS PAGE}

\section{WAS INTENTIONALLY \\ LEFT BLANK}




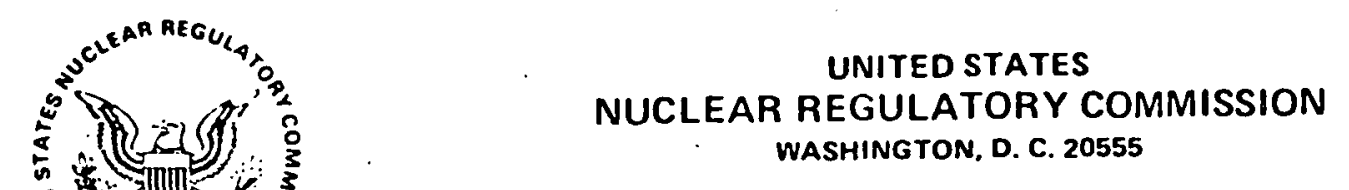

OCT 151979

FCTC:RHO

$71-6346$

General Atomic Company

ATTN: Mr. William R. Mowry

P. 0. Box 81608

San Diego, CA 92138

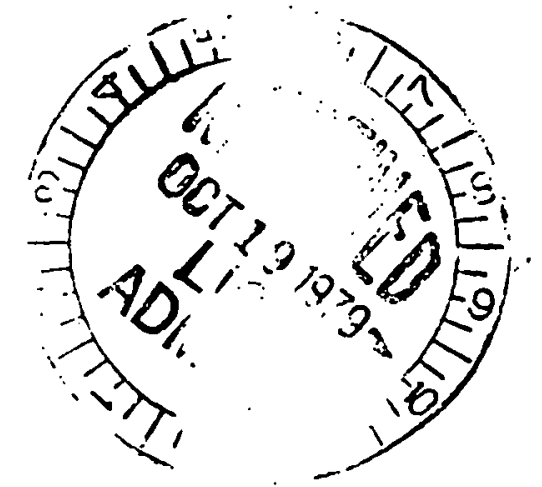

Gentlemen:

Enclosed is Certificate of Compliance No. 6346, Revision No. 3, for the Model No. FSV-1 shipping container. This certificate supersedes, in its entirety, Certificate of Compliance No. 6346, Revision 2, dated August 25, 1977.

Changes made to the enclosed certificate are indicated by vertical lines in the margin.

General Atomic Company and Public Service Company of Colorado have been registered as users of this package under the general license provisions of 10 CFR $\$ 71.12(\mathrm{~b})$ or 49 CFR $\$ 173.393 a$.

This approval constitutes authority to use this package for shipment of radioactive material and for the package to be shipped in accordance with the provisions of 49 CFR $5173.393 \mathrm{a}$.

Sincerely,

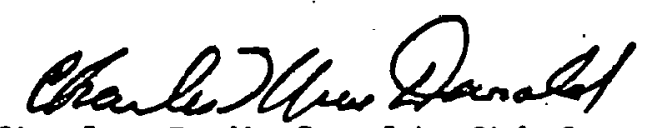

Charles E. MacDonald, Chief

Transportation Certification Branch

Division of Fuel Cycle and Material Safety

Enclosure: As stated

cc: w/encl

Mr. Richard R. Rawl

Department of Transportation

Public Service Company of Colorado

ATTN: Mr. l. K. Fuller

P.0. Box 361

Platteville, Co 80651 
im NRC.618

$(12-73)$

10 CFA 71
U.S. NUCLEAR REGULATORY COMMISSION

CERTIFICATE OF COMPLIANCE

For Radioactive Materials Packages

\begin{tabular}{|c|c|c|c|c|c|c|}
\hline $1 .(a) . c$ & $\begin{array}{c}\text { Certificate Number } \\
6346\end{array}$ & $\begin{array}{l}\text { 1.(b) Révision No. } \\
3\end{array}$ & $\begin{array}{l}\text { 1.(c) Package Identification No. } \\
\text { USA/6346/B( )F }\end{array}$ & $\stackrel{1 .(d)}{1}$ & Pages No. & $\begin{array}{c}\text { 1.(e) Total No. Pages } \\
3\end{array}$ \\
\hline
\end{tabular}

2. PREAmbí:

2.(a) This certificate is issued to satisfy Sections 173.393a, 173.394, 173.395, and 173.396 of the Department of Transportation Hazardous Materials Regulations (49 CFR 170-189 and 14 CFR 103) and Sections 146-19-10a and 146-19-100 of the Department of Transportation Dangerous Cargoes Regulations (46 CFR 146-149), as amended.

2.(b) The packaging and contents described in item 5 below, meets the safety standards set forth in Subpart C of Title 10, Code of Federal Regulations, Part 71, "Packaging of Radioactive Materials for Transport and Transportarion of Radioactive Material Under Certain Conditions."

2.(c) This certificate does not relieve the consignor from compliance with any règuiremenent of the regulatlurss ul ilıe U.J. Department of Transportatior: or oitier apflicable regulatory agencies, inciuding the governinent of any countn; through er illio which the peckege will be transported.

3. This certificate is issued on the basis of a safety analysis report of the package design or application-

3.(a) Prepared by (Name and address):

General Atomic Company

P. 0. Box 87608

San Diego, CA 92136 3.(b) Title and identification of report or application:

Gulf General Atomic, Inc. application dated May 20, 1969, as supplemented.

3.(c) Docket No. 71-6346

4. CONDITIONS

This certificate is conditional upon the fulfilling of the requirements of Subpart D of 10 CFR 71, as applicable, and the conditions specified in item 5 below.

5. Description of Packaging and Authorized Contents, Model Number. Fissile Class, Orher Conditions, and Refeiences:

\section{(a) Packaging}

(1) Mode1 No.: FSV-1

(2) Description

The cask is cylindrical, 2u8" long and 28" dlameter for musl ur its length except for the top flange which is $11-3 / 8$ " thick and 31 " in diameter. The cask utilizes stainless steel encased depleted uranium as primary shielding. The cask's inner container, for fiueled contents, has a cavity of 16-5/8" diameter and $18 /-5 / 8 "$ long. The fuel conlenls are hexagonal cross section elements and are loaded into the cask's inner container, six in one column. The cask may utilize either of two closure configurations. One closure system utilizes an outer cover consisting of 3-3/4" stainless steel together depleted uranium, 2-1/4" thick, and an inner lid of 2-1/4" thick stainless steel. The primary seal is provided by two 0-rings, one metallic and the other silicone. The alternate closure system utilizes $4.75^{\prime \prime}$ thick alloy steel and 4.14" of depleted uranium. The alternate closure system requires the use of an impact limiter at the top during transport. The alternate closure is sealed by a molded dual concentric silicone elastomer seal ring with a test port between the seals. A gas sample port penetrates through the lid into the container. The gas test port is sealed with a cher valve and primary plug with a silicone 0 -ring. 
page 2 - Certificate No. 6346 - Revision No. 3 - Docket No. 71-6346

(a) Packaging (continued)

(3) Drawings

The packaging is constructed in accordance with National Lead Company Drawings Nos.: 40065D, Rev. 1; 70085F, Rev. 5; 70086F, Rev. 7; 70094F, Rev. 5; 40155D, Rev. 1; 70105F, Rev. 5; 70104F, Rev. 5; and. 70296F, Rev. 2.

The packaging with its alternate closure system utilizes the above drawings except that closures with impact limiter are constructed as shown on General Atomic Company Drawings Nos. GADR 55-2-1, Issue A; GADR 55-2-2, Issue $A$; and GADR 55-2-3, Issue $A$.

(b) Contents

(1) Type and form of material

(i) Irradiated fuel elements consisting of graphite body, hexagonal in horizontal cross section, approximately 31.2 inches high and 14.2 inches across the flats. Each fuel element.prior to irradiation contains thorium and uranium enriched to a maximum of $93.5 \mathrm{w} / 0$ in the U-235 isotope.

(ii) Solid nonfissile irradiated hardware and neutron source components.

(2) Maximum quantity of material per package

Not to exceed a decay heat generation of $4.1 " \mathrm{kw}$ and:

(i) Item $5(b)(1)(i)$ above:

Six fuel elements each containing $1.4 \mathrm{~kg}$ of enriched uranium and $11.3 \mathrm{~kg}$ of thorium prior to irradiation and weighing $300 \mathrm{lbs}$;

(ii) Item $5(b)(1)(i i)$ above:

As needed, appropriate component spacers shall be used in the cask cavity to limit movement of contents during shipment.

(c) Fissile Class

III

Maximum number of packages per shipment

One (1)

6. The alternate closure system shall be leak tested prior to (1) first use and periodically in accordance with Section I.G.2 and (2) each use in accordance with Section I.G.1, to Addendum I, General Atomic Company Safety Analysis Report GADR-55. 
Page 3 -Certificate No. 6346 - Revision No. 3 - Docket No. 71-6346

7. The spent fuel container main flange seal(s) and the al ternate closure system fuel container primary plug silicone 0 -ring shall be replaced at least every 12 months.

8. The package authorized by this certificate is hereby approved for use under the generaT license provisions of 10 CFR $571.12(\mathrm{~b})$.

9. Expiration date: October 31, 1980.

\section{REFERENCES}

Gulf General Atomic, Inc. application dated May 20, 1969.

Supplements dated: December 2, 1969; June 17 and July 27, 1970; August. 3, 1971; June 15, 1977; August 15, 1978; and February 27, Apri7 6, September 6, and October $12,1979$.

FOR THE U.S. NUCLEAR. REGULATORY COMMISSION

Date: $\quad$ CCT 15.1979

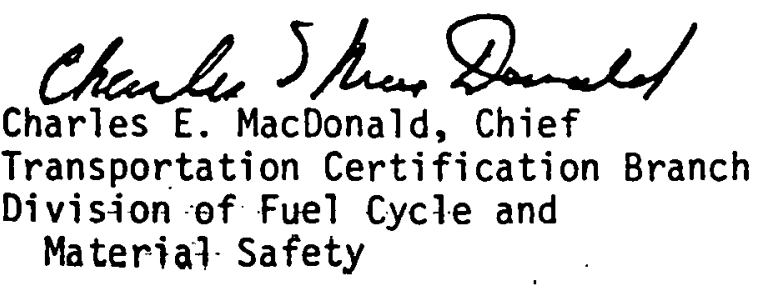


APPENDIX C 


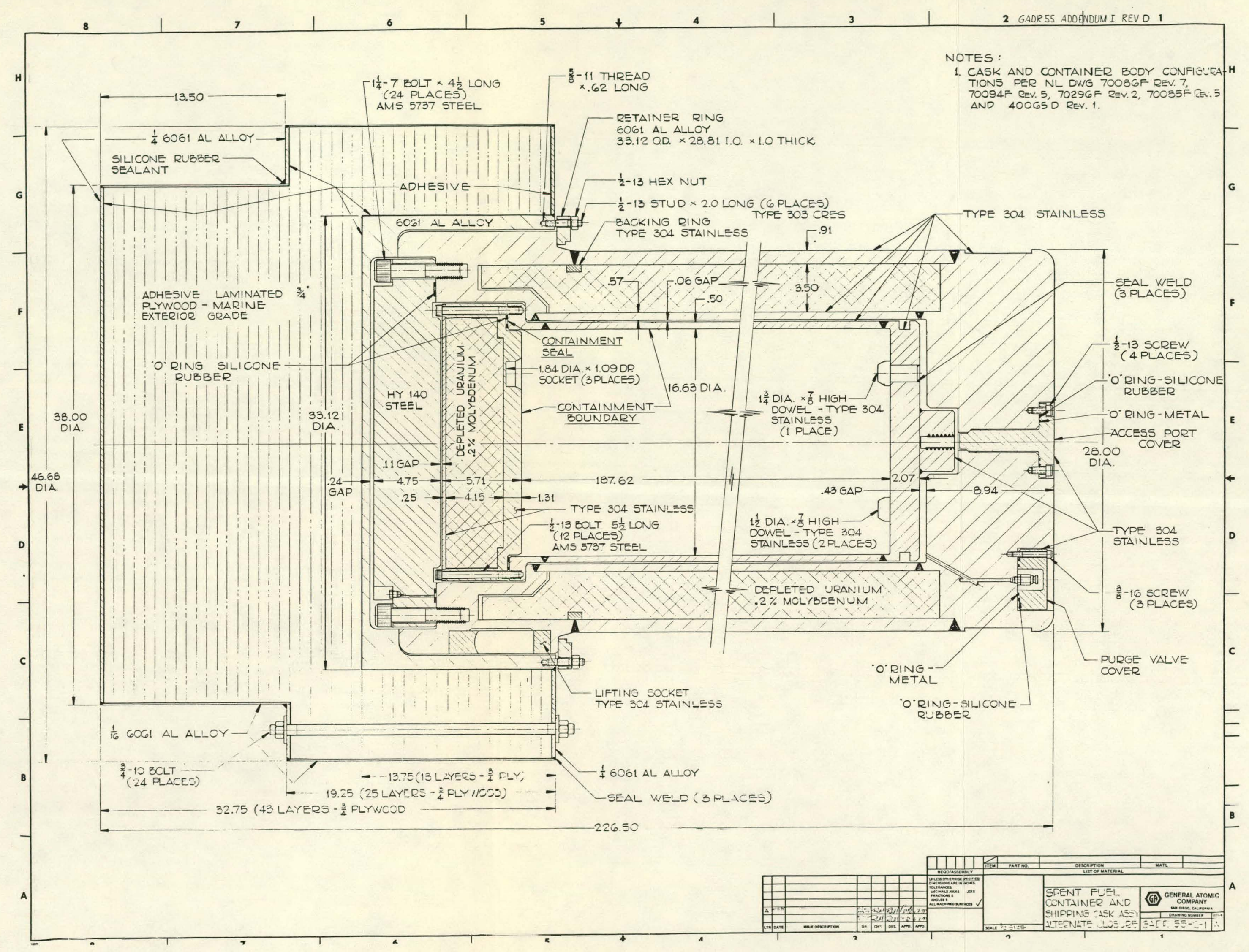




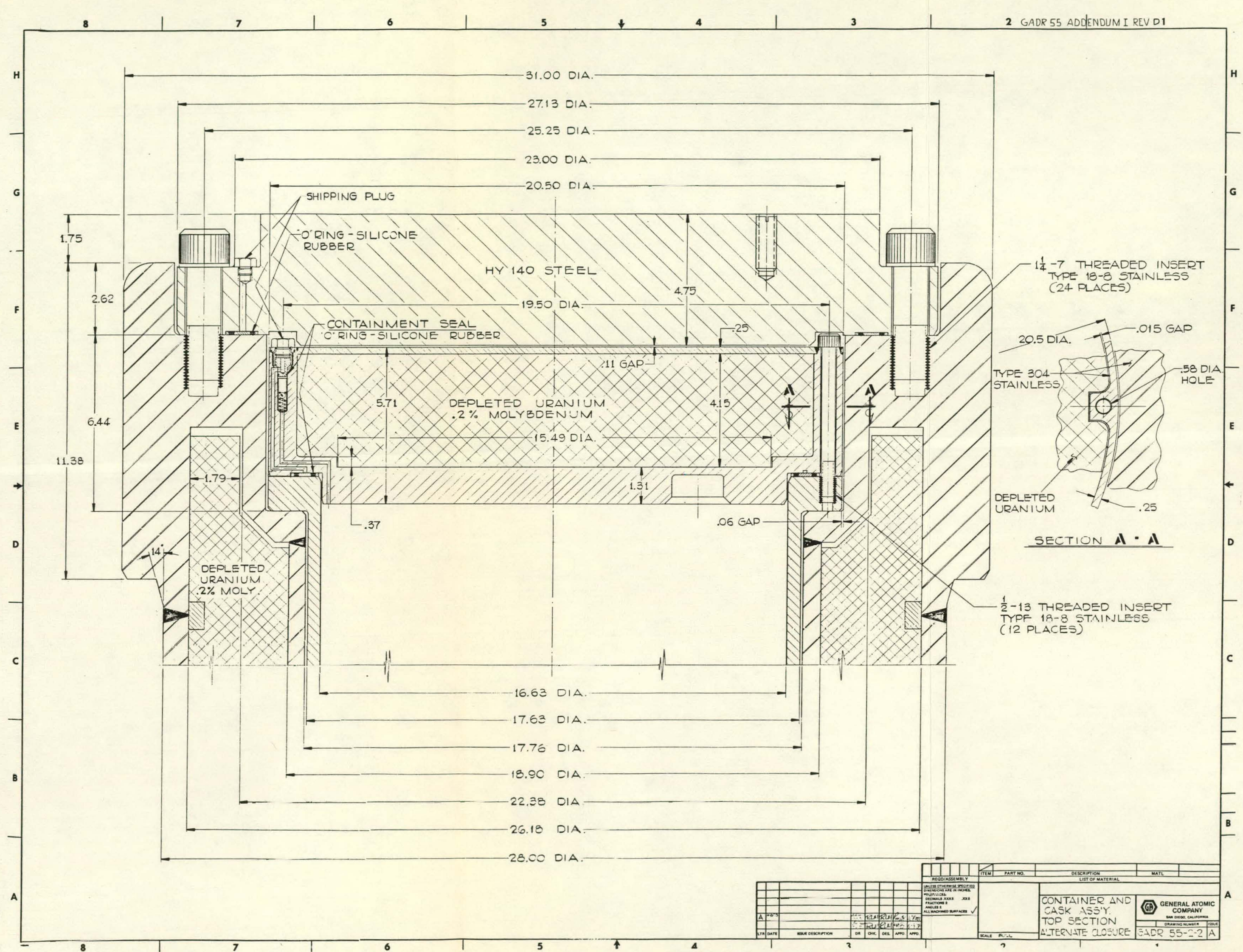




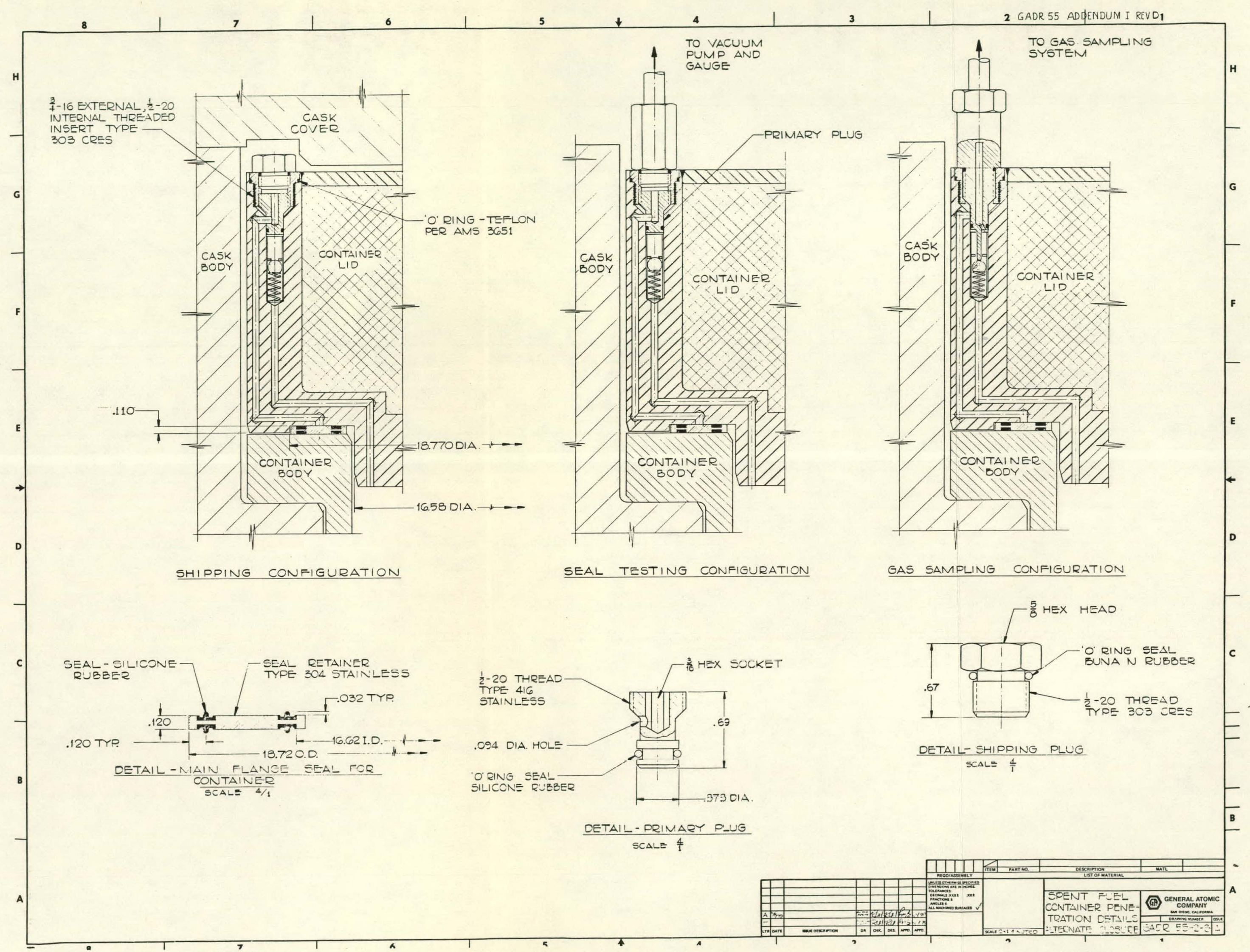




\section{PAGES 165 to 168 WERE INTENTIONALLY LEFT BLANK}


APPENDIX D 
THIS PAGE

\section{WAS INTENTIONALLY LEFT BLANK}




\section{REACTOR EXPERIMENTS, \\ 963 TERMINAL WAY, SAN CARLOS, CALIFORNIA 91070 \\ Phone: (415) 592-3355 Cable Address: REACTEX \\ TELEX: 345505 (REACTEX SCLS)}

I N C.

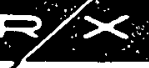

Bulletin S-82

- July 1979

\section{BORO-SILICONE SHIELDING}

Type 236 borated silicone is fire-resistant and has a high hydrogen content. It will withstand temperatures up to $400^{\circ} \mathrm{F}\left(204^{\circ} \mathrm{C}\right)$ on a continuous bas is.

Type 236 Boro-Silicone has a hydrogen content equivalent to two-thirds that of pure water. In addition, it contains.I weight-percent boron for capturing thermal neutrons and reducing capture gamma radiation. Although this is a solid material, it is quite resilient, thus minimizing any possible damage in the event of creation of secondary missiles. It is strong enough for handling and selfsupport purposes. The density of the material is $1.6 \mathrm{~g} / \mathrm{cc}$. Type 236 BoroSilicone is a self-extinguishing material. It is available in a variety of shapes and sizes.

\section{TECHNICAL DATA}

Properties

Hydrogen: $4.4 \times 10^{22}$ atoms/cc

Boron: $9.0 \times 10^{20}$ atoms/cc

Weight-Percent Boron: $1.0 \%$

Macroscopic Thermal Neutron Cross Section, $\sum=0.68 \mathrm{~cm}^{-1}$

Density: $1.6 \mathrm{~g} / \mathrm{cc}=100 \mathrm{lbs} / \mathrm{cu} \mathrm{ft}$

Recommended Temperature Limit: $400^{\circ} \mathrm{F}=205^{\circ} \mathrm{C}$

Machinability: Good

Hardness: Shore "A" Durometer Scale $=60$

Flammability (ASTM D635): Self-extinguishing with glowing combustion. Average time to self-extinguish $=0$ seconds. Average extent of burning $=0.2^{\prime \prime}$.

Coefficient of Thermal Conductivity: $5.8 \times 10^{-3} \mathrm{cal}-\mathrm{cm} / \mathrm{sec} \mathrm{cm}{ }^{2} \mathrm{oC}$ $=1.4 \mathrm{BTU}-\mathrm{ft} / \mathrm{hr} \mathrm{ft} 2$ of

Heat Capacity (Specific Heat): $0.4 \mathrm{cal} / \mathrm{g}^{\circ} \mathrm{C}$

Cubical Coefficient of Expansion: $5.2 \times 10^{-4} \mathrm{cc} / \mathrm{cc}^{\circ} \mathrm{C}$ $=3 \times 10^{-4} \mathrm{cu}$ in/ $\mathrm{cu}$ in ${ }^{\circ} \mathrm{F}$

Linear Coefficient of Expansion: $1.7 \times 10^{-4} \mathrm{~cm} / \mathrm{cm}^{\circ} \mathrm{C}$ $=1 \times 10^{-4} \mathrm{in} / \mathrm{in}^{\circ} \mathrm{F}$

Tensile Strength (ASTM D638): 59 psi

Radiation Resistance, gammas: $2 \times 10^{8}$ rads

Radiation Resistance; neutrons: $5 \times 10^{17} \mathrm{n} / \mathrm{cm}^{2}$ 


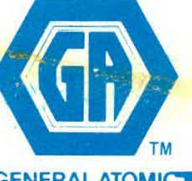

GENERAL ATOMIC

GENERAL ATOMIC COMPANY

P. O. BOX 81608

SAN DIEGO, CALIFORNIA 02130 